\title{
CRUZETAS DE POLÍMEROS RECICLADOS: CARACTERIZAÇÃO DOS MATERIAIS, ANÁLISE NUMÉRICA E ENSAIOS DE MODELOS REDUZIDOS
}

\begin{abstract}
Dissertação apresentada à Escola de Engenharia de São Carlos da Universidade de São Paulo, como parte dos requisitos para a obtenção do Título de Mestre em Engenharia de Estruturas.
\end{abstract}

Orientador: Libânio Miranda Pinheiro

\author{
São Carlos
}

Fevereiro de 2007 
FOLHA DE JULGAMENTO

Candidata: Engenheira GLÁUCIA MARIA DALFRÉ

Dissertação defendida e julgada em 16/02/2007 perante a Comissão Julgadora:

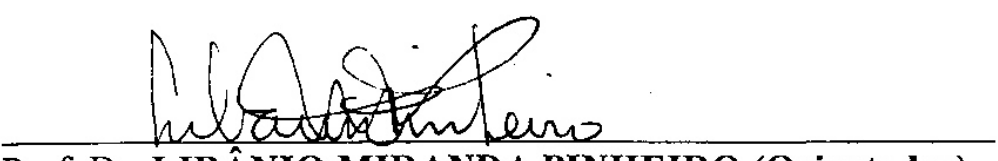

APROVAPA

Prof. Dr. LIBÂNIO MIRANDA PINHEIRO (Orientador)

(Escola de Engenharia de São Carlos/USP)

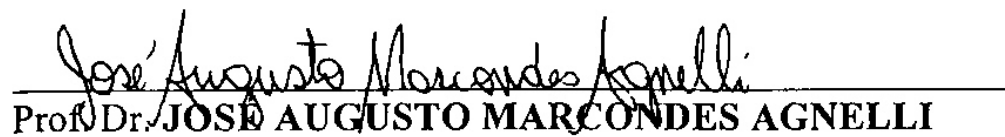

APROVADA

(Universidade Federal de São Carlos/UFSCar)

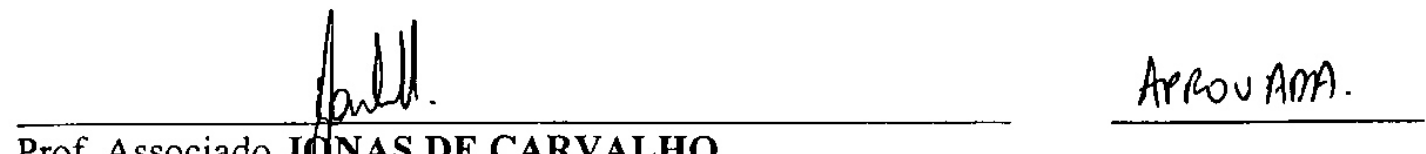

Prof. Associado J NAS DE CARVALHO

(Escola de Engenhhria de São Carlos/USP)
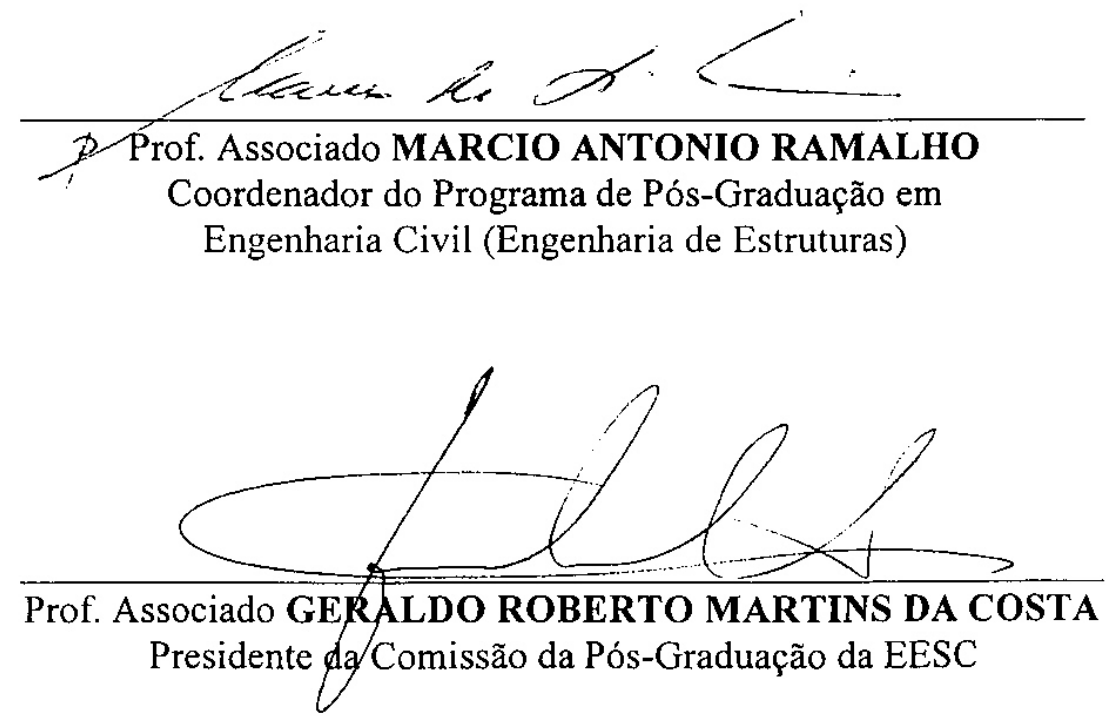


\section{DEDICATÓRIA}

Aos meus queridos pais, José Roberto e Ana Maria, simplesmente por tudo. 


\section{AGRADECIMENTOS}

Agradeço a Deus, luz da minha vida, minha inspiração, minha força e meu amigo de todas as horas.

Ao Professor Libânio Miranda Pinheiro, pela excelente orientação, apoio, incentivo e, principalmente, pela amizade e compreensão.

Aos professores Antônio Alves Dias, Carlito Calil Júnior, Benedito de Moraes Purquerio, Carlos Alberto Fortulan, Jonas de Carvalho, Dirceu Spinelli, José Ricardo Tarpani, Benedito de Souza Bueno, da EESC/USP, e ao Professor José Augusto Marcondes Agnelli, do DEMa/UFSCar, que gentilmente permitiram a utilização de seus laboratórios para a execução dos ensaios experimentais e, principalmente, pelas grandes e valiosas contribuições.

Ao empresário João Dimas Rodrigues Martins, por ceder seu tempo, seu conhecimento técnico e as instalações de sua empresa, para usufruto desta pesquisa.

Ao engenheiro Wanderley Jaime Esmael, pelo incentivo, apoio, amizade e pelas longas conversas sobre polímeros.

Aos meus pais, que souberam compreender minha ausência, dando sempre apoio e compreensão, para me transformar no que sou.

A toda minha família, que sempre apoiou e acreditou em mim.

Ao meu namorado Cilmar, pelo amor, paciência, dedicação, incentivo e apoio, mesmo estando longe.

A todas as amizades conquistadas nesta etapa: Fernanda, Mariana, Marianinha, Bia, Camila, Alice, Daniela, Tatianne, Dênis, Marlos, Saulo, Gustavo, Filipe, Luiz, André, Ronaldo, Eduardo, Pedro, Júlio, Codá, Ricardo, João Paulo... e muitos outros amigos e amigas, pelos momentos de alegria e apoio que, direta ou indiretamente, contribuíram para este trabalho. Um agradecimento, em especial, para Karenina, lara e Lívia, por serem tão especiais.

À CAPES, pela bolsa de estudos, e à FAPESP, pelo auxílio financeiro que propiciou o desenvolvimento da pesquisa.

Aos funcionários do Departamento de Engenharia de Estruturas da EESC/USP, especialmente Rosi e Nadir, pela atenção e eficiência nos serviços prestados.

Ao corpo técnico responsável pela execução dos ensaios: Jaime, do LaMEM, Cléver, do Laboratório de Geotêxteis do Departamento de Geotecnia, Sr. João e Cassius, do Departamento de Engenharia de Materiais, Aeronáutica e Automobilismo - SMM: meu agradecimento e respeito.

A todas as amigas de Limeira, em especial, Mônica, Taís, Rafaela e Maraísa, pelo apoio e incentivo que me ajudaram a chegar até aqui. 


\section{RESUMO}

DALFRÉ, G. M. Cruzetas de polímeros reciclados: caracterização dos materiais, análise numérica e ensaios de modelos reduzidos. Dissertação (Mestrado) - Escola de Engenharia de São Carlos, Universidade de São Paulo, 166p., São Carlos-SP, Brasil.

Atualmente, a madeira ainda é o material mais usado nas cruzetas das redes aéreas de distribuição de energia elétrica no Brasil, o que vem causando problemas às companhias distribuidoras de energia elétrica quanto a: (i) degradação devida a defeitos e a ataques de fungos e de insetos, (ii) aumento dos custos operacionais, para a substituição das peças danificadas e (iii) problemas ambientais, uma vez que a matéria-prima está se tornando escassa e apresenta restrições ambientais. Nesse sentido, estudos vêm sendo realizados visando a substituição da madeira por outros materiais, tais como aço, concreto e materiais poliméricos reforçados com fibras. Embora os materiais termoplásticos com função estrutural sejam de uso bastante recente, quando comparados com madeira, concreto ou metais, vários fatores contribuem para sua utilização (e.g., o alto consumo energético na produção do aço e do cimento e a abundância de material plástico com custo competitivo). Diante disso, este trabalho tem por objetivo contribuir para o desenvolvimento de uma cruzeta de polímero reciclado, de modo que ela seja comercialmente competitiva e que apresente vantagens quando comparada com as demais cruzetas existentes no mercado, tais como peso reduzido, facilidade de instalação e possibilidade de retorno de parte do capital investido, uma vez que, quando danificadas, o material pode ser novamente reciclado. Para tanto, realizou-se uma análise das propriedades geométricas de possíveis seções transversais para as cruzetas. Uma vez definidas as seções mais adequadas, foram feitos modelos reduzidos de cruzetas poliméricas e ensaios experimentais, cujos resultados foram validados por análise numérica feita com o programa ANSYS. Constatou-se que os modelos numéricos desenvolvidos representaram de forma satisfatória o comportamento verificado nos ensaios e comprovaram a viabilidade de empregar os polímeros reciclados em cruzetas e em outros elementos estruturais. Entretanto, com era de se esperar, será necessário melhorar algumas de suas características, tais como a resistência e a rigidez.

Palavras-chave: cruzetas, polímeros reciclados, propriedades, ensaios mecânicos, análise numérica. 


\section{ABSTRACT}

DALFRÉ, G. M. Recycled polymer crossarms: characterization of the materials, numerical analysis and tests in reduced models. M. Sc. Dissertation - Sao Carlos School of Engineering, University of Sao Paulo, 166p., Sao Carlos - SP, Brazil.

Nowadays, wood is still the most used material in crossarms of aerial power distribution lines in Brazil. However, it has caused problems to power utilities concerning (i) degradation due to defects and attacks of fungi and insects, (II) higher operational costs to replace damaged pieces and (III) environmental problems, as the raw material has become scarce and presented environmental restrictions. In this sense, studies have been conducted aiming to replace wood by other materials, such as steel, concrete and polymeric materials reinforced with short fibers. Although thermoplastic materials with structural function have a recent use, when compared to wood, concrete or metals, several factors contribute to their application (e.g., high energetic consumption in the production of steel and cement and the abundance of plastic material with competitive cost). Therefore, this work aims contribute to the development of a recycled polymer crossarm, to be commercially competitive, with advantages over the ones existing in the market, such as lower weight, easiness of installation and possibility of recovering part of the invested capital, when damaged, the material can be recycled again. An analysis of the geometric properties of possible transversal sections for the crossarms was conducted. After defining the most adequate sections, reduced models of polymeric crossarms and experimental tests were made. The results were validated by numerical analysis performed by ANSYS. The numerical models developed satisfactorily represented the behavior verified in the tests, proving the viability of using the recycled polymers in crossarms and other structural elements. However, as expected, some of their characteristics, such as resistance and stiffness, must be improved.

Key-words: crossarms, recycled polymers, properties, mechanical tests, finite element analysis. 
Figura 2.1 - "Maison Plastique“

Figura 2.2 - Monsanto House of the Future

Figura 2.3 - Casa plástica, por Rudolf Doernach

Figura 2.4 - Utilização de GFRP em estrutura

Figura 2.5 - Covent Garden Flower Market (a) e Edifício American Express (b)

Figura 2.6 - Estrutura produzida com perfis de FRP pultrusados

Figura 2.7 - Ponte sobre o rio Hudson construída com plástico reforçado com fibra de vidro

Figura 2.8 - Dormentes de plástico reciclado produzidos pela Polywood

Figura 2.9 - Residência japonesa construída em plástico

Figura 2.5 - Exemplos de aplicação de elementos estruturais em plásticos

Figura 2.11 - Rede convencional de distribuição de energia

Figura 2.12 - Rede aérea compacta protegida de distribuição de energia

Figura 2.13 - Rede secundária isolada

Figura 2.14 - Estrutura básica para construção de sistema aéreo

Figura 3.1 - llustração esquemática dos diagramas $\sigma$ versus $\varepsilon$ de um polímero com 0 aumento da temperatura

Figura 3.2 - Comportamento esquemático da resistência de polímeros em função da velocidade de carregamento e da umidade

Figura 3.3 - Ilustração do fenômeno da deformação por fluência

Figura 3.4 - Alongamento em função do tempo para diversos níveis de tensão

Figura 3.5 - Curvas $\sigma \times \mathrm{N}$ para alguns termoplásticos à temperatura ambiente

Figura 3.6 - Curvas $\sigma \times \mathrm{N}$ para alguns termoplásticos à temperatura ambiente

Figura 3.7 - Equipamento utilizado para ensaio de impacto

Figura 3.8 - Exemplos do efeito da temperatura sobre resistência ao impacto

Figura 3.9 - Resistividade volumétrica

Figura 3.10 - Resistividade superficial 
Figura 3.11 - Moldagem por extrusão $\quad 42$

Figura 3.12 - Moldagem por sopro - via injeção 43

Figura 3.13 - Moldagem por sopro - via extrusão 43

Figura 3.14 - Termomoldagem 44

Figura 3.15 - Moldagem por injeção 44

Figura 3.16 - Calandragem $\quad 45$

$\begin{array}{ll}\text { Figura } 3.17 \text { - Pultrusão } & 45\end{array}$

Figura 4.1 - Cruzetas de madeira $\quad 47$

Figura 4.2 - Cruzeta de 2,00 metros - Medidas em mm 48

Figura 4.3 - Arranjo para ensaio de cruzetas de 2,00 metros e 2,40 metros - Medidas 50 em $\mathrm{mm}$

Figura 4.4 - Ensaio de cruzetas de madeira $\quad 50$

Figura 4.5 - Cruzeta retangular de $1900 \mathrm{~mm}$ - Medidas em mm 51

Figura 4.6 - Cruzeta retangular de $2300 \mathrm{~mm}$ - Medidas em mm 51

Figura 4.7 - Cruzeta T de $1900 \mathrm{~mm}$ - Medidas em mm 52

Figura 4.8 - Cruzeta L de $1700 \mathrm{~mm}$ - Medidas em mm 52

Figura 4.9 - Arranjos para os ensaios em cruzetas de concreto armado 53

Figura 4.10 - Cruzeta metálica com comprimento de 1000 mm - Medidas em mm 54

Figura 4.11 - Cruzeta metálica com comprimento de 2400 mm - Medidas em mm 54

Figura 4.12 - Cruzeta metálica com comprimento de 3000 mm - Medidas em mm 54

Figura 4.13 - Arranjo para ensaio de cruzetas de 1900mm - Medidas em mm 55

Figura 5.1 - Tipos de seções transversais - Medidas em mm 60

Figura 5.2 - Momentos de inércia $\quad 61$

Figura 5.3 - Massa versus custo $\quad 61$

Figura 5.4 - Seções transversais dos modelos reduzidos, com comprimento de (a) 65 $600 \mathrm{~mm}$ e (b) $800 \mathrm{~mm}$

Figura 6.1 - Dimensões, em mm, dos corpos-de-prova de tração, compressão, 69 flexão e impacto

Figura 6.2 - Dimensões do corpo-de-prova de tração segundo a Norma ASTM D638/03 
Figura 6.3 - Ensaio dos corpos-de-prova de tração - PU

Figura 6.4 - Ensaio dos corpos-de-prova de tração - PEAD

Figura 6.5 - Dimensões do corpo-de-prova de compressão

Figura 6.6 - Ensaio dos corpos-de-prova de compressão

Figura 6.7 - Dimensões do corpo-de-prova de impacto segundo a Norma ASTM 256/04

Figura 6.8 - Fixação de corpos-de-prova para ensaios Izod

Figura 6.9 - Ensaio dos corpos-de-prova de impacto

Figura 6.10 - Dimensões do corpo-de-prova de flexão segundo a Norma ASTM D790/03 - medidas em $\mathrm{mm}$

Figura 6.11 - Ensaio dos corpos-de-prova de flexão

Figura 6.12 - Seções transversais para os ensaios-piloto - Comprimentos de (a) $600 \mathrm{~mm}$ e (b) $800 \mathrm{~mm}$

Figura 6.13 - Configuração de ensaio para cruzetas: (a) segundo a NBR 8458:1984 e (b) adaptação para o ensaio da cruzeta polimérica

Figura 6.14 - Ensaio de flexão nos modelos de material polimérico

Figura 7.1 - Seções transversais - sem furos de fixação

Figura 7.2 - Seções transversais - com furos de fixação

Figura 7.3 - Elemento finito tipo SOLID45

Figura 7.4 - Elemento finito tipo BEAM189

Figura 7.5 - Tipos de seções pré-definidas do elemento BEAM189

Figura 7.6 - Exemplo de modelo de comportamento de materiais - valores convencionais e corrigidos: (a) PU e (b) PEAD

Figura 7.7 - Detalhes (a) dos apoios e do dispositivo de aplicação de carga, utilizados no ensaio experimental, e da vinculação e do acoplamento de nós na análise numérica, para (b) Solid45 e (c) Beam189

Figura 7.8 - Malhas para os modelos numéricos - Solid45

Figura 7.9 - Malhas para os modelos numéricos - Beam189

Figura 7.10 - Malhas para os modelos numéricos - Solid45

Figura 8.1 - Curva média do ensaio de tração da amostra de poliuretano 
Figura 8.3 - Curva média do ensaio de compressão da amostra de poliuretano

Figura 8.4 - Curva média do ensaio de flexão da amostra de poliuretano

Figura 8.5 - Dispositivo utilizado no ensaio de flexão de cruzetas poliméricas

Figura 8.6 - Curva força versus flecha do ensaio de flexão na cruzeta de seção 1

Figura 8.7 - Configuração de ensaio para cruzetas: (a) segundo NBR 8458:1984 e (b) adaptação para o ensaio da cruzeta polimérica

Figura 8.8 - Curva força versus flecha do ensaio de flexão na cruzeta de seção 2

Figura 8.9 - Curva força versus flecha do ensaio de flexão na cruzeta de seção 3

Figura 8.10 - Curva força versus flecha do ensaio de flexão na cruzeta de seção 5

Figura 8.11 - Curva força versus flecha do ensaio de flexão na cruzeta de seção 10

Figura 8.12 - Comparação das curvas obtidas no ensaio de flexão com o resultado numérico (Solid45) do modelo de cruzeta polimérica - seção 1

Figura 8.13 - Evolução das tensões de Von Mises ao longo do carregamento - seção 1

Figura 8.14 - Comparação das curvas obtidas no ensaio de flexão com o resultado numérico (Solid45) do modelo de cruzeta polimérica - seção 2

Figura 8.15 - Evolução das tensões de Von Mises ao longo do carregamento - seção 2

Figura 8.16 - Comparação das curvas obtidas no ensaio de flexão com o resultado numérico (Solid 45) do modelo de cruzeta polimérica - seção 3

Figura 8.17 - Evolução das tensões de Von Mises ao longo do carregamento - seção 3

Figura 8.18 - Comparação das curvas obtidas no ensaio de flexão com o resultado numérico (Solid45) do modelo de cruzeta polimérica - seção 5

Figura 8.19 - Comparação das curvas obtidas no ensaio de flexão com o resultado numérico (Solid45) do modelo de cruzeta polimérica - seção 10

Figura 8.20 - Evolução das tensões de Von Mises ao longo do carregamento - seção 10

Figura 8.21 - Curvas obtidas na análise numérica, com o elemento finito Solid45, do modelo de cruzeta polimérica - seção 4

Figura 8.22 - Flecha máxima (a) e tensões de Von Mises (b) para carga de 280N seção 4

Figura 8.23 - Curvas obtidas na análise numérica, com o elemento finito Solid45, do modelo de cruzeta polimérica - seção 6

Figura 8.24 - Flecha máxima (a) e tensões de Von Mises (b) para carga de 270N - seção 6 
Figura 8.25 - Curvas obtidas na análise numérica, com o elemento finito Solid45, do 116 modelo de cruzeta polimérica - seção 7

Figura 8.26 - Flecha máxima (a) e tensões de Von Mises (b) para carga de 100N 116 seção 7

Figura 8.27 - Curvas obtidas na análise numérica, com o elemento finito Solid45, do 117 modelo de cruzeta polimérica - seção 8

Figura 8.28 - Flecha máxima (a) e tensões de Von Mises (b) para carga de 150N - 117 seção 8

Figura 8.29 - Curvas obtidas na análise numérica, com o elemento finito Solid45, do modelo de cruzeta polimérica - seção 9 - seção circular maciça

Figura 8.30 - Flecha máxima (a) e tensões de Von Mises (b) para carga de 150N 118 seção 9

Figura 8.31 - Comparação das curvas de cruzetas poliméricas com e sem furos de fixação, obtidas por meio de simulação numérica (Solid45)

Figura 8.32 - Curvas força versus flecha - Solid45 e Beam189

Figura 8.33 - Curvas força versus flecha para o protótipo 1 - Solid45

Figura 8.34 - Curvas força versus flecha para o protótipo 2 - Solid45

Figura 8.35 - Curvas força versus flecha para o protótipo 3 - Solid45

Figura 8.36 - Evolução das tensões de Von Mises ao longo do carregamento - protótipo 1

Figura 8.37 - Evolução das tensões de Von Mises ao longo do carregamento - protótipo 2

Figura 8.38 - Evolução das tensões de Von Mises ao longo do carregamento - protótipo 3

Figura A.1 - Representação esquemática do dispositivo de ensaio de traço uniaxial

Figura A.2 - Geometria e dimensões típicas de corpos-de-prova para ensaio de tração em polímeros

Figura A.3 - Diagrama tensão versus deformação para material com comportamento linear (a) e não linear (b)

Figura A.4 - Geometria dos corpos-de-prova para ensaios de flexão em polímeros

Figura A.5 - Representação esquemática de ensaio de flexão $m$ três pontos

Figura A.6 - Corpo-de-prova utilizado no ensaio de flexão

Figura A.7 - Corpo-de-prova utilizado no ensaio de compressão (a) e representação esquemática de ensaio de compressão (b) 
xviii

Figura A.8 - Corpo-de-prova utilizado no ensaio de impacto

Figura B.1 - Modelo linear de desenvolvimento

Figura B.2 - Etapas simplificadas do processo de reciclagem mecânica de plásticos

Figura Ap. 1 - Curvas do ensaio de tração da amostra de poliuretano 165

Figura Ap. 2 - Curvas do ensaio de compressão da amostra de poliuretano 165

Figura Ap. 3 - Curvas do ensaio de flexão da amostra de poliuretano 166

Figura Ap. 4 - Curvas do ensaio de tração da amostra de PEAD reciclado 166 


\section{LISTA DE TABELAS}

Tabela 1.1 - Valores de venda para resinas termoplásticas 02

Tabela 1.2 - Consumo de energia elétrica para fabricação de alguns materiais 04

Tabela 2.1 - Protótipos de casas plásticas

Tabela 2.2 - Valores médios de algumas características dos materiais de construção 15

Tabela 3.1 - Módulos de elasticidade típicos (à temperatura ambiente) 24

Tabela 3.2 - Valores típicos para as constantes 29

Tabela 3.3 - Valores típicos de coeficientes de expansão térmica 31

Tabela 3.4 - Temperaturas de distorção típicas de alguns plásticos no ensaio à $1820 \mathrm{~N}$ 32

Tabela 3.5 - Constante dielétrica $(\mathrm{K})$ para diversos materiais

Tabela 3.6 - Poderes caloríficos de diversos materiais 37

Tabela 3.7 - Tabela comparativa entre fibras de carbono, vidro e aramida

Tabela 4.1 - Espécies de madeira 48

Tabela 4.2 - Resistência à flexão 49

Tabela 4.3 - Resistência à flexão 52

Tabela 4.4 - Resistência à flexão 55

Tabela 4.5 - Tabela comparativa de massas 56

Tabela 4.6 - Tabela comparativa de custos 57

Tabela 5.1 - Propriedades das seções transversais 60

Tabela 5.2 - Grandezas efetivas 63

Tabela 5.3 - Constantes Físicas 63

Tabela 5.4 - Fatores de escala 64

Tabela 6.1 - Características da mistura 68

Tabela 6.2 - Propriedades após cura completa $\left(7\right.$ dias a $25^{\circ} \mathrm{C}$ ou 14 horas a $40^{\circ} \mathrm{C}$ ) 68

Tabela 8.1 - Valores encontrados no ensaio de tração das amostras de poliuretano 94

Tabela 8.2 - Valores encontrados no ensaio de tração das amostras de PEAD 95

Tabela 8.3 - Valores encontrados no ensaio de compressão das amostras de poliuretano 96

Tabela 8.4 - Valores encontrados no ensaio de flexão das amostras de poliuretano 97

Tabela 8.5 - Valores encontrados no ensaio de impacto das amostras de poliuretano 97

Tabela 8.6 - Valores encontrados no ensaio do modelo e previsão de resultados 
para o protótipo

Tabela 8.7 - Previsão de resultados para modelo e protótipo, após a correção do 99 esquema estático

Tabela 8.8 - Valores encontrados no ensaio do modelo e previsão de resultados 101 para o protótipo

Tabela 8.9 - Previsão de resultados para modelo e protótipo, após a adaptação do 101 esquema estático

Tabela 8.10 - Valores encontrados no ensaio do modelo e previsão de resultados 102 para o protótipo

Tabela 8.11 - Previsão de resultados para modelo e protótipo, após correção do 102 esquema estático

Tabela 8.12 - Valores encontrados no ensaio do modelo e previsão de resultados 103 para o protótipo

Tabela 8.13 - Previsão de resultados para modelo e protótipo, após a correção do 103 esquema estático

Tabela 8.14 - Valores encontrados no ensaio do modelo e previsão de resultados 104 para o protótipo

Tabela 8.15 - Previsão de resultados para modelo e protótipo, após correção do 105 esquema estático

Tabela 8.16 - Comparação dos valores encontrados na análise numérica dos 124 protótipos de cruzeta polimérica com os valores da norma NBR 8458:1984 


\section{SUMÁRIO}

1. INTRODUÇÃO

1.1. Considerações iniciais 01

1.2. Objetivos 03

1.3. Justificativa 03

1.4. Justificativa específica 04

1.5. Etapas de Trabalho 05

1.6. Estrutura da Dissertação 06

1.7. Histórico dos polímeros 07

2. APLICAÇÕES EM CONSTRUÇÕES 09

2.1. Construção Civil 09

2.2. Sistemas de distribuição de Energia 15

$\begin{array}{ll}\text { 2.1.1. Histórico } & 15\end{array}$

2.1.2. Sistemas de distribuição de energia elétrica 16

3. ENGENHARIA DE POLÍMEROS 19

3.1. Definição dos polímeros 19

3.2. Classificação dos polímeros 19

3.3. Propriedades dos polímeros $\quad 21$

3.3.1. Módulo de elasticidade 23

3.3.2. Resistência à tração $\quad 24$

3.3.3. Resposta dependente do tempo (fluência e relaxação de tensão 25

3.3.4. Coeficiente de Poisson 27

3.3.5. Resistência à fadiga 27

3.3.6. Resistência ao impacto (tenacidade) 29

3.4. Propriedades térmicas 30

3.4.1. Ponto de fusão cristalino e temperatura de transição vítrea 31

3.4.2. Entalpia 31

3.4.3. Coeficiente de expansão térmica 31

3.4.4. Temperatura de distorção 32

3.4.5. Condutividade térmica 32

3.5. Propriedades elétricas 32 
3.5.1. Resistividade volumétrica 33

3.5.2. Resistividade superficial 33

3.5.3. Constante dielétrica 34

3.5.4. Rigidez dielétrica 34

3.5.5. Resistência dielétrica 35

3.5.6. Fator de potência 35

3.5.7. Resistência ao arco 35

3.6. Propriedades óticas 35

3.7. Outras propriedades $\quad 35$

3.7.1. Características de desgaste $\quad 35$

3.7.2. Usinabilidade 36

3.7.3. Tolerâncias dimensionais 36

3.7.4. Absorção de água 36

3.7.5. Inflamabilidade 36

3.7.6. Resistência aos efeitos ambientais 38

3.8. Alteração das propriedades dos plásticos 38

3.8.1. Antiestáticos 39

3.8.2. Agentes de processamento / Lubrificantes 39

3.8.3. Corantes 39

3.8.4. Plastificantes $\quad 40$

3.8.5. Biocidas $\quad 40$

3.8.6. Reforços $\quad 40$

3.9. Processamento de polímeros 41

3.9.1. Moldagem por extrusão 42

3.9.2. Moldagem por sopro 42

3.9.3. Termomoldagem 44

3.9.4. Moldagem por injeção 44

3.9.5. Calandragem 45

3.9.6. Pultrusão 45

4. CRUZETAS

4.1. Considerações Iniciais $\quad 47$

4.2. Cruzetas de madeira $\quad 47$

4.3. Cruzetas de concreto armado 51

4.4. Cruzetas metálicas $\quad 54$ 
4.5. Particularidades das cruzetas

4.5.1. Massa 56

4.5.2. Custo e durabilidade 56

\section{ESTUDO DAS PROPRIEDADES DAS SEÇÕES TRANSVERSAIS E DE MODELOS} REDUZIDOS

5.1. Considerações Iniciais 59

5.2. Estudo das propriedades das seções transversais 59

5.2.1. Modelos de seções transversais $\quad 59$

5.3. Modelos em escala reduzida $\quad 62$

5.3.1. Aspectos gerais da modelagem física 62

5.3.2. Análise Dimensional 62

5.3.3. Teoria da homogeneidade dimensional 63

5.3.4. Grandezas físicas, dimensões e unidades 63

5.3.5. Condições de semelhança física 64

5.3.6. Aplicação da teoria dos modelos reduzidos às cruzetas 65

6. INVESTIGAÇÃO EXPERIMENTAL

6.1. Considerações iniciais $\quad 67$

6.2. Fabricação dos moldes de silicone e corpos-de-prova 67

6.3. Dimensões dos corpos-de-prova 68

6.4. Fabricação dos moldes de silicone 69

6.5. Moldagem dos corpos-de-prova em poliuretano 70

6.6. Ensaios mecânicos $\quad 70$

6.6.1. Realização dos ensaios de tração 71

6.6.2. Realização dos ensaios de compressão 73

6.6.3. Realização dos ensaios de impacto Izod 73

6.6.4. Realização dos ensaios de flexão 76

$\begin{array}{ll}\text { 6.7. Modelos de cruzeta em escala reduzida } & 78\end{array}$

6.8. Considerações finais 79

7. ASPECTOS DA MODELAGEM NUMÉRICA 81

7.1. Considerações iniciais 81

7.2. Geometria dos modelos analisados 81

7.3. Elementos finitos utilizados 83 
7.4. Critérios adotados para a análise não-linear da cruzeta 85

7.5. Simulação numérica 88

7.5.1. Modelos de cruzeta polimérica 88

$\begin{array}{ll}\text { 7.6. Considerações finais } & 91\end{array}$

$\begin{array}{ll}\text { 8. RESULTADOS } & 93\end{array}$

8.1. Ensaio dos corpos-de-prova 93

8.1.1. Ensaio de tração 93

8.1.2. Ensaio de compressão 95

8.1.3. Ensaio de flexão 96

8.1.4. Ensaio de impacto 97

8.2. Ensaio de flexão nos modelos de cruzeta 97

8.2.1. Análise experimental de cruzeta polimérica 97

a) Seção transversal tipo 1

b) Seção transversal tipo $2 \quad 100$

c) Seção transversal tipo $3 \quad 101$

d) Seção transversal tipo 5

e) Seção transversal tipo $10 \quad 104$

8.2.2. Comparação dos resultados experimentais e numéricos 105

a) Seção transversal tipo $1 \quad 105$

b) Seção transversal tipo $2 \quad 107$

c) Seção transversal tipo $3 \quad 109$

d) Seção transversal tipo 5

e) Seção transversal tipo 10

8.2.3. Resultados complementares da análise numérica 113

a) Seção transversal tipo 4

b) Seção transversal tipo 6

c) Seção transversal tipo $7 \quad 116$

d) Seção transversal tipo $8 \quad 117$

e) Seção transversal tipo 9

8.2.4. Estudo da influência de furos 119

8.2.5. Comparação entre os elementos Solid45 e Beam189 121

8.2.6. Simulação numérica de flexão em protótipos de cruzetas de PEAD 122

$\begin{array}{ll}\text { 8.3. Considerações finais } & 128\end{array}$ 
9. CONCLUSÕES E SUGESTÕES

9.1. Considerações finais

9.1.1. Comentários sobre a análise experimental

9.1.2. Simulação numérica dos modelos poliméricos

9.2. Sugestões para trabalhos futuros

BIBLIOGRAFIA

ANEXO A - Roteiro Básico de Ensaios Mecânicos

ANEXO B - Reciclagem

APÊNDICE A - Fôrmas para modelos de cruzetas e moldes de silicone 


\section{INTRODUÇÃO}

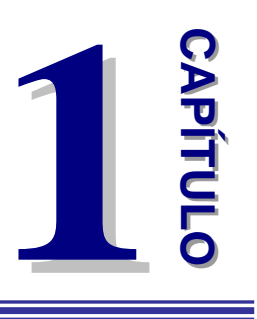

\subsection{Considerações iniciais}

A evolução da humanidade se confunde com a descoberta dos materiais. Para atender suas necessidades, o homem vem produzindo ferramentas e fabricando objetos.

No início, os materiais mais usados eram a pedra, a madeira e o barro. Depois, vieram os metais. Com a Revolução Industrial houve a descoberta de novas ligas, um aperfeiçoamento nos processos de produção e uma busca incessante de novos materiais e tecnologias que pudessem aumentar o rendimento e a lucratividade das empresas. No século XX ocorreu um grande avanço nas pesquisas sobre novos materiais, principalmente no campo dos materiais sintéticos e, dentre eles, estão os termoplásticos. É comum observar que peças inicialmente produzidas com outros materiais, particularmente metal ou madeira, têm sido substituídas por outras de plástico. Essas peças, quando devidamente projetadas, cumprem seu papel apresentando, na maioria das vezes, um desempenho superior ao do material antes utilizado.

No ambiente técnico, o termo "plástico", que vem do grego plastikós, é designado para o grupo de materiais sintéticos que são processados, aquecidos e moldados até que se obtenha a geometria desejada. Os plásticos são formados por moléculas, principalmente sintéticas e orgânicas, chamadas de polímeros (do grego: poli - muitas, mero - partes). Polietilenos, polipropileno, poliestireno, poliéster, nylon e teflon® são exemplos de polímeros industriais.

Os plásticos têm sido usados em grande escala na produção de embalagens, principalmente de produtos alimentícios, utensílios domésticos e eletrodomésticos, além de suas aplicações científico-tecnológicas e em diversas áreas da indústria e da engenharia, como têm ocorrido com a engenharia civil. A popularização dos plásticos se deve, basicamente, ao seu peso específico reduzido, razoável resistência, possibilidade de uso na fabricação de peças das mais variadas formas e baixo custo de produção, quando comparado a outros materiais. A tabela 1.1 apresenta os valores de venda para alguns tipos de resinas termoplásticas, novas e recicladas, encontrados no mercado. 
Tabela 1.1 - Valores de venda para resinas termoplásticas.

\begin{tabular}{|c|c|}
\hline \multicolumn{2}{|c|}{ Resinas Termoplásticas (Recicladas) } \\
\hline Material & Preço (R\$) \\
\hline PEAD colorido (injeção)* & 2,40 \\
\hline PEAD colorido (sopro) ${ }^{\star}$ & 2,40 \\
\hline PEAD branco (sopro)* & 2,90 \\
\hline PEAD preto** & 2,00 \\
\hline PP canela (extrusão)* & 3,10 \\
\hline PP colorido (injeção)* & 2,40 \\
\hline PP preto** & 2,20 \\
\hline PEBD natural** & 3,20 \\
\hline PEBD branco** & 3,00 \\
\hline PEBD preto** & 2,00 \\
\hline \multicolumn{2}{|c|}{ Resinas Termoplásticas (Novas) } \\
\hline Material & Preço (R\$) \\
\hline$P P * *$ & 5,15 \\
\hline$P S^{\star *}$ & 4,80 \\
\hline \multicolumn{2}{|c|}{ * Dannaplas (informação pessoal) ${ }^{1}$} \\
\hline
\end{tabular}

Analisando-se os dados, pode-se observar que a diferença de preço, considerandose o PP reciclado (preto) e o novo é de 134\%, o que comprova seu baixo custo em relação a um material novo e abre um leque de possibilidades de utilização, tais como para a fabricação de elementos estruturais.

Segundo Parente (2006), o emprego de materiais termoplásticos reciclados para a produção de elementos estruturais estimulará o aumento da reciclagem dos plásticos no País, agregando valor e tornando mais nobre o produto da reciclagem. Assim, serão retirados dos aterros sanitários e lixões materiais que podem levar até 450 anos para se degradar e, ao mesmo tempo, serão criados inúmeros postos de trabalho, desde a coleta seletiva do resíduo, seu processamento e produção, o desenvolvimento de novos produtos e aplicações, até a venda do produto final.

A proposta inicial do grupo de pesquisas em que este trabalho se insere era estudar as cruzetas de polietileno de alta densidade (PEAD) e verificar a necessidade do uso de cargas e de adições, para adequar essas cruzetas para o emprego em redes de distribuição de energia elétrica.

Porém, o custo para extrusão dos modelos de cruzetas de PEAD seria muito alto, dada a necessidade de fabricação de matrizes e calibradores, indispensáveis na linha de produção.

\footnotetext{
${ }^{1}$ Cotação recebida por glauciam@sc.usp.br, em 28 de julho de 2006.
}

${ }^{2}$ Cotação recebida por glauciam@sc.usp.br, em 28 de julho de 2006. 
Para contornar este problema, foi decidido o uso de poliuretano (PU), numa composição que resultasse características mecânicas semelhantes às do PEAD. O PU utilizado, por ser uma resina líquida, pode ser moldado em laboratório.

Neste trabalho, portanto, será considerado o PU. Em outro trabalho, desenvolvido em paralelo e com conclusão prevista para meados de 2007, estão sendo estudadas as características do PEAD.

Devido às pequenas dimensões dos corpos-de-prova, as matrizes e os calibradores para sua extrusão não tem custo proibitivo, e estão sendo fabricados com apoio financeiro da FAPESP. A extrusão desses corpos-de-prova está sendo feita pela IPEX, empresa de São Carlos, parceira nesta linha de pesquisa.

\subsection{Objetivos}

Este trabalho considera, portanto, o desenvolvimento de uma cruzeta polimérica, de modo que ela seja compatível com as normas técnicas e que seja produzida com um material que proporcione maior durabilidade e que, ao final da sua vida útil, possa ser reciclado ou vendido, obtendo-se assim um retorno de capital, com a sua venda.

Os objetivos específicos são:

- Pesquisar a literatura existente sobre o comportamento estrutural de materiais poliméricos;

- Avaliar experimentalmente propriedades mecânicas (resistência e módulo de elasticidade) do sistema à base de poliuretano, por meio de ensaios de: (i) tração, (ii) compressão, (iii) flexão e (iv) impacto;

- Estudar seções maciças e vazadas, fazendo uma análise comparativa de resistência, rigidez, densidade e custos;

- Realizar ensaios experimentais de flexão para as seções adotadas;

- Comparar as características mecânicas de cruzetas de material polimérico com as de outros materiais;

- Obter dados e evidências técnicas que indiquem ou não a viabilidade da aplicação de materiais poliméricos em cruzetas;

- Sugerir outros materiais que possam ser adicionados aos materiais poliméricos, a fim de se obter uma melhoria em suas propriedades.

\subsection{Justificativa}

Nos últimos anos, os termoplásticos têm ocupado um espaço cada vez maior em aplicações que utilizavam outros tipos de materiais, como madeira, ferro, aço, alumínio, 
outros metais e ligas metálicas, etc. Esse grande avanço foi motivado pela versatilidade dos termoplásticos, uma vez que estes podem reproduzir as características de outros materiais, muitas vezes com vantagens.

Além disso, existe a possibilidade de adição de cargas ou de reforços na matriz polimérica, além de vários tipos de aditivos para diversas finalidades, tais como auxiliar o processamento, agir contra a degradação por ação ultravioleta, dentre outros. Existe também a possibilidade de se trabalhar com blendas e combinar as vantagens de polímeros diferentes.

Nos últimos tempos, alguns desafios têm surgido, e um deles está relacionado ao consumo de energia, que antes não tinha grande relevância, devido ao seu baixo custo e abundância, mas que agora tem sido um assunto muito discutido e colocado em destaque, no cenário nacional e mundial.

Com relação a este assunto, Ferraroli et al. (2001) apresentam os valores indicados na tabela 1.2, relativos à massa específica e ao consumo de energia para a fabricação de alguns materiais e dos termoplásticos: poliestireno de alto impacto (HIPS), poliestireno (PS) e tereftalato de polietileno (PET).

Tabela 1.2 - Consumo de energia elétrica para fabricação de alguns materiais. Fonte: Ferraroli et al. (2001).

\begin{tabular}{|c|c|c|}
\hline Material & $\begin{array}{c}\text { Massa Específica } \\
\left(\mathrm{kg} / \mathrm{m}^{3}\right)\end{array}$ & $\begin{array}{l}\text { Consumo de Energia Elétrica } \\
\qquad\left(\mathrm{MWh} / \mathrm{m}^{3}\right)\end{array}$ \\
\hline Vidro & 2600 & 2,08 \\
\hline Aço & 7500 & 10,40 \\
\hline Alumínio & 2700 & 92,00 \\
\hline HIPS & 1050 & 1,41 \\
\hline PS & 1050 & 1,02 \\
\hline PET & 1330 & 2,93 \\
\hline
\end{tabular}

Essa tabela indica o consumo de energia elétrica para a produção de um metro cúbico de material. Segundo Ferraroli et at. (2001), a comparação engloba todo o ciclo de vida do material, desde sua extração até a obtenção do produto final. Analisando-se os dados, pode-se observar que o consumo energético para a fabricação dos materiais tradicionais, com exceção do vidro, é bem superior ao dos materiais termoplásticos, assim como sua massa específica final.

\subsection{Justificativa específica}

As interrupções no sistema de distribuição de energia elétrica provocam grandes prejuízos às concessionárias e aos clientes. Com o objetivo de evitar essas interrupções, é 
importante que se promovam estudos sobre novos materiais, compósitos e estruturas que possam ser utilizadas no sistema de distribuição.

Segundo Silva (2003), nos sistemas de distribuição de energia tem-se um número muito grande de cruzetas de madeira, e suas substituições anuais atingem patamares de milhares de unidades. As madeiras utilizadas para essas cruzetas, a cada dia que passa, sofrem mais restrições ambientais para o seu uso. Isto faz com que seja mais difícil obter madeiras que possuam uma durabilidade aceitável para o emprego nas redes de distribuição.

Nesse contexto, este trabalho tem por objetivo o desenvolvimento de uma cruzeta polimérica, com características de rigidez e durabilidade compatíveis com as normas vigentes. Também tem por objetivo a utilização de plásticos reciclados, incentivando assim a reciclagem de materiais antes descartados, e contribuindo com questões ambientais.

O trabalho descrito ao longo deste projeto faz parte de uma linha de pesquisa sobre Elementos Estruturais de Polímeros Reciclados, que envolve não só alunos e docentes do Departamento de Engenharia de Estruturas (SET/EESC/USP), como também pesquisadores de outros departamentos da EESC/USP.

Devido às baixas rigidez e resistência do poliuretano $(P U)$ e do polietileno de alta densidade (PEAD), quando comparadas às dos materiais estruturais usualmente empregados na construção civil, este trabalho deverá ser complementado por outros, em que serão obtidos blendas e compósitos adequados para aplicação dos materiais poliméricos com função estrutural. Já que este projeto consiste no primeiro trabalho experimental do SET, realizado no âmbito dessa nova linha de pesquisa, deverá fornecer subsídios aos demais que o sucederão.

\subsection{Etapas de Trabalho}

Este trabalho foi feito com o desenvolvimento das seguintes etapas: revisão bibliográfica, ensaios para caracterização dos materiais, investigação experimental e modelagem numérica de modelos de cruzeta em escala reduzida.

A primeira etapa consiste em uma revisão bibliográfica sobre o comportamento estrutural dos materiais termoplásticos e de suas aplicações no campo da Engenharia Civil, de modo a fornecer os conhecimentos necessários para a realização desta pesquisa.

A segunda etapa aborda o desenvolvimento de uma metologia de fabricação dos corpos-de-prova de tração, compressão, flexão e impacto, segundo as Normas Técnicas ASTM D638-03, ASTM D695-02a, ASTM D790-96a e ASTM D256-04, respectivamente, utilizando um sistema à base de poliretano. 
A terceira etapa corresponde à avaliação das propriedades mecânicas em tração, compressão, flexão e impacto de um sistema à base de poliuretano, por meio de ensaios experimentais em laboratório, à pressão e temperatura ambientes.

$\mathrm{Na}$ quarta etapa foi desenvolvida uma metodologia para fabricação de modelos de cruzetas, foi feita sua avaliação experimental em laboratório e o confronto dos valores experimentais com os valores obtidos pelo Método dos Elementos Finitos (MEF), tendo em vista a validação da utilização de cruzetas poliméricas em redes de distribuição de energia elétrica.

\subsection{Estrutura da Dissertação}

No Capítulo 1 são apresentados os objetivos da pesquisa, a justificativa e os métodos empregados para o desenvolvimento deste trabalho, finalizando com um histórico dos materiais poliméricos.

O Capítulo 2 traz uma revisão bibliográfica sobre os plásticos, sua evolução e primeiras aplicações, até a sua inserção como material de construção. Engloba também o estado da arte, os trabalhos e as conquistas recentes da aplicação dos plásticos como material constituinte de elementos estruturais.

No Capítulo 3 é feita uma breve apresentação dos plásticos existentes, a partir de sua classificação e características gerais, além de um enfoque mais aprofundado nas propriedades mecânicas e características físicas dos plásticos, com ênfase nos aspectos que são necessários a um projeto estrutural.

O Capítulo 4 descreve os principais tipos e materiais das cruzetas existentes, assim como seu arranjo e metodologia de ensaio. Nesse capítulo também é feita uma breve abordagem entre alguns parâmetros, tais como custo e massa, entre cruzetas poliméricas, metálicas, de madeira e de concreto armado.

No Capítulo 5 é feito um estudo sobre os fatores que influenciam as seções transversais (e.g., quantidade de material e rigidez). Faz-se também uma abordagem sobre os parâmetros e conceitos envolvidos na utilização de modelos reduzidos.

São descritos, no Capítulo 6, todos os aspectos da pesquisa experimental, tais como (a) método adotado para fabricação dos corpos-de-prova, (b) ensaios de caracterização dos materiais, (c) etapas de confecção e montagem dos modelos e (d) procedimento e esquema de ensaio, dentre outros.

No Capítulo 7 apresenta-se a simulação numérica por meio de um software baseado no Método dos Elementos Finitos (MEF). 
O Capítulo 8 apresenta a análise e a discussão dos resultados da investigação experimental e da simulação numérica dos modelos reduzidos, além da extrapolação de resultados para modelos reais.

E por último, no Capítulo 9, encontram-se as considerações finais, as conclusões do trabalho e algumas sugestões para futuras pesquisas relacionadas com polímeros reciclados.

\subsection{Histórico dos polímeros}

Até o início do século passado, o homem só conhecia as macromoléculas orgânicas de origem natural, como, por exemplo, a madeira e a lã. Dentre muitas outras aplicações, esses materiais eram muito utilizados na fabricação de vários objetos na construção civil e no vestuário.

Um grande avanço na história da indústria de plásticos foi a descoberta do processo de vulcanização da borracha em 1839 (a partir do látex, um polímero natural, que já era largamente empregado), por Charles Goodyear. Em 1865 foi descoberto o processo de acetilação da celulose, resultando em produtos comerciais de grande uso, como as fibras de rayon, celofane, dentre outros. O próximo grande passo foi a nitração da celulose, resultando na nitrocelulose, que foi comercializada primeiramente por Hyatt, em 1870. Desse produto foi obtido o celulóide, que começou a ser muito utilizado pela indústria cinematográfica.

Em 1909 o americano Leo Hendrik Baekeland, de origem belga, produziu a primeira substância plástica sintética, a baquelite. Desde então, a indústria e o uso de polímeros não parou de crescer.

Hermann Staudinger, em 1924, propôs que os poliésteres e a borracha natural possuíam estruturas químicas lineares. Devido aos seus estudos, recebeu posteriormente o Prêmio Nobel em Química (1953), por ser o pioneiro na química de macromoléculas. Em 1928, Wallace H. Carothers, pesquisador do Laboratório Central de Pesquisa da DuPont, realizou estudos sobre polímeros lineares obtidos por condensação de monômeros difuncionais. Seu grupo de pesquisa desenvolveu e estudou o neopreno, os poliésteres e as poliamidas. Um membro desse grupo, Paul J. Flory, receberia em 1974 o Prêmio Nobel em Química, por sua contribuição na investigação da química de polímeros.

Entre 1930 e 1942, vários polímeros foram descobertos, como o copolímero de estirenobutadieno (1930); a poliacrilonitrila, os poliacrilatos, o poli(acetato de vinila) e o copolímero de estireno-acrilonitrila (1936); os poliuretanos (1937); o poliestireno e o poli(tetraflúor-etileno) (teflon) (1938); a resina melamina-formaldeído (fórmica) e o poli(tereftalato de etileno) (1941); fibras de 
poliacrilonitrila (orlon) e os poliésteres insaturados (1942). A primeira indústria a produzir o nylon foi a Du Pont em 1938, sendo a fabricação do nylon-6 (perlon) iniciada no ano seguinte pela I. G. Faber. Nessa época, na Alemanha, P. Schlack realizou a primeira polimerização por abertura de anel de um composto orgânico cíclico, ao produzir o nylon-6 a partir da caprolactama.

Após a Segunda Guerra Mundial, a fabricação e a comercialização dos materiais poliméricos alcançaram um grande desenvolvimento, surgindo as resinas epoxídicas (1947) e ABS (1948), além do desenvolvimento do poliuretano. A década de 50 foi marcada pelo aparecimento de vários polímeros, como o polietileno linear, o polipropileno, o poliacetal, o policarbonato, o poli(óxido de fenileno) e de novos copolímeros. Outro avanço significativo no estudo da química de polímeros ocorreu em 1953, com a descoberta da polimerização esteroespecifica, por Karl Ziegler e Giulio Natta. Esses pesquisadores receberam o Prêmio Nobel em Química de 1963, pelo estudo desse tipo de polimerização.

Nos anos 60, os plásticos deixaram de substituir apenas as madeiras e começaram a ser utilizados em embalagens, substituindo o papelão e o vidro, enquanto que nos anos 70 , os plásticos tomaram o lugar de algumas ligas leves.

Nos anos 80, a produção de plásticos se tornou bastante intensa e diversificada, tornando essa indústria química uma das principais no Mundo.

Devido à crescente necessidade de novos materiais poliméricos, vários centros de pesquisa, indústrias e universidades têm realizado estudos científicos e tecnológicos, desenvolvendo polímeros com as mais variadas propriedades químicas e físicas. Hoje, o mundo moderno não é concebível sem a presença dos plásticos e das borrachas, podendo o progresso de um país ser medido pelo seu nível de produção de plásticos. Segundo fontes recentes, tais como o Sindicato da Indústria de Resinas Plásticas (SIRESP), Cerqueira e Hemais (2001) e o Jornal de Plásticos, o consumo per capita de plásticos em 1995 no Brasil foi de 14 kg/hab/ano e em 2006 passou a 26 kg/hab/ano, mas ainda é muito baixo quando comparado com outros países como Singapura, Taiwan, Japão, Estados Unidos e países da Europa Ocidental. Entretanto, esse consumo no Brasil tem aumentado significativamente nos últimos anos, o que comprova o desenvolvimento da indústria de produção e de transformação de plásticos no país e, principalmente, a melhor qualidade dos produtos. 


\section{APLICAÇÕES EM CONSTRUÇÕES}

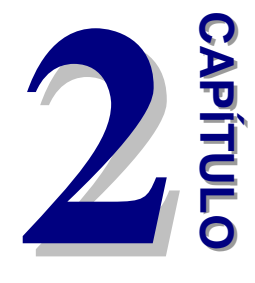

\subsection{Construção Civil}

Até há pouco tempo, a palavra plástico era mais associada às indústrias automotiva, naval e aeroespacial. Hoje, ela também está presente no cotidiano da engenharia civil e se pode relacioná-la a diversas aplicações, tais como: membranas geotêxteis utilizadas para controlar a passagem de água e reforço do solo; filmes de polietileno (PE) para proteção contra a umidade, vento, produtos químicos e pó; espumas de poliuretano para isolação térmica de edifícios; fabricação de forros, tubos e esquadrias de poli(cloreto de vinila) (PVC), dentre outros.

Segundo Quarmby (1976), os plásticos vêm sendo utilizados como materiais de construção há muito tempo. Em 1933 alguns protótipos de casas plásticas já haviam sido construídos em vários países, principalmente na Alemanha, na Suécia e nos Estados Unidos. Entretanto, depois da Segunda Guerra Mundial, os Estados Unidos e a Grã-Bretanha começaram a utilizar os plásticos, de modo mais sistemático, como materiais de construção.

Em 1955 foi construída por lonel Schein, Yves Magnant, R.A. Coulon e Antoine Fasani a primeira casa totalmente feita com plástico, a "Maison Plastique" (Fig. 2.1). O seu projeto foi baseado em uma concha de caracol e consistia de uma célula básica circular com cozinha, banheiro e dormitório, e previa futuras ampliações que poderiam ser feitas de acordo com as necessidades do proprietário.

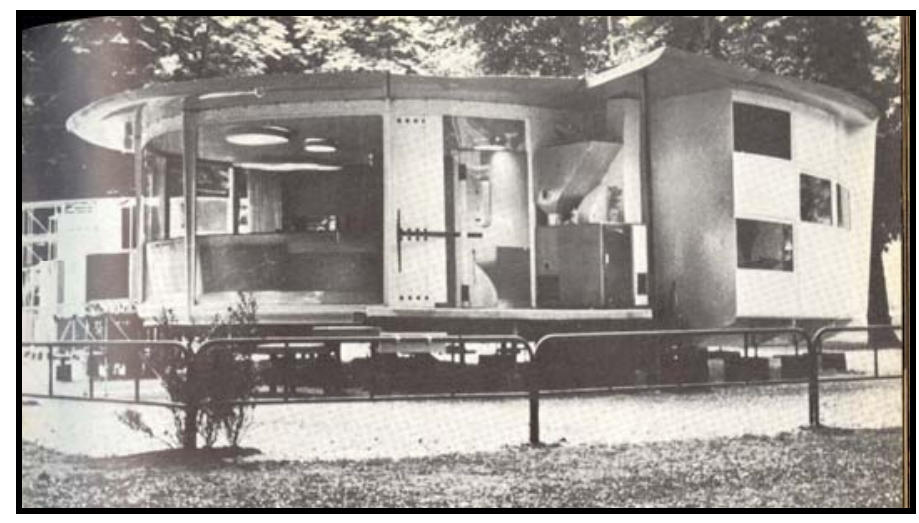

Figura 2.1 - "Maison Plastique".

Fonte: http://www.dr-z.net/article_info.php/articles_id /1.

Devido à falta de conhecimento sobre a tecnologia dos plásticos, foram necessárias muitas adaptações de projeto e o acabamento foi manual. Para sua construção foram utilizados 15 tipos diferentes de plásticos, que possuíam três tonalidades: amarelo, azul e 
vermelho. Ao todo, foram construídos 70 protótipos dessa casa. Em 1974, devido ao elevado preço do plástico virgem, ao embargo do petróleo e à grande competitividade das estruturas de concreto e de aço, foi encerrada a produção desse tipo de casa (http://www.drz.net/article_info.php/articles_id /1).

Segundo Quarmby (1976), em 1941, na Escócia, a Building Plastics Research Corporation, de Glasqow, apresentou algumas propostas para construção de casas modulares. Esse sistema consistia na utilização de painéis de plástico padronizados, que serviam como acabamento interno e externo da obra.

Em 1957, nos Estados Unidos, Monsanto e um grupo de arquitetos do Massachusetts Institute of Techonology (MIT) construíram a "House of the Future" (Fig. 2.2), que ficou exposta na Disneylândia durante dez anos. Ela foi construída sobre um pilar de concreto e sua estrutura tinha formato de cruz grega, o que lhe forneceu alta resistência estrutural. Para sua construção foram utilizados $30000 \mathrm{~kg}$ de poliéster reforçado com fibra de vidro, sob forma de painéis-sanduíche, tapetes e mobiliário.

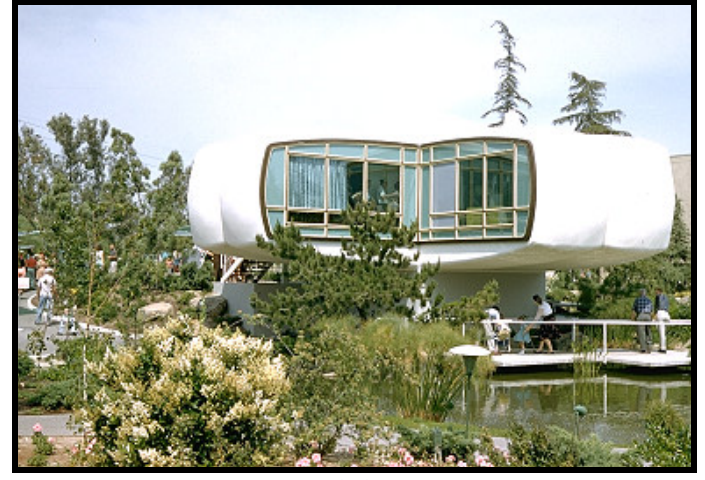

(a)

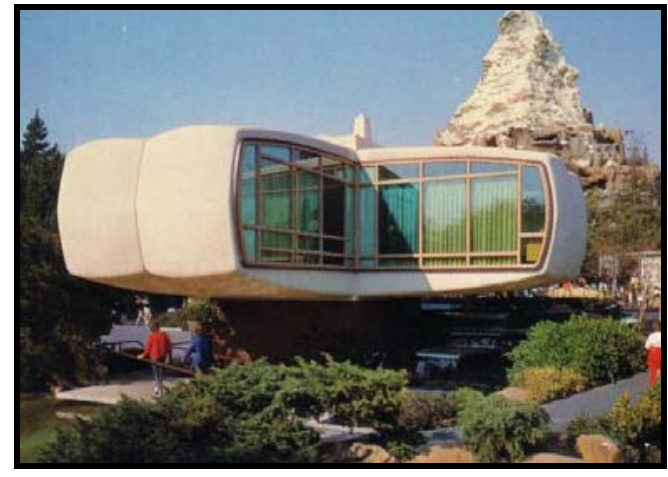

(b)

Figura 2.2 - Monsanto House of the Future.

Fonte: http://www.yesterland.com/futurehouse.html.

Em 1959 foi construída, por Rudolf Doernach, a primeira casa plástica da Alemanha (Fig. 2.3). Sua estrutura era formada por quatro paredes plásticas idênticas e a cobertura, por uma estrutura de fibra de vidro.

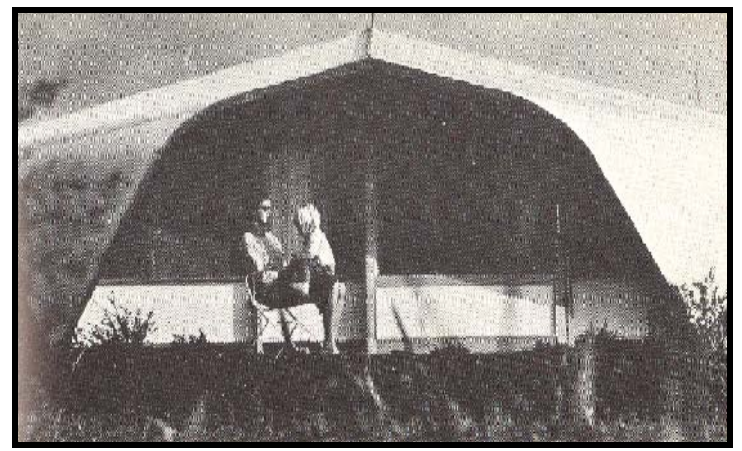

Figura 2.3 - Casa plástica, por Rudolf Doernach.

Fonte: Quarmby (1976). 
Depois da Segunda Guerra Mundial foram feitos diversos protótipos de casas construídas com material plástico, e os mais relevantes, além dos já citados anteriormente, são apresentados na tabela 2.1 .

Tabela 2.1 - Protótipos de casas plásticas.

Fonte: www.arq.ufsc.br/ labcon/arq5661/trabalhos_2004-2/plasticos/exemplos.

\begin{tabular}{c|l|c}
\hline Ano & \multicolumn{1}{|c|}{ Obra } & País \\
\hline 1956 & Casa no salão de utilidades domésticas & França \\
\hline 1957 & Cabine hoteleira móvel & França \\
\hline 1957 & Célula Montecatini & Itália \\
\hline 1958 & Casa dos Mosproject & Rússia \\
\hline 1961 & Abrigo de estrada de ferro & Grã-Bretanha \\
\hline 1961 & Casa Mex & França \\
\hline 1962 & Casa experimental & URSS \\
\hline 1965 & Casa-concha & França \\
\hline 1966 & Casa Trigon & Suiça \\
\hline 1967 & Casa esferóide & Bélgica \\
\hline 1968 & Casa de férias (estrutura dobrada ) & México \\
\hline 1968 & Casa do futuro & Finlândia \\
\hline 1969 & Casa redonda & Suíça \\
\hline
\end{tabular}

Segundo Hollaway (2003), a indústria da construção civil começou a projetar e a aceitar efetivamente os compósitos poliméricos como um material viável depois que as primeiras estruturas sofisticadas para embarcadouros foram projetadas no Reino Unido e construídas na África.

Em 1974, em Lancashire, foi construído um edifício em que toda sua estrutura utilizava compósitos como materiais de construção. O sistema construtivo utilizado nessa obra é composto por uma série de unidades dos blocos, em que foi empregado um método de produção manual. A estrutura (Fig. 2.4) mostrou ser extremamente rígida, devido à sua geometria.

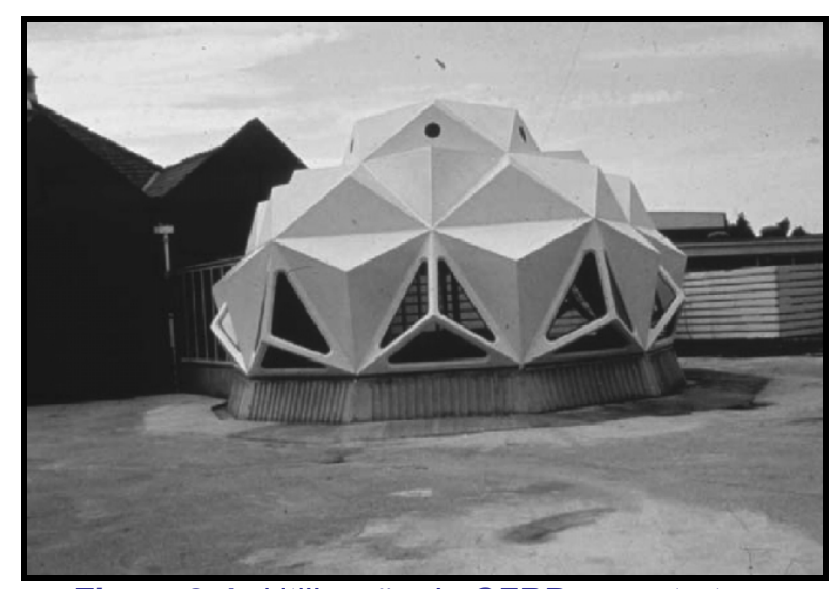

Figura 2.4 - Utilização de GFRP em estrutura. Fonte: Hollaway (2003). 
Durante as décadas de 1970 e 1980 vários edifícios foram construídos no Reino Unido, tais como a Escola Morpeth, a Casa Mondial e o Covent Garden Flower Market, em Londres, e o Edifício American Express (Fig. 2.5), em Brighton. Esses edifícios foram construídos com vigas e pilares de concreto ou aço, os quais foram reforçados com GFRP (polímero reforçado com fibra de vidro). Esses compósitos eram geralmente produzidos usando disposição aleatória da fibra de vidro.

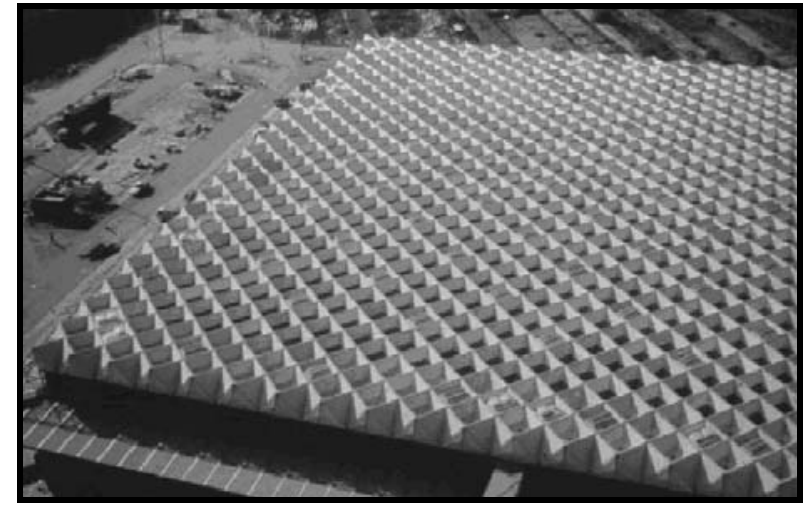

(a)

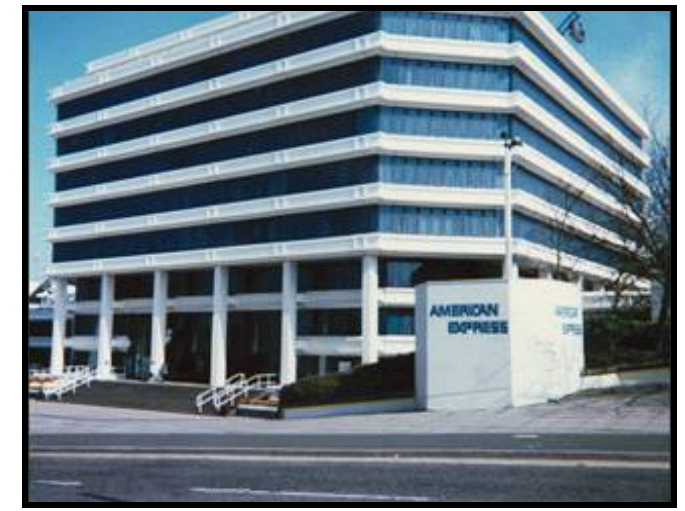

(b)

Figura 2.5 - Covent Garden Flower Market (a) e Edifício American Express (b). Fonte: Hollaway (2003).

Ainda durante esse período, foram produzidas estruturas de compósitos poliméricos pultrusados, como é mostrado em figura 2.6.

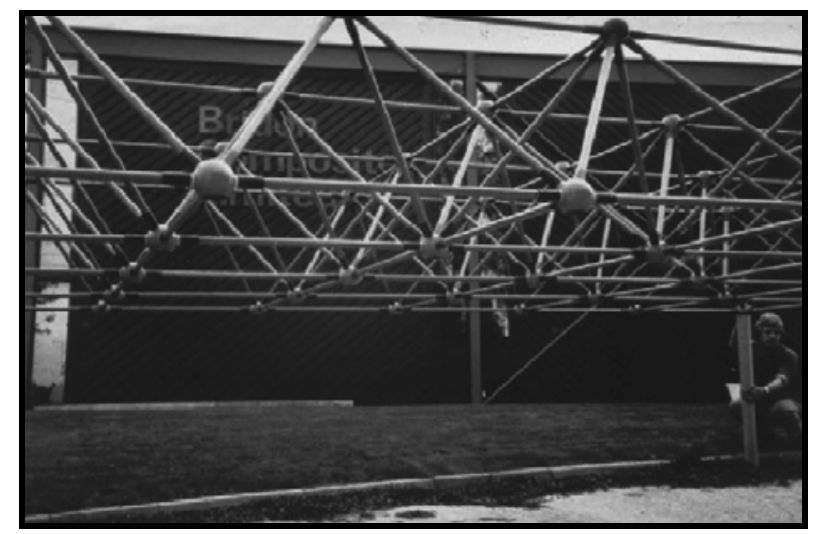

Figura 2.6 - Estrutura produzida com perfis de FRP pultrusados.

Fonte: Hollaway (2003).

De 1990 a 2000 a utilização de materiais compósitos de polímeros fez grandes avanços no campo da construção civil, principalmente na área das pontes.

Na figura 2.7 pode-se ver uma ponte que foi construída em 2000, sobre o rio Hudson, em New York, a qual possui um vão de $9 \mathrm{~m}$ e largura de $3,35 \mathrm{~m}$. Para sua construção, foram utilizados $5000 \mathrm{~kg}$ de polietileno de alta densidade reforçado com fibra de vidro e $2500 \mathrm{~kg}$ de aço, para as conexões e os tirantes. 


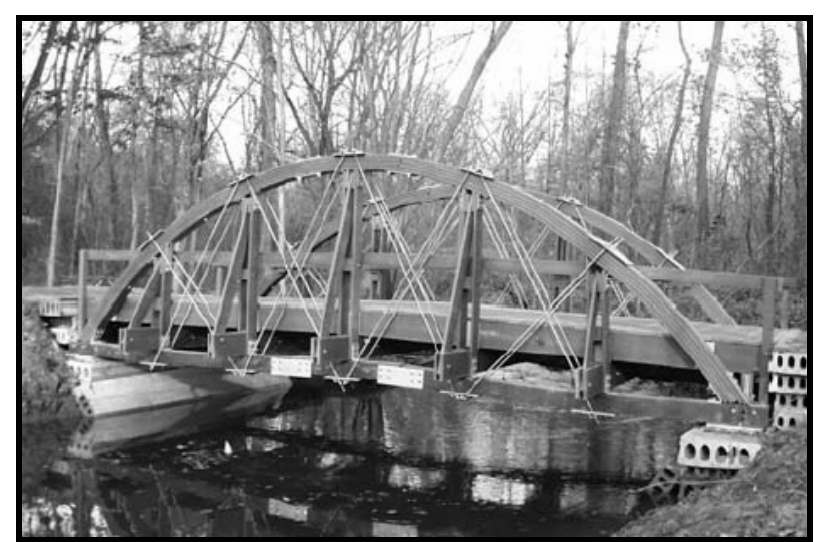

Figura 2.7 - Ponte sobre o rio Hudson construída com plástico reforçado com fibra de vidro. Fonte: Krishnaswamy (2001).

Outra ponte foi construída em 2002 sobre o rio Mullica, em New Jersey, com vão de 14m e largura de 3,5m. Para sua construção foram utilizados $14000 \mathrm{~kg}$ de polietileno de alta densidade e poliestireno.

Além das pontes, está se fazendo uso do plástico na produção de elementos estruturais, como por exemplo, dormentes para ferrovias.

Nosker e Renfree, pesquisadores da AMIPP, e o Centro de Materiais Avançados via Processamento de Polímeros Imiscíveis, da Universidade Rutgers em New Jersey (Estados Unidos), estão desenvolvendo materiais estruturais por meio da utilização de blendas poliméricas, como PEAD/PS, e da combinação com outros materiais como cerâmicas e metais. Esse novo material estrutural vem sendo utilizado para a fabricação de vigas de seção I e de pilares de plástico.

Algumas empresas, como a Tietek, U.S. Plastic Lumber, Polywood e Cogumelo estão produzindo os dormentes de polímeros reciclados, e uma das vantagens desses elementos é que, além de serem feitos com material reciclado, possuem o mesmo sistema de fixação dos dormentes de madeira (Figura 2.8).

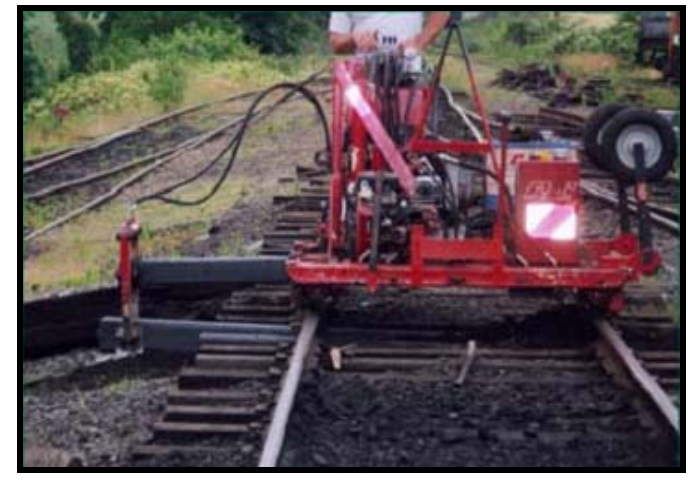

(a)

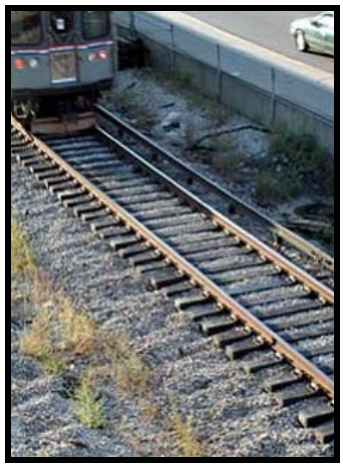

(b)

Figura 2.8 - Dormentes de plástico reciclado produzidos pela Polywood Plastic Lumber, de New Jersey.

Fonte: Schut (2004). 
Em 2002, o arquiteto japonês Kengo Kuma projetou e construiu uma residência de dois pavimentos utilizando plástico reforçado com fibra de vidro (FRP) para a produção das vigas e painéis (Fig. 2.9).

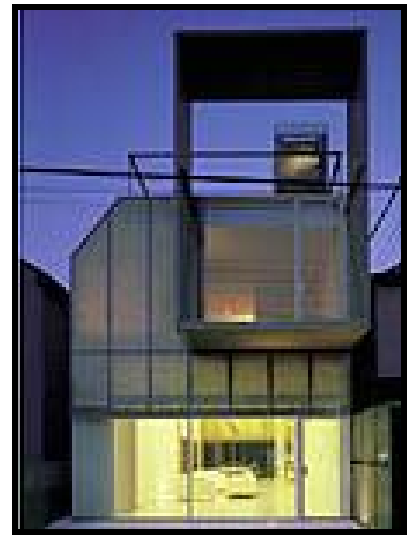

(a)

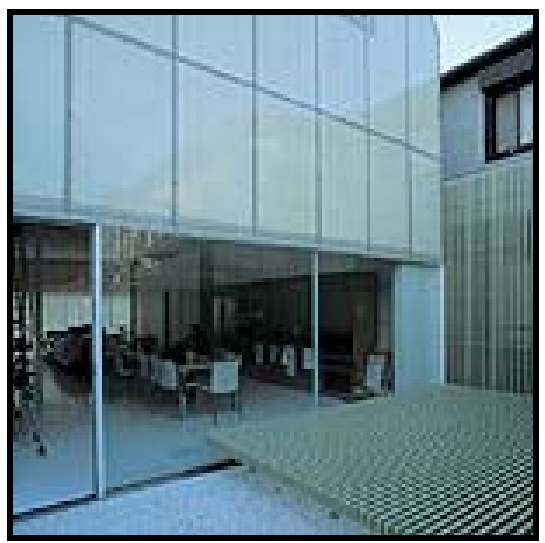

(b)

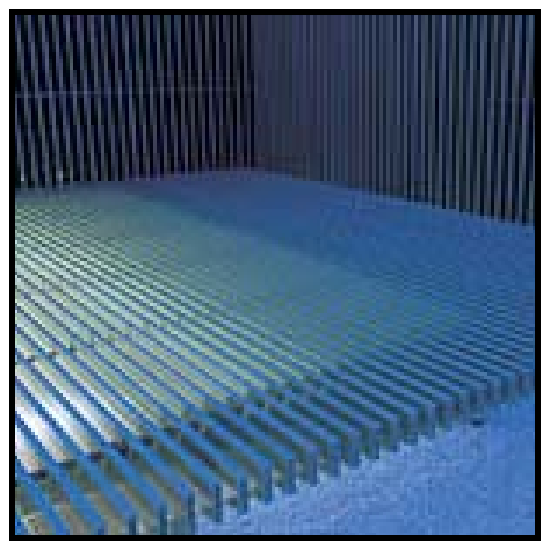

(c)

Figura 2.9 - Residência japonesa construída em plástico

Fonte: http://www.architectureweek.com/2005/0914/design_1-2.html.

Sullivan et al. (1999) desenvolveram um compósito polimérico a partir de material plástico reciclado. Esse compósito é sugerido aos mais diversos usos na construção e especialmente para substituição de elementos que são produzidos com madeira, tais como dormentes de ferrovias, meio-fios de estacionamentos, estacas em marinas, deques de piscinas, mourões, cruzetas, dentre outros. A figura 2.10 apresenta alguns elementos estruturais produzidos em plástico.

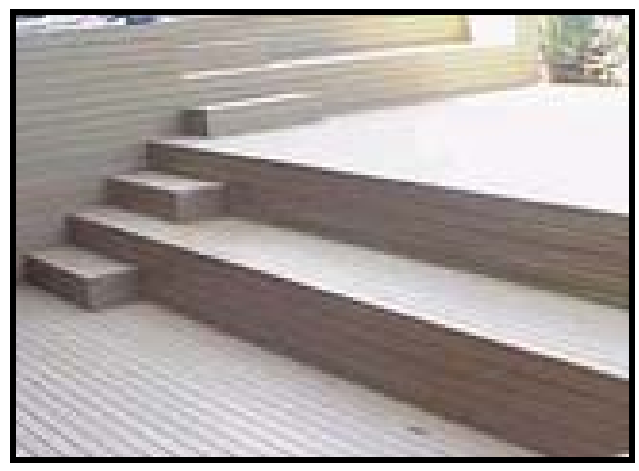

(a)

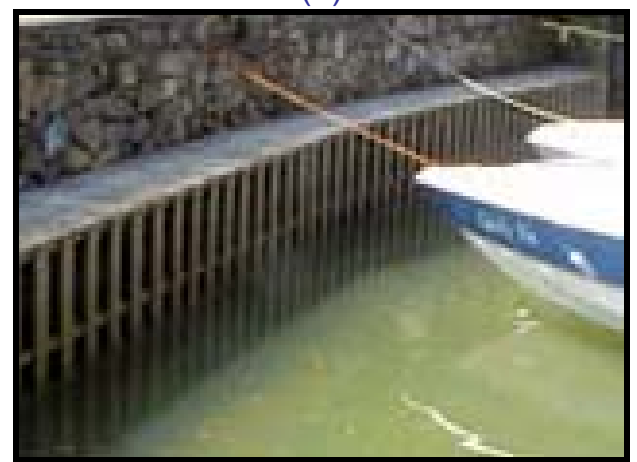

(c)

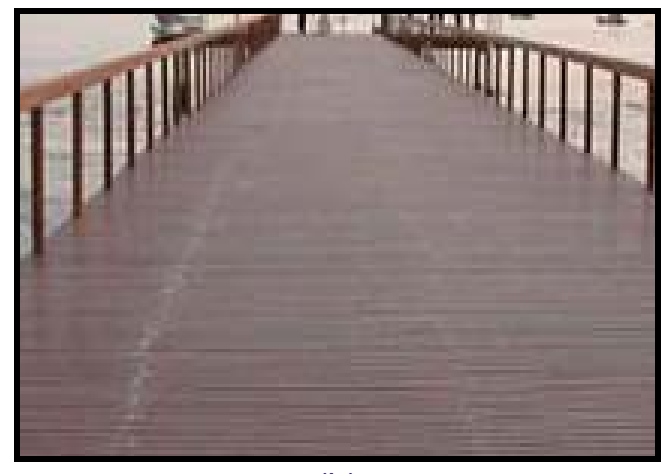

(b)

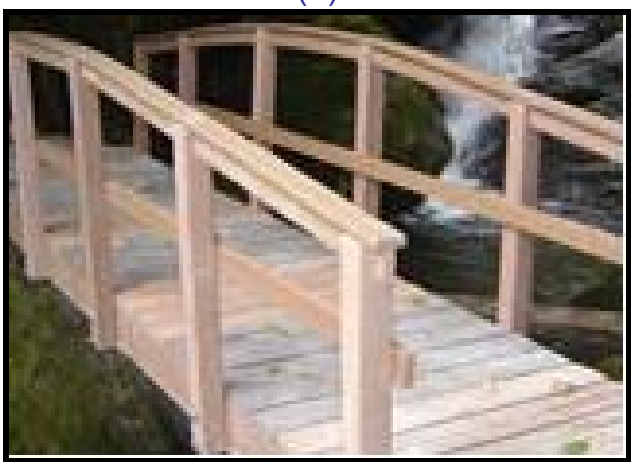

(d)

Figura 2.10 - Exemplos de aplicação de elementos estruturais em plásticos:

(a) deques, (b) marinas, (c) piers e (d) guarda-corpo.

Fonte: www.cogumelo.com.br. 
Com o objetivo de situar os materiais plásticos entre os materiais convencionais utilizados na construção civil, a tabela 2.2 traz algumas características desses materiais.

Tabela 2.2 - Valores médios de algumas características dos materiais de construção.

Fonte: Rocha (1990).

\begin{tabular}{|c|c|c|c|c|c|}
\hline \multirow{3}{*}{ Material } & \multicolumn{5}{|c|}{ Características } \\
\hline & \multirow{2}{*}{$\begin{array}{c}\text { Densidade } \\
\left(\mathrm{g} / \mathrm{cm}^{3}\right)\end{array}$} & \multicolumn{2}{|c|}{ Tensão de ruptura (MPa) } & \multirow{2}{*}{$\begin{array}{l}\text { Coeficiente de } \\
\text { dilatação térmica } \\
\text { linear }\left(10-6 /{ }^{\circ} \mathrm{C}\right)\end{array}$} & \multirow{2}{*}{$\begin{array}{c}\text { Temperatura máxima } \\
\text { de utilização }\left({ }^{\circ} \mathrm{C}\right)\end{array}$} \\
\hline & & Tração & Compressão & & \\
\hline $\begin{array}{c}\text { Aço para } \\
\text { construção civil }\end{array}$ & $7,8-7,9$ & $\geq 370$ & 370 & 12,5 & $400-500$ \\
\hline Concreto & $2,5-2,8$ & $1,5-3,5$ & $20-40$ & 12 & 250 \\
\hline $\begin{array}{l}\text { Plásticos rígidos } \\
\text { não reforçados }\end{array}$ & $0,8-2,2$ & $10-150$ & $7-200$ & $50-250$ & $60-150$ \\
\hline $\begin{array}{c}\text { Plásticos } \\
\text { reforçados }\end{array}$ & $1,2-2,3$ & $200-1000$ & $150-500$ & $15-30$ & $150-250$ \\
\hline Espumas rígidas & $0,02-0,1$ & $0,2-2$ & $0,1-1$ & $100-200$ & 70 \\
\hline
\end{tabular}

Analisando-se os dados, observa-se que os plásticos reforçados podem atender às solicitações de tração e de compressão necessárias para aplicações na construção civil. Entretanto, deve-se fazer um estudo minucioso para aplicações submetidas a elevadas temperaturas, prevendo-se a utilização de aditivos para melhorar suas propriedades térmicas. Com relação aos plásticos rígidos não reforçados, percebe-se que os valores apresentados apresentam grande variabilidade, que pode ter sido ocasionada pela grande gama de polímeros considerados nesta análise.

As propriedades já citadas, juntamente com a alta durabilidade, o baixo custo de manutenção e a dificuldade cada vez maior de se obter madeira de qualidade, tornam os compósitos termoplásticos reciclados uma alternativa à madeira, que pode ser utilizada para aplicações mais nobres como, por exemplo, mobiliário.

\subsection{Sistemas de distribuição de energia}

\subsubsection{Histórico}

A utilização de postes e de cruzetas teve seu início com o uso da energia elétrica e do telégrafo. Devido à necessidade de se fazer a distribuição de energia gerada e a transmissão de mensagens entre localidades diferentes, foi necessária a utilização de cabos e, para a sustentação deles, postes e cruzetas.

O emprego da energia elétrica no país teve seu início em 1883 com a instalação da Usina Hidroelétrica Ribeirão do Inferno, na cidade de Diamantina, Minas Gerais, que foi destinada primeiramente ao fornecimento de força motriz a serviços de mineração (Silva, 2003). Depois dessa usina, várias outras foram construídas, principalmente no Estado de 
Minas Gerais. A Usina Monjolinho, de 1893, em São Carlos, é a primeira do Estado de São Paulo, e a mais antiga em operação no país.

Segundo Gomes (1986), a partir das primeiras instalações que datam do final do século XVIII, a aplicação da energia elétrica foi se ampliando tanto nos países desenvolvidos como nos países em desenvolvimento, como o Brasil. Até a primeira década do século $\mathrm{XX}$, essas pequenas usinas geradoras de energia elétrica visavam o atendimento dos serviços públicos instalados nas cidades, predominantemente para fornecimento de força motriz a unidades industriais, sobretudo do setor têxtil, o atendimento da iluminação pública e privada e, em particular, fornecendo tração aos bondes utilizados para o transporte coletivo. A necessidade de atender à crescente demanda por iluminação, abastecimento de água, esgoto, transportes e telefonia, e a impossibilidade de seu atendimento diretamente por parte da administração pública, levou a instituição definitiva do regime de concessões para a prestação dos serviços públicos, como ocorre atualmente.

\subsubsection{Sistemas de distribuição de energìa elétrica}

O sistema de distribuição pode ser definido como a parte de um sistema de potência destinado ao transporte e à distribuição de energia elétrica, a partir do barramento secundário de uma subestação (onde termina a transmissão ou subtransmissão) até os pontos de consumo.

Existem diversos sistemas de distribuição de energia elétrica, dentre os quais podem ser citados o sistema de redes nuas, redes aéreas compactas, que são subdivididas em protegidas de média tensão e isoladas de baixa e média tensão, rede com cabos pré-reunidos de média tensão, redes subterrâneas, etc.

As redes aéreas convencionais são caracterizadas por condutores nus (Fig. 2.11). Por estarem desprotegidas contra as influências do meio, apresentam altas taxas de falhas, como a interrupção no fornecimento de energia, provocada pelo contato dos galhos das árvores, a queima de eletrodomésticos, o comprometimento da iluminação pública, dentre outras.

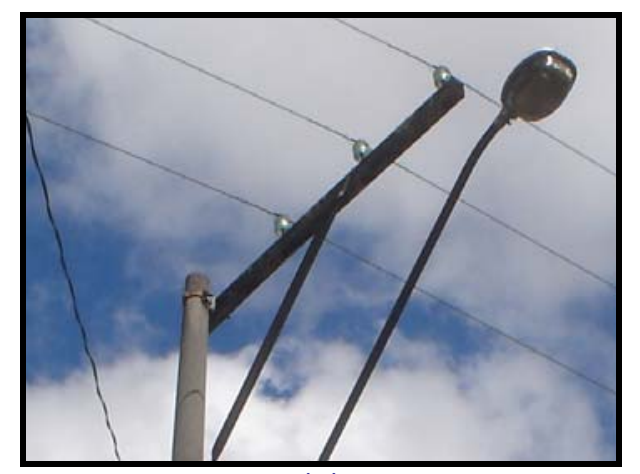

(a)

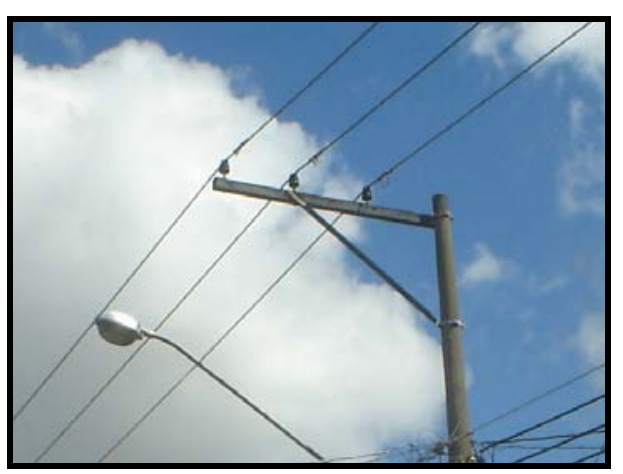

(b)

Figura 2.11 - Rede convencional de distribuição de energia. 
As redes aéreas compactas protegidas (Fig. 2.12) são constituídas de espaçadores plásticos, instalados em uma distância de oito a dez metros, e têm a função de apoiar os condutores, dispondo-os num arranjo triangular. Um cabo de aço mensageiro sustenta esses espaçadores e absorve todo o esforço mecânico, deixando os condutores ligeiramente tracionados.

As redes secundárias isoladas (Fig. 2.13) são utilizadas em razão das exigências requeridas pelo meio ambiente, ou seja, em áreas densamente arborizadas, com galhos em contato permanente com os condutores. Nesse tipo de rede, são utilizados três condutores isolados, blindados, trançados e reunidos em torno de um cabo mensageiro de sustentação, fazendo com que esse sistema seja totalmente isolado (CEMIG).

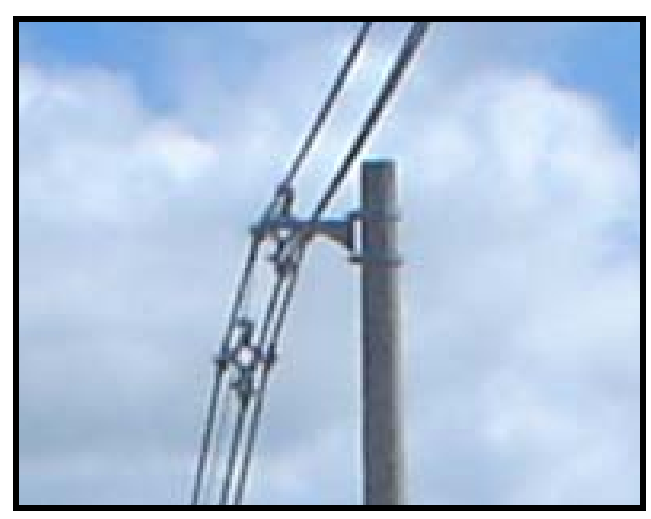

(a)

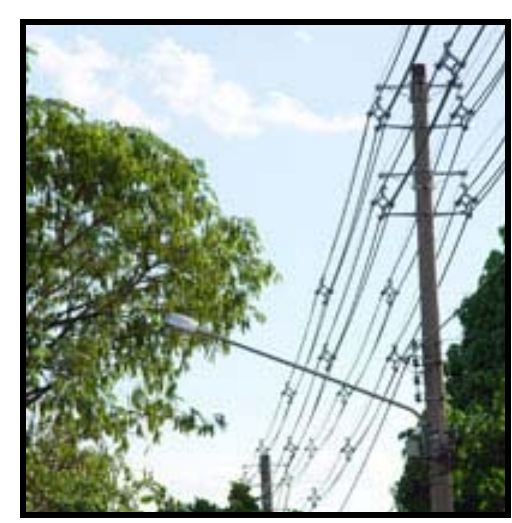

(b)

Figura 2.12 - Rede aérea compacta protegida de distribuição de energia.

Fonte: Celg.

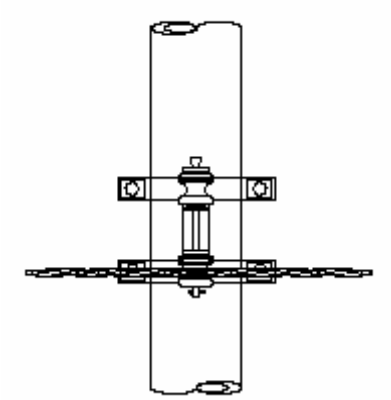

Figura 2.13 - Rede secundária isolada.

Fonte: CPFL.

A rede de distribuição subterrânea é aquela constituída de cabos e acessórios instalados sob a superfície do solo, diretamente enterrados ou em dutos (Eletropaulo).

Neste trabalho será estudado um elemento da rede de distribuição aérea convencional, as cruzetas, cuja função é sustentar os condutores de energia elétrica, conforme ilustrado na figura 2.14 . 

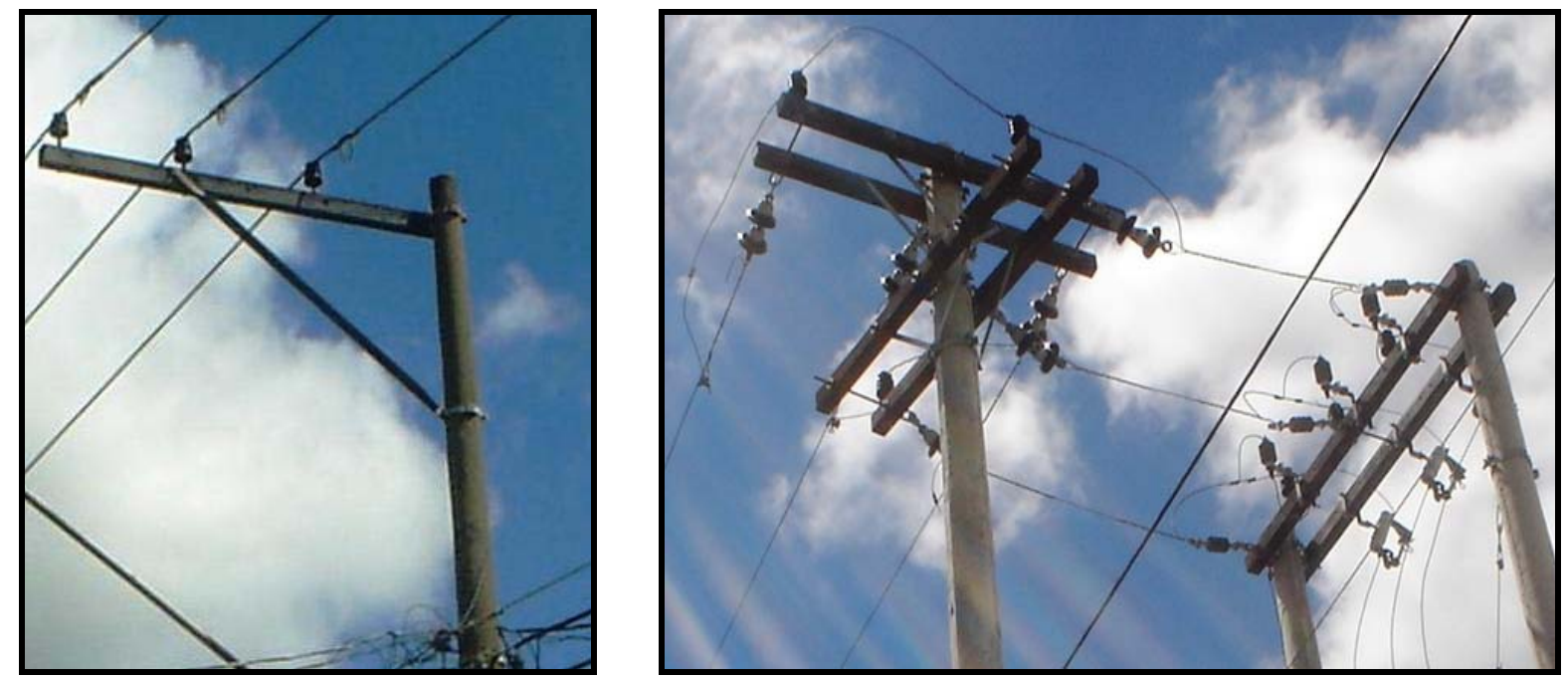

Figura 2.14 - Estrutura básica para construção de sistema aéreo.

Inicialmente, os postes e cruzetas eram feitos de madeira. Devido ao fato da madeira estar sujeita aos ataques de organismos e conseqüente degradação, foi necessário o desenvolvimento de novos materiais. Hoje, já existem postes e cruzetas de concreto, cruzetas de madeira de reflorestamento, madeira compensada e de plástico reciclado, objeto deste trabalho. 


\section{ENGENHARIA DE POLÍMEROS}

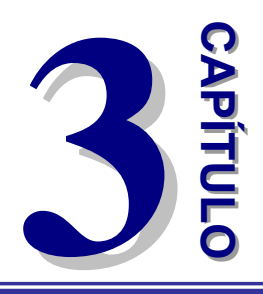

\subsection{Definição dos polímeros}

A palavra polímero possui origem grega e significa muitas (poli) partes ou unidades de repetição (meros). Os polímeros são materiais orgânicos ou inorgânicos, naturais ou sintéticos, de alto peso molecular, que possuem estrutura molecular formada pela repetição de pequenas unidades, chamadas monômeros. Essa molécula inicial (monômero) vai sucessivamente se unindo a outras, formando o dímero (duas moléculas), o trímero (três moléculas), o tetrâmero (quatro moléculas), até chegar ao polímero. Devido ao seu grande tamanho, as moléculas de um polímero são chamadas macromoléculas.

O mecanismo químico de formação dos plásticos possui o nome de polimerização e é o processo pelo qual as unidades básicas, os monômeros, são reunidos. Há dois meios comuns de fazer isso, conduzindo a estruturas moleculares intrinsecamente diferentes e, portanto, a propriedades diferentes.

A polimerização por adição implica em ligar os monômeros juntos numa cadeia, em geral pela aplicação de calor e pressão, na presença de um catalisador. Os monômeros podem ser do mesmo tipo ou de diferentes tipos, como em copolimerização. A polimerização por adição forma cadeias articuladas, com vários graus de ramificação. Isso normalmente conduz a materiais flexíveis, com a rigidez aumentando com o comprimento das cadeias e a quantidade de ramificações. Também produz, geralmente, propriedades "termoplásticas", permitindo que o material seja amolecido sob calor. Polimerização por condensação implica uma reação química entre dois monômeros, levando a uma reconstituição de sua estrutura molecular e à eliminação de um subproduto como água, com uma estrutura resultante, freqüentemente mais interligada do que a produzida pela polimerização de adição.

Os termoplásticos, que são produzidos com polimerização por adição ou por condensação, amolecem sob a aplicação de calor.

\subsection{Classificação dos polímeros}

Os polímeros, sob o ponto de vista das características tecnológicas, podem ser divididos em dois grandes grupos: os termoplásticos e os termofixos (termorrígidos). 
Os termoplásticos, também chamados de plásticos, são os mais encontrados no mercado. Podem ser amolecidos ou liqüefeitos por aquecimento e endurecimento diversas vezes, sem perder suas propriedades, e alguns podem até dissolver-se em vários solventes. Logo, sua reciclagem é possível, característica bastante desejável atualmente. Sob temperatura ambiente, podem ser maleáveis, rígidos ou mesmo frágeis. Possuem estrutura molecular formada por moléculas lineares dispostas na forma de cordões soltos, mas agregados, como num novelo de lã. Polietileno (PE), polipropileno (PP), poli(tereftalato de etileno) (PET), policarbonato (PC), poliestireno (PS), poli(cloreto de vinila) (PVC), poli(metilmetacrilato) (PMMA) são alguns exemplos de termoplásticos. Segundo Agnelli (2005), os termoplásticos podem ser subdivididos em convencionais, especiais e de engenharia.

O grupo dos termoplásticos convencionais ou de grande uso é formado por cinco polímeros principais: polietileno de baixa densidade (LDPE), polietileno de alta densidade (HDPE), polipropileno (PP), poli(cloreto de vinila) (PVC) e poliestireno (PS). Os termoplásticos desse grupo representam aproximadamente $52,5 \%$ do consumo total de todos os polímeros produzidos. Esses materiais são consumidos em grande escala e são caracterizados pelo baixo custo, facilidade de processamento e aplicações que não requerem um alto desempenho mecânico.

O grupo dos termoplásticos especiais ou para aplicações especiais é formado por poli(metacrilato de metila) PMMA (acrílico), politetraflúor-etileno PTFE (Teflon), poli(cloreto de vinilideno), poli(fluoreto de vinilideno), dentre outros. Representam aproximadamente $2 \%$ do consumo total de todos os polímeros produzidos. Esses materiais são utilizados para aplicações específicas, não possuem um grande consumo e podem apresentar custo elevado e dificuldades de processamento.

O grupo dos termoplásticos de engenharia é formado pelos materiais caracterizados como sendo os plásticos de alto desempenho, que apresentam diversas propriedades importantes para aplicação em engenharia, tais como alta rigidez, dureza, tenacidade, resistência ao impacto, térmica e química, estabilidade dimensional, processabilidade sem muitos problemas, grande variedade e possibilidade de aplicações, dentre outras. O seu consumo representa aproximadamente $6,5 \%$ do consumo total de todos os polímeros.

Com relação aos termorrígidos (ou termofixos), esse grupo é representado pelos plásticos rígidos, frágeis e estáveis a variações de temperatura. Esse tipo de material utiliza o aquecimento para dar formato a uma peça apenas uma vez, visto que não pode mais amolecer. O aquecimento do polímero acabado promove decomposição do material antes de sua fusão, tornando sua reciclagem complicada. É formada por uma estrutura com 
ligações cruzadas químicas primárias entre macromoléculas, formando uma rede, presos por meio de numerosas ligações, não se movimentando com tanta liberdade como nos termoplásticos. Pode-se fazer analogia com uma rede de malha fina. Apresentam aproximadamente $10 \%$ do consumo total de polímeros.

Além das citadas anteriormente, existe um tipo de classificação que leva em conta as características mecânicas dos polímeros. Sob o ponto de vista do comportamento mecânico, os polímeros podem ser divididos em três grandes grupos: elastômeros (ou borrachas), plásticos e fibras.

Os elastômeros (borrachas) estão situados em uma classe intermediária entre os termoplásticos e os termorrígidos: não são fusíveis, mas apresentam alta elasticidade, não sendo rígidos como os termofixos. Sua estrutura molecular é similar à do termorrígido, mas há menor número de ligações químicas primárias entre as macromoléculas. Esse tipo de polímero pode ser estirado repetidamente e, após a retirada do esforço mecânico, o material volta rapidamente ao seu comprimento inicial, em virtude do baixo número de ligações moleculares. Possuem reciclagem complicada, devido à incapacidade de fusão.

Os plásticos podem ser definidos como materiais orgânicos estáveis nas condições normais de uso, mas que, em algum estágio de sua fabricação, são fluídos, podendo ser moldados por aquecimento, pressão ou ambos. Polietileno, polipropileno e poliestireno são alguns exemplos de polímeros desse grupo.

As fibras são corpos em que a razão de aspecto [razão comprimento (I)/espessura(d)] é muito elevada. Os polímeros desse grupo geralmente são formados por macromoléculas lineares, orientadas longitudinalmente (no sentido do eixo da fibra). Poliésteres, poliamidas e poliacrilonitrila são exemplos de polímeros desse grupo.

Entre os termoplásticos existem diversas outras classificações dos polímeros, que não serão abordadas neste trabalho. As definições aqui apresentadas servem para situar o material que será utilizado no decorrer do trabalho.

\subsection{Propriedades dos polímeros}

Os polímeros possuem diversas propriedades para avaliação de seu desempenho mecânico e podem ser divididas em: mecânicas, térmicas, elétricas, óticas, resistência química, dentre outras. Segundo Marczak (2004), os plásticos possuem algumas características comuns que os diferenciam dos materiais usualmente empregados em engenharia, como os metais. A quantificação e o emprego correto dessas propriedades são em geral mais complexas do que para os materiais convencionais. No entanto, essa 
diferenciação é a principal responsável pelo fato do comportamento em serviço de peças plásticas ser bastante distinto do relativo aos metais, por exemplo.

O peso é outra característica importante, já que plásticos são sempre mais leves que os materiais cerâmicos e os metálicos, o que os torna particularmente atrativos para diversos ramos industriais.

Neste capítulo serão abordadas somente as propriedades de maior relevância para a aplicação dos polímeros como material para confecção de cruzetas.

O comportamento característico dos plásticos em comparação com o dos materiais metálicos usuais fica evidente pelas suas propriedades mecânicas. Segundo Marczack (2004), a primeira distinção que deve ser evidenciada é o comportamento geometricamente não-linear dos plásticos, isto é, a relação carga versus deslocamento não é linear, mesmo que o material ainda não tenha ultrapassado seu limite de escoamento, ou seja, os plásticos normalmente possuem grande flexibilidade, conforme o tipo de polímero e os aditivos usados na sua formulação.

Segundo Chaves (1999), o comportamento mecânico de um polímero pode ser caracterizado por suas propriedades de tensão versus deformação, ou seja, a partir do momento em que se aplica uma tensão no polímero para deformá-lo até provocar sua ruptura.

De acordo com Rocha (1990), o comportamento dos materiais plásticos face às solicitações mecânicas é frequentemente designado por viscoelástico. Assim, os plásticos possuem características comuns aos sólidos de Hooke e aos fluídos Newtonianos e são afetados pelo tempo de atuação das solicitações e pela temperatura.

Em um ensaio, os parâmetros ou as grandezas que caracterizam o comportamento mecânico dos polímeros devem ser sempre associados às condições de temperatura e ao tempo de solicitação da carga. De uma maneira geral, os erros mais comuns estão relacionados a projetar componentes plásticos com níveis de tensão ou módulos de elasticidade muito altos ou que não levam em conta o efeito da temperatura.

As propriedades mecânicas, segundo Rocha (1990), podem ser citadas como:

- tração (módulo de elasticidade, resistência à tração, alongamento na ruptura);

- flexão e compressão;

- cisalhamento e resistência ao impacto;

- resiliência (capacidade de um material absorver energia quando deformado elasticamente e liberá-la quando descarregado);

- desenvolvimento de calor em carregamento cíclico; 
- resistência à fadiga e outras propriedades mecânicas de longo prazo (fluência e relação de tensão);

- dureza;

- resistência à fricção; e

- resistência à abrasão.

\subsubsection{Módulo de elasticidade}

O módulo de elasticidade de um material é responsável em parte pela rigidez do componente e, por isso, possui papel importante durante a seleção do material. No caso dos plásticos, deve-se levar em conta que o módulo de elasticidade é muito mais suscetível às variações de temperatura do que se está acostumado com outros materiais, tais como os metais (Marczak, 2004). A figura 3.1 ilustra a comportamento de um polímero quando submetido à variação de temperatura.

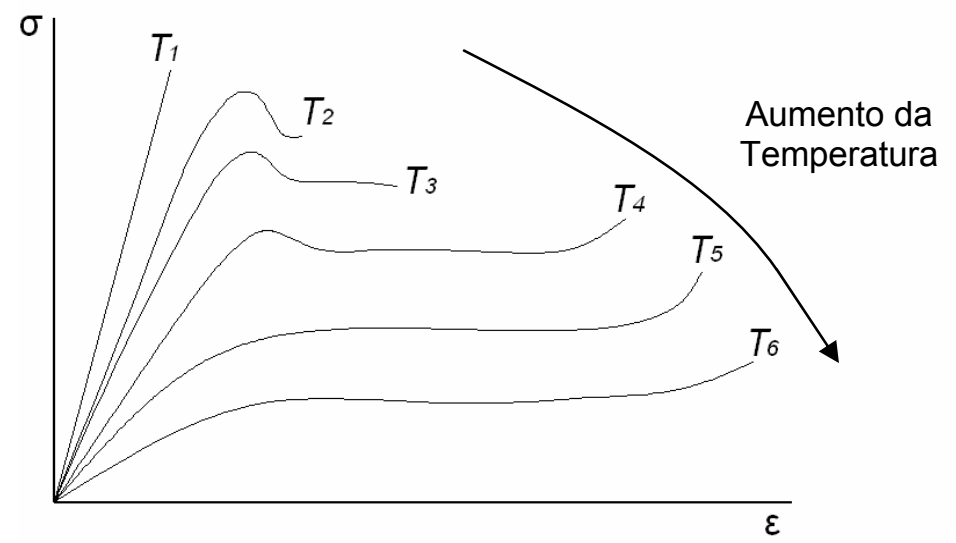

Figura 3.1 - Ilustração esquemática dos diagramas $\sigma$ versus $\varepsilon$ de um polímero com o aumento da temperatura.

Fonte: Marczak (2004).

Mano e Mendes (1999) definem a elasticidade como uma característica encontrada em todos os materiais, tanto na compressão como na tração, que depende da natureza química, da temperatura e da velocidade de deformação aplicada. Quanto à deformação, ela pode se apresentar sob duas formas: elástica (em faixa estreita ou larga) ou inelástica.

A deformação elástica em faixa estreita é reversível e possui alto módulo de elasticidade. Nesse tipo de deformação ocorre o afastamento ou a aproximação entre os átomos e uma mudança entre os ângulos das deformações químicas. Seu comportamento pode ser comparado ao de uma mola quando submetida à tração, na qual, após a retirada da força aplicada, a deformação é totalmente recuperada, obedecendo à Lei de Hooke, isto é, a deformação é proporcional à força aplicada. Essa é a deformação típica dos metais, mas também ocorre nos polímeros cristalinos, nos que estão abaixo da temperatura de transição vítrea ou então naqueles que possuem estrutura reticulada. 
A deformação elástica em faixa larga também é reversível, mas possui baixo módulo de elasticidade e depende da configuração molecular do material. Os polímeros possuem cadeias moleculares longas e entrelaçadas. Quando são aplicadas pequenas forças de tração, ocorre um desembaraçamento inicial das moléculas, que depois disso passam a reagir à ação das forças. Nessa fase, a deformação pode ser totalmente recuperada. Essa é a deformação típica da borracha natural vulcanizada, que possui estrutura reticulada.

A tabela 3.1 faz uma comparação quanto ao módulo de elasticidade de alguns materiais.

Tabela 3.1 - Módulos de elasticidade típicos (à temperatura ambiente).

\begin{tabular}{l|c}
\multicolumn{2}{c}{ Fonte: Marczak (2004). } \\
\hline \multicolumn{1}{c}{ Material } & $E$ (MPa) \\
\hline Compostos grafite-epóxi & 280000 \\
\hline Aço & 210000 \\
\hline Alumínio & 70000 \\
\hline Epóxi reforçado com fibra de vidro & 40000 \\
\hline Poliéster reforçado com fibra de vidro & 14000 \\
\hline Nylons reforçado com 30\% de fibra de vidro & 10000 \\
\hline Acrílicos & 3500 \\
\hline Resinas epóxi & 3100 \\
\hline Policarbonato & 3100 \\
\hline Acetal copolímero & 2900 \\
\hline Polietileno de alto peso molecular & 700 \\
\hline
\end{tabular}

\subsubsection{Resistência à tração}

A resistência dos polímeros é dependente da temperatura, da velocidade de carregamento e de alguns fatores ambientais, como a umidade. A Fig.3.2a ilustra o efeito da velocidade de carregamento sobre a resistência, enquanto a Fig.3.2b mostra a influência da umidade em materiais como o Nylon.

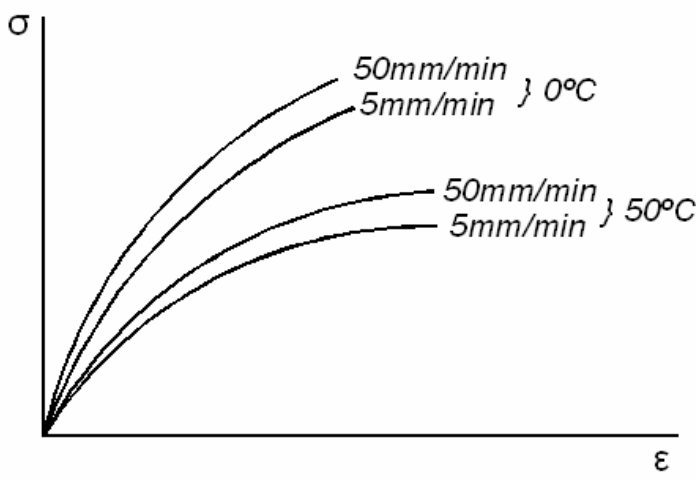

(a)

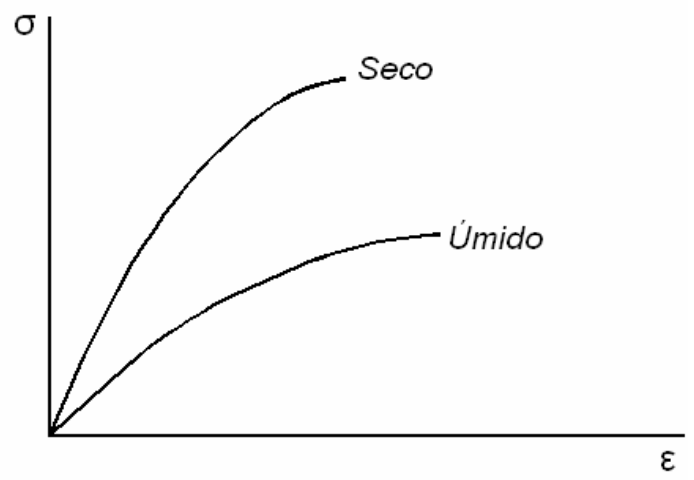

(b)

Figura 3.2 - Comportamento esquemático da resistência de polímeros em função da velocidade de carregamento e da umidade.

Fonte: Marczak (2004). 


\subsubsection{Resposta dependente do tempo (fluência e relaxação de tensão)}

Segundo Marczak (2004), fluência (creep) é definida como sendo uma deformação continuamente ativa sobre o material, mesmo para uma tensão constante. É uma característica típica dos plásticos por ocorrer mesmo à temperatura ambiente, embora o fenômeno seja muito influenciado pela temperatura. Uma vez aplicado um nível de tensão, material responde imediatamente, de forma similar à dos metais. Se a carga é mantida por um longo tempo, entretanto, o processo de deformação continua lentamente (Fig. 3.3).

Portanto, a fluência se refere a uma adaptação contínua do material à carga aplicada. Quando a fluência é linear, é possível definir um parâmetro chamado módulo de fluência $(J)$.

$$
J(t)=\frac{\varepsilon(t)}{\sigma}
$$

É esse parâmetro que o projetista deve empregar para prever corretamente o comportamento de materiais plásticos. Seu valor deve ser escolhido dos catálogos de fabricantes, e leva em conta uma estimativa da carga aplicada, sua duração e as condições de temperatura presentes durante a operação do componente.
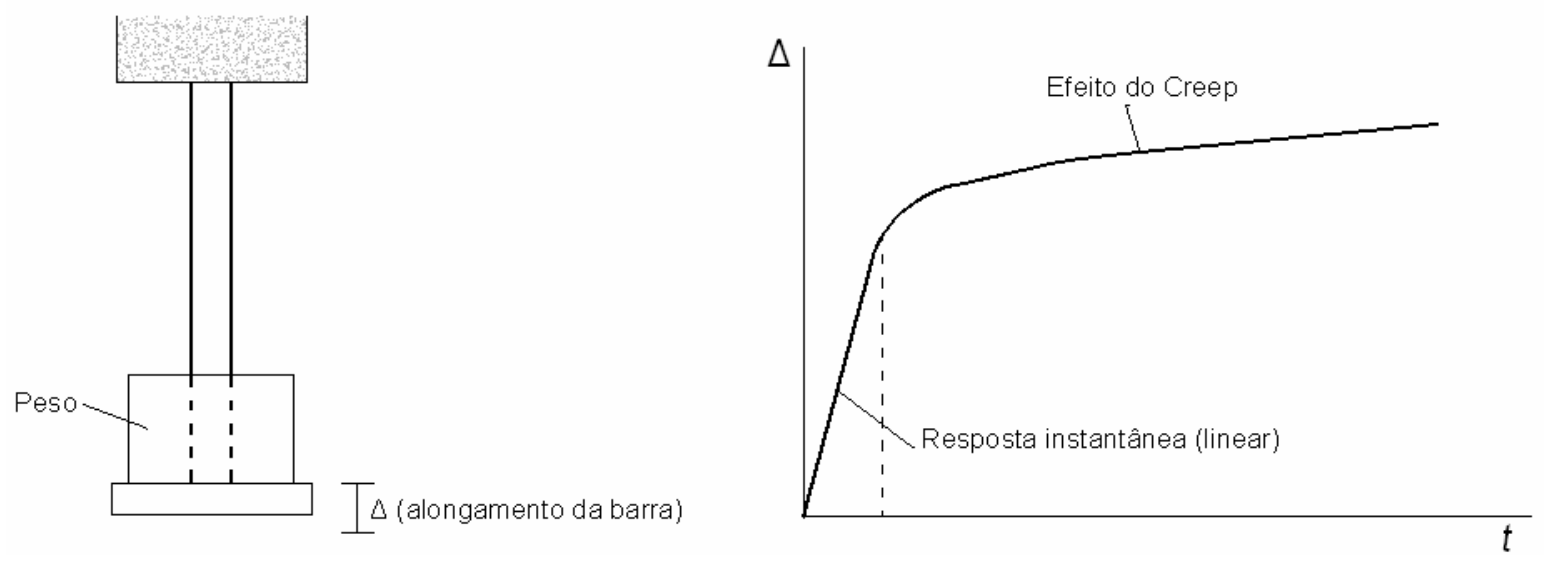

Figura 3.3 - llustração do fenômeno da deformação por fluência.

Fonte: Marczak (2004).

Algumas cargas, como fibra de vidro e carbono, quando incorporadas à matriz polimérica, reduzem o fenômeno da deformação por fluência.

Ao se projetar com plásticos deve-se lembrar que a fluência é afetada por:

- Carga (tensão);

- Temperatura;

- Duração da carga; e 
- Ambiente (umidade e elementos químicos agressivos).

Para tensão constante, a equação (3.1) mostra que se a deformação é aumentada, J deve ser reduzido. Como a deformação cresce com o tempo e com a temperatura, o módulo de fluência decresce com essas variáveis.

Em uma situação inversa, em que a deformação é mantida constante, verifica-se que a tensão vai diminuindo com o tempo. Esse comportamento reflete um rearranjo das cadeias do polímero para se adaptar à carga aplicada, e é chamado de relaxação de tensão.

Considerando $\varepsilon$ como a deformação, ao longo do tempo, e $\sigma$ como sendo a tensão aplicada, o módulo de relaxação pode ser considerado análogo ao módulo de fluência e ser definido por:

$$
Y(t)=\frac{\varepsilon(t)}{\sigma}
$$

Essa variável tem grande importância em aplicações como vedações, espaçadores, encaixes sob pressão e peças parafusadas, já que a carga de montagem não é mantida ao longo da vida do componente.

É comum os fabricantes recomendarem uma tensão máxima de projeto, que tem uma aplicação similar à do módulo de fluência. A tensão de projeto recomendada para peças de acrílico injetadas é de 3,5 $\mathrm{MPa}$, mesmo com a tensão de ruptura podendo chegar a $70 \mathrm{MPa}$. Os projetistas normalmente prestam atenção a este último valor, devidamente reduzido por um coeficiente de segurança, mas isto pode não ser suficiente para evitar danos no componente.

Portanto, apenas tensões/deformações muito baixas apresentam relaxação/fluência desconsideráveis. A Fig. 3.4 ilustra o alongamento de um material plástico em função do tempo, em vários níveis de tensão constante. Não apenas o alongamento é significativamente reduzido quando a tensão aplicada também o é, como somente para tensões muito baixas atinge-se um patamar em que a fluência é desprezível. Esses níveis de tensão devem ser empregados como um critério de projeto. Nas publicações especializadas, os dados de fluência são normalmente apresentados em gráficos logarítmicos, com a escala de tempo podendo chegar a milhares de horas. 


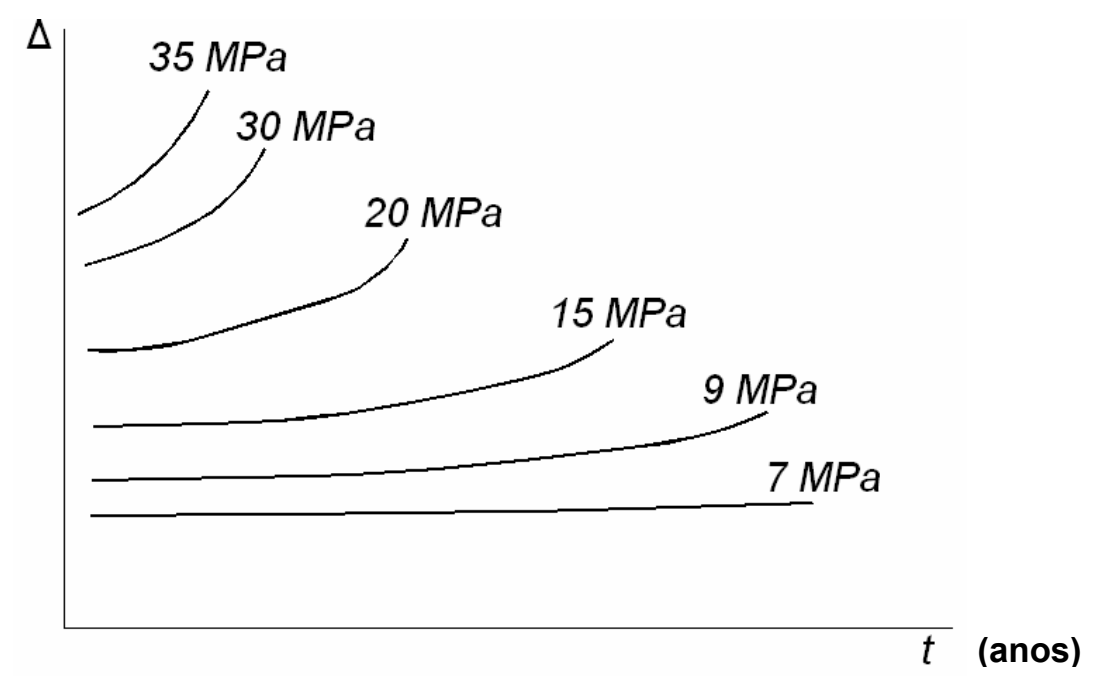

Figura 3.4 - Alongamento em função do tempo para diversos níveis de tensão. Fonte: Marczak (2004).

Problemas que apresentam características de fluência e de relaxação não podem ser resolvidos por relações constitutivas lineares, como a Lei de Hooke. Essa classe de problemas pertence à viscoelasticidade, e precisa ser modelada com relações apropriadas.

Sob efeito de temperatura, a maior parte dos materiais apresenta algum grau de viscoelasticidade. No caso de plásticos, no entanto, quase todos os polímeros amorfos se comportam viscoelasticamente. Por outro lado, esse comportamento viscoelástico pode ser aproximado como linear, na maior parte dos casos.

\section{d) Coeficiente de Poisson}

Segundo Marczak (2004), o coeficiente de Poisson depende da temperatura e do tempo de aplicação da carga. Sua faixa de variação vai de 0,2 até 0,4 para a maioria dos plásticos à temperatura ambiente, mas esses valores são suscetíveis a grandes variações, devido à composição química e às aditivações dos polímeros.

\section{e) Resistência à fadiga}

A resistência dos plásticos à fadiga depende da composição química do polímero, da temperatura, da freqüência do carregamento e da amplitude das tensões e das deformações, pois essas variáveis podem favorecer uma manifestação maior dos fenômenos viscoelásticos.

Para uma estimativa inicial da vida dos plásticos, pode-se usar as curvas de vida $\boldsymbol{\sigma} \mathrm{x}$ $\boldsymbol{N}$. Essas curvas não fornecem uma análise precisa, mas podem ser usadas para se obter 
uma estimativa de vida, principalmente para materiais que suportam altos ciclos $\left(N>10^{3}\right)$. A figura 3.5 ilustra curvas $\sigma \times N$ para alguns plásticos comuns.

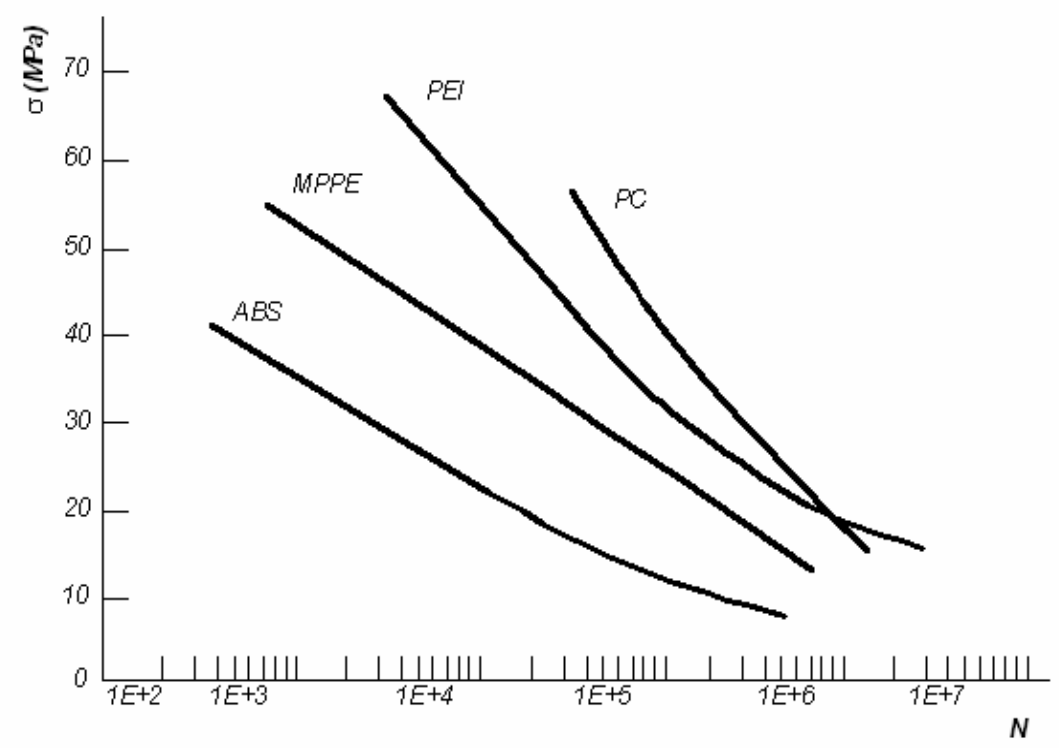

Figura 3.5 - Curvas $\sigma \times \mathrm{N}$ para alguns termoplásticos à temperatura ambiente.

Fonte: Marczak (2004).

Essa escala logarítmica pode ser aproximada pela curva de Wöhler, que é dada pela expressão 3.3, na qual os valores $C$ e $m$ são tabelados:

$$
\sigma=C \cdot N^{m}
$$

Devido ao fato dos plásticos apresentarem problemas de fadiga de baixo ciclo e, devido a esse fato, não ser recomendado o controle de amplitude de tensão, utilizam-se as curvas de Coffin-Mason (Fig. 3.6), que relacionam os ciclos de solicitação (até a ruptura) com a deformação do material, e que podem ser aproximadas pela equação 3.4.

$$
\frac{\mathrm{E}}{2}=C(2 N)^{m}
$$

Outro parâmetro relacionado à fadiga dos plásticos é a possibilidade de ocorrência de rupturas superficiais (trincas) nesses materiais, após uso prolongado ou quando ele é submetido a intempéries. Nesses casos, após o aparecimento das trincas, a previsão de vida depende da velocidade de propagação dessas trincas. A taxa de propagação das trincas é dada pela Lei de Paris (Eq. 3.5), em que a é o comprimento da trinca, $\Delta \mathrm{K}$ é a amplitude do fator de intensidade de tensões da trinca e $A^{\prime}$ e $m$ são valores fornecidos pela tabela 3.2 (Marczak, 2004).

$$
\frac{d a}{d N}=A^{\prime} \cdot \Delta K^{m}
$$


Tabela 3.2 - Valores típicos para as constantes.

Fonte: Marczak (2004).

\begin{tabular}{l|c|c}
\hline \multicolumn{1}{c|}{ Material } & $\boldsymbol{A}^{\prime}$ & $\boldsymbol{m}$ \\
\hline Aço de baixa liga & $0,42 \times 10^{-11}$ & 3,00 \\
\hline Alumínio & $4,56 \times 10^{-11}$ & 2,90 \\
\hline Cobre & $0,34 \times 10^{-11}$ & 3,90 \\
\hline Nylon 6-6 & $1,50 \times 10^{-8}$ & 3,20 \\
\hline PMMA & $2,30 \times 10^{-5}$ & 4,70 \\
\hline Policarbonato & $9,50 \times 10^{-5}$ & 2,60 \\
\hline PPO & $4,70 \times 10^{-6}$ & 3,00 \\
\hline Poliestireno & $3,10 \times 10^{-5}$ & 2,20 \\
\hline PVC & $2,90 \times 10^{-6}$ & 1,50 \\
\hline
\end{tabular}

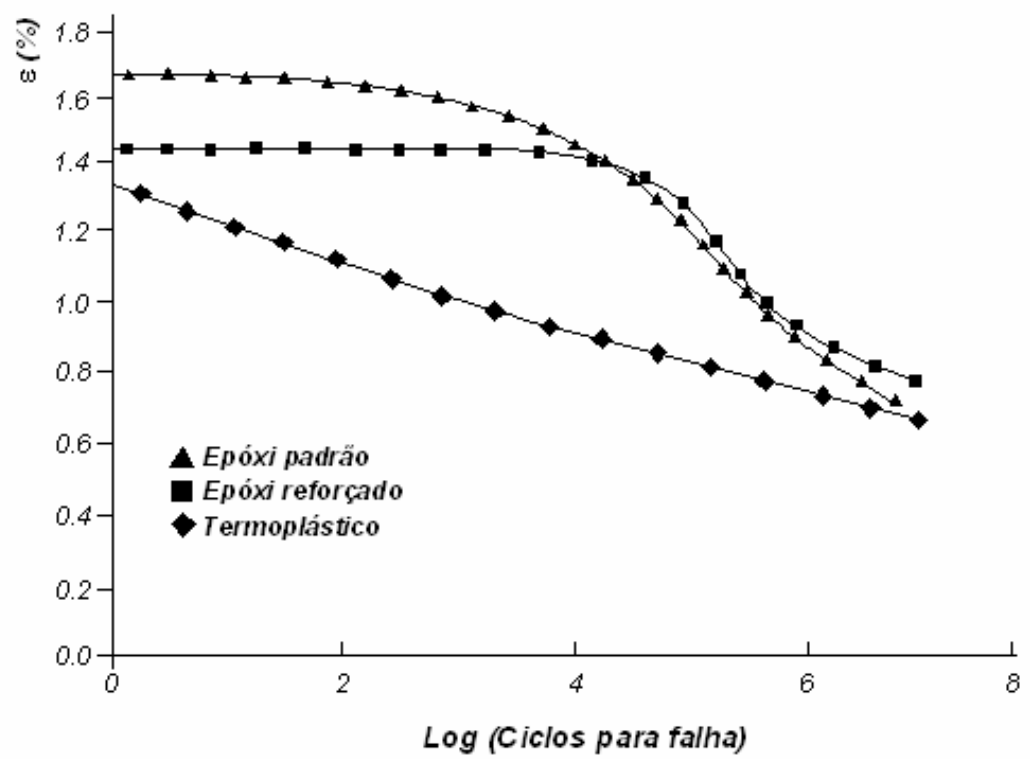

Figura 3.6 - Curvas $\varepsilon \times N$ para alguns termoplásticos à temperatura ambiente. Fonte: Marczak (2004).

\section{f) Resistência ao impacto (tenacidade)}

Segundo Marczak (2004), muitos plásticos apresentam elevada resistência ao impacto, e tal propriedade é utilizada na substituição de outros materiais, como, por exemplo, na substituição do vidro na fabricação de faróis para carros, janelas de carros, dentre outros.

Ao se projetar um novo produto, é indispensável conhecer todas as propriedades do material e realizar ensaios sob todas as condições de uso pretendidas, para validar a sua utilização. Não existe um único ensaio para predizer o comportamento de plásticos ao impacto, sob as diversas condições de uso possíveis. Então, a resistência ao impacto é comumente avaliada adaptando-se ensaios de impacto usados em outros materiais, como 
os metálicos: Izod, Charpy, Gardner, impacto à tração, teste de temperatura de fragilização, dentre outros. (Fig. 3.7).

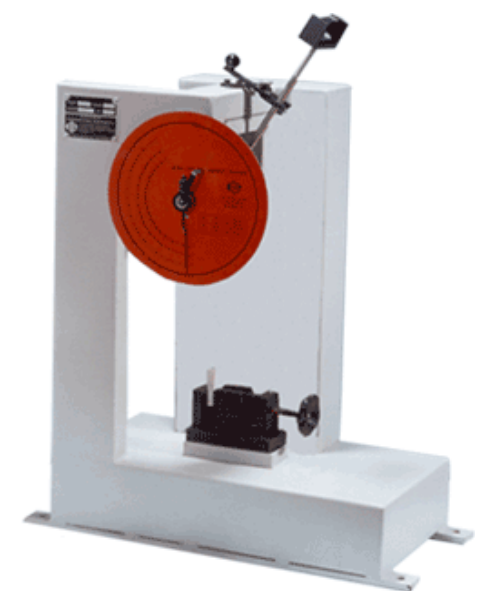

Figura 3.7 - Equipamento utilizado para ensaio de impacto.

A resistência ao impacto sofre grande alteração com a temperatura. A figura 3.8 ilustra a rápida mudança nesse comportamento com a variação de temperatura, para alguns polímeros comuns.

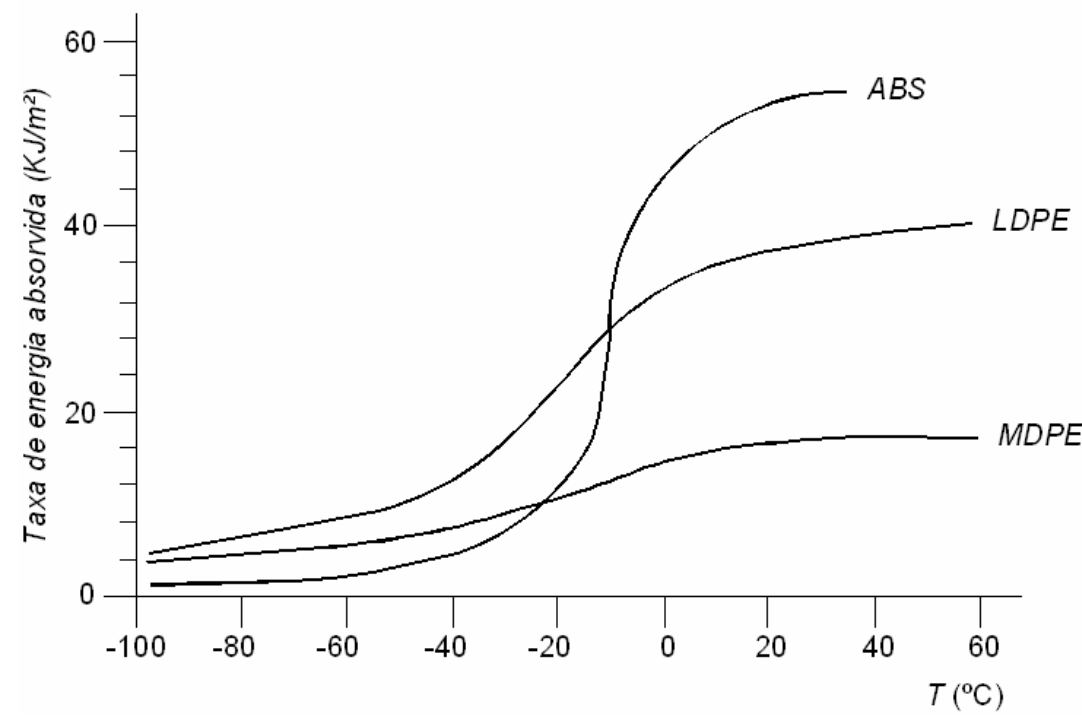

Figura 3.8 - Exemplos do efeito da temperatura sobre resistência ao impacto. Fonte: Marczack (2004).

\subsection{Propriedades térmicas}

As propriedades térmicas dos polímeros estão relacionadas à sua estrutura e composição molecular. Quando submetidos a temperaturas muito baixas, os plásticos são frágeis. À medida que a temperatura aumenta, o material adquire certa elasticidade, até que, em elevadas temperaturas, se funde (Rocha, 1990).

Talvez a mais importante propriedade térmica dos plásticos seja seu baixo ponto de fusão, que varia da temperatura ambiente até $250^{\circ} \mathrm{C}$, embora alguns plásticos especiais exijam até $400^{\circ} \mathrm{C}$. Disso decorre o baixo consumo de energia para conformação, com 
reflexos óbvios nos custos de produção. Por outro lado, componentes plásticos tendem a mudar consideravelmente suas dimensões, em relação a outros materiais como o aço ou mesmo o alumínio, quando sofrem variações de temperatura.

Portanto, essas propriedades devem ser consideradas em todo projeto de elementos plásticos, principalmente em aplicações de maior precisão (Marczak, 2004).

\subsubsection{Ponto de fusão cristalino (Tf) e temperatura de transição vítrea (Tg)}

A temperatura de fusão cristalina $\left(T_{f}\right)$, para os polímeros semicristalinos, e a temperatura de transição vítrea $\left(T_{g}\right)$, para os polímeros amorfos, são as principais transições térmicas dos polímeros, pois estão associadas com a mudança do estado físico dos materiais.

$A T_{g}$, em termoplásticos amorfos, geralmente está associada à temperatura limite de trabalho desses materiais e é muito importante, pois diversas propriedades físicas e mecânicas apresentam grande redução antes de atingir seu valor máximo.

$A T_{f}$ de termoplásticos semicristalinos é definida como sendo a temperatura na qual os últimos vestígios da estrutura cristalina do polímero desaparecem sob aquecimento, a qual pode ser monitorada por diversas técnicas experimentais, como difração de raios- $X$, calorimetria exploratória diferencial, dentre outras (Souza, 2005).

\subsubsection{Entalpia}

A entalpia pode ser definida como a quantidade total de calor necessário para mudar a temperatura de um material de massa unitária, de uma temperatura de referência (geralmente, $20^{\circ} \mathrm{C}$ ) para outra temperatura.

\subsubsection{Coeficiente de expansão térmica}

A tabela 3.3 mostra alguns valores típicos de coeficientes de expansão térmica ( $\alpha$ ).

Tabela 3.3 - Valores típicos de coeficientes de expansão térmica.

Fonte: Marczak (2004).

\begin{tabular}{c|c}
\hline Material & $\alpha\left(\mathrm{m} / \mathrm{m} /{ }^{\circ} \mathrm{C}\right)$ \\
\hline Polietileno & $7,8 \times 10^{-5}$ \\
\hline Acrílicos & $3,3 \times 10^{-5}$ \\
\hline Policarbonato & $2,1 \times 10^{-5}$ \\
\hline Alumínio & $7,2 \times 10^{-6}$ \\
\hline $\begin{array}{c}\text { Policarbonato reforçado com } \\
\text { fibra de vidro (30\%) }\end{array}$ & $5,0 \times 10^{-6}$ \\
\hline Aço & $4,4 \times 10^{-6}$ \\
\hline Vidro & $2,2 \times 10^{-6}$ \\
\hline
\end{tabular}


Fazendo uma comparação entre o polietileno e o aço, por exemplo, pode-se ver que o primeiro possui a cerca de 17 vezes maior que o último. Segundo Parente (2006), uma forma de atenuar a influência da variação de temperatura é fazendo a adição de fibras, naturais ou sintéticas, na matriz polimérica.

\subsubsection{Temperatura de distorção ao calor (deformação tếrmica)}

Além de alterar suas dimensões, a resistência e o módulo de elasticidade, as propriedades dos materiais plásticos são reduzidas com o aumento da temperatura. A caracterização desse comportamento é complexa, mas existe um teste que fornece informações superficiais sobre o desempenho de um plástico sob carga e efeito de temperatura. Esse teste permite a obtenção da chamada temperatura de distorção ao calor (HDT). Basicamente, esse teste submete um corpo-de-prova biapoiado à flexão simples, com um carga concentrada (456 N ou $1820 \mathrm{~N}$ ), e mede-se o deslocamento central. A temperatura é então aumentada até que um certo valor de deslocamento seja ultrapassado. Essa é a temperatura de distorção. A tabela 3.4 mostra alguns valores típicos.

Tabela 3.4 - Temperaturas de distorção típicas de alguns plásticos no ensaio à $1820 \mathrm{~N}$. Fonte: Marczak (2004).

\begin{tabular}{l|c}
\hline \multicolumn{1}{c|}{ Material } & $\begin{array}{c}\text { HDT } \\
\left({ }^{\circ} \mathbf{C}\right)\end{array}$ \\
\hline Silicones & 455 \\
\hline $\begin{array}{l}\text { Nylon reforçado com fibra } \\
\text { de vidro (30\%) }\end{array}$ & 260 \\
\hline $\begin{array}{l}\text { Resina epóxi reforçada com } \\
\text { fibra de vidro }\end{array}$ & 205 \\
\hline $\begin{array}{l}\text { Acetal reforçado com fibra } \\
\text { de vidro }\end{array}$ & 165 \\
\hline Policarbonato & 145 \\
\hline Nylon de uso geral & 105 \\
\hline Acrílico & 83 \\
\hline Polipropileno & 60 \\
\hline
\end{tabular}

\subsubsection{Condutividade têrmica}

Segundo Marczak (2004), os polímeros são bons isolantes térmicos e sua condutividade térmica é cerca de 300 a 2500 vezes menor que a dos metais, sendo assim recomendados em aplicações que requeiram isolamento térmico, principalmente na forma de espumas.

\subsection{Propriedades elétricas}

Segundo Marczak (2004), os plásticos são bons isolantes elétricos, o que se verifica pelo seu uso intensivo em produtos elétricos. 
Com a adição de cargas especiais condutoras, como limalha de ferro e negro de fumo, podem ser produzidos polímeros fracamente condutores, evitando-se assim o acúmulo de eletricidade estática, que é perigosa em certas aplicações. Condições ambientais como umidade e temperatura também podem alterar as propriedades isolantes dos plásticos.

Dentre as propriedades elétricas mais importantes, pode-se citar as indicadas nos itens a seguir.

\subsubsection{Resistividade volumétrica}

Souza (2005) define resistividade volumétrica como a resistência elétrica de um material dielétrico (neste caso, de um material plástico) com dimensões unitárias, o qual é submetido a uma diferença de potencial (tensão) nas suas faces opostas em contato com dois eletrodos em paralelo, como é ilustrado na figura 3.9.

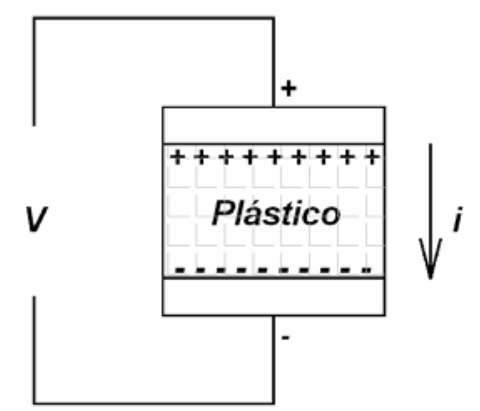

Figura 3.9 - Resistividade volumétrica. Fonte: Marczack (2004).

Admitindo que $\rho_{\vee}$ é a resistividade volumétrica, E' é a diferença de potencial, $I_{v}$ é a corrente, $R_{v}$ é a resistência da amostra, $A$ " é a área do eletrodo e t' a espessura da amostra, o cálculo da resistividade elétrica, segundo a Norma ASTM D-257, é feito por meio da equação 3.6.

$$
\rho_{v}=\frac{\mathrm{E}^{\prime}}{I_{v}} \cdot \frac{A^{\prime \prime}}{t^{\prime}}=\frac{R_{v} \cdot A^{\prime \prime}}{t^{\prime}}
$$

Os dados de resistividade volumétrica são utilizados para o cálculo da espessura da parede de componentes de circuitos elétricos e para comparar a qualidade de isolamento elétrico dos materiais para efeitos de seleção, avaliando a influência da composição do material e o ambiente a que será submetido, tais como temperatura, umidade, dentre outros (Souza, 2005).

\subsubsection{Resistividade superficial}

Segundo Marczak (2004), a resistividade superficial é similar à volumétrica, mas medida como a razão entre a voltagem suprida em corrente contínua e a parcela de corrente 
elétrica que flui através de uma superfície de largura unitária, como é ilustrado na figura 3.10.

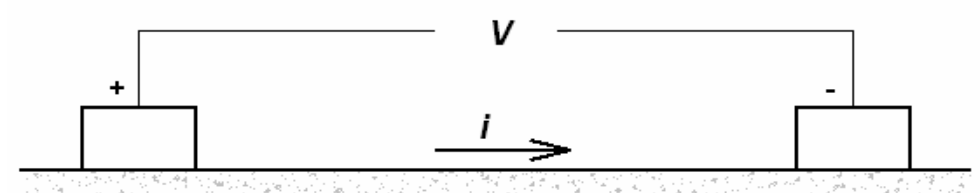

Figura 3.10 - Resistividade superficial. Fonte: Marczack (2004).

A resistividade superficial mede a vazão da corrente através da superfície do isolante elétrico, o que é uma característica importante quando o material ensaiado é indicado para uso em aplicações elétricas e eletrônicas, pois a contaminação da superfície do material pode comprometer seu desempenho isolante (Souza, 2005).

\subsubsection{Constante dielétrica}

Segundo Mano ${ }^{1}$ apud Silva (2003), a constante dielétrica $K$ é uma característica correlacionada à energia eletrostática que pode ser armazenada em um capacitor que possui o material a ser analisado como um dielétrico e é medida pela razão entre a capacitância do capacitor que contém o material e a capacitância do sistema, porém, o material isolante é o ar.

Tabela 3.5 - Constante dielétrica $(K)$ para diversos materiais.

Fonte: Mussoi e Villaça (2000).

\begin{tabular}{l|c}
\hline \multicolumn{1}{c|}{ Material } & Constante dielétrica $\boldsymbol{K}$ \\
\hline Água & 78 \\
\hline Cerâmica & $\geq 10$ \\
\hline Vidro & 4 a 10 \\
\hline Policarbonato & 3 \\
\hline Poliéster & 3 a 3,2 \\
\hline Polipropileno & 2,1 a 2,3 \\
\hline Poliestireno & 2,5 \\
\hline Baquelite & 4,8 \\
\hline
\end{tabular}

\subsubsection{Rigidez dielétrica}

Segundo Mano apud Silva (2003), a rigidez dielétrica indica em que grau um material é isolante. Essa propriedade é medida pela tensão elétrica que o material suporta antes que aconteça uma perfuração do material isolante.

\footnotetext{
${ }^{1}$ MANO, Eloísa B. Introdução a polímeros. Edição Edgard Blücher Ltda., 3. ed., São Paulo, 1985.
} 


\subsubsection{Resistência dielétrica}

A resistência dielétrica é a medida da máxima tensão que o material isolante (nesse caso, o plástico) pode suportar em um minuto sem provocar ruptura (geralmente, um furo) em uma amostra de determinada espessura. Esse teste é muito utilizado para controlar a qualidade de um material isolante já fabricado, como em fios e cabos elétricos, nos quais não é possível medir-se a resistividade pelos testes padrões.

\subsubsection{Fator de potência}

Segundo Mano apud Silva (2003), o fator de potência é a medida relativa da perda dielétrica do material quando ele é utilizado como isolante, e essa propriedade é utilizada para medir a qualidade de um material isolante. É dado como a razão entre a potência dissipada pelo material isolante e a máxima potência que seria fornecida ao sistema, mantendo-se os mesmos valores de diferença de potencial e intensidade da corrente.

\subsubsection{Resistência ao arco}

Segundo Mano apud Silva (2003), a resistência ao arco está relacionada a rigidez dielétrica e a elevadas temperaturas. É uma medida das condições de perda das características dielétricas ao longo da superfície de um isolante, causada pela formação de caminhos condutivos na superfície do material.

\subsection{Propriedades óticas}

Segundo Marczak (2004), as propriedades óticas mais importantes são a opacidade do material, a transparência, a translucidez (quantidade de luz que atravessa o material), o índice de amarelamento (aparência) e o índice de refração (refração da luz).

\subsection{Outras propriedades}

Apresentam-se a seguir outras propriedades relativas aos polímeros.

\subsubsection{Características de desgaste}

Segundo Marczak (2004), as medidas de desgaste podem indicar a resistência a riscos (importante na limpeza do componente), resistência à abrasão ou resistência à perda de material (quando há contato deslizante entre dois componentes) e à capacidade de uma superfície manter sua aparência durante o manuseio.

$\mathrm{Na}$ seleção de um plástico resistente ao desgaste, é fundamental determinar precisamente sob quais condições o componente será empregado. 


\subsubsection{Usinabilidade}

Segundo Marczak (2004), a usinagem de materiais plásticos é similar à dos metais, porém a geometria da ferramenta e a velocidade de corte devem ser ajustadas adequadamente, pois existe o risco de ocorrer um aumento de temperatura durante esse processo. A seleção de velocidades de corte, tipo e geometria da ferramenta e avanço devem ser previamente estudadas, devido à baixa condutividade térmica dos plásticos, assim como o fluido de corte que será empregado, pois ele pode reagir quimicamente com o material que está sendo usinado.

De uma maneira geral, as tolerâncias para usinagem de plásticos devem ser maiores que as empregadas em usinagem de metais, devido à expansão térmica e às alterações de forma que o material sofre pelas relaxações de tensões internas. Em alguns casos, pode ser necessária uma pré-usinagem da peça, com dimensões ligeiramente maiores, e a realização de um alívio de tensões antes da usinagem final.

\subsubsection{Tolerâncias dimensionais}

As tolerâncias de forma, como cilindricidade, conicidade, planicidade, dentre outras, devem levar em conta o processo de fabricação do componente, já que, devido ao resfriamento do polímero durante o processamento, pode ser necessário que sejam feitas modificações nos moldes (Marczak, 2004). A especificação de tolerâncias dimensionais para peças em plástico não é a mesma utilizada para os metais, e nem sempre o projetista está apto a levar em conta todos os aspectos necessários. Diante disso, é importante um trabalho conjunto entre os diversos profissionais envolvidos na fabricação do produto, como os engenheiros de materiais, mecânicos e civis, por exemplo.

\subsubsection{Absorção de água}

A absorção de água é a quantidade de água absorvida por uma peça ou artigo plástico, quando imerso em água por um determinado período de tempo. Segundo Rocha (1990), com relação aos polímeros, a maior parte desses materiais são insolúveis em água, entretanto, eles podem absorvê-la e ter algumas de suas propriedades afetadas, como a resistência elétrica e as propriedades mecânicas.

\subsubsection{Inflamabilidade}

Para algumas aplicações dos materiais termoplásticos, como embalagens, quando sua reciclagem é inviável, é desejável que esses materiais possam ser incinerados com facilidade. Entretanto, para outras aplicações, como na indústria da construção civil, é desejável que esses materiais apresentem adequada resistência ao fogo (Souza, 2005). 
Visando sua utilização, a avaliação dos plásticos pode incluir a determinação das características de inflamabilidade dos materiais (características na queima), características de ignição a partir de diferentes fontes térmicas e elétricas, condutibilidade elétrica, outras características elétricas, físicas e mecânicas e ensaios analíticos. Além disso, também se pode avaliar a retenção das propriedades dos materiais em sua exposição, por períodos prolongados, a temperaturas elevadas (envelhecimento no ar/forno), exposição à água, a raios-ultravioletas, ao frio, dentre outros.

Segundo Silva (2003), a combustão dos polímeros ou de qualquer outro tipo de material é a combinação de uma série de processos físico-químicos, que resultam na conversão dos reagentes iniciais em produtos de combustão.

A queima dos polímeros é formada pelos seguintes estágios:

- Processo primário térmico, em que uma fonte externa de calor fornece energia ao material, aumentando sua temperatura e alterando as características térmicas e geométricas do material;

- Processo primário químico, em que a fonte externa de calor pode fornecer radicais livres e acelerar o processo de decomposição do material;

- Processo de decomposição, que se inicia após o polímero aumentar a temperatura de degradação, liberando líquidos, gases e combustíveis sólidos carbonizados;

- Ignição, que ocorre quando gases combustíveis e oxigênio atmosférico estão disponíveis em quantidades suficientes, podendo ser induzida por uma fonte externa de chamas ou ocorrendo espontaneamente;

- Combustão, que ocorre após a ignição e se mantém quando existe uma fonte contínua de calor, material e oxigênio suficiente;

- Propagação das chamas, que depende da taxa de composição dos polímeros, do volume de materiais inflamáveis e da geometria e do tipo de superfície do material termoplástico;

- Emissão de fumaça e gases tóxicos, que depende do tipo de pirólise dos polímeros.

A título indicativo, na tabela 3.6 são apresentados os poderes caloríficos de diversos materiais.

Tabela 3.6 - Poderes caloríficos de diversos materiais.

Fonte: Rocha (1990).

\begin{tabular}{c|c}
\hline Material & $\begin{array}{c}\text { Poder calorífico } \\
\text { (KJ/g) }\end{array}$ \\
\hline Policarbonato & 29 \\
\hline Epoxídicos & 33 \\
\hline Madeira & 18 \\
\hline Carvão & 35 \\
\hline Butano & 49 \\
\hline Hidrogênio & 125 \\
\hline
\end{tabular}


Analisando-se os dados, conclue-se que os plásticos possuem poder calorífico elevado. Entretanto, o comportamento do polímero ao fogo pode ser melhorado pela adição de retardantes de chama (cloreto, brometo, fósforo ou sais minerais), por meio da aplicação de revestimento anti-chama, dentre outros.

\subsubsection{Resistência aos efeitos ambientais}

Os materiais plásticos podem sofrer alterações devido a sua exposição a fatores ambientais, tais como umidade, produtos químicos (líquidos ou vapores), exposição ao sol, altas temperaturas, água e vapor quente, bactérias e fungos. A exposição ao sol é um fator muito importante e pode causar degradação dos plásticos, pois a luz solar emite radiação ultravioleta que pode degradar os polímeros.

Opacidade e escurecimento são sinais de que 0 material pode ter sofrido degradações; entretanto, em alguns casos, pode não ocorrer uma alteração visual na aparência do material, mas isto não significa que não haja alguma degradação das propriedades mecânicas, como diminuição da tensão de ruptura ou resistência ao impacto.

Materiais plásticos, devido ao fato de não enferrujarem, podem ter um melhor desempenho que os metais em ambientes corrosivos. Por outro lado, quanto mais resistente a produtos químicos, mais difícil é a colagem/soldagem dos plásticos, já que sua colagem geralmente requer algum tipo de ataque químico. A resistência química também é um fator crítico quando o produto deve ser pintado, pois os solventes presentes nas tintas devem ser compatíveis com o material empregado no produto.

Outra característica dos plásticos, que possui reflexos ambientais, é a porosidade. $O$ espaço entre as macromoléculas dos polímeros é relativamente grande, o que confere baixa densidade ao polímero. Entretanto, esse espaçamento entre moléculas faz com que a difusão de gases através dos plásticos seja alta, o que limita sua utilização como material de embalagem.

\subsection{Alteração das propriedades dos plásticos}

Segundo Souza (2005), o maior problema na utilização dos plásticos são suas baixas resistência e rigidez. Todavia, existem três métodos para compensar essas deficiências, dentre os quais pode-se citar: (i) utilização criteriosa dos conceitos de "design" (isto é, estudo do formato e dimensionamento estrutural) para peças técnicas ou pela incorporação de elementos estruturais, tais como nervuras, seções caixões, costelas de reforço; (ii) utilização de blendas poliméricas e (iii) incorporação de cargas minerais e fibras de altos módulos de elasticidade e de alta resistência. 
O uso de aditivos, corantes, cargas e reforços traz uma série de vantagens, tais como:

- Redução do custo de produção com a utilização de cargas inorgânicas inertes.

- Aumento da resistência mecânica com a adição de fibras ou cargas minerais.

- Atenuação do efeito da radiação ultravioleta, uniformidade visual e aumento da resistência com a utilização de negro de fumo.

- Utilização de aditivos plastificantes para obtenção de plásticos mais ou menos flexíveis e tenazes.

Os aditivos são responsáveis por mudanças de propriedades específicas. Dentre os aditivos mais comuns usados com termoplásticos e termorrígidos estão os antioxidantes (utilizados para aumentar a estabilidade do material a altas temperaturas), agentes antiestáticos, biocidas, retardantes de chama, modificadores de resistência ao impacto, agentes espumantes, redutores de fricção, fungicidas e estabilizantes UV (Marczak, 2004).

A seguir, apresentam-se exemplos de aditivos e razões de seu uso.

\subsubsection{Antiestáticos}

A maioria dos polímeros apresentam baixa condutividade elétrica, sendo suscetíveis à formação de eletricidade estática, resultando em risco de faíscas e atração de partículas de sujeira. Os agentes antiestáticos atraem umidade para a superfície dos plásticos, aumentando assim sua condutividade elétrica (Crawford, 1987).

\subsubsection{Agentes de processamento / lubrificantes}

Os lubrificantes são adicionados aos polímeros para melhorar a fluidez durante o processamento, seja reduzindo a viscosidade de fusão cristalina (lubrificantes internos) ou reduzindo a adesão entre as superfícies metálicas do equipamento de processamento com o polímero fundido (lubrificantes externos). Segundo Crawford (1987), graxa ou estearato de cálcio reduzem a viscosidade dos plásticos derretidos, facilitando assim o processo de moldagem, e óleos minerais podem ser utilizados em formulações de polímeros, para facilitar a desmoldagem.

\subsubsection{Corantes}

Um outro grupo de aditivos são os corantes, utilizados para alterar a aparência dos materiais. Podem ser cargas orgânicas ou pós inorgânicos e devem ser escolhidos de modo que eles sejam compatíveis com o material base, método de processamento e aplicação desejada para o componente (Marczak,2004). 
É necessário também em aplicações em que as propriedades óticas têm peso, especialmente em materiais transparentes como acrílicos, policarbonato e estireno, já que o uso de corantes pode transformar um material incolor em opaco (Marczak, 2004).

\subsubsection{Plastificantes}

São materiais de baixa massa molar, capazes de alterar as propriedades e características de moldagem dos plásticos (Crawford, 1987).

\subsubsection{Biocidas}

São agentes químicos que controlam ou impedem o crescimento bacteriano. Normalmente as poliolefinas e os polímeros vinílicos são resistentes ao ataque de bactérias, enquanto a borracha natural, celulose e seus derivados são susceptíveis a ataques microbianos.

\subsubsection{Reforços}

Quando se avalia o desempenho mecânico de termoplásticos para a produção de peças destinadas a aplicações na engenharia, às vezes enfrentam-se dois fatores aparentemente limitantes na utilização desses materiais, tais como: (i) manutenção da rigidez e da resistência mecânica a elevadas temperaturas de serviço e a longos períodos de carregamento e (ii) baixa tenacidade e resistência ao impacto, para a maioria dos termoplásticos. Com relação à fragilidade mecânica dos plásticos rígidos, esta pode ser resolvida pelo processo de tenacificação, com incorporação de aditivos elastoméricos ou com utilização de blendas poliméricas.

A melhoria na rigidez e na resistência mecânica de termoplásticos pode ser conseguida por meio de: (i) utilização de conceitos de projeto e de dimensionamento estrutural, produzindo painéis ocos por processos de moldagem a sopro, painéis-sanduíche e moldados com espumas estruturais, ou pela incorporação de elementos estruturais, tais como nervuras e costelas de reforço; (ii) fabricação de blendas poliméricas e (iii) adição de cargas minerais e fibras de altos módulos de resistência na matriz polimérica (Souza, 2005).

Com relação à terceira opção, a utilização de reforços, visando a mudança da resistência dos plásticos, pode ser feita por meio de fibras de carbono, fibras de vidro, mica e aramidas, que podem ser adicionados na forma de fibras curtas, filamentos longos, flocos, esferas ou grãos. A tabela 3.7 permite uma comparação entre as propriedades das fibras de carbono, vidro e aramida. 
Tabela 3.7 - Tabela comparativa entre fibras de carbono, vidro e aramida.

Fonte: Fibertex.

\begin{tabular}{c|c|c|c|c}
\hline \multirow{2}{*}{ Propriedades } & \multirow{2}{*}{ Unidades } & \multicolumn{3}{|c}{ Tipos de fios } \\
\cline { 3 - 5 } & & Fibra de carbono & Fibra de vidro & Fibra de aramida \\
\hline Absorção de umidade & $\mathrm{N}$ & 0,04 & 0,3 & 4,5 \\
\hline Resistência à tração & $\mathrm{kg} / \mathrm{mm}^{2}$ & 420 & 220 & 350 \\
\hline Densidade específica & $\mathrm{g} / \mathrm{cm}^{3}$ & 1,8 & 2,55 & 1,44 \\
\hline Elongação na ruptura & $\%$ & 1,4 & 4,8 & 3,6 \\
\hline
\end{tabular}

As principais vantagens na utilização de fibras e cargas reforçantes em termoplásticos são:

- Aumento do módulo de elasticidade do compósito;

- Aumento da resistência mecânica (tração, flexão e compressão) e, dependendo do tipo de carga e de matriz utilizada, das propriedades de tenacidade e de resistência ao impacto do compósito;

- Melhoria substancial na resistência à fluência;

- Melhoria na resistência mecânica a longo prazo, dentre as quais durabilidade e resistência à fadiga;

- $\quad$ Aumento na temperatura de termo-distorção (HDT);

- Aumento da estabilidade dimensional, redução da expansão térmica e encolhimento de moldados;

- Modificação nas características reológicas, elétricas e da permeabilidade dos compósitos (Souza,2005).

Entretanto, a utilização de reforços aumenta a rigidez do elemento à custa da diminuição da resistência ao impacto, além de aumentar o desgaste de ferramentas de corte, no caso de usinagem de pré-formas.

\subsection{Processamento de polímeros}

O processamento (ou moldagem) é a transformação de um material em um produto polimérico. A escolha do processo de transformação depende: (i) das características da peça com relação a sua forma e dimensões, (ii) características do material polimérico que será utilizado para a produção da peça e (iii) quantidade das peças que serão produzidas.

Os processos mais importantes para produção de elementos termoplásticos são: extrusão, sopro, termomoldagem e injeção, dentre outros. 


\subsubsection{Moldagem por extrusão}

O processo de moldagem por extrusão (Fig. 3.11) é usado para a produção de barras, fitas, mangueiras, tubos e perfilados, ou seja, elementos lineares com comprimento desejado.

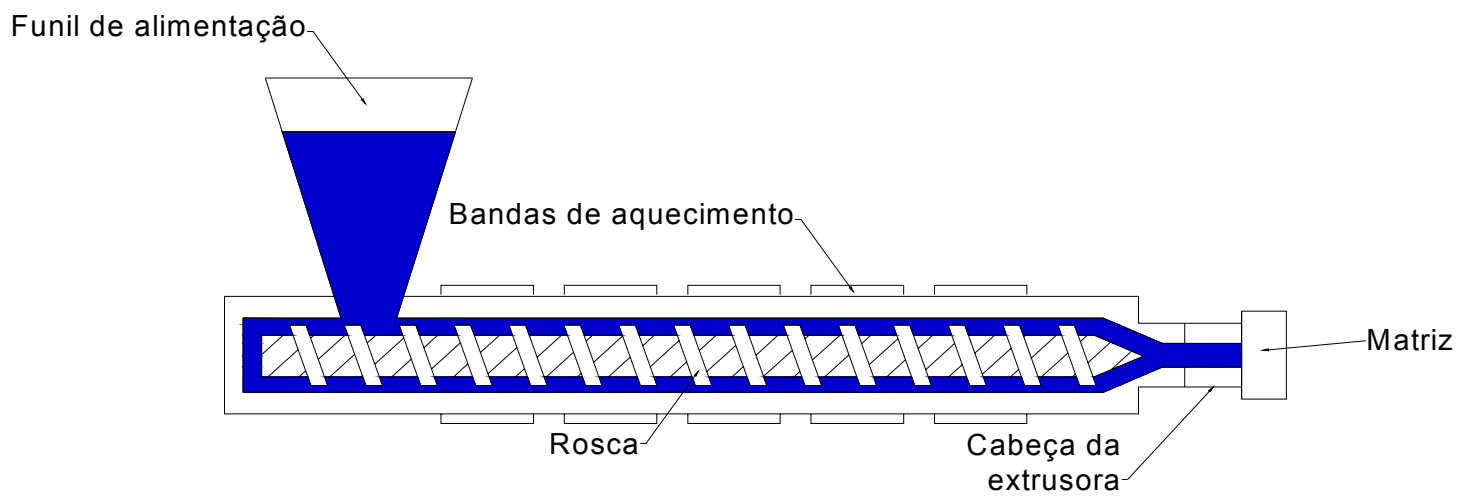

Figura 3.11 - Moldagem por extrusão. Fonte: Rocha (1990).

Nesse processo, o material plástico cai de um funil de alimentação para a rosca, que é acionada por um motor elétrico. Essa rosca-sem-fim giratória empurra continuamente o material dentro de um cilindro, que tem temperaturas diferentes em cada uma de suas zonas, o que faz com que o material se funda, flua através de uma tela e passe pelo orifício de uma matriz, assumindo assim a forma desejada. Se o produto final necessitar ter dimensões precisas ou que a espessura da parede seja uniforme, é necessária a utilização de equipamento de calibragem, que possui a função de modelar e resfriar o material extrusado, mantendo assim suas dimensões finais. O próximo passo para da produção dos elementos é o seu resfriamento com posterior corte em suas dimensões de projeto (Anônimo, 1985).

\subsubsection{Moldagem por sopro}

O processo de moldagem por sopro é em geral utilizado na obtenção de peças ocas por meio da insuflação de ar no interior do molde, de forma a permitir a expansão da massa plástica até a obtenção da forma desejada. Os processos de moldagem por sopro podem ser separados em 2 tipos: moldagem por sopro via injeção (e injeção com estiramento) e moldagem por sopro via extrusão.

No processo de moldagem por sopro via injeção (Fig. 3.12) ocorre o fechamento do molde; posteriormente, é introduzido ar comprimido para expandir a peça oca até a forma final e, após o resfriamento, é feita a extração da peça soprada. 


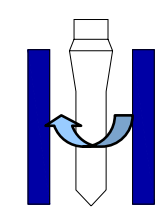

Aquecimento

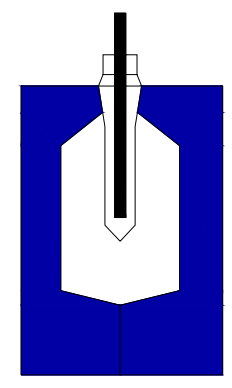

Sopro

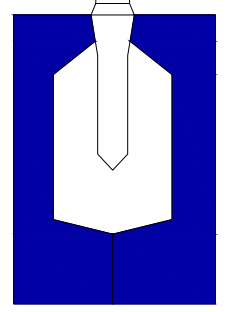

Fechamento do molde

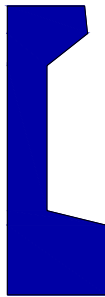

Ejeção

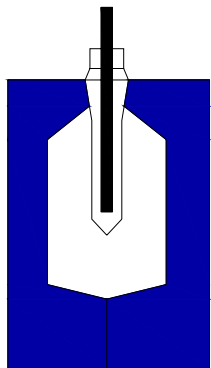

Estiramento

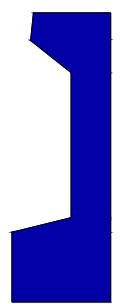

Figura 3.12 - Moldagem por sopro - via injeção.

Fonte: LEPCom - UFMG (2007).

No processo de moldagem por sopro via extrusão (Fig. 3.13), as peças são obtidas por meio de um modelo de tamanho adequado, que é pressionado com ar comprimido contra as paredes da cavidade da ferramenta, cujo formato ajusta-se ao diâmetro externo da garrafa. A ferramenta é resfriada, fazendo com que o material plástico se solidifique, permitindo sua remoção.
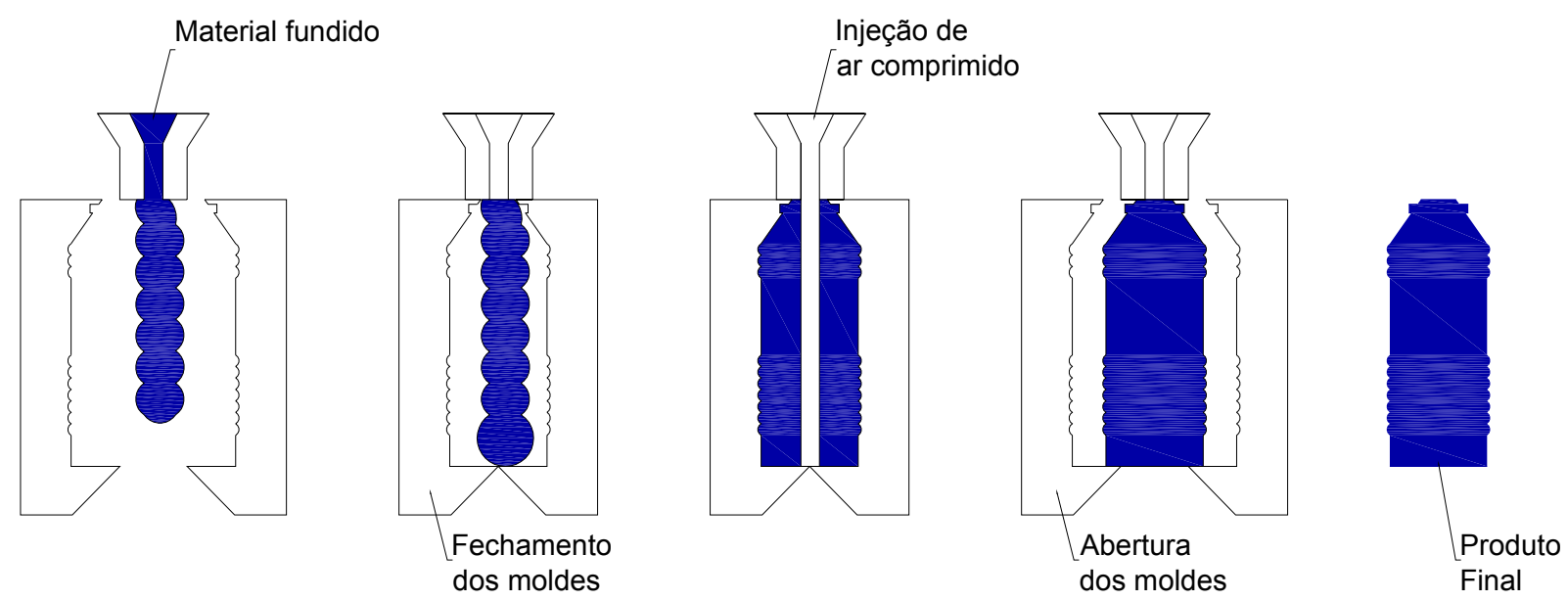

Figura 3.13 - Moldagem por sopro - via extrusão.

Fonte: Rocha (1990). 


\subsubsection{Termomoldagem}

Esse processo é utilizado para conformação de chapas, sendo o mais utilizado devido ao seu baixo custo e ao fato de que, por causa das baixas pressões, empregam moldes leves e simples.

A termomoldagem (Fig. 3.14) consiste na fixação da chapa termoplástica sobre um molde evacuável, aquecendo-a até que ela fique amolecida e removendo-se o ar contido entre a chapa e o molde. A pressão atmosférica, então, força a chapa de encontro aos contornos do molde. Quando ela endurece, o molde pode ser removido.
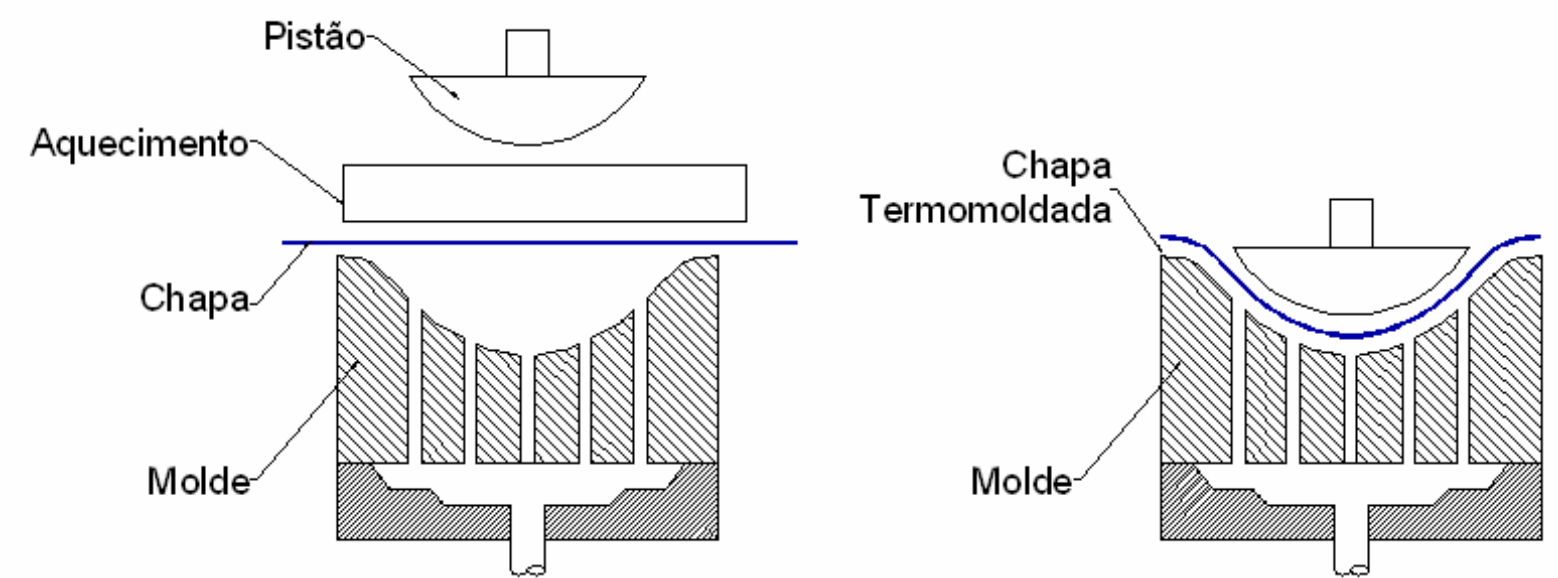

Figura 3.14 - Termomoldagem.

Fonte: Rocha (1990).

\subsubsection{Moldagem por injeção}

Ao contrário da extrusão, a moldagem por injeção (Fig. 3.15) é um processo descontínuo, formado por ciclos. Nesse processo, o operador da máquina de injeção abastece a máquina com o material granular, que é comprimido, aquecido e se funde. $O$ material fundido é injetado na cavidade do molde, empurrando o ar à frente do material na cavidade. Esse material, em contato com as paredes do molde, se resfria e se solidifica. $O$ molde pode, então, ser aberto, permitindo a remoção do produto final.

Funil de alimentação

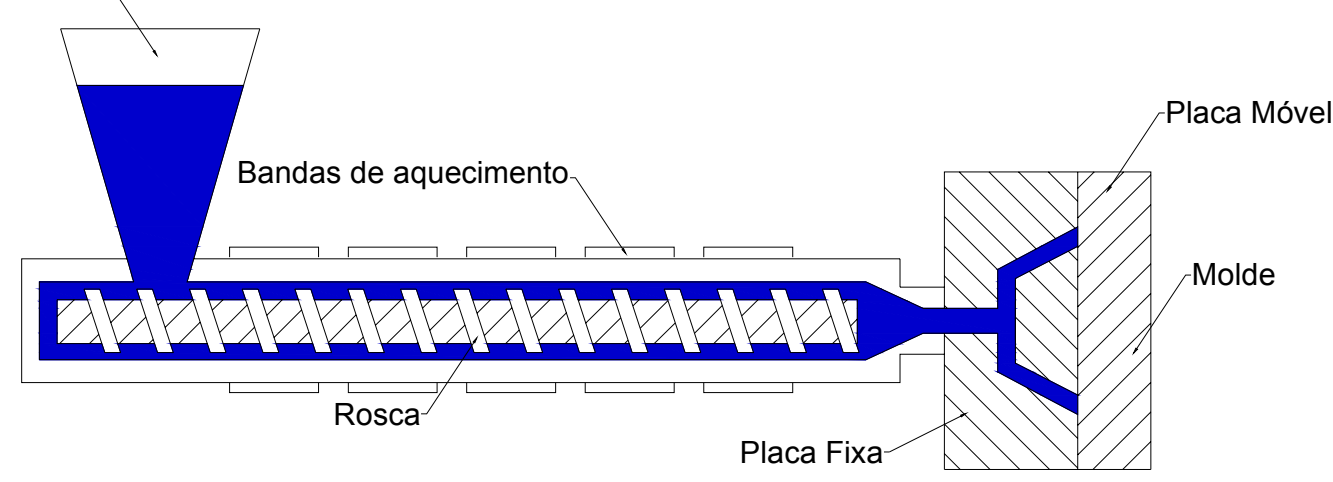

Figura 3.15 - Moldagem por injeção. Fonte: Rocha (1990). 


\subsubsection{Calandragem}

Esse processo é utilizado para produção de fios e chapas (Fig. 3.16). Nele, o material fundido é forçado a passar entre cilindros aquecidos, que rodam a diferentes velocidades. $A$ espessura do produto final é regulada pelo afastamento dos cilindros.

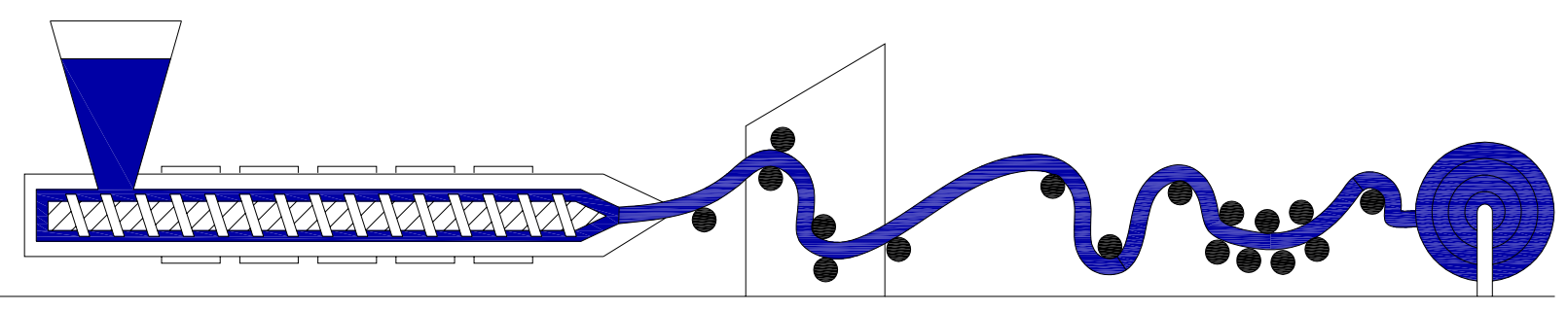

Figura 3.16 - Calandragem

Fonte: Rocha (1990).

\subsubsection{Pultrusão}

O processo de pultrusão (Fig. 3.17) é um método de fabricação, contínuo e mecanizado, para fabricação de perfis lineares de seção transversal constante (como vergalhões, vigas, canaletas e tubos). Para sua produção utilizam-se resinas poliéster, epoxi estervinílica ou fenólica, reforçadas com fibras de vidro.

Os reforços de vidro são baseados principalmente nos rovings diretos, que são dispostos de maneira a proporcionar um reforço longitudinal. Outros tipos de reforços são as mantas de fios contínuos ou tecidos, que proporcionam o reforço transversal, e também os véus de acabamento superficial. Escolhido o tipo de reforço, faz-se sua impregnação com resina, assim como a introdução de cargas e aditivos (e.g., retardadores de chama). Em seguida, o material passa pelo molde, que tem a função de produzir a forma e polimerizar a resina impregnada. Posteriormente, o perfil pultrudido é então travado e tracionado por uma cinta contínua ou por um sistema de permutação. A última etapa consiste de sistema de corte, que tem o objetivo de conferir ao perfil o comprimento desejado. A velocidade típica da pultrusão com sistemas de resinas termofixas é de 0,5 a $2 \mathrm{~m} /$ minuto (www.owenscorning.com.br).
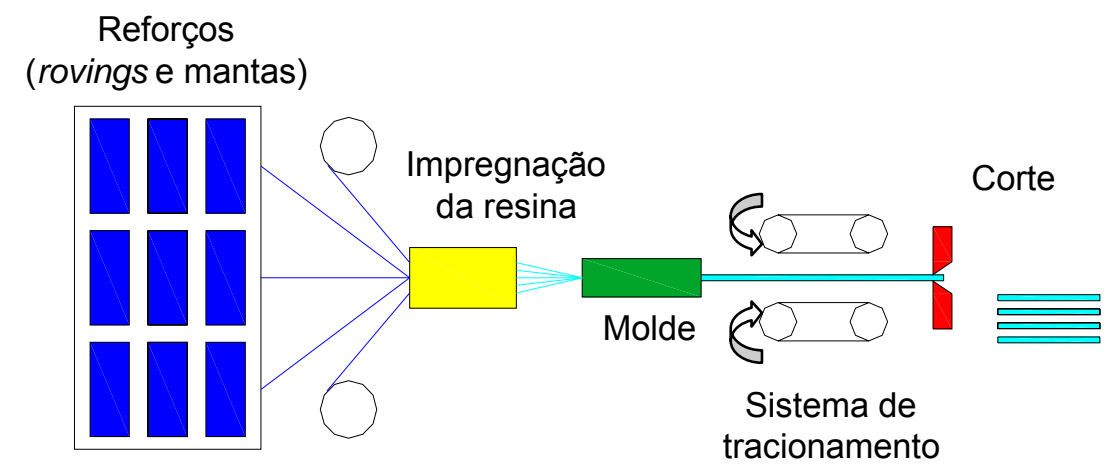

Figura 3.17 - Pultrusão.

Fonte: www.owenscorning.com.br 


\section{CRUZETAS}

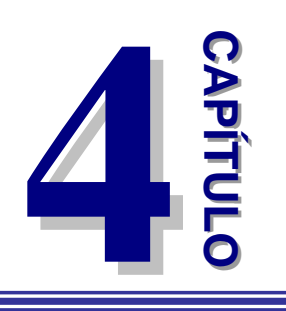

\subsection{Considerações Iniciais}

Cruzetas são peças de eixo retilíneo, sem emendas, destinadas a suportar condutores e equipamentos de redes aéreas de distribuição de energia elétrica.

Os materiais mais utilizados para sua fabricação são madeira, concreto armado e aço. Neste trabalho a escolha da cruzeta se justifica devido a sua larga aplicação nos sistemas aéreos de distribuição de energia e à grande ocorrência de falhas desse elemento. Segundo Silva (2003), as cruzetas de madeira para as redes de distribuição de energia elétrica atualmente entregues à Elektro - Eletricidade e Serviços SA possuem durabilidade inferior a cinco anos. Esse autor afirma também que, durante a instalação desses elementos, suas deficiências são detectadas; entretanto, essas cruzetas passaram em todos os ensaios determinados nas normas mas, mesmo assim, o fato de terem sido aprovadas não significa que estão isentas de defeitos que comprometerão seu desempenho durante sua vida útil.

Visando a produção de elementos com maior durabilidade que os convencionais, juntamente com a proposta de se utilizar polímeros como um novo material para a fabricação das cruzetas, é necessário que se conheçam as particularidades de cada elemento. Sendo assim, neste capítulo são abordados os requisitos de projeto para cruzetas de madeira, concreto armado e metálicas. Além disso, apresenta-se um breve estudo sobre a massa dos elementos, assim como seu custo.

\subsection{Cruzetas de madeira}

A NBR 8458:1984 é a norma que fixa as condições elegíveis para a preparação e o recebimento de cruzetas de madeira, de seção retangular, não preservadas, destinadas a redes aéreas de energia elétrica, como as mostradas na Figura 4.1.
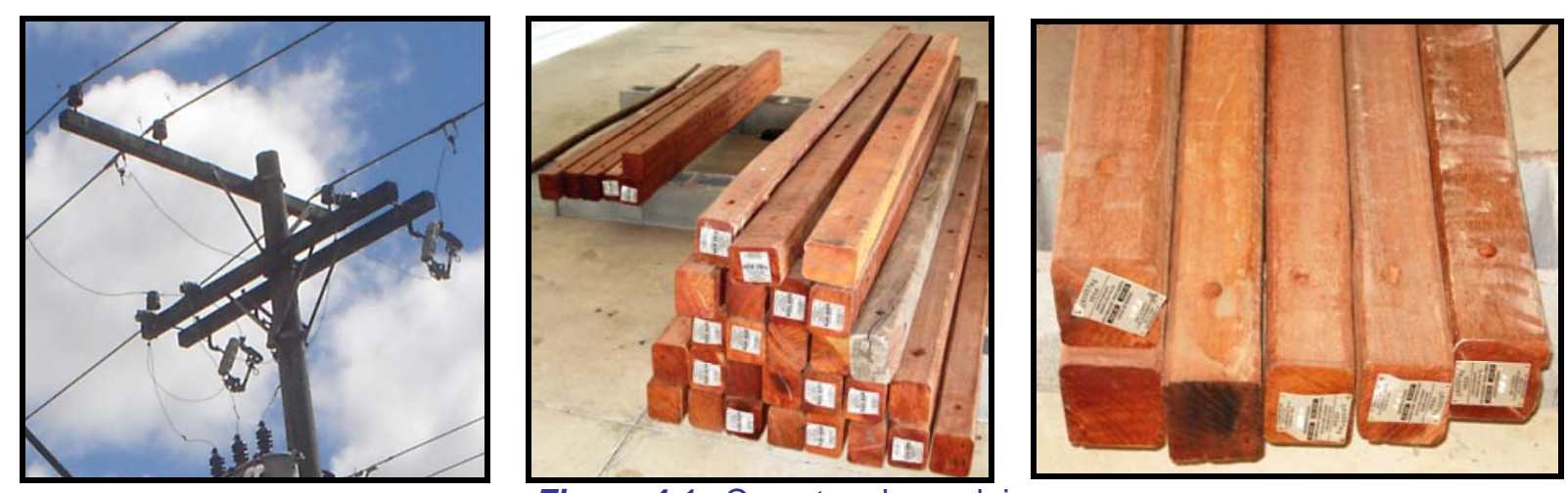

Figura 4.1 - Cruzetas de madeira. 
Segundo essa norma, as cruzetas de madeira devem ser fabricadas utilizando madeiras das seguintes espécies (Tabela 4.1), que podem ser madeira de lei e puro cerne. Além das citadas, outras espécies de madeira, como a Canafístula, Eucalipto (dos tipos Alba, Citriodora e Tereticornis) e Peroba também podem ser utilizados para a fabricação de cruzetas, desde que atendam as características mecânicas e de durabilidade das madeiras de lei.

Tabela 4.1 - Espécies de madeira.

Fonte: NBR 8458:1984.

\begin{tabular}{|c|c|c|}
\hline Espécie & Abrev. & Designação botânica \\
\hline Angico vermelho & $A G$ & Piptadenia rígida \\
\hline Angico preto & $\mathrm{AE}$ & Piptadenia macrocarpa \\
\hline Angelim pedra & AP & Dinizia excelsa \\
\hline Aroeira & AR & Astronium urundeúva \\
\hline Braúna & BR & Melanoxylon brauna \\
\hline Cabriúva vermelha & $\mathrm{CV}$ & Myroxylon Balsamun \\
\hline Cabriúva parda & $\mathrm{CP}$ & Myrocarpus sp \\
\hline Faveiro & FV & Pterodon pubscens \\
\hline Garapa & GP & Apuleia sp \\
\hline Imbuia & IB & Ocotea porosa \\
\hline Ipê & IP & Tabeluia sp \\
\hline Itapirucu & IT & Goniorrachis marginalis \\
\hline Jatobá & JB & Hymenaea sp \\
\hline Maçaranduba & $\mathrm{MB}$ & Manilka longifolia \\
\hline Pequi & $\mathrm{PQ}$ & Cariocar sp \\
\hline Pau-pereira & PR & Platycyamus regnellii \\
\hline Roxinho & $\mathrm{RX}$ & Peltogyne sp \\
\hline Sucupira amarela & SA & Ferreirea spectabilis \\
\hline Sucupira parda & SP & Bowdichia sp e Diplotropis sp \\
\hline Sucupira vermelha & SV & Lecythis sp \\
\hline Sassafrás & SS & Ocotea pretiosa \\
\hline
\end{tabular}

As dimensões das cruzetas de madeira são especificadas na norma NBR 8459:1984, que padroniza as cruzetas de madeira para redes de distribuição de energia elétrica. Segundo essa norma, as cruzetas de madeira podem possuir comprimento de 2,00 metros, 2,40 metros, 5,00 metros e 6,00 metros (Figura 4.2). Neste trabalho serão estudadas as cruzetas com comprimento de 2,00 metros.

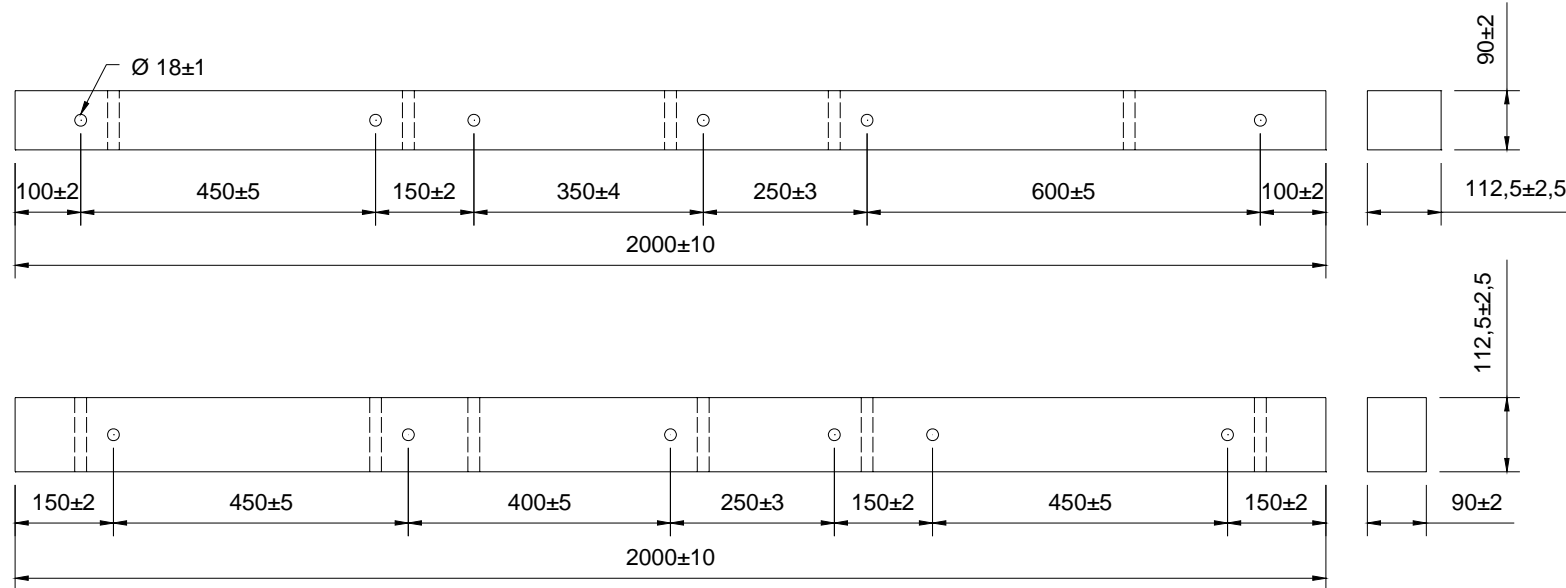

Figura 4.2 - Cruzeta de 2,00 metros - Medidas em mm.

Fonte: NBR 8459:1984. 
Com relação à resistência à flexão, segundo a NBR 8458:1984, a resistência nominal é carga que a cruzeta pode suportar sem sofrer deformações permanentes (deve ser considerada como uma força contida no plano de aplicação dos esforços, passando pelo eixo da cruzeta). As cruzetas devem satisfazer as exigências de flechas e de cargas de ruptura, conforme os valores descritos na Tabela 4.2 .

Tabela 4.2 - Resistência à flexão.

Fonte: NBR 8458:1984.

\begin{tabular}{c|c|c|c|c}
\hline \multirow{2}{*}{$\begin{array}{c}\text { Comprimento } \\
\text { (L) } \mathbf{m m}\end{array}$} & $\begin{array}{c}\text { Descrição do } \\
\text { carregamento }\end{array}$ & $\begin{array}{c}\text { Resistência (F) } \\
\text { N }\end{array}$ & \multicolumn{2}{|c}{ Flecha (mm) } \\
\cline { 3 - 5 } & Nominal & 4000 & Máxima & $\begin{array}{c}\text { Residual } \\
\text { máxima }\end{array}$ \\
\hline \multirow{3}{*}{2000} & Máximo excepcional & 5600 & 100 & 5 \\
\cline { 2 - 5 } & Mínimo de ruptura & 8000 & -------- & -------- \\
\hline \multirow{3}{*}{2400} & Nominal & 4000 & 115 & 5 \\
\cline { 2 - 5 } & Máximo excepcional & 5600 & 163 & 8 \\
\cline { 2 - 5 } & Mínimo de ruptura & 8000 & -------- & -------- \\
\hline \multirow{3}{*}{5000} & Nominal & 4000 & 95 & 4 \\
\cline { 2 - 5 } & Máximo excepcional & 5600 & 132 & 7 \\
\cline { 2 - 5 } & Mínimo de ruptura & 8000 & -------- & -------- \\
\hline \multirow{3}{*}{$\mathbf{6 0 0 0}$} & Nominal & 4000 & 140 & 6 \\
\cline { 2 - 5 } & Máximo excepcional & 5600 & 200 & 10 \\
\cline { 2 - 5 } & Mínimo de ruptura & 8000 & -------- & -------- \\
\hline
\end{tabular}

Obs.:

Resistência à flexão nominal: Valor da resistência, indicada e garantida pelo fabricante que a peça deve suportar continuamente, na direção e sentido indicados, no plano de aplicação e passando pelo eixo da peça, de grandeza tal que não produza, em nenhum plano transversal, momento fletor que prejudique a qualidade dos materiais e trincas, exceto as capilares.

Limite de carregamento excepcional: Corresponde a uma sobrecarga de $40 \%$ sobre a resistência nominal.

Carga de ruptura: Carga no mínimo igual a duas vezes a resistência nominal, que provoca a ruptura da peça em uma seção transversal. A ruptura é definida pela carga máxima indicada no aparelho de medida dos esforços, carregando-se a peça de modo contínuo.

O arranjo para o ensaio à flexão das cruzetas de 2,00 metros e 2,40 metros de comprimento é esquematizado na Figura 4.3. Segundo a NBR 8458:1984, os dois esforços (F) devem ser iguais e aplicados simultaneamente em cada face da cruzeta. Além disso, deverão ser ensaiadas as quatro faces da cruzeta, medindo-se as flechas em ambos os topos da cruzeta. 
L

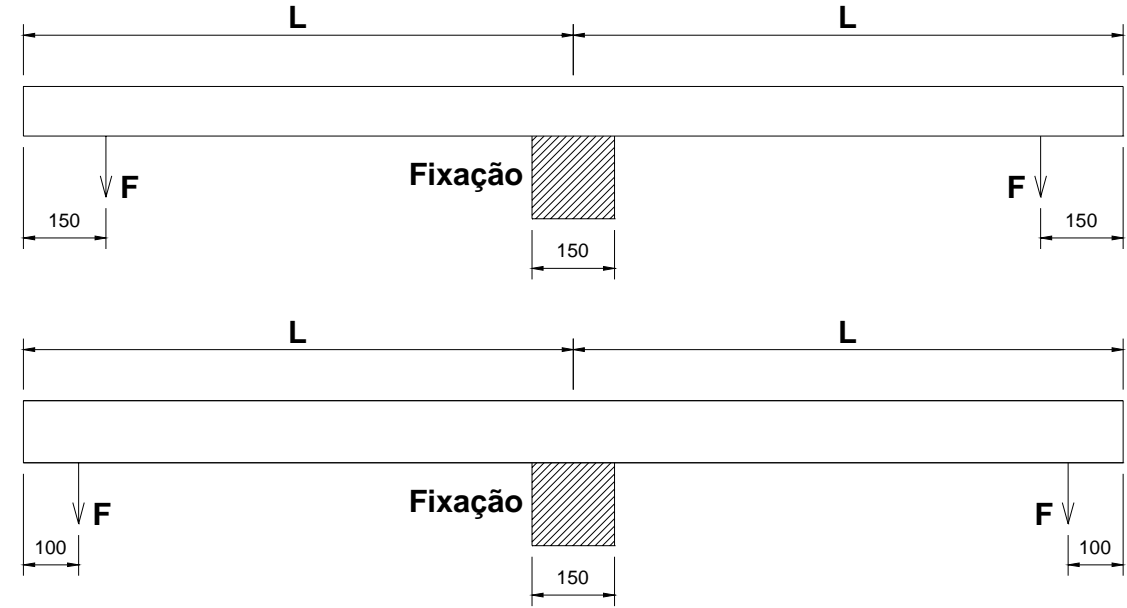

Figura 4.3 - Arranjo para ensaio de cruzetas de 2,00 metros e 2,40 metros - Medidas em mm.

Fonte: NBR 8458:1984.

A seguir, é ilustrado um ensaio real de flexão em cruzetas de madeira, no qual se percebe o arranjo utilizado, o mecanismo adotado para aplicação de cargas e o método utilizado para medição da flecha (Fig. 4.4).
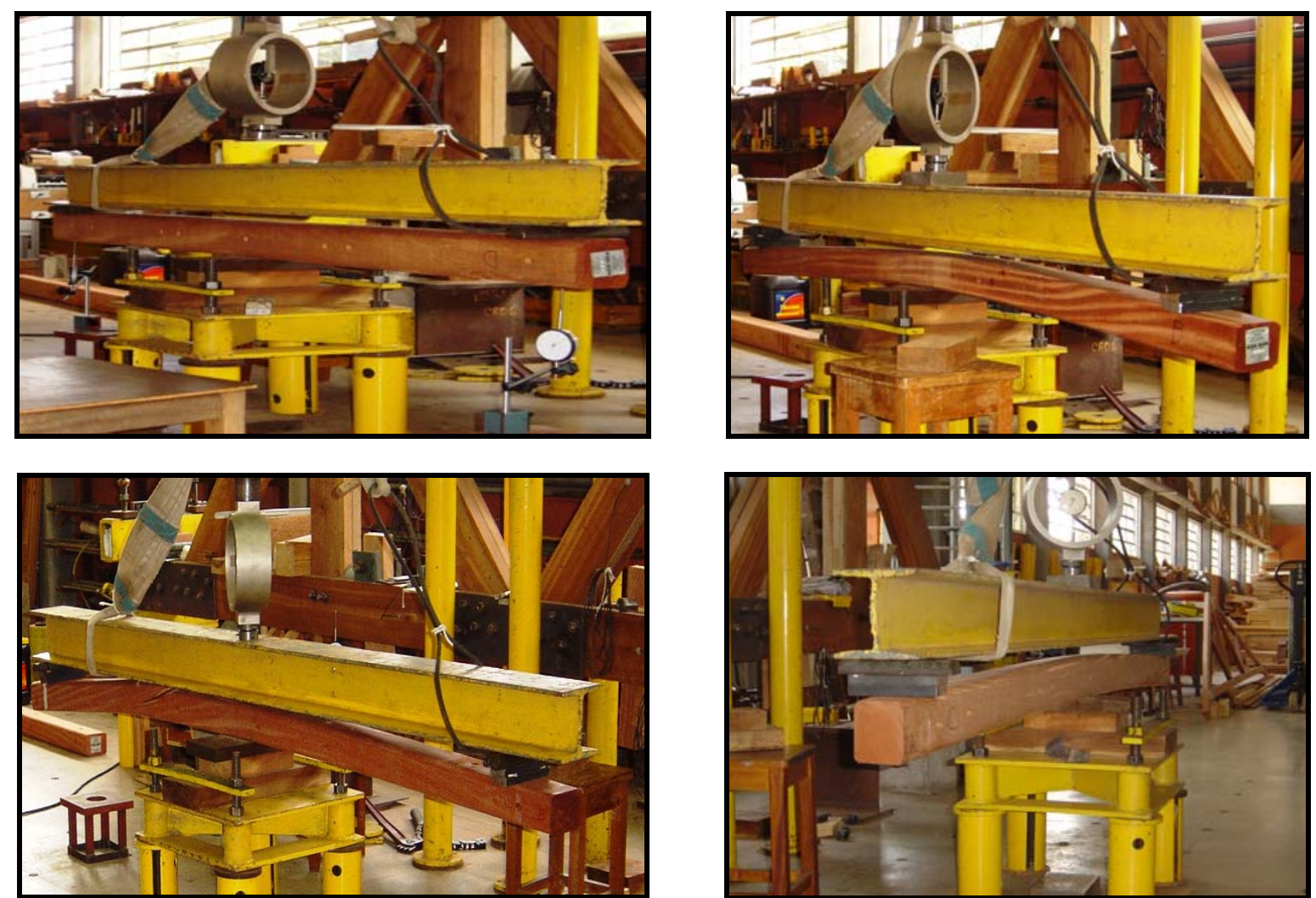

Figura 4.4 - Ensaio de cruzetas de madeira.

Além da resistência à flexão, a NBR 8458:1984 também fixa outros parâmetros que devem ser observados nas cruzetas, tais como defeitos e teor de umidade da madeira, tolerâncias 
dimensionais, condições de armazenamento, inspeção para o recebimento do elemento, dentre outros.

\subsection{Cruzetas de concreto armado}

A NBR 8454:1984 é a norma que fixa comprimentos nominais, formatos, resistências nominais e furações das cruzetas de concreto armado destinadas a redes aéreas de energia elétrica.

Essa norma padroniza três formatos possíveis para a produção de cruzetas de concreto: retangular, T e L.

Existem três comprimentos possíveis, cuja utilização depende do formato da cruzeta. As cruzetas com do tipo $L$ possuem comprimento de $1900 \mathrm{~mm}$ ou $2300 \mathrm{~mm}$; as do tipo $T$ possuem comprimento de $1900 \mathrm{~mm}$ e as do tipo $\mathrm{L}$ possuem comprimento de $1700 \mathrm{~mm}$.
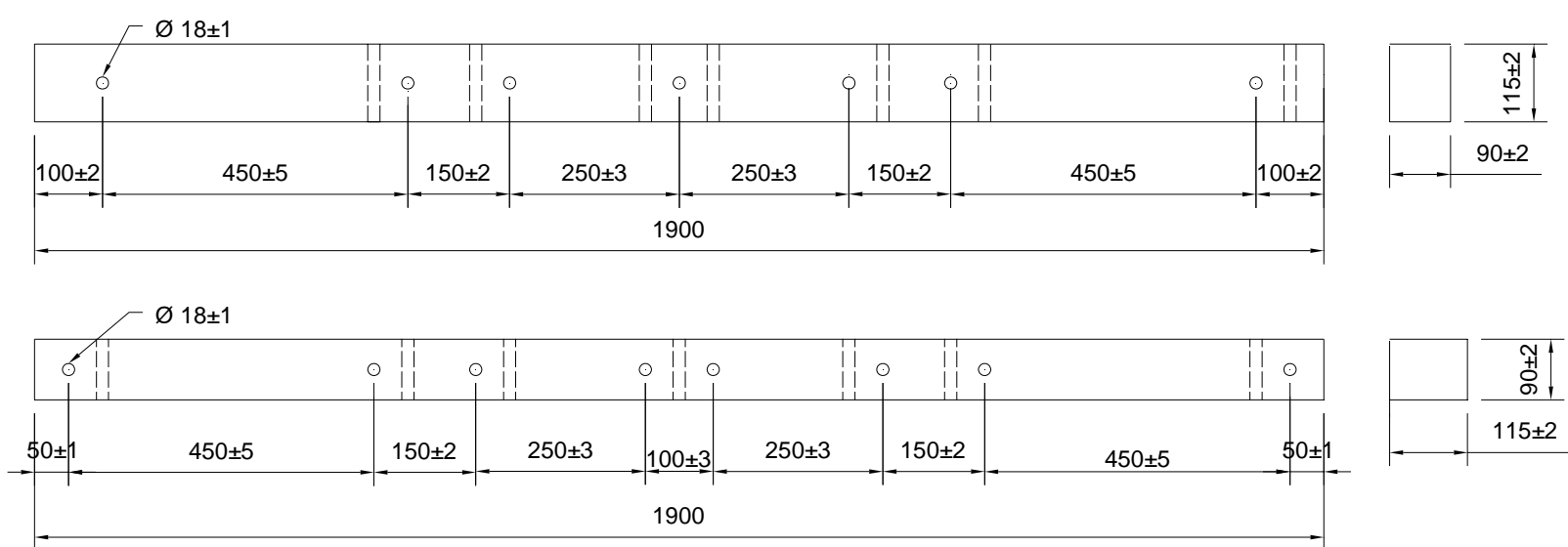

Figura 4.5 - Cruzeta retangular de $1900 \mathrm{~mm}$ - Medidas em mm.

Fonte: NBR 8454:1984.
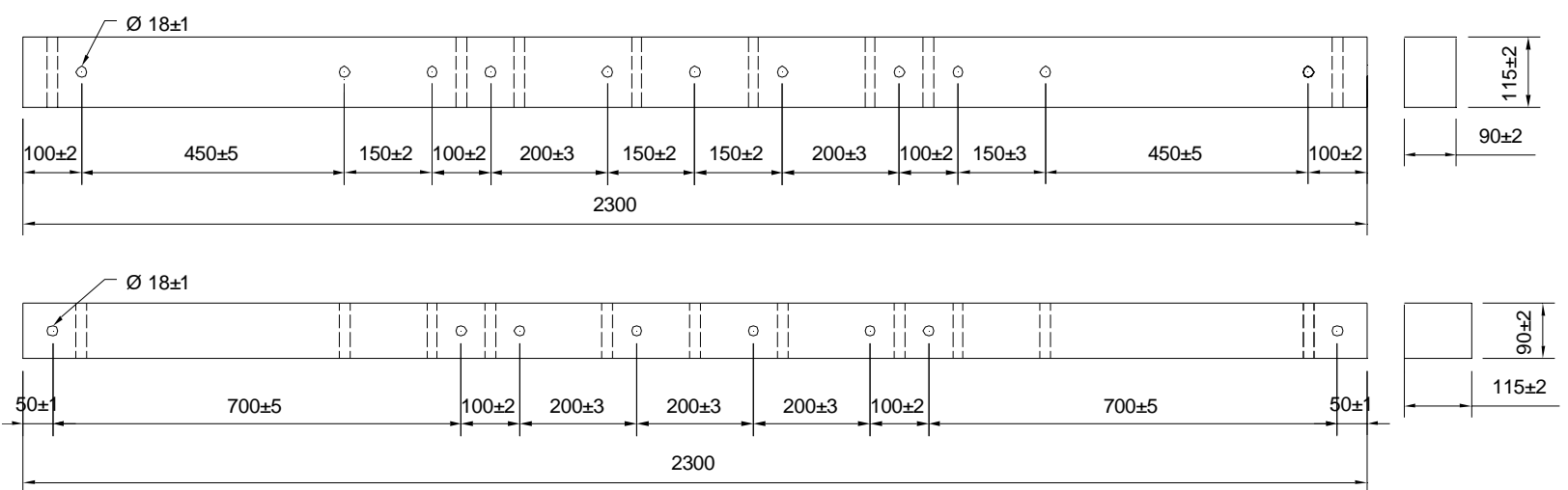

Figura 4.6 - Cruzeta retangular de $2300 \mathrm{~mm}$ - Medidas em $\mathrm{mm}$.

Fonte: NBR 8454:1984. 


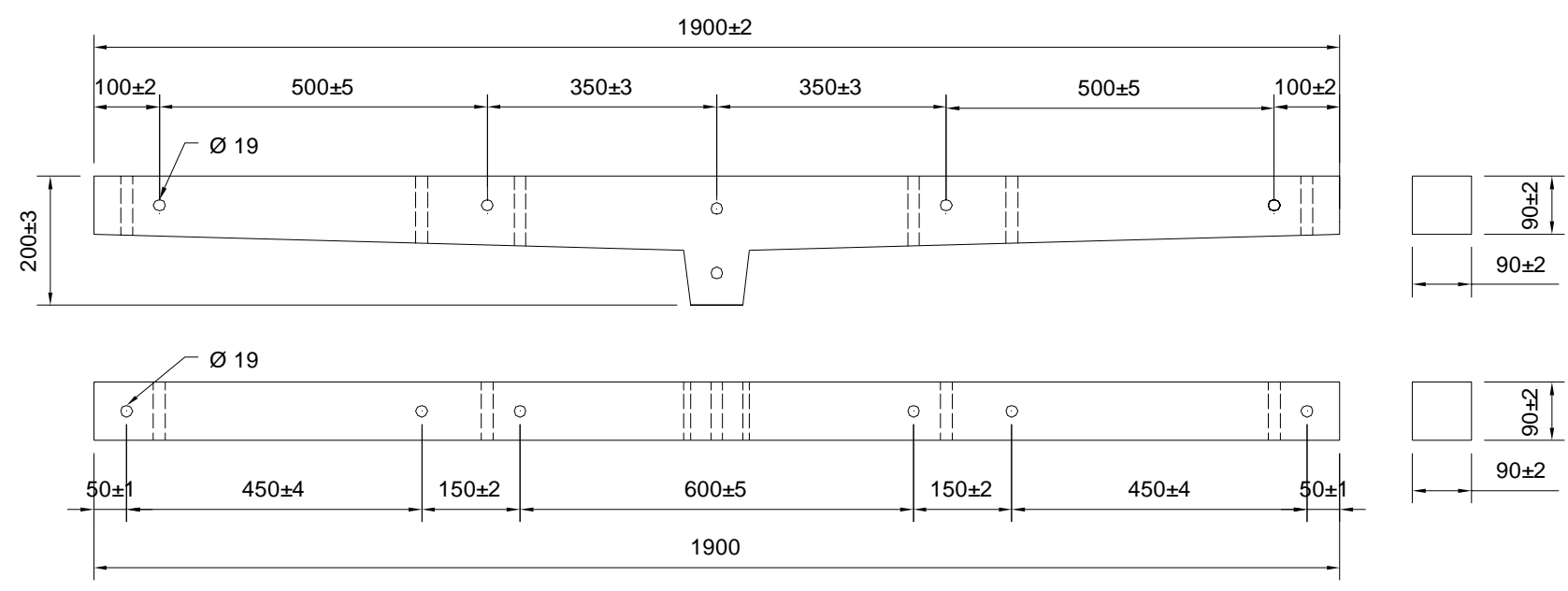

Figura 4.7 - Cruzeta T de $1900 \mathrm{~mm}$ - Medidas em mm.

Fonte: NBR 8454:1984.

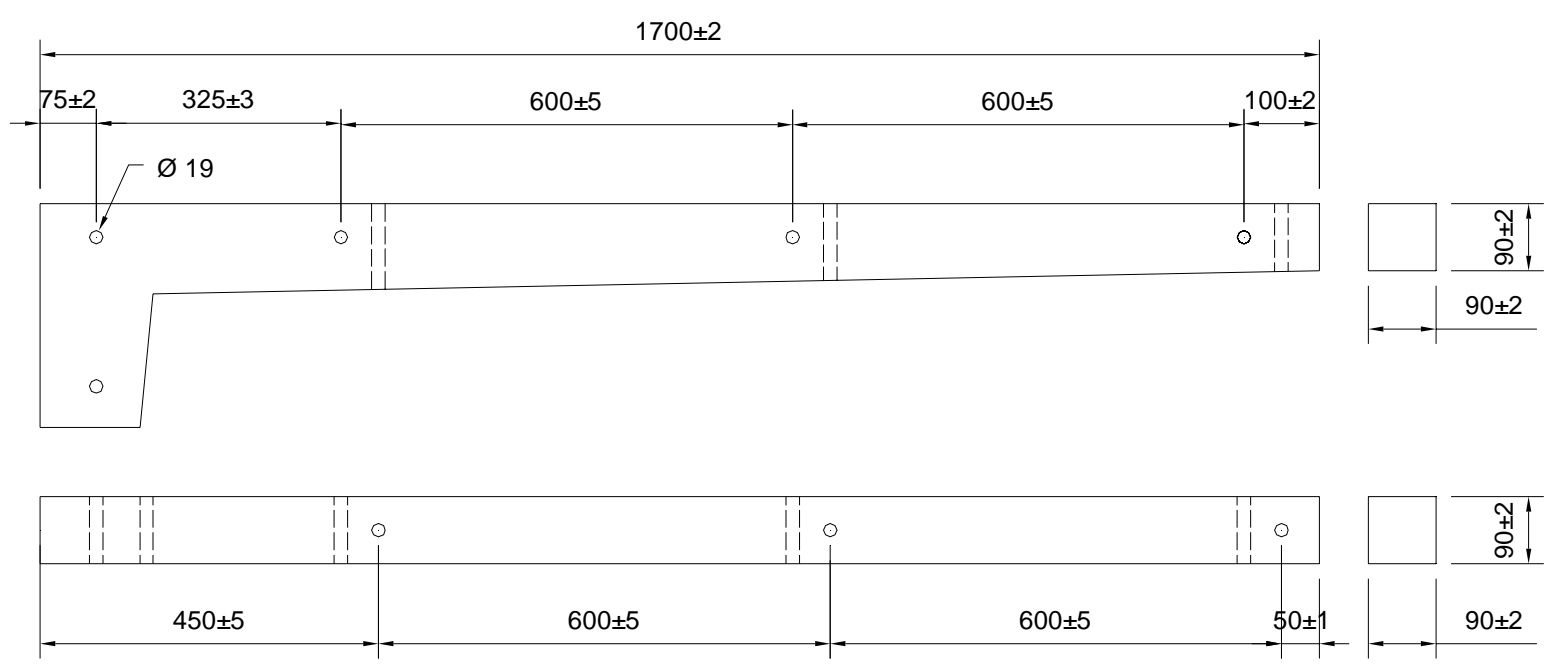

Figura 4.8 - Cruzeta L de $1700 \mathrm{~mm}$ - Medidas em mm.

Fonte: NBR 8454:1984.

Quanto à resistência nominal, a Tabela 4.3 apresenta os valores das resistências nominais que devem ser suportadas por cada tipo de cruzeta. Esses esforços devem obedecer à NBR 8454:1984 ou aos esforços especificados pelos contratantes das obras de redes de distribuição de energia elétrica.

Tabela 4.3 - Resistência à flexão.

Fonte: NBR 8454:1984.

\begin{tabular}{c|c|c|c}
\hline \multirow{4}{*}{ Tipo de cruzeta } & \multicolumn{3}{|c}{ Resistência nominal (N) } \\
\cline { 2 - 4 } & Horizontal & Vertical & Longitudinal \\
\hline Retangular & 2000 & 2000 & 2000 \\
\hline T & 2000 & 2000 & 2000 \\
\hline L & 3000 & 1500 & 1500 \\
\hline
\end{tabular}

A força de ruptura deve ser igual ou superior ao dobro do esforço nominal aplicado. A flecha máxima permitida deve ser igual ou inferior a 1,5\% do comprimento entre o ponto de 
aplicação da carga nominal e o ponto de engastamento, e a flecha residual, após aplicação de $140 \%$ da carga nominal, dever ser igual ou inferior a 0,35\% do comprimento entre o ponto de aplicação da carga e o ponto de engastamento.

Além da NBR 8454:1984, as cruzetas de concreto armado também devem obedecer a NBR 6124:1980, pois esta prescreve o método de ensaio em postes, cruzetas, estruturas compostas e outros elementos acessórios de concreto destinados a suportar linhas aéreas de transmissão e distribuição de energia elétrica e de comunicação. Essa norma fixa o método de ensaio para a determinação da elasticidade, carga de ruptura, absorção de água e espessura do cobrimento em postes e cruzetas de concreto armado.

$\mathrm{Na}$ figura 4.9, são ilustrados, segundo o Departamento Estadual de habitação e obras públicas do Sergipe, os diversos arranjos para ensaios mecânicos nas cruzetas de concreto armado: (a) ensaio de esforço vertical realizado em todos os tipos de cruzeta, (b) ensaio do esforço horizontal para cruzetas em formato retangular e T, (c) ensaio de esforço longitudinal para todos os tipos de cruzetas e (d) ensaio de esforço horizontal para a cruzeta de formato $L$.

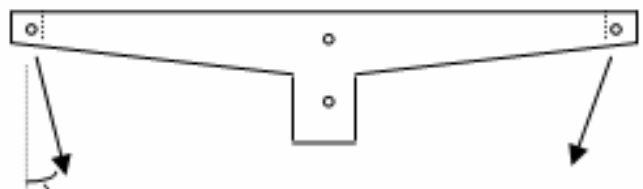

(Ângulo máx. $7^{\circ}$ )

(a)

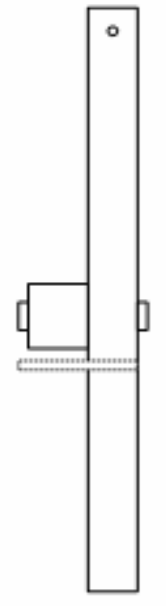

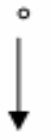

(c)

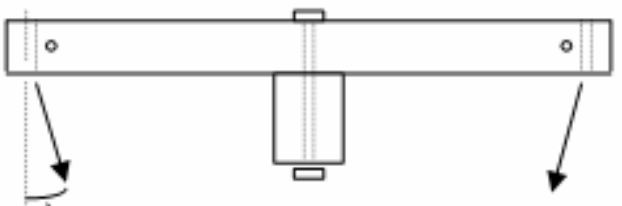

(Ângulo máx. $7^{\circ}$ )

(b)

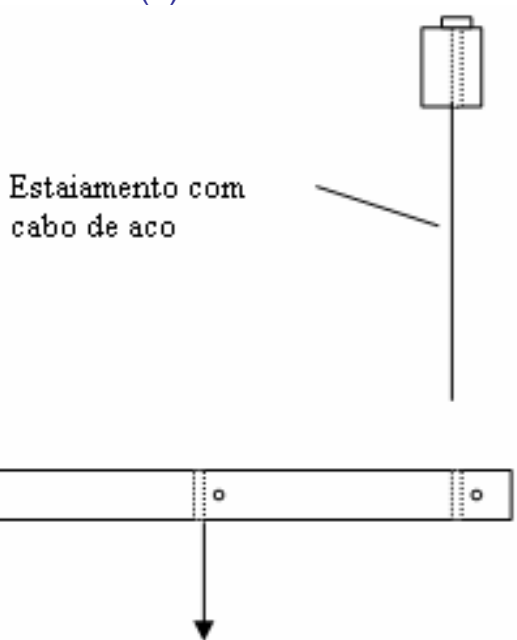

Figura 4.9 - Arranjos para os ensaios em cruzetas de concreto armado. Fonte: http://www.cehop.se.gov.br/ 


\subsection{Cruzetas metálicas}

As cruzetas metálicas são produzidas com aço carbono laminado ABNT 1010 ou 1020 e, visando sua proteção, são revestidas com zinco pelo processo de imersão a quente conforme prevê a NBR 8158:1983.

Nas figuras 4.10 a 4.12 são ilustradas algumas possíveis dimensões para as cruzetas metálicas, assim como a respectiva posição dos furos.

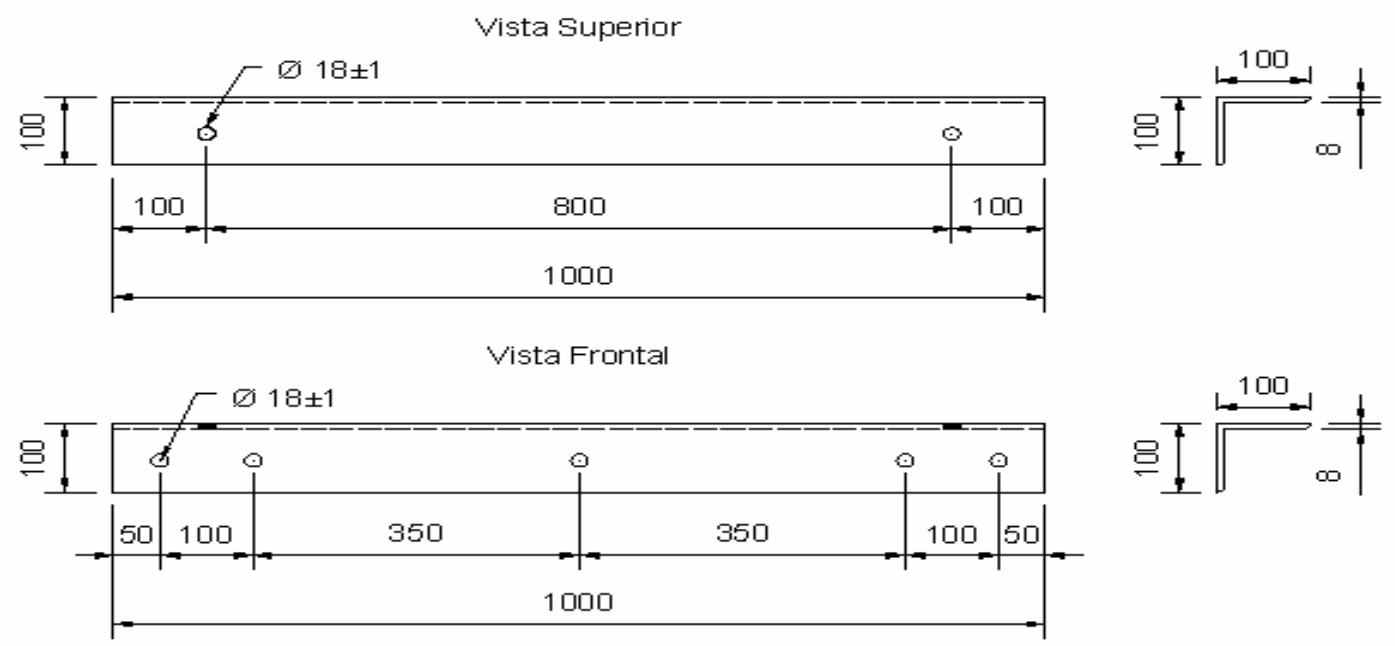

Figura 4.10 - Cruzeta metálica com comprimento de $1000 \mathrm{~mm}$ - Medidas em mm.

Fonte: www.ceee.com.br.
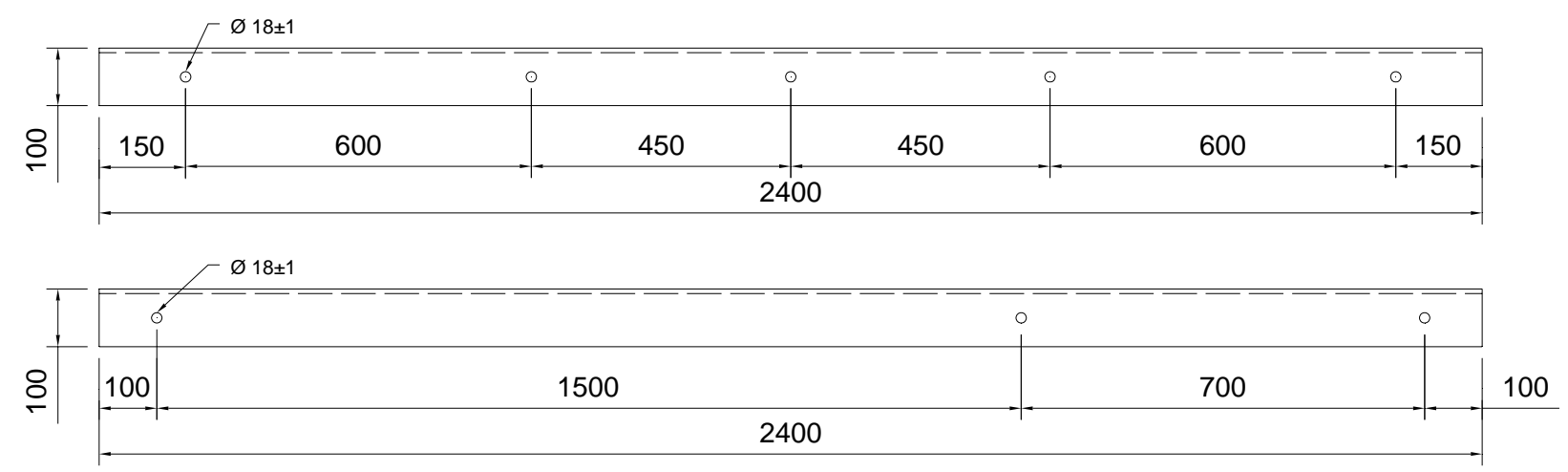

Figura 4.11 - Cruzeta metálica com comprimento de 2400 mm - Medidas em mm.

Fonte: www.ceee.com.br.
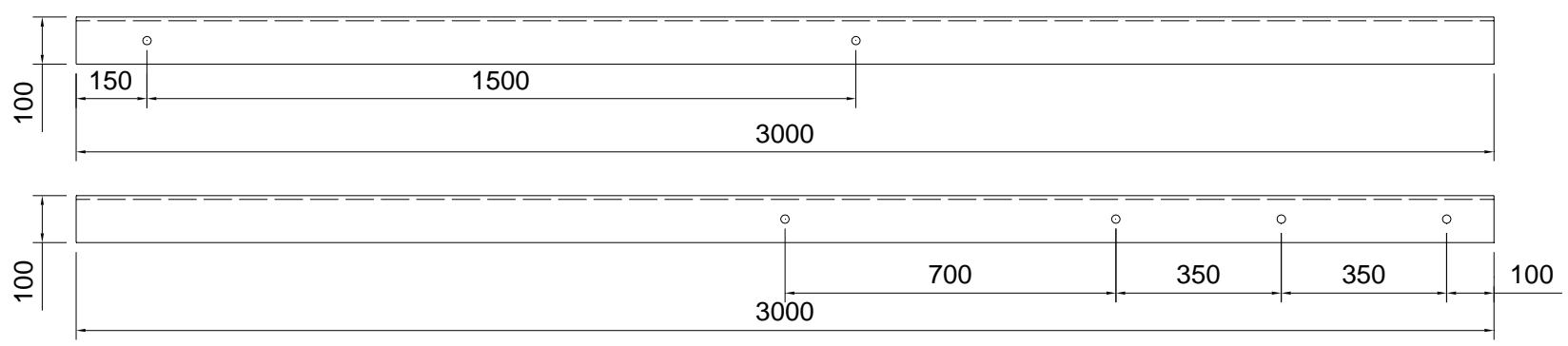

Figura 4.12 - Cruzeta metálica com comprimento de 3000 mm - Medidas em mm.

Fonte: www.ceee.com.br. 
Além das cruzetas apresentadas anteriormente, ainda existem diversos tipos de seções transversais, comprimentos e posições de furação que são determinadas pelas concessionárias de energia elétrica.

Quanto ao arranjo para o ensaio de flexão, segundo a Companhia de Energia Elétrica do Paraná (COPEL), os ensaios em cruzetas com comprimento de $1900 \mathrm{~mm}$ devem seguir o esquema ilustrado na figura 4.13, para ambas as faces.

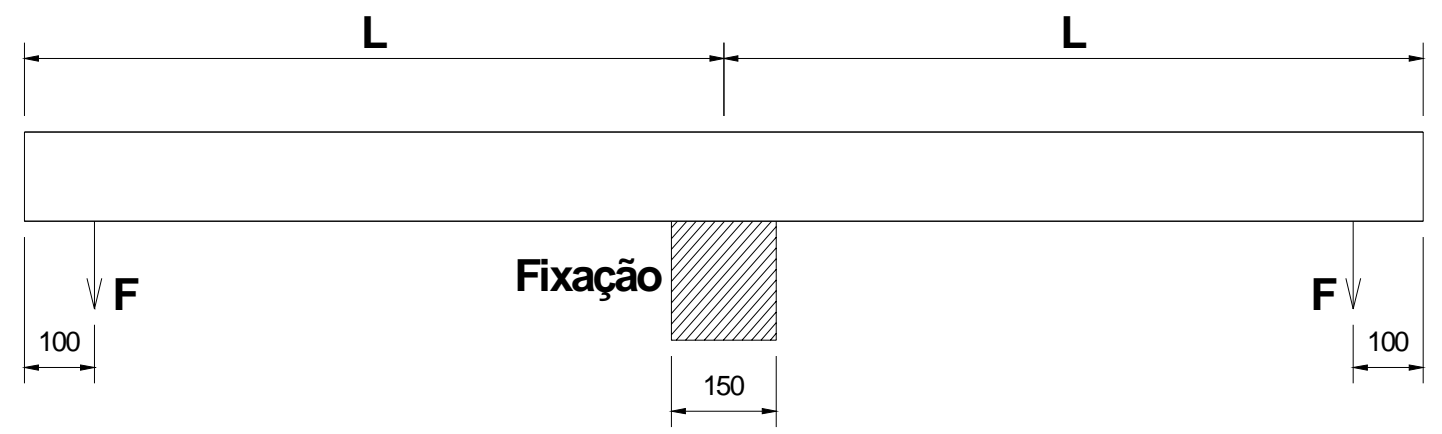

Figura 4.13 - Arranjo para ensaio de cruzetas de 1900mm - Medidas em mm.

Fonte: Copel.

Quanto à resistência à flexão, a Tabela 4.4 apresenta os valores que devem ser suportadas pela cruzeta ilustrada na Figura 4.12.

Tabela 4.4 - Resistência à flexão.

Fonte: NBR 8454:1984.

\begin{tabular}{|c|c|c|c|c|}
\hline \multirow{2}{*}{$\begin{array}{l}\text { Comprimento } \\
\text { (L) } \mathrm{mm}\end{array}$} & \multirow{2}{*}{$\begin{array}{l}\text { Descrição do } \\
\text { carregamento }\end{array}$} & \multirow{2}{*}{$\begin{array}{c}\text { Resistência (F) } \\
\text { N }\end{array}$} & \multicolumn{2}{|c|}{ Flecha $(\mathrm{mm})$} \\
\hline & & & Máxima & $\begin{array}{r}\text { Residua } \\
\text { máxima }\end{array}$ \\
\hline \multirow{3}{*}{1900} & Nominal & 1000 & 13 & --------- \\
\hline & Máximo excepcional & 1400 & 34 & 3 \\
\hline & Mínimo de ruptura & 2000 & |------- & |------- \\
\hline
\end{tabular}

\subsection{Particularidades das cruzetas}

Existem diversos parâmetros que servem como base de comparação para a aquisição de um determinado elemento, dentre os quais destacam-se: massa, custo e durabilidade.

Os próximos itens farão uma análise simplificada de alguns desses parâmetros, comparando-os com os de uma cruzeta de polímero reciclado. 


\subsubsection{Massa}

A massa de um elemento, assim como suas dimensões, são parâmetros importantes a serem observados, pois definem a necessidade de emprego de equipamentos para sua instalação e os de custos de transporte.

Sabendo-se que os materiais usuais empregados na fabricação de cruzetas são madeira, concreto armado e aço, é possível se fazer uma comparação desses materiais com os plásticos, obtendo-se assim a massa aproximada de cada elemento, conforme discriminado na Tabela 4.5.

Tabela 4.5 - Tabela comparativa de massas.

\begin{tabular}{|c|c|c|c|c|c|}
\hline Material & Seção (cm) & $\begin{array}{c}\text { Comprimento } \\
(\mathrm{cm})\end{array}$ & $\begin{array}{c}\text { Densidade } \\
\left(\mathrm{g} / \mathrm{cm}^{3}\right)\end{array}$ & Volume $\left(\mathrm{cm}^{3}\right)$ & Massa (kg) \\
\hline Cabriúva-parda & $9,0 \times 11,25$ & 200 & 0,91 & 20250 & 18,43 \\
\hline Cabriúva-vermelha & $9,0 \times 11,25$ & 200 & 0,95 & 20250 & 19,24 \\
\hline Imbuía & $9,0 \times 11,25$ & 200 & 0,65 & 20250 & 13,16 \\
\hline Concreto armado & $9,0 \times 11,5$ & 200 & 2,50 & 20700 & 51,75 \\
\hline Aço ABNT 1010 ou 1020 & $L-10 \times 10 \times 0,08$ & 200 & 7,50 & 1587 & 11,90 \\
\hline \begin{tabular}{c|} 
PEAD \\
\end{tabular} & $9,0 \times 11,25$ & 200 & 0,95 & 20250 & 19,24 \\
\hline PP & $9,0 \times 11,25$ & 200 & 0,91 & 20250 & 18,43 \\
\hline PS & $9,0 \times 11,25$ & 200 & 1,00 & 20250 & 20,25 \\
\hline
\end{tabular}

Adotando-se um comprimento padrão de dois metros para este estudo, e considerando-se que todas as seções transversais são maciças, exceto às das cruzetas metálicas, cuja seção adotada é igual à ilustrada na fig. 4.9, pode-se dizer que as massas das cruzetas de madeira e de plástico são equivalentes. A menor massa encontrada é para a cruzeta metálica. Entretanto, essa grande diferença é dada pelo formato diferenciado de sua seção transversal e, conseqüentemente, menor consumo de material para sua fabricação.

Uma das maneiras de se conseguir cruzetas plásticas com menor consumo de material e menor massa será através de estudos que promovam otimização da seção transversal, sem que haja comprometimento das demais propriedades necessárias para o bom desempenho do elemento. Esse estudo será apresentado no capítulo 5.

\subsubsection{Custo e durabilidade}

O custo para a aquisição de um elemento também é um dos fatores que impulsiona sua escolha, assim como sua durabilidade.

Tomando-se como base dois dos materiais mais utilizados na confecção de cruzetas das redes de distribuição de energia elétrica, é possível se comparar os preços de venda sugeridos para esses elementos (Tabela 4.6). 
Tabela 4.6 - Tabela comparativa de custos.

Fonte: www.jabu.com.br e www.postes.com.br

\begin{tabular}{|c|c|c|}
\hline Material & Descrição & Valor (R\$) \\
\hline \multirow{2}{*}{ Madeira } & Cruzeta de madeira 90x90x2000mm & 45,35 \\
\hline & Cruzeta de madeira 90x90x2400mm & 53,35 \\
\hline \multirow{2}{*}{$\begin{array}{c}\text { Concreto } \\
\text { Armado }\end{array}$} & Cruzeta de concreto $90 \times 115 \times 2100 \mathrm{~mm}$ & 62,00 \\
\hline & Cruzeta de concreto $90 \times 115 \times 2400 \mathrm{~mm}$ & 62,00 \\
\hline
\end{tabular}

A partir desses dados percebe-se que a cruzeta de madeira com comprimento de $2,40 \mathrm{~m}$ possui custo $13 \%$ inferior, quando comparada à de concreto armado.

Considerando o preço do PEAD reciclado igual a $R \$ 2,40 / \mathrm{kg}$, uma seção transversal maciça de 90x90mm e comprimento de 2,40 metros, encontram-se uma massa de 18,5 kg e um custo de $\mathrm{R} \$ 44,40$, admitindo-se somente com gasto de material. A esse custo deve-se somar o transporte, gastos com matrizes, equipamentos e mão-de-obra para a produção do elemento.

Admitindo-se que a cruzeta de material polimérico reciclado possua um custo final superior aos da cruzeta de madeira e de concreto armado, deve-se levar em conta sua maior durabilidade e a diminuição de custos operacionais das concessionárias, decorrentes das trocas desses elementos. Outro aspecto muito importante está ligado ao fato de que, devido à utilização de material reciclado, ele pode ser novamente processado e utilizado na produção de um novo elemento ou ser vendido, resgatando-se assim parte do capital investido na aquisição do elemento. 


\section{ESTUDO DAS PROPRIEDADES DAS SEÇÕES TRANSVERSAIS E DE MODELOS REDUZIDOS}

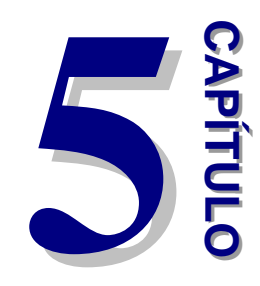

\subsection{Considerações Iniciais}

Para a análise do comportamento das cruzetas e o estudo das propriedades das seções transversais, serão utilizados modelos em escalas reduzidas. A utilização desses modelos justifica-se pelo elevado custo necessário para produção de matrizes e calibradores, para produção dos protótipos das cruzetas.

Com relação ao estudo das propriedades das seções transversais, pelo fato deste trabalho propor a utilização dos polímeros como material para fabricação de cruzetas e, também, prevendo economia de material através de alterações nas seções transversais, é necessário que seja feito um estudo das propriedades dessas seções, no que diz respeito a sua rigidez, custo, facilidade de produção e viabilidade financeira.

\subsection{Estudo das propriedades das seções transversais}

O estudo das propriedades das seções transversais tem o objetivo de propor uma nova seção transversal, em relação à maciça, que é tradicionalmente utilizada nas cruzetas de madeira e de concreto armado, visando um menor consumo de material e obtendo rigidez apropriada a sua aplicação, diminuindo assim os custos de produção e sua massa unitária.

Neste estudo serão levados em conta: (i) tipo de seção transversal, (ii) consumo de material para sua fabricação, (iii) rigidez e (iv) custo para sua produção.

\subsubsection{Modelos de seções transversaìs}

Para o estudo das propriedades das seções transversais foram analisados dez tipos possíveis de seções para os protótipos, sendo três maciças e sete vazadas, conforme dimensões ilustradas na figura 5.1, admitindo-se comprimento de 2 metros. Nos quatro primeiros tipos de seções será feito um estudo do comportamento da cruzeta de material polimérico aplicando-se a escala 1:2,5, enquanto que nos demais, será aplicada a escala 1:3,33. Essas dimensões foram adotadas em função dos perfis metálicos disponíveis no comércio, para confecção das fôrmas dos modelos reduzidos.

Com relação às propriedades das seções transversais, tais como área, volume e momentos de inércia, a Tabela 5.1 apresenta os valores encontrados para cada seção. 0 
levantamento dos momentos de inércia das seções transversais estudadas neste trabalho foi feito utilizando-se o software Autocad 2006.

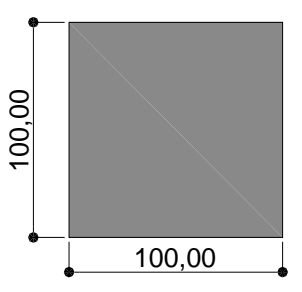

Seção 1

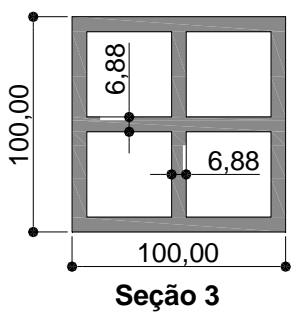

Seção 3

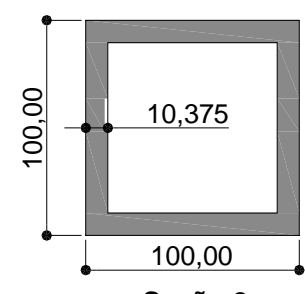

Seção 2

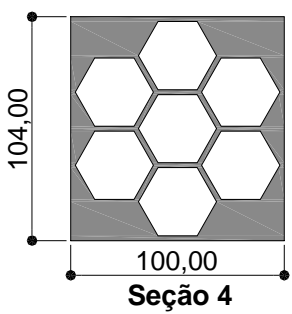

Seção 4

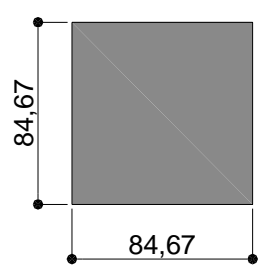

Seção 5

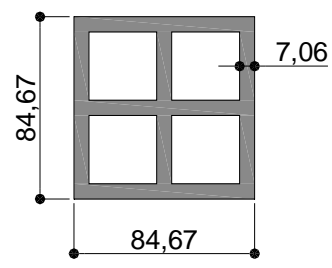

Seção 7

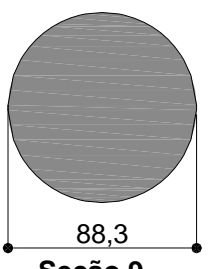

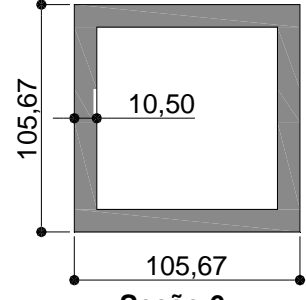

Seção 6

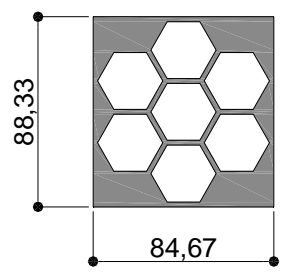

Seção 8

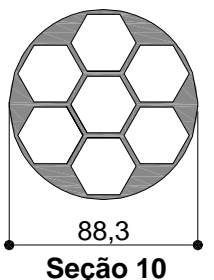

Figura 5.1 - Tipos de seções transversais - Medidas em mm.

Tabela 5.1 - Propriedades das seções transversais.

\begin{tabular}{|c|c|c|c|c|}
\hline Seção & Área $\left(\mathrm{cm}^{2}\right)$ & Volume $\left(\mathrm{cm}^{3}\right)$ & $\begin{array}{c}\text { Momento de } \\
\text { inércia relativo } \\
\text { ao eixo } \times\left(\mathrm{cm}^{4}\right)\end{array}$ & $\begin{array}{c}\text { Momento de } \\
\text { inércia relativo } \\
\text { ao eixo y }\left(\mathrm{cm}^{4}\right)\end{array}$ \\
\hline 1 & 100,00 & 20000,00 & 833,33 & 833,33 \\
\hline 2 & 37,19 & 7438,88 & 504,62 & 504,62 \\
\hline 3 & 37,00 & 7399,22 & 409,14 & 409,14 \\
\hline 4 & 42,89 & 8577,89 & 592,96 & 518,29 \\
\hline 5 & 71,68 & 14336,86 & 428,22 & 428,22 \\
\hline 6 & 39,97 & 7994,00 & 610,67 & 610,67 \\
\hline 7 & 31,36 & 6272,39 & 242,55 & 242,55 \\
\hline 8 & 32,35 & 6470,20 & 315,88 & 274,75 \\
\hline 9 & 61,11 & 12223,06 & 297,15 & 297,15 \\
\hline 10 & 30,80 & 6160,52 & 126,88 & 126,88 \\
\hline
\end{tabular}

Considerando-se a densidade do polietileno de alta densidade (PEAD) como sendo igual a 0,95g/cm³ (http://www.incomplast.com.br/polietil.htm) e seu preço igual a $\mathrm{R} \$ 2,40 / \mathrm{kg}$ (Tabela 1.1 Capítulo 1 - PEAD colorido para injeção), respectivamente, é possível calcular a quantidade de material necessário para se produzir as cruzetas de materiais poliméricos, assim como seu custo de produção, considerando-se a estimativa de custo de produção de $R \$ 1,00 / \mathrm{kg}$ de material 
processado. Considerando-se o módulo de elasticidade como um valor constante e utilizando os momentos de inércia apresentados na tabela 5.1, pode-se fazer uma analogia sobre a rigidez à flexão do material $(\mathrm{E} \cdot \mathrm{I})$, que é definida como sendo o módulo de elasticidade vezes o momento de inércia, e seu custo (Fig. 5.2 e 5.3)

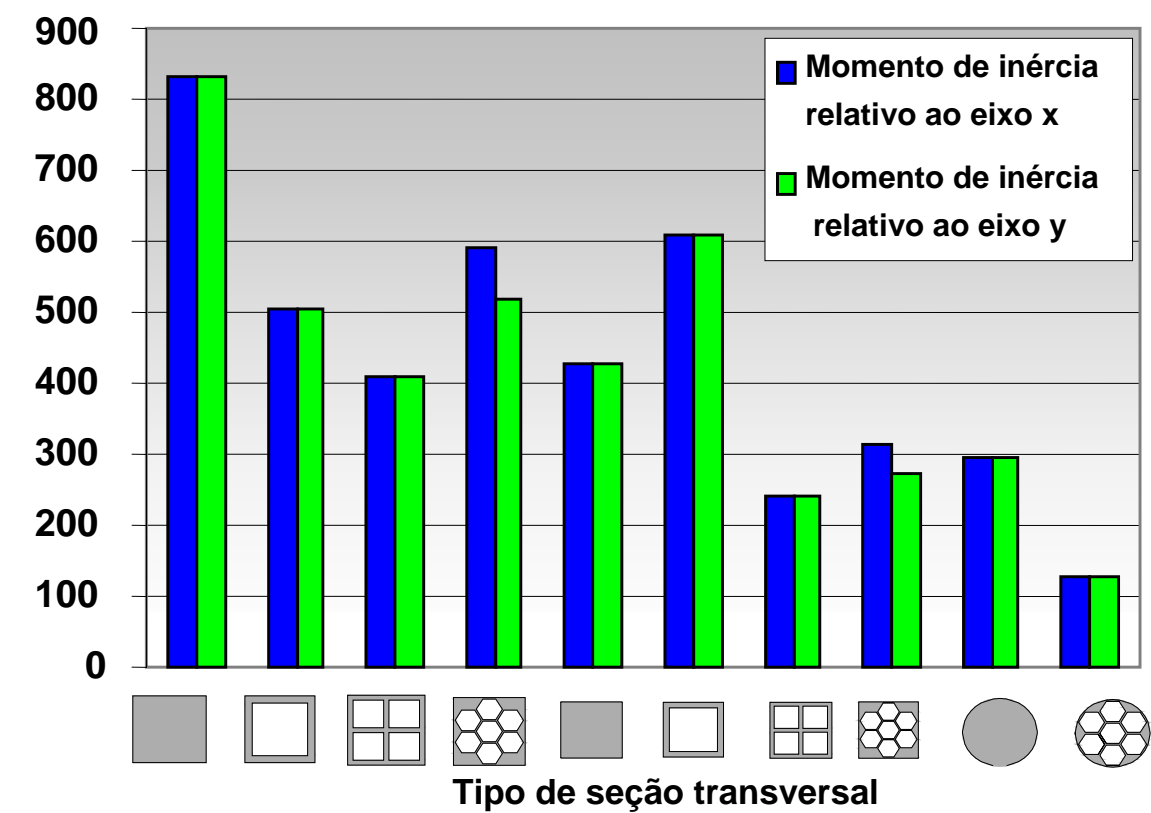

Figura 5.2 - Momentos de inércia.

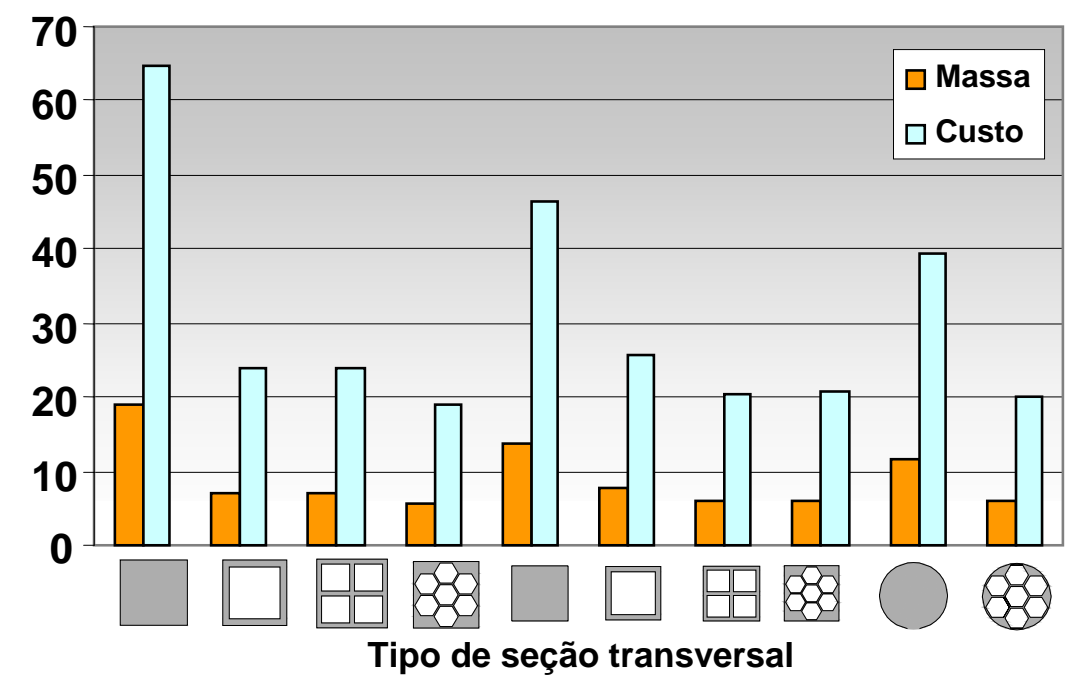

Figura 5.3 - Massa versus custo.

Comparando-se as seções 1 e 4, por exemplo, percebe-se que a economia com o consumo de material é de $240 \%$. Entretanto, existe uma redução de $40 \%$ do momento de inércia e, conseqüentemente, da rigidez do material à flexão.

Com relação à produção das cruzetas, levando-se em conta os tipos de seções transversais, as seções maciças possuem maior custo inicial para produção, decorrente do 
maior custo para produção das matrizes e calibradores, quando comparado ao de uma seção vazada.

\subsection{Modelos em escala reduzida}

Neste item serão apresentadas as teorias da análise dimensional e dos modelos físicos reduzidos, além de sua utilização no estudo dos modelos reduzidos de cruzetas de materiais poliméricos.

\subsubsection{Aspectos gerais da modelagem física}

Segundo Andolfato (2002), a necessidade de se estudarem os fenômenos naturais fez com que o cientista Galileu Galilei apresentasse na sua obra "A fraqueza relativa dos grandes" o primeiro estudo dos efeitos das escalas. Depois disso, outros cientistas também estudaram esse assunto e, com o passar dos anos, chegaram à Teoria da Análise Dimensional e Semelhança dos Modelos Físicos, que conhecemos atualmente.

Para a aplicação da teoria da análise dimensional é necessário que se faça a determinação das características físicas capazes de relacionar protótipos e modelos. "Para que os resultados obtidos na experimentação de modelos em laboratório possam ser estendidos para a representação de um protótipo, é necessário primeiramente que exista a semelhança geométrica" (Carneiro ${ }^{1}$ apud Andolfato, 2002).

\subsubsection{Análise dimensional}

$\mathrm{Na}$ análise dimensional é sempre adotada uma forma explícita, onde uma das variáveis, geralmente a dependente, é a incógnita do problema. Todas as demais variáveis e constantes físicas universais ou específicas constituem os dados do problema e devem ser considerados como variáveis independentes.

Embora a análise dimensional seja incapaz, por si só, de encontrar a formulação completa de uma lei física, ela fornece indicações sobre combinações dos parâmetros envolvidos, de modo a reduzir o número total de variáveis a serem incluídas nas equações.

Uma das principais aplicações da análise dimensional é o estabelecimento das condições de semelhança física, possibilitando assim comparações entre os protótipos e os modelos utilizados em ensaios. Para que um modelo possa representar um protótipo, ou seja, para que os resultados obtidos nos ensaios com modelos possam ser estendidos aos protótipos, é preciso que exista semelhança entre eles, a começar pela semelhança geométrica.

\footnotetext{
${ }^{1}$ CARNEIRO, F.L. Análise Dimensional e teoria da semelhança e dos modelos físicos. Rio de Janeiro: UFRJ, 1996, 256p.
} 


\subsubsection{Teoria da homogeneidade dimensional}

Quando se trabalha com modelos em escala reduzida, é essencial considerar a homogeneidade dimensional, ou seja, assegurar que nas equações matemáticas utilizadas para descrever algum estado ou fenômeno físico, as dimensões (produtos das potências das unidades base) têm que ser iguais para todos os membros envolvidos.

Assim, o princípio da homogeneidade dimensional consiste em que toda equação que exprima uma lei física ou descreva um processo físico deva ser homogênea, relativamente a cada grandeza de base, continuando assim a ser válida, desde que se façam as mudanças das unidades fundamentais.

\subsubsection{Grandezas físicas, dimensões e unidades}

A Tabela 5.2 mostra as grandezas efetivas, que são aquelas que podem ser medidas, enquanto a Tabela 5.3 mostra as constantes físicas, que são grandezas que surgem no estudo de várias equações, relacionadas geralmente ao estudo de uma invariância em alguma propriedade fundamental da matéria ou do espaço-tempo.

Tabela 5.2 - Grandezas efetivas.

Fonte: Calil Júnior (1988).

\begin{tabular}{l|c|c}
\hline $\begin{array}{c}\text { Grandezas } \\
\text { efetivas }\end{array}$ & $\begin{array}{c}\text { Sistema } \\
\text { Massa }\end{array}$ & $\begin{array}{c}\text { Sistema } \\
\text { Força }\end{array}$ \\
\hline Comprimento & {$[\mathrm{L}]$} & {$[\mathrm{L}]$} \\
\hline Tempo & {$[\mathrm{T}]$} & {$[\mathrm{T}]$} \\
\hline Massa & {$[\mathrm{M}]$} & {$\left[\mathrm{F} \mathrm{L}^{-1} \mathrm{~T}^{2}\right]$} \\
\hline Força & {$\left[\mathrm{M} \mathrm{L} \mathrm{^{-2 } ]}\right.$} & {$[\mathrm{F}]$} \\
\hline Temperatura & {$[\theta]$} & {$[\theta]$} \\
\hline Velocidade & {$\left[\mathrm{L} \mathrm{T}^{-1}\right]$} & {$\left[\mathrm{L} \mathrm{T}^{-1}\right]$} \\
\hline Pressão e Tensão & {$\left[\mathrm{M} \mathrm{L}^{-1} \mathrm{~T}^{-2}\right]$} & {$\left[\mathrm{F} \mathrm{L}^{-2}\right]$} \\
\hline Momento & {$\left[\mathrm{M} \mathrm{L}^{2} \mathrm{~T}^{-2}\right]$} & {$[\mathrm{F} \mathrm{L}]$} \\
\hline Momento de Inércia & {$\left[\mathrm{L}^{4}\right]$} & {$\left[\mathrm{L}^{4}\right]$} \\
\hline Deformação & {$[1]$} & {$[1]$} \\
\hline
\end{tabular}

Tabela 5.3 - Constantes Físicas. Fonte: Calil Júnior (1988).

\begin{tabular}{c|c|c}
\hline Constantes Físicas & $\begin{array}{c}\text { Sistema } \\
\text { Massa }\end{array}$ & $\begin{array}{c}\text { Sistema } \\
\text { Força }\end{array}$ \\
\hline Peso Específico & {$\left[\mathrm{M} \mathrm{L}^{-2} \mathrm{~T}^{-2}\right]$} & {$\left[\mathrm{F} \mathrm{L}^{-3}\right]$} \\
\hline Densidade & {$\left[\mathrm{M} \mathrm{L}^{-3}\right]$} & {$\left[\mathrm{F} \mathrm{L}^{-4} \mathrm{~T}^{2}\right]$} \\
\hline Módulo de Elasticidade & {$\left[\mathrm{M} \mathrm{L}^{-1} \mathrm{~T}^{-2}\right]$} & {$\left[\mathrm{F} \mathrm{L}^{-2}\right]$} \\
\hline Coeficiente de Poisson & {$[1]$} & {$[1]$} \\
\hline $\begin{array}{c}\text { Coeficiente Linear de } \\
\text { Dilatação Térmica }\end{array}$ & {$\left[\theta^{-1}\right]$} & {$\left[\theta^{-1}\right]$} \\
\hline
\end{tabular}




\subsubsection{Condições de semelhança física}

Quando dois processos são semelhantes, é possível prever o comportamento de um deles quando é conhecido o comportamento do outro. Na experimentação por meio de modelos, os dois processos físicos semelhantes são o protótipo e o modelo, dos quais o modelo é o mais fácil de ser ensaiado em laboratório, pois são produzidos em escala geométrica reduzida, mas há casos em que se adotam modelos maiores que os protótipos.

Além da semelhança geométrica, é necessário que os processos físicos também sejam semelhantes. A relação entre as magnitudes de uma grandeza nos dois processos é chamada de analogia com a escala das dimensões geométricas e do tempo, escala ou fator de escala. Assim, em uma experimentação, se o modelo é reduzido, a escala geométrica é menor que a unidade. Em geral, a escala é representada pela equação 5.1 , em que a unidade é o numerador, designada com o símbolo $\mathrm{k}$ ou $\lambda$.

$$
k_{i}=\lambda_{i}=\frac{x_{m}}{x_{p}}=\frac{1}{x_{p} / x_{m}}=1:\left(x_{p} / x_{m}\right)
$$

Assim, para que se possa adotar que o comportamento do protótipo seja o mesmo do modelo, é necessário que as unidades de medidas do modelo sejam iguais às unidades de medida do protótipo multiplicadas pelos fatores de escala correspondentes (Equação 5.2).

$$
x_{m}=k_{i} \cdot x_{p}
$$

Os fatores de escala para as variáveis dependentes, independentes e constantes físicas são listados na Tabela 5.4.

Tabela 5.4 - Fatores de escala.

Fonte: Souza (2004).

\begin{tabular}{l|c|c}
\hline \multicolumn{1}{c|}{ Grandeza } & Dimensão & Fatores de escala, $\mathbf{k}_{\mathbf{i}}$ \\
\hline Ângulo $(\alpha)$ & -------- & 1 \\
\hline Coeficiente de expansão linear $\left(\alpha_{\mathrm{T}}\right)$ & $\theta^{-1}$ & 1 \\
\hline Coeficiente de Poisson $(v)$ & -------- & 1 \\
\hline Deformação $(\varepsilon)$ & -------- & 1 \\
\hline Deslocamento $(\delta)$ & $\mathrm{L}$ & $\mathrm{K}_{\mathrm{i}}$ \\
\hline Diâmetro $(\mathrm{D})$ & $\mathrm{L}$ & $\mathrm{K}_{\mathrm{i}}$ \\
\hline Dimensão linear $(\mathrm{l})$ & $\mathrm{L}$ & $\mathrm{K}_{\mathrm{i}}$ \\
\hline Espessura (t) & $\mathrm{L}$ & $\mathrm{K}_{\mathrm{i}}$ \\
\hline Força concentrada $(\mathrm{F})$ & $\mathrm{F}$ & $\mathrm{K}_{\mathrm{i}}{ }^{2}$ \\
\hline Força por unidade de comprimento $(\mathrm{F} / \mathrm{l})$ & $\mathrm{F} \mathrm{L}^{-1}$ & $\mathrm{~K}_{\mathrm{i}}$ \\
\hline Módulo de Elasticidade $(\mathrm{E})$ & $\mathrm{F} \mathrm{L}^{-2}$ & 1 \\
\hline Pressão $(p)$ & $\mathrm{F} \mathrm{L}^{-2}$ & 1 \\
\hline Temperatura $(\theta)$ & $\theta$ & 1 \\
\hline Tempo $(\mathrm{T})$ & $\mathrm{T}$ & $\mathrm{K}_{\mathrm{i}}{ }^{2}$ \\
\hline Tensão $(\sigma)$ & $\mathrm{F} \mathrm{L}^{-2}$ & 1 \\
\hline
\end{tabular}




\subsubsection{Aplicação da teoria dos modelos reduzidos às cruzetas}

Para a fabricação das cruzetas de material polimérico em escala reduzida, foram aplicadas as hipóteses apresentadas anteriormente. As dimensões dos protótipos das cruzetas são as ilustradas na Figura 5.1, para um comprimento de 2000 mm.

Considerando os protótipos com esse comprimento, os modelos com comprimento de $800 \mathrm{~mm}$ e $600 \mathrm{~mm}$, respectivamente, e aplicando-se a Equação 5.1, tem-se que:

$$
\begin{gathered}
k_{i}=\lambda_{i}=\frac{1}{2000 \mathrm{~mm} / 800 \mathrm{~mm}}=1: 2,5 \\
k_{i}=\lambda_{i}=\frac{1}{2000 \mathrm{~mm} / 600 \mathrm{~mm}}=1: 3,33
\end{gathered}
$$

Assim, as escalas obtidas são 1:2,5 e 1:3,33. Aplicando-se essas escalas nas seções a serem estudadas neste trabalho, obtêm-se as seções ilustradas na figura 5.4.

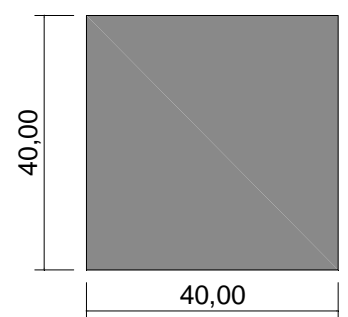

Seção 1

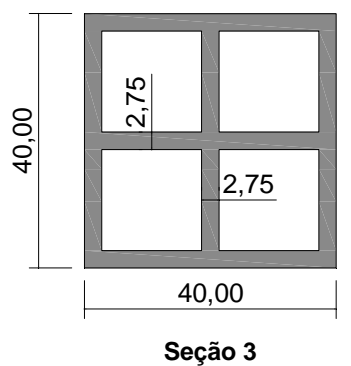

Seção 3

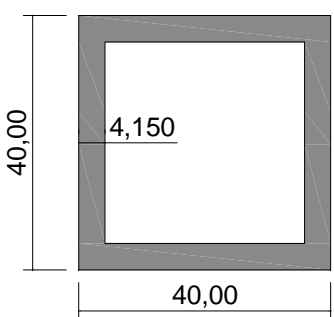

Seção 2

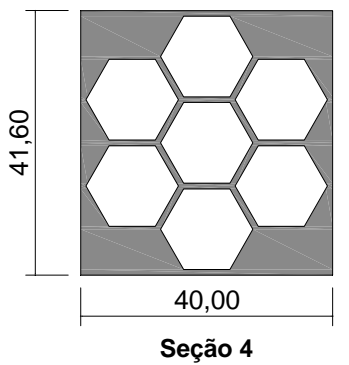

Seção 4

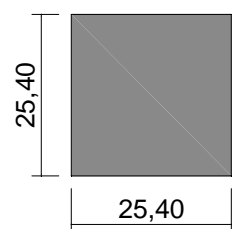

Seção 5

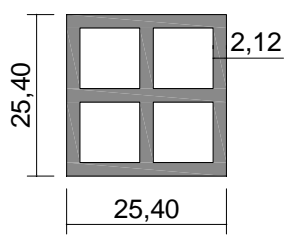

Seção 7

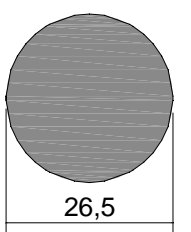

Seção 9

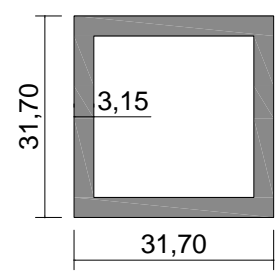

Seção 6

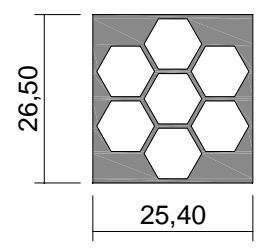

Seção 8

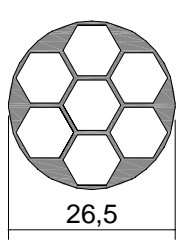

Seção 10

(a)

(b)

Figura 5.4 - Seções transversais dos modelos reduzidos, com comprimento de (a) $600 \mathrm{~mm}$ e (b) $800 \mathrm{~mm}$. 
Com relação às cargas a serem aplicadas nos modelos, por meio das relações demonstradas na tabela 5.6 e aplicando a escala 1:2,5 para os modelos com comprimento de $800 \mathrm{~mm}$, têm-se os seguintes carregamentos:

$$
\begin{aligned}
& F^{\prime}=F \cdot K_{i}^{2} \\
& F^{\prime}=4000 N \cdot\left(\frac{1}{2,5}\right)^{2} \\
& F^{\prime}=640 N \quad \text { (carga nominal) } \\
& F^{\prime}=5600 N \cdot\left(\frac{1}{2,5}\right)^{2} \\
& F^{\prime}=896 N \text { (carregamento máximo) } \\
& F^{\prime}=8000 N \cdot\left(\frac{1}{2,5}\right)^{2} \\
& F^{\prime}=1280 N \quad \text { (carga de ruptura) }
\end{aligned}
$$

Analogamente, para o modelo com comprimento de $600 \mathrm{~mm}$ e escala 1:3,33, foram obtidos os seguintes carregamentos:

$$
\begin{aligned}
& F^{\prime}=F \cdot K_{i}^{2} \\
& F^{\prime}=4000 N \cdot\left(\frac{1}{3,33}\right)^{2} \\
& F^{\prime}=360 N \text { (carga nominal) } \\
& F^{\prime}=5600 N \cdot\left(\frac{1}{3,33}\right)^{2} \\
& F^{\prime}=504 N \text { (carregamento máximo) } \\
& F^{\prime}=8000 N \cdot\left(\frac{1}{3,33}\right)^{2} \\
& F^{\prime}=720 N \text { (carga de ruptura) }
\end{aligned}
$$

Os valores obtidos para os modelos representam os protótipos, ou seja, podem ser estendidos aos protótipos, pois existe semelhança entre eles, tanto pela geometria quanto pelos carregamentos. Devido à limitação do deslocamento do travessão da máquina utilizada para o ensaio (neste caso, a máquina de ensaios universal Dartec), cujo deslocamento máximo do pistão é de $10 \mathrm{~cm}$, em alguns casos, não foi possível aplicar o carregamento previamente calculado, uma vez que o material é flexível e apresenta grandes deformações. Os valores de carregamento aplicados aos modelos, assim com suas flechas, são apresentados no Capítulo 8. 


\section{INVESTIGAÇÃO EXPERIMENTAL}

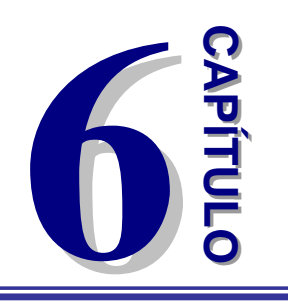

\subsection{Considerações iniciais}

Neste capítulo apresenta-se a investigação experimental desenvolvida para o estudo de cruzetas de materiais poliméricos. Os ensaios foram conduzidos no Laboratório do Departamento de Materiais, Aeronáutica e Automobilística - SMM, Laboratório de Geotêxteis do Departamento de Geotecnia - SGS, Laboratório de Madeira e Estruturas de Madeiras - LaMEM, da EESC, e no Laboratório do Departamento de Engenharia de Materiais do DEMa, da Universidade Federal de São Carlos.

A investigação experimental foi dividida em duas partes:

- Caracterização dos materiais poliméricos;

- Ensaios dos modelos de cruzetas poliméricas em escala reduzida com comprimentos 600 e $800 \mathrm{~mm}$.

\subsection{Material utilizado}

Um dos objetivos deste trabalho é comprovar a viabilidade de empregar os polímeros reciclados como material estrutural.

O material escolhido inicialmente para o estudo de cruzetas foi o polietileno de alta densidade (PEAD) reciclado, pois é um dos materiais poliméricos mais abundantes. Candian (2007) fez um estudo desse material e realizou ensaios químicos, como análise termogravimétrica (TG) e calorimetria exploratória diferencial (DSC). O próximo passo de seu trabalho é a realização de ensaios mecânicos de tração, compressão, flexão e impacto, caracterizando assim o material reciclado.

Neste trabalho, devido ao elevado investimento para a moldagem dos modelos de cruzeta em polietileno de alta densidade reciclado em escala real, foram produzidos modelos em escala reduzida, utilizando um sistema à base de poliuretano fundível da marca Huntsman, indicado para aplicações que requeiram alta resistência à abrasão, impacto, flexibilidade, alongamento e rasgo, simulando assim as características dos materiais termoplásticos. Foi utilizado um sistema Rencast composto por: 6414A, 5073A e XD 4609.

A escolha desse material é justificada pelo fato de que ele é indicado aos mais diversos usos, tais como simulação de peças termoplásticas, reproduções rápidas, cópia de modelos, 
produção de moldes e protótipos, atendendo assim a necessidade deste trabalho. A intenção inicial era simular as propriedades de um PEAD.

Com relação às características da mistura e às propriedades obtidas após cura completa do material, a tabelas 6.1 e 6.2 apresentam, respectivamente, os valores esperados, levando em conta a proporção de cada mistura.

Tabela 6.1 - Características da mistura.

Fonte: Maxepoxi Industrial e Comercial Ltda.

\begin{tabular}{|c|c|c|c|c|}
\hline Componente $\mathrm{A}$ & $5073 \mathrm{~A}$ & $5073 A$ & ---------- & ----------- \\
\hline Componente B & ----------- & $6414 A$ & $6414 A$ & $6414^{A}$ \\
\hline Componente C & XD 4609 & XD 4609 & XD 4609 & XD 4608 \\
\hline Cor & Castanho & Caramelo & marrom & Bege \\
\hline Proporção de mistura (por peso) & 100:20:00 & $50: 50: 45$ & $100: 70$ & $100: 41: 00$ \\
\hline Espessura máxima (mm) & 100 & 100 & 20 & 10 \\
\hline Viscosidade da mistura $25^{\circ} \mathrm{C}$ (mPas) & 4.000 & 3.000 & 2.700 & 5.200 \\
\hline Tempo de uso $25^{\circ} \mathrm{C}-1 \mathrm{~kg}$ (minutos) & $20-25$ & ---------- & $15-22$ & $15-20$ \\
\hline Tempo de endurecimento (horas) & $4-10$ & $10-16$ & $4-10$ & $4-10$ \\
\hline
\end{tabular}

Tabela 6.2 - Propriedades após cura completa (7 dias a $25^{\circ} \mathrm{C}$ ou 14 horas a $40^{\circ} \mathrm{C}$ ). Fonte: Maxepoxi Industrial e Comercial Ltda.

\begin{tabular}{|c|c|c|c|c|}
\hline Componente A & $5073 \mathrm{~A}$ & 5073A & ----------- & ---------- \\
\hline Componente B & ---------- & $6414 A$ & $6414 A$ & $6414 \mathrm{~A}$ \\
\hline Componente C & XD 4609 & XD 4609 & XD 4609 & XD 4608 \\
\hline Densidade (g/cm $\left.{ }^{3}\right)$ & 1,10 & 1,10 & 1,10 & 1,10 \\
\hline Dureza Shore - Norma ISO 868 & 45A & 80A & 55D & 67D \\
\hline Resistência à tração (N/mm²) - Norma ISO 527 & 3 & 6 & 11 & 21 \\
\hline Alongamento até ruptura (\%) - ISO 527 & 270 & 200 & 135 & 127 \\
\hline Resistência à abrasão (mg) - Norma NEMA & ca. $7-14$ & Ca. 7 - 14 & ca. $7-14$ & ca. 7 - 14 \\
\hline
\end{tabular}

Baseando-se nas propriedades apresentadas nas tabelas 6.1 e 6.2, foi definida uma mistura de Rencast 5073A, Rencast 6414A e Rencast XD 4609 na relação estequiométrica de 50:50:45, obtendo-se assim material com tonalidade caramelo, densidade de aproximadamente $1,10 \mathrm{~g} / \mathrm{cm}^{3}$ após a cura, dureza Shore de $80 A$ e resistência à tração de $6 \mathrm{MPa}$. Entretanto, os corpos-de-prova obtidos com essa relação estequiométrica mostraram-se muito flexíveis. Então, foi feita uma nova moldagem, utilizando os componentes 6414A e XD 4609, na relação estequiométrica de 100:70, obtendo-se um material com tonalidade marrom, dureza Shore de 55D e resistência à tração de $11 \mathrm{MPa}$.

\subsection{Dimensões dos corpos-de-prova}

Após a aquisição dos materiais, foram feitos estudos preliminares nos quais se buscou a metodologia mais adequada para a confecção dos corpos-de-prova em poliuretano, a fim de se evitarem possíveis falhas durante o processo de fabricação (e.g., bolhas). 
Para a obtenção dos corpos-de-prova em poliuretano adotaram-se as especificações das normas ASTM D638-03, ASTM D695-02a, ASTM D790-96a e ASTM D256-04, para os testes de tração, compressão, flexão e impacto, respectivamente, cujas dimensões são ilustradas na figura 6.1 .
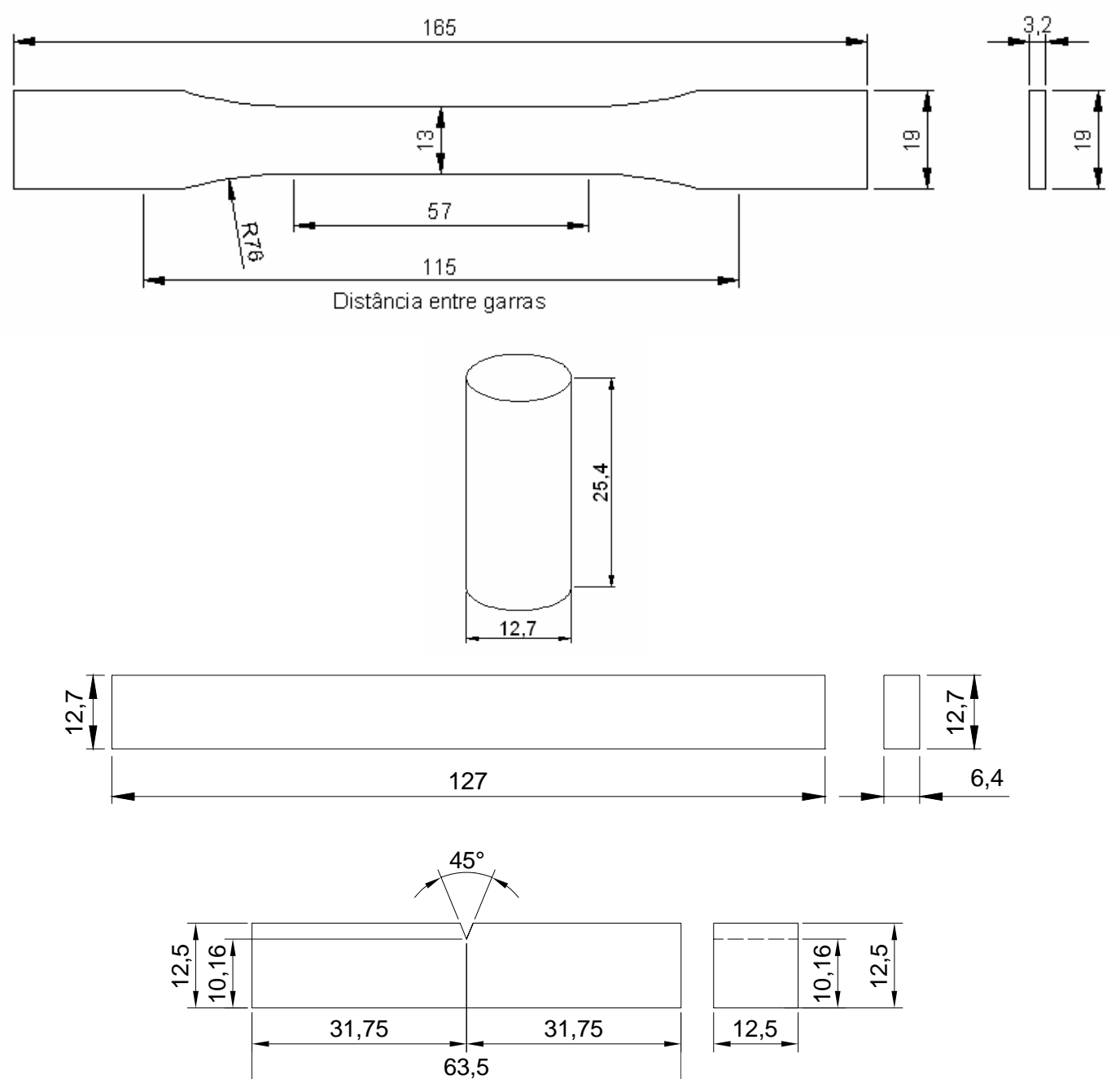

Figura 6.1 - Dimensões, em mm, dos corpos-de-prova de tração, compressão, flexão e impacto.

\subsection{Fabricação dos moldes de silicone}

Para a fabricação dos moldes de silicone para os corpos-de-prova de flexão e de impacto, utilizaram-se caixas de moldagem, feitas com bastões poliméricos e elastômero de silicone da marca hard ${ }^{\mathrm{TM}}$, com massa específica de $1,10 \mathrm{~g} / \mathrm{cm}^{3}$. A geometria de reprodução dos moldes de silicone foi obtida a partir de modelos em aço (CP de flexão e impacto) e de material polimérico (CP de tração e compressão). Assim, foi possível reproduzir fielmente os CP em poliuretano.

Com o objetivo de agilizar a fabricação dos corpos-de-prova, foram feitos moldes com capacidade de produção simultânea de seis corpos-de-prova de tração, seis de compressão, sete 
de flexão e sete de impacto. Esses moldes foram produzidos no Laboratório de Tribologia e Compósitos (LTC) do Departamento de Engenharia Mecânica da Escola de Engenharia de São Carlos (SEM/EESC/USP) e tiveram supervisão do Prof. Benedito de Moraes Purquerio.

\subsection{Moldagem dos corpos-de-prova em poliuretano}

As etapas para obtenção dos corpos-de-prova de tração, compressão, flexão e impacto são apresentadas a seguir:

- Misturar os sistemas à base de poliuretano Rencast 6414A e XD 4609, à pressão e temperatura ambiente, segundo a relação estequiométrica de 100:70, respectivamente. Para isso, utilizou-se uma balança eletrônica da marca Ohaus, modelo TS4KD, com sensibilidade de 0,01g;

- Agitar a mistura por aproximadamente dois minutos, a fim de fazer sua homogeneização;

- Colocar o recipiente contendo a mistura dentro de um dessecador acoplado a uma bomba de vácuo. Esse procedimento tem o objetivo de eliminar o excesso de bolhas de ar que surgem durante a mistura. O tempo de permanência da mistura no vácuo é de aproximadamente 5 minutos. Nesta etapa, utilizou-se uma bomba de vácuo Pfeiffer Balzers, com capacidade de pressão de $1 \times 10^{-4} \mathrm{mbar}$ e fluxo de $8 \mathrm{~m}^{3} / \mathrm{h}$;

- Derramar a mistura nos moldes de silicone;

- Após a cura (aproximadamente 12 horas), desmoldar os corpos-de-prova, desocupando o molde para a próxima moldagem a ser realizada.

\subsection{Ensaios mecânicos}

As propriedades mecânicas dos materiais poliméricos são de grande importância e interesse científico e tecnológico devido à necessidade de atender as aplicações destinadas a esses materiais e, também, devido ao fato que, por meio da análise dessas propriedades, são feitas considerações sobre o melhor material polimérico que deverá ser adotado em uma determinada peça ou produto. Valores de propriedades mecânicas, tais como módulo de elasticidade, resistência à compressão, dentre outros, podem servir como base de comparação do desempenho mecânico entre diversos polímeros, assim como para a avaliação da necessidade de alteração do polímero-base pela utilização de cargas, reforços, aditivos ou plastificantes.

Esses ensaios são realizados através da aplicação de uma solicitação ao material sob condições controladas (deformação a velocidade constante, até a ruptura do material ou até que a tensão ou deformação alcance um valor pré-estabelecido), obtendo assim curvas tensão versus deformação (Canevarolo, 2004). 


\subsubsection{Ensaios de tração}

Os ensaios de tração são especificados pela norma ASTM D638-03 e permitem que seja feita uma caracterização qualitativa e visada à pesquisa e desenvolvimento de novos materiais. Tem o intuito de determinar as propriedades mecânicas associadas a este tipo de carregamento.

Através desses ensaios são obtidas curvas tensão versus deformação, a partir das quais podem ser obtidos: (i) módulo de elasticidade à tração, (ii) tensão e deformação no ponto de escoamento, (iii) tensão e deformação na ruptura e (iv) tensão máxima.

De acordo com essa Norma, o corpo-de-prova para materiais plásticos rígidos ou semi-rígidos é do tipo 1 e deve obedecer às dimensões ilustradas na figura 6.2.

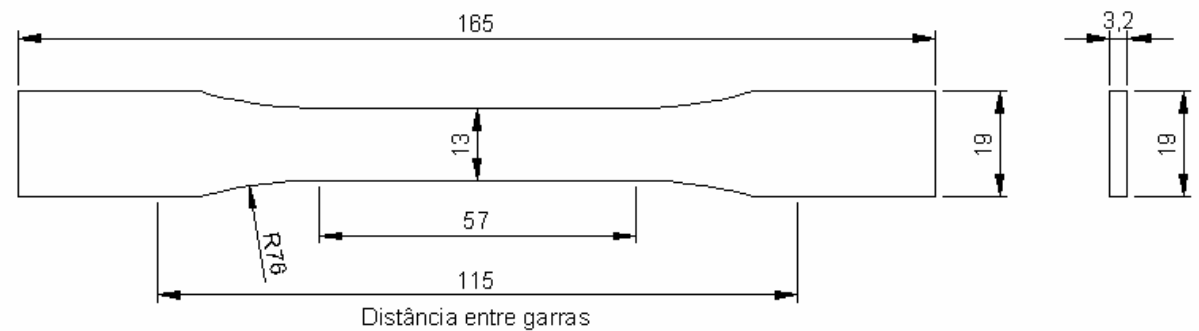

Figura 6.2 - Dimensões do corpo-de-prova de tração segundo a Norma ASTM D638/03.

Os ensaios de tração nos corpos-de-prova de PU foram realizados no dia 16 de agosto de 2006, no Laboratório do Núcleo de Ensaios de Materiais e Análise de Falhas (NEMAT) do Departamento de Engenharia de Materiais (SMM) da EESC, e acompanhados pelo doutorando Cassius Ruckert. A temperatura ambiente foi de $26,4^{\circ} \mathrm{C}$ e a umidade, $52 \%$, ambas admitidas pela norma. O equipamento utilizado foi à máquina de ensaio universal EMICTM, modelo DL 10000, com célula de carga com capacidade de $10000 \mathrm{~N}$, fundo de escala de $100 \mathrm{~N}$, interligada ao software Tesc - versão 1.13. Para esse ensaio foram utilizados cinco corpos-de-prova, número mínimo previsto na Norma, ensaiados a uma velocidade de aplicação da carga igual a $5 \mathrm{~mm} / \mathrm{min}$ (Fig. 6.3).

Também foi realizado um ensaio de tração (piloto) do PEAD, obtendo assim algumas propriedades para uso na análise numérica de protótipos de cruzetas poliméricas. Os ensaios de tração nos corpos-de-prova também foram realizados no Laboratório do Núcleo de Ensaios de Materiais e Análise de Falhas (NEMAT) do Departamento de Engenharia de Materiais (SMM) da EESC, no dia 12 de janeiro de 2007. O equipamento utilizado foi a máquina de ensaio universal EMIC $^{\text {TM }}$, modelo DL 10000, com célula de carga com capacidade de $10000 \mathrm{~N}$, fundo de escala de 100N, interligada ao software Tesc - versão 1.13 (Fig.6.4). 


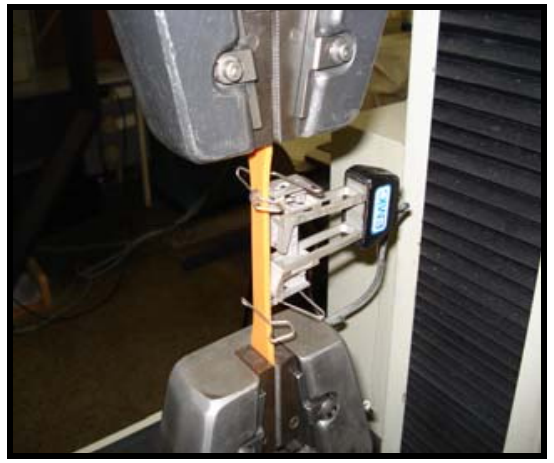

(a)

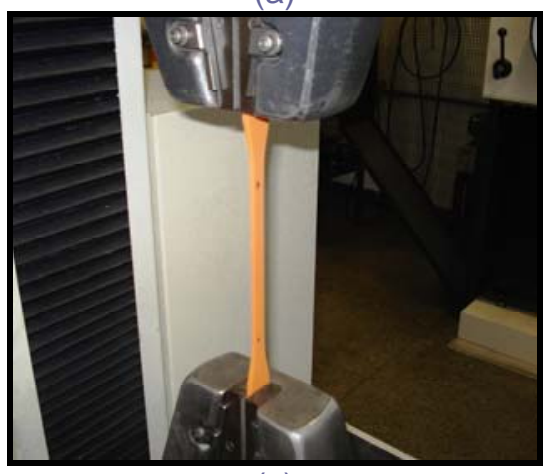

(c)

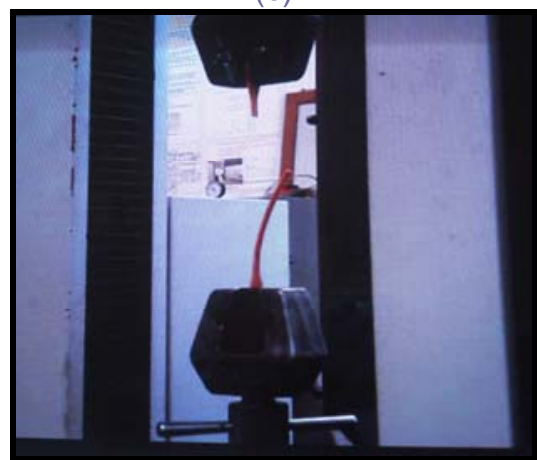

(e)

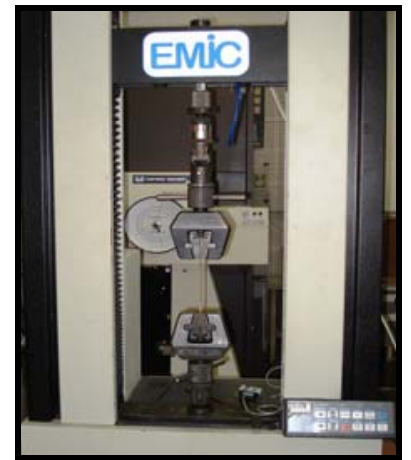

(b)

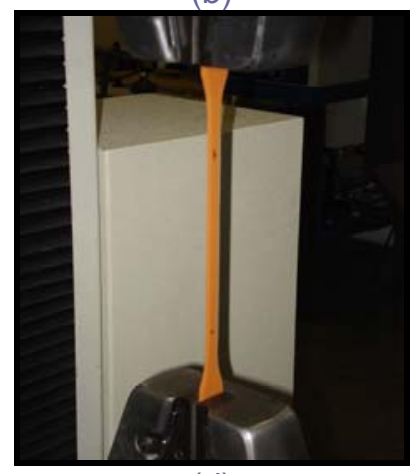

(d)

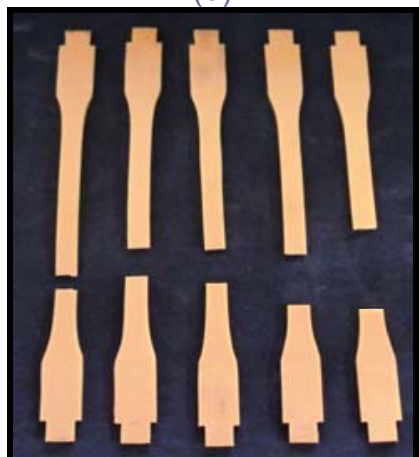

(f)

Figura 6.3 - Ensaio dos corpos-de-prova de tração - PU

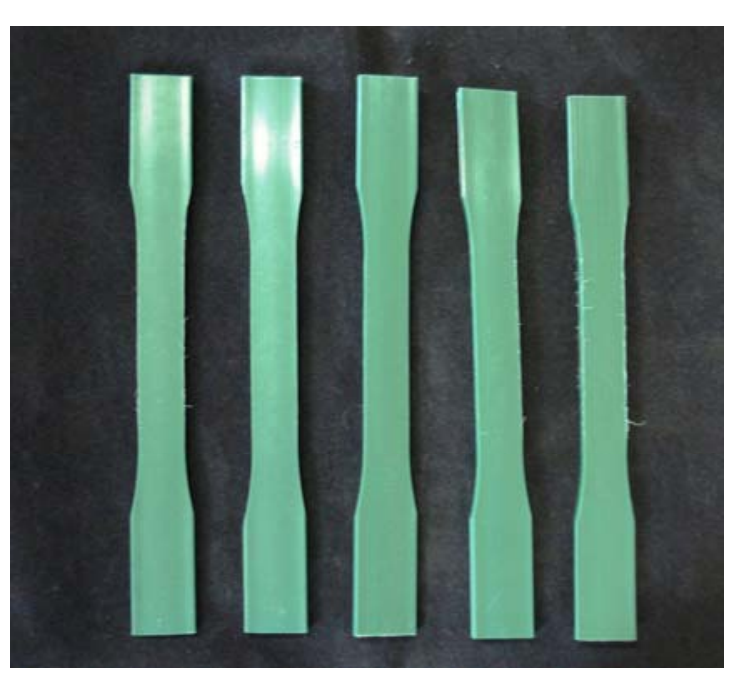

(a)

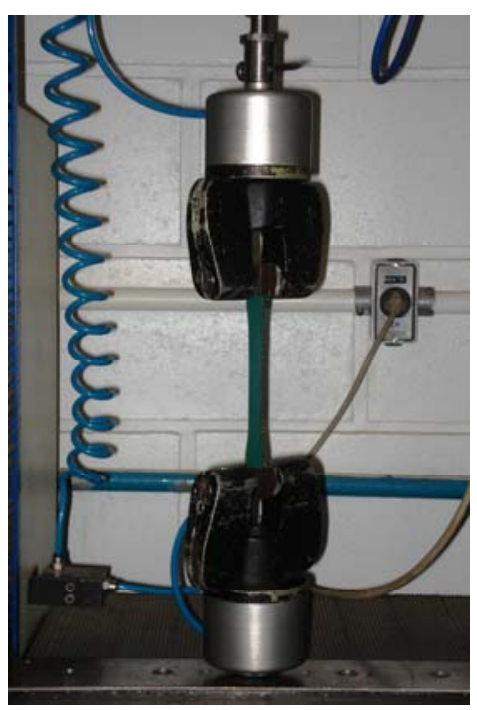

(b)

Figura 6.4 - Ensaio dos corpos-de-prova de tração - PEAD. 
Os ensaios foram realizados de acordo com norma ASTM D638-03. Entretanto, não foram conduzidos até a ruptura, uma vez que o objetivo era somente obter alguns dados necessários para a implementação da análise numérica, tais como módulo de elasticidade e comportamento do material no regime elástico e no escoamento.

\subsubsection{Ensaios de compressão}

O ensaio de compressão é regido pela norma ASTM D695-02a, que determina as propriedades de plásticos rígidos. De acordo com essa Norma, o corpo-de-prova deve obedecer às dimensões ilustradas na figura 6.5 .

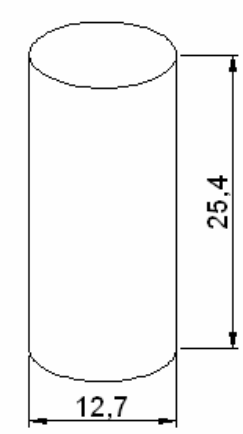

Figura 6.5 - Dimensões do corpo-de-prova de compressão.

Fonte: Norma ASTM D695/02a.

O ensaio experimental foi realizado no dia 30 de agosto de 2006, no Laboratório do Núcleo de Ensaios de Materiais e Análise de Falhas (NEMAT) do Departamento de Engenharia de Materiais (SMM) da EESC. A temperatura foi de $26^{\circ} \mathrm{C}$ e a umidade do ambiente, de $50 \%$, ambas admitidas pela norma. O equipamento utilizado foi a máquina de ensaio universal EMIC ${ }^{\mathrm{TM}}$, modelo DL 10000, com célula de carga com capacidade de $10000 \mathrm{~N}$, fundo de escala de $100 \mathrm{~N}$, interligada ao software Tesc - versão 1.13. Para esse ensaio foram utilizados cinco corpos-de-prova, número mínimo previsto na Norma, ensaiados a uma velocidade de aplicação da carga igual a 1,3mm/min (Fig. 6.6).

\subsubsection{Realização dos ensaios de impacto Izod}

O ensaio de impacto é regido pela norma ASTM D256/04, que determina a resistência ao impacto de plásticos e visa medir a energia cinética necessária para romper um corpo-de-prova sob condições padronizadas. Tal energia é calculada em joule por metro $(\mathrm{J} / \mathrm{m})$ ou kilojoule por metro quadrado $\left(\mathrm{kJ} / \mathrm{m}^{2}\right)$, de acordo com o sistema internacional de unidades. Testes de resistência ao impacto são eminentemente comparativos e, portanto, muito úteis quando se deseja fazer um "Ranking" de vários materiais, para especificar o melhor para uma determinada aplicação. 


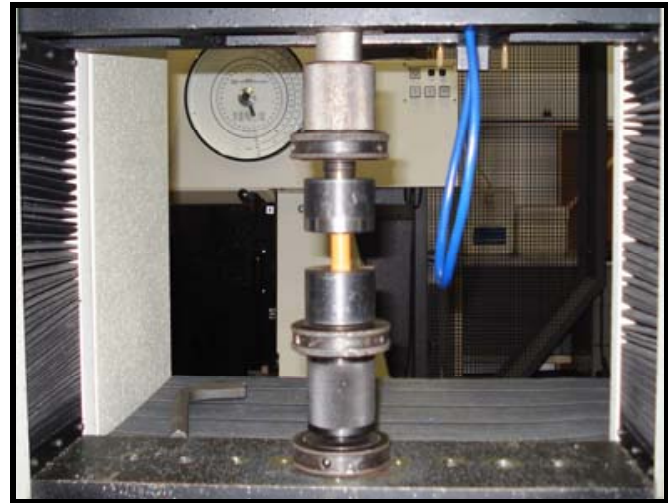

(a)

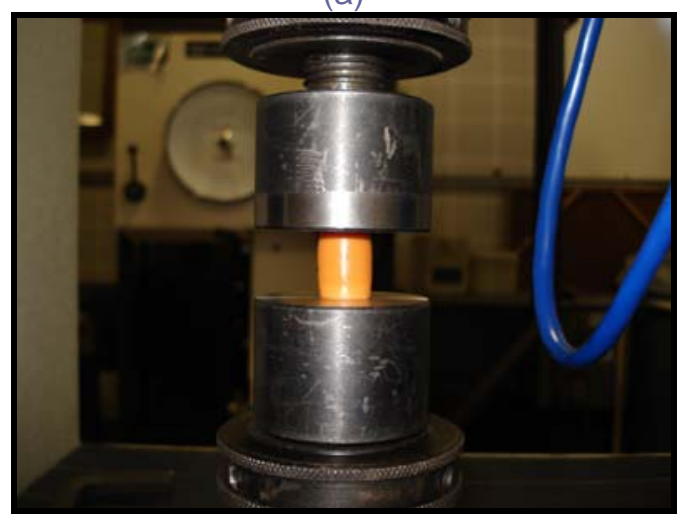

(c)

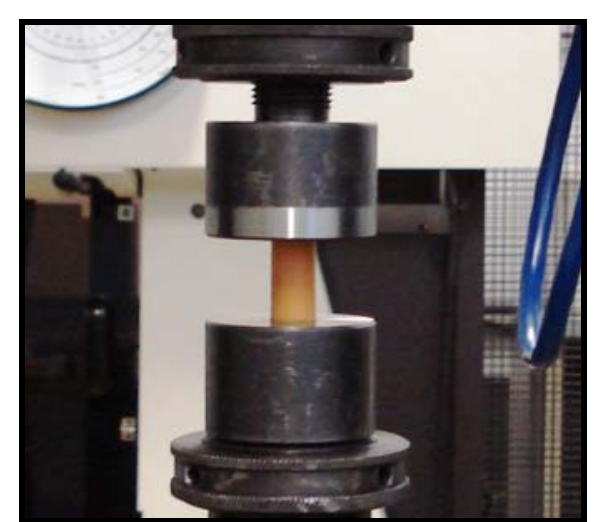

(b)

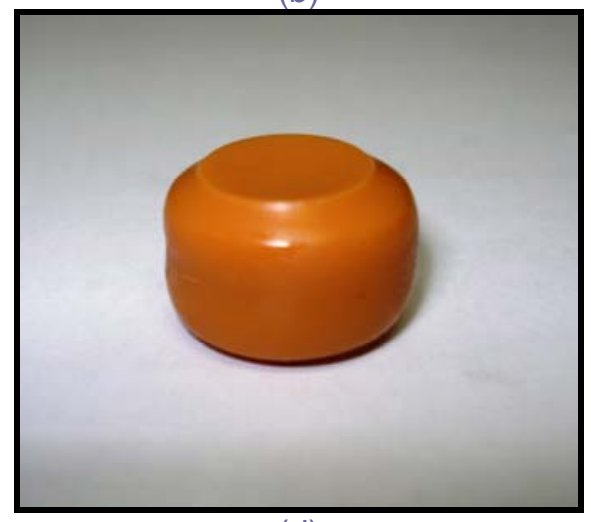

(d)

Figura 6.6 - Ensaio dos corpos-de-prova de compressão.

Porém, quando se comparam dois polímeros, é importante lembrar que a resistência ao impacto pelo método IZOD não deve ser considerada isoladamente como indicador da resistência mecânica do material, mesmo porque existem muitos polímeros que são sensíveis ao entalhe e, em virtude disso, irão exibir uma elevada concentração de tensões na região posterior ao entalhe. Portanto, determinados polímeros de engenharia que têm excelentes propriedades mecânicas, como, por exemplo, o nylon e o poliacetal, têm relativamente baixa resistência ao impacto pelo método IZOD.

Trata-se de um método utilizado para determinar a resistência à quebra de corposde-prova padronizados, submetidos ao choque de um pêndulo também padronizado. A resistência ao impacto é definida como sendo a energia necessária para "romper" o corpode-prova, que é igual à soma das energias para os seguintes fins:

- Iniciar a fratura do corpo-de-prova;

- Propagar a fratura ao longo desse corpo-de-prova;

- Separá-lo totalmente em duas partes;

- Dobrar o corpo-de-prova;

- Produzir vibração no braço do pêndulo;

- Produzir vibração ou movimento horizontal na estrutura da máquina;

- Vencer o atrito do sistema de sustentação do pêndulo e da resistência do ar; 
- Deformar plasticamente o corpo-de-prova na linha do impacto;

- Vencer o atrito causado pelo contato do pêndulo com a superfície.

O corpo-de-prova (figura 6.7) utilizado nesse tipo de ensaio deve ser entalhado, e isto se justifica devido à necessidade de promover concentração de tensões localizadas na extremidade do entalhe, promovendo fratura frágil ao invés de fratura dúctil.

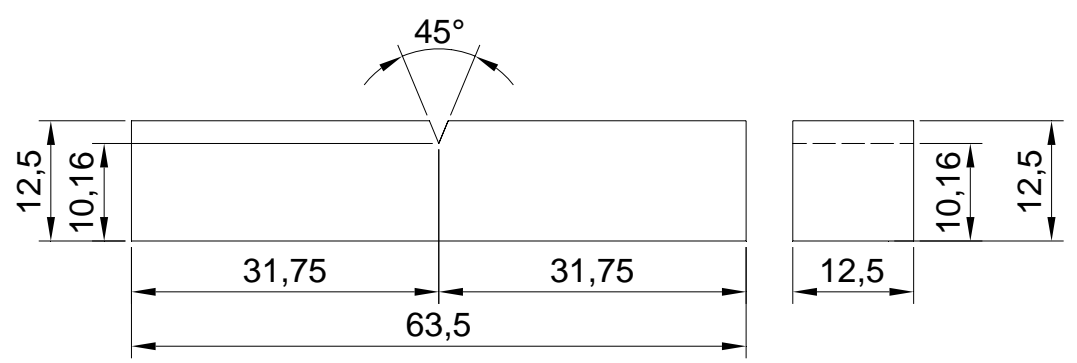

Figura 6.7 - Dimensões do corpo-de-prova de impacto segundo a Norma ASTM 256/04.

No ensaio Izod o corpo-de-prova é colocado na posição vertical em relação à base do equipamento (Fig. 6.8), e seu entalhe é voltado ao lado no qual o martelo do pêndulo atingirá o corpo-de-prova.

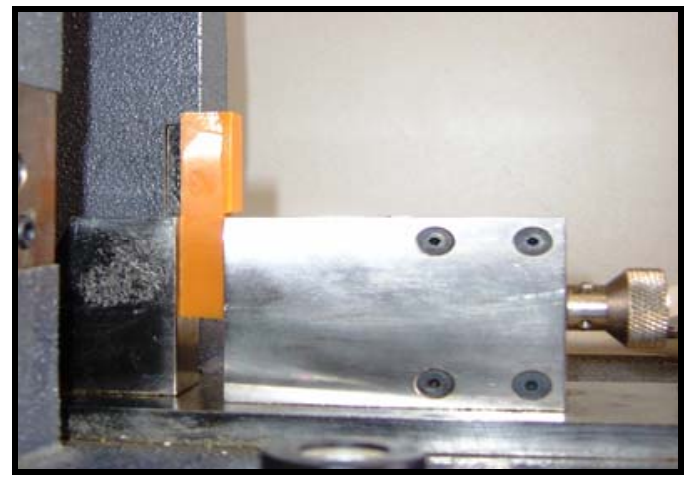

Figura 6.8 - Fixação de corpos-de-prova para ensaios Izod.

O equipamento utilizado nesse ensaio é formado por três unidades: a base, onde se fixa o corpo-de-prova, o pêndulo e o sistema de energia de impacto. Na extremidade do pêndulo, é fixado um martelo, que pode ter diferentes pesos, devido à tenacidade do material e à espessura do corpo-de-prova.

O procedimento de ensaio consiste em zerar a escala de medida de energia. Em seguida fixa-se o corpo-de-prova na base do equipamento, libera-se o martelo e registra-se o valor da energia utilizada para romper o corpo-de-prova. Essa energia lida é expressa em joule (J), e para o cálculo da energia de impacto, divide-se o valor de energia pela espessura do corpo-de-prova $(\mathrm{J} / \mathrm{m})$ ou pela área da seção da seção transversal do entalhe $\left(\mathrm{kJ} / \mathrm{m}^{2}\right)$. 
Esse ensaio experimental foi realizado no dia 27 de novembro de 2006, no Departamento de Engenharia de Materiais - DEMa/UFSCar, com acompanhamento do Professor José Augusto Agnelli. Foram ensaiados cinco corpos-de-prova (mínimo previsto em norma) e, para sua realização, utilizou-se o equipamento para ensaio de impacto EMIC TM, com pêndulo de 5,4J (Fig. 6.9).

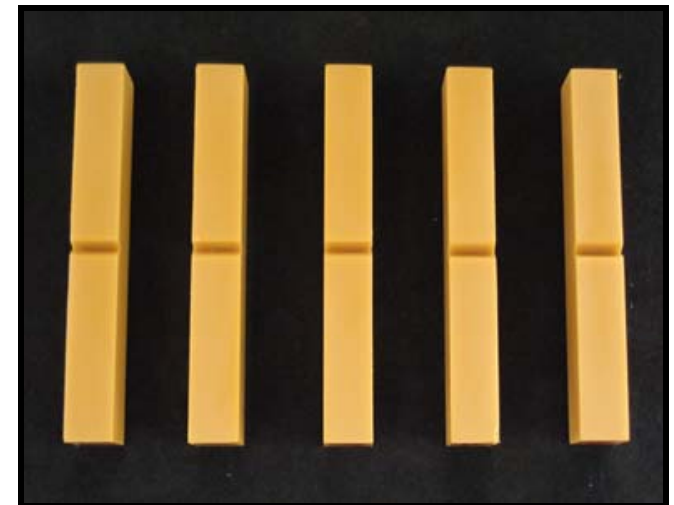

(a)

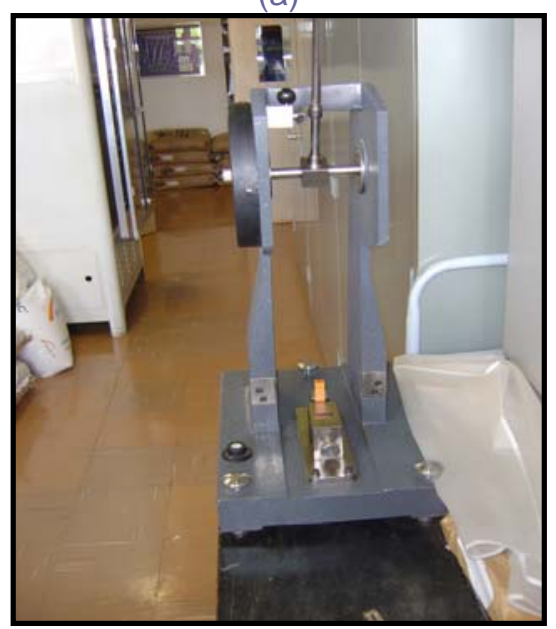

(c)

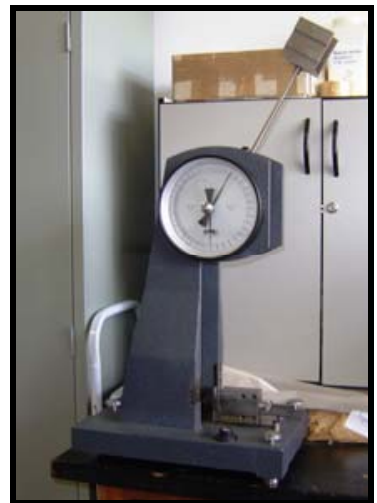

(b)

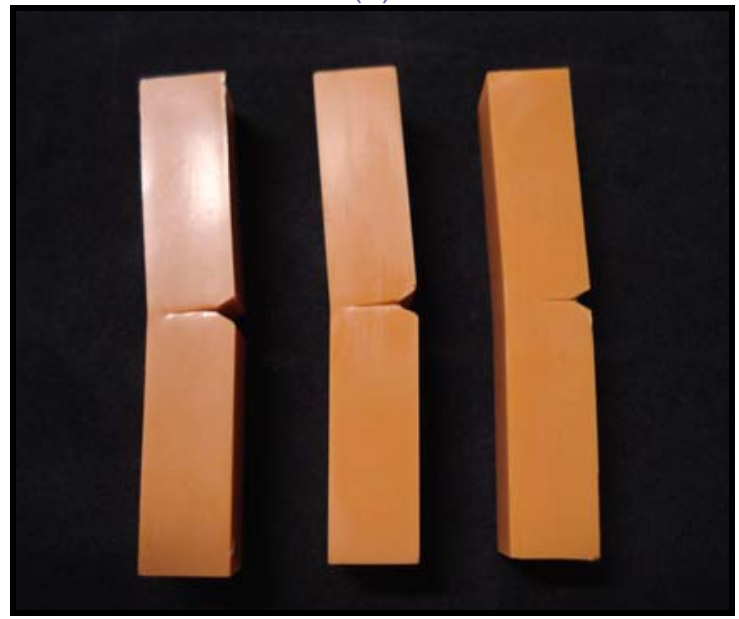

(d)

Figura 6.9 - Ensaio dos corpos-de-prova de impacto.

\subsubsection{Ensaios de flexão}

O ensaio de flexão é regido pela norma ASTM D790/03, que determina as propriedades à flexão de plásticos rígidos.

Para materiais moldados (termoplásticos ou termorrígidos), os corpos-de-prova para o ensaio de flexão devem obedecer às dimensões ilustradas na figura 6.10.

A distância entre os apoios deve ser ajustada de modo que a razão entre o vão e a altura do corpo-de-prova (L/h) seja igual a 16. Assim, a distância entre apoios ( $L$ ) é igual a $102,4 \mathrm{~mm}$. 

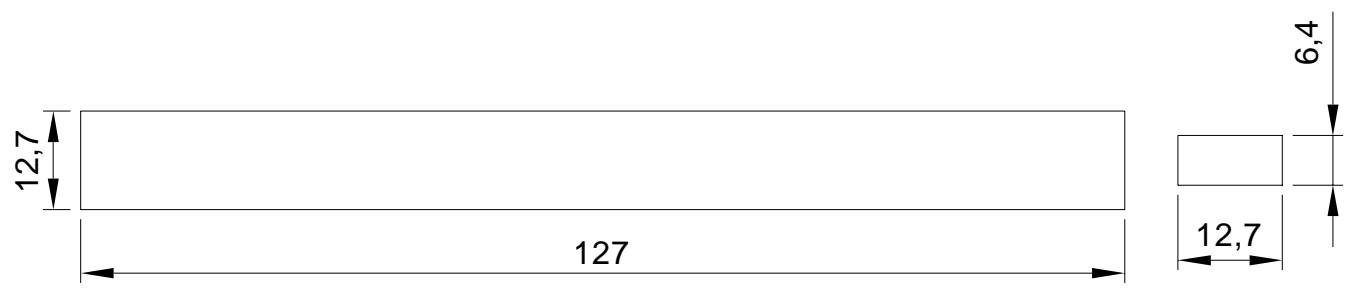

Figura 6.10 - Dimensões do corpo-de-prova de flexão Segundo a Norma ASTM D790/03 - medidas em mm.

Para um ensaio de flexão em três pontos, o deslocamento $(D)$ no meio do vão é dado por:

$$
D=\frac{r \cdot L^{2}}{6 \cdot h}
$$

Para a deformação máxima permitida $r=5 \%=0,05 \mathrm{~mm} / \mathrm{m}$, sendo $L=102,4 \mathrm{~mm}$ e $\mathrm{h}=6,4 \mathrm{~mm}$, resulta:

$$
D=\frac{0,05 \cdot 102,4^{2}}{6 \cdot 6,4}=13,65 \mathrm{~mm}
$$

A velocidade da travessa fixa é calculada a partir da taxa de deformação a ser utilizada (Equação 6.2). Sendo $R$ é a velocidade da travessa fixa, $L$ a distância entre os apoios, $h$ a altura do corpo-de-prova e $z$ é a taxa de deformação na superfície oposta ao carregamento, com $L=102,4 \mathrm{~mm}$ e $z=0,01 \mathrm{~mm} / \mathrm{mm} / \mathrm{min}$, resulta:

$$
\begin{gathered}
R=\frac{z L^{2}}{6 d} \\
R=\frac{0,01 \cdot 102,40^{2}}{6 \cdot 6,4}=2,73 \mathrm{~mm} / \mathrm{min}
\end{gathered}
$$

O ensaio experimental foi realizado no dia 23 de novembro de 2006, no Laboratório de Geotêxteis do Departamento de Geotecnia - SGS da EESC, acompanhado pelo técnico Cléver Aparecido Valentin. A temperatura foi de $26^{\circ} \mathrm{C}$ e a umidade do ambiente, de $50 \%$, ambas admitidas pela norma. O equipamento utilizado para ensaio das amostras de poliuretano foi a máquina de ensaio universal EMIC ${ }^{\mathrm{TM}}$, modelo DL 30000, com célula de carga com capacidade de $1000 \mathrm{~N}$, interligada ao software MTest - versão 3.00. Para esse ensaio foram utilizados cinco corpos-de-prova, número mínimo previsto na Norma, ensaiados a uma velocidade de aplicação da carga igual a 2,73/min (Fig. 6.11). 


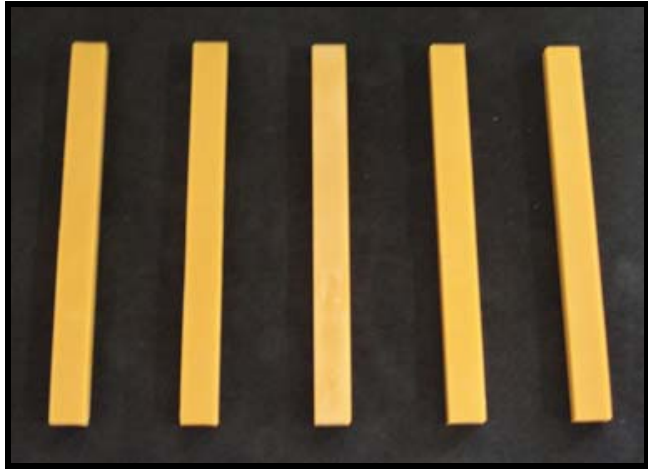

(a)

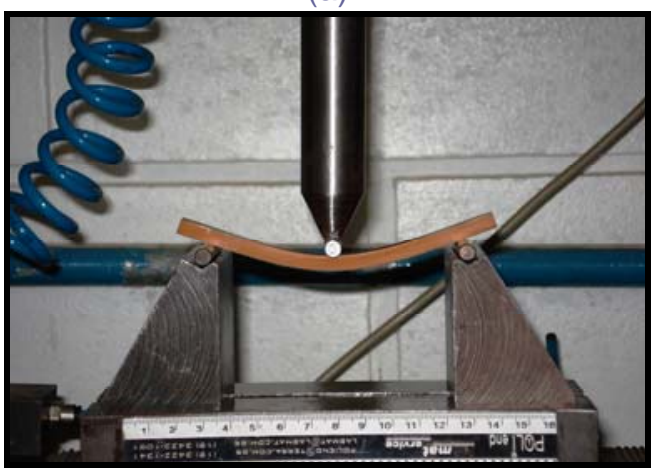

(c)

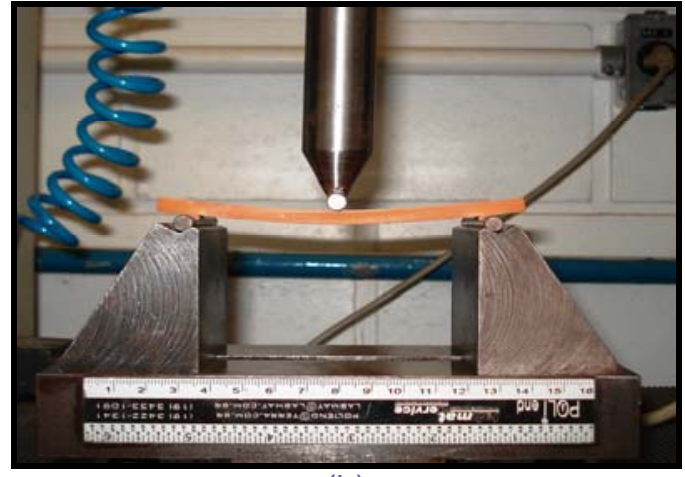

(b)

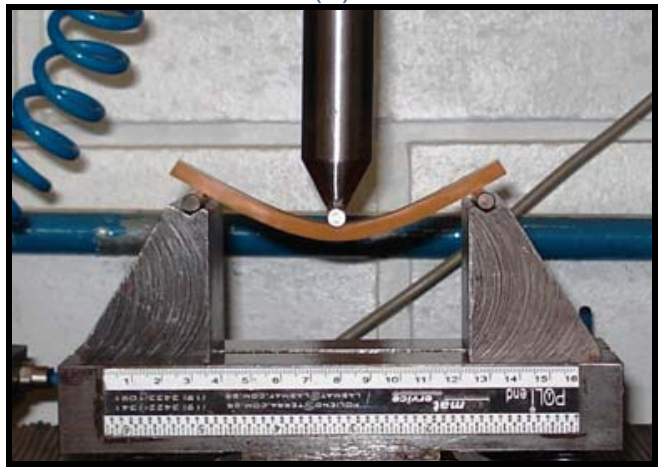

(d)

Figura 6.11 - Ensaio dos corpos-de-prova de flexão.

\subsection{Modelos de cruzeta em escala reduzida}

Foram produzidos cinco modelos em escala reduzida, com as seções transversais ilustradas na Figura 6.12 com o objetivo de validar os métodos de moldagem e de modelagem numérica propostos.
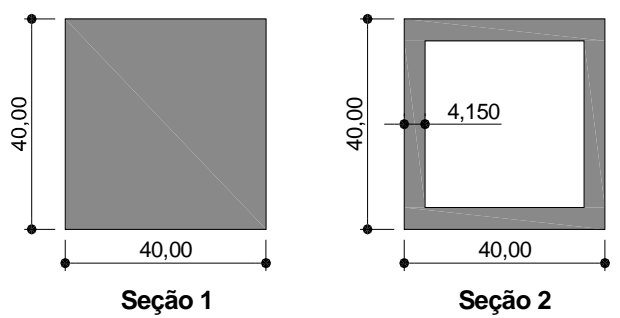

(a)

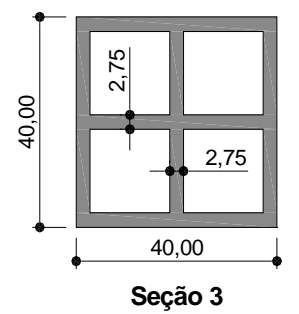

Figura 6.12 - Seções transversais para os ensaios-piloto - Comprimentos de (a) 600mm e
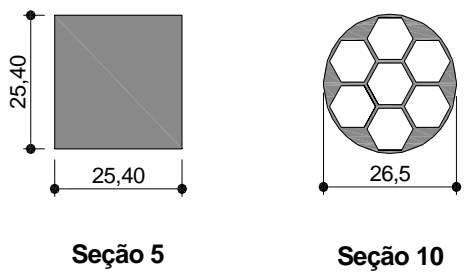

Seção 10 (b)

Para a moldagem foi utilizada uma plataforma de vidro, a fim de evitar possíveis imperfeições na base do elemento e nos tubos metálicos, que serviram de fôrma para o poliuretano.

O ensaio de flexão nas cruzetas poliméricas foi baseado na norma NBR 8458:1984, que padroniza as cruzetas de madeira para redes de distribuição de energia elétrica, a qual especifica as dimensões, o arranjo para o ensaio à flexão e as condições de carregamentos e resistências a serem obtidas nesse ensaio. Entretanto, devido às dimensões dos modelos, 
o ensaio sofreu algumas alterações quanto a sua configuração. A figura 6.13 ilustra o ensaio em cruzetas de madeira, conforme rege a norma, e a maneira como foi executado.

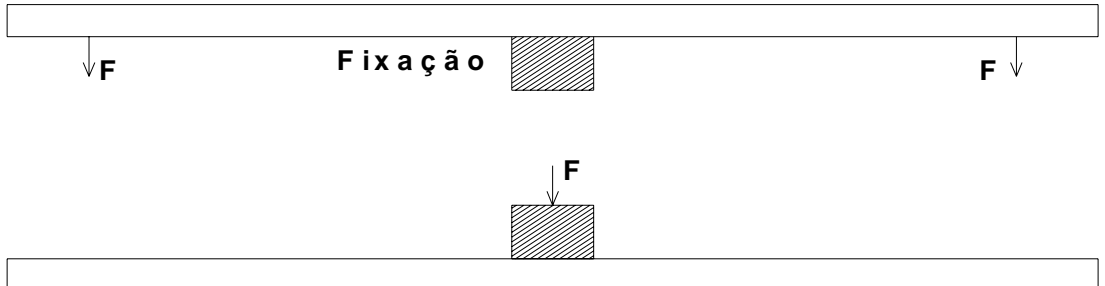

(b)

Figura 6.13 - Configuração de ensaio para cruzetas: (a) segundo a NBR 8458:1984 e (b) adaptação para o ensaio da cruzeta polimérica.

Esses ensaios foram realizados no Laboratório de Madeira e Estruturas de Madeiras LaMEM da EESC, acompanhados pelo técnico Jaime, nos dias 08 e 09 de Novembro e 20 a 22 de Dezembro de 2006.

Utilizou-se a máquina de ensaios universal DARTEC, com capacidade de $100 \mathrm{kN}$. Pelo fato de não existir uma velocidade normalizada para a realização do ensaio de flexão, adotou-se velocidade constante de $0,2 \mathrm{~mm} / \mathrm{min}$. A figura 6.14 mostra os ensaios de flexão para as cruzetas com seções transversais dos tipos 1, 2, 3, 5 e 10.

Devido à limitação do deslocamento do travessão da máquina, cujo valor máximo é de $10 \mathrm{~cm}$, em alguns casos, não foi possível aplicar o carregamento calculado no capítulo 5.

Para se obter o carregamento e o deslocamento real do modelo, de acordo com a configuração de ensaio fornecida pela norma [Fig. 6.13(a)], basta fazer a correção do esquema estático, obtendo-se, assim, resultados aproximados. Essa correção possibilita uma comparação entre os resultados experimentais e os obtidos de acordo com a NBR 8458:1984.

\subsection{Considerações finais}

Neste capítulo foi realizado o programa experimental previsto, incluindo ensaios dos corpos-de-prova e de alguns modelos de cruzetas poliméricas. Embora não tenha sido possível confeccionar todos os modelos previstos, pode-se perceber que:

- A produção dos modelos, mesmo sendo um processo artesanal, possibilitou a obtenção de elementos com bom acabamento superficial e estabilidade dimensional;

- Os modelos, devido a suas dimensões reduzidas, possibilitaram adequado posicionamento na máquina de ensaios, facilitando os procedimentos de execução e minimizando possíveis erros durante os ensaios;

- Faz-se necessária a aquisição de uma célula de carga com baixa capacidade de carga para a execução de ensaios com polímeros, uma vez que as disponíveis no Departamento de Engenharia de Estruturas (SET/EESC) são de elevada capacidade. 

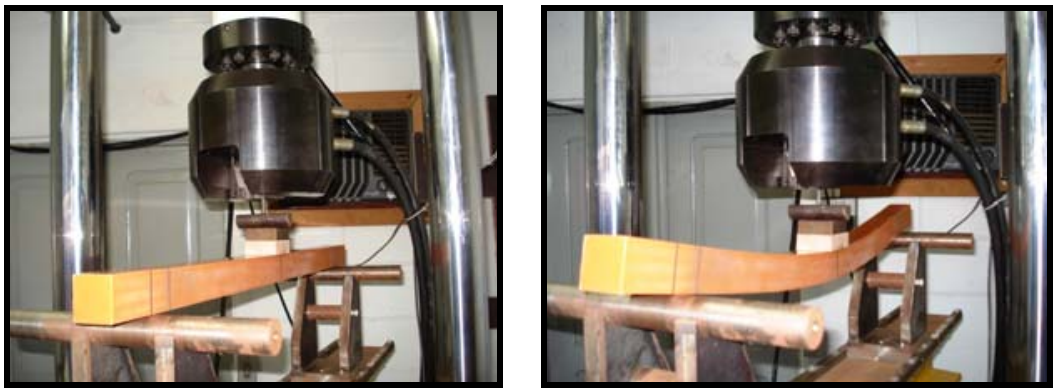

(a) Seção transversal do tipo 1
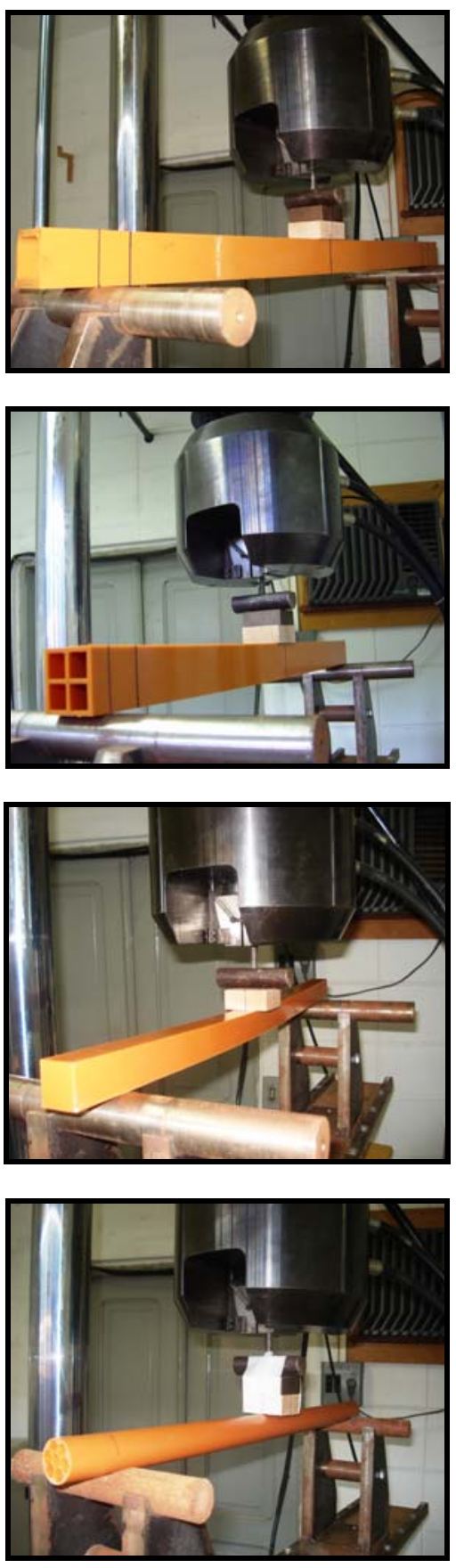

Seção transversal do tipo 5

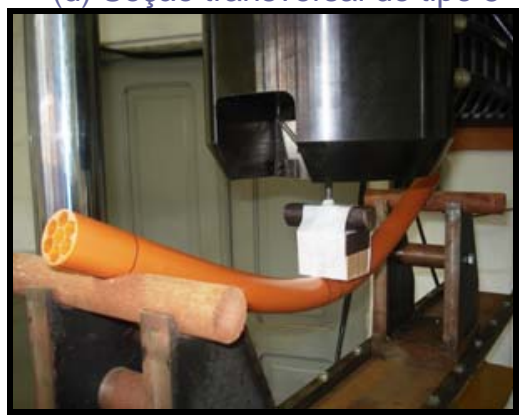

(e) Seção transversal do tipo 10

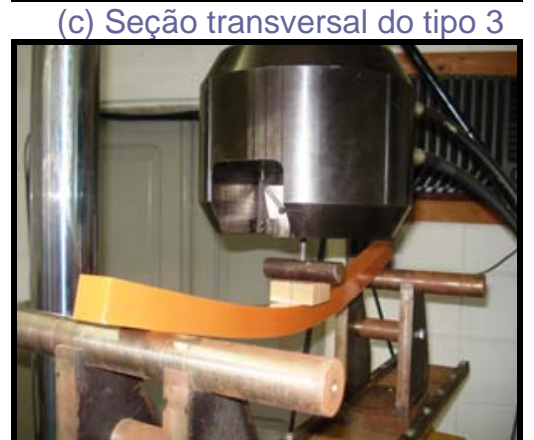

(b) Seção transversal do tipo 2
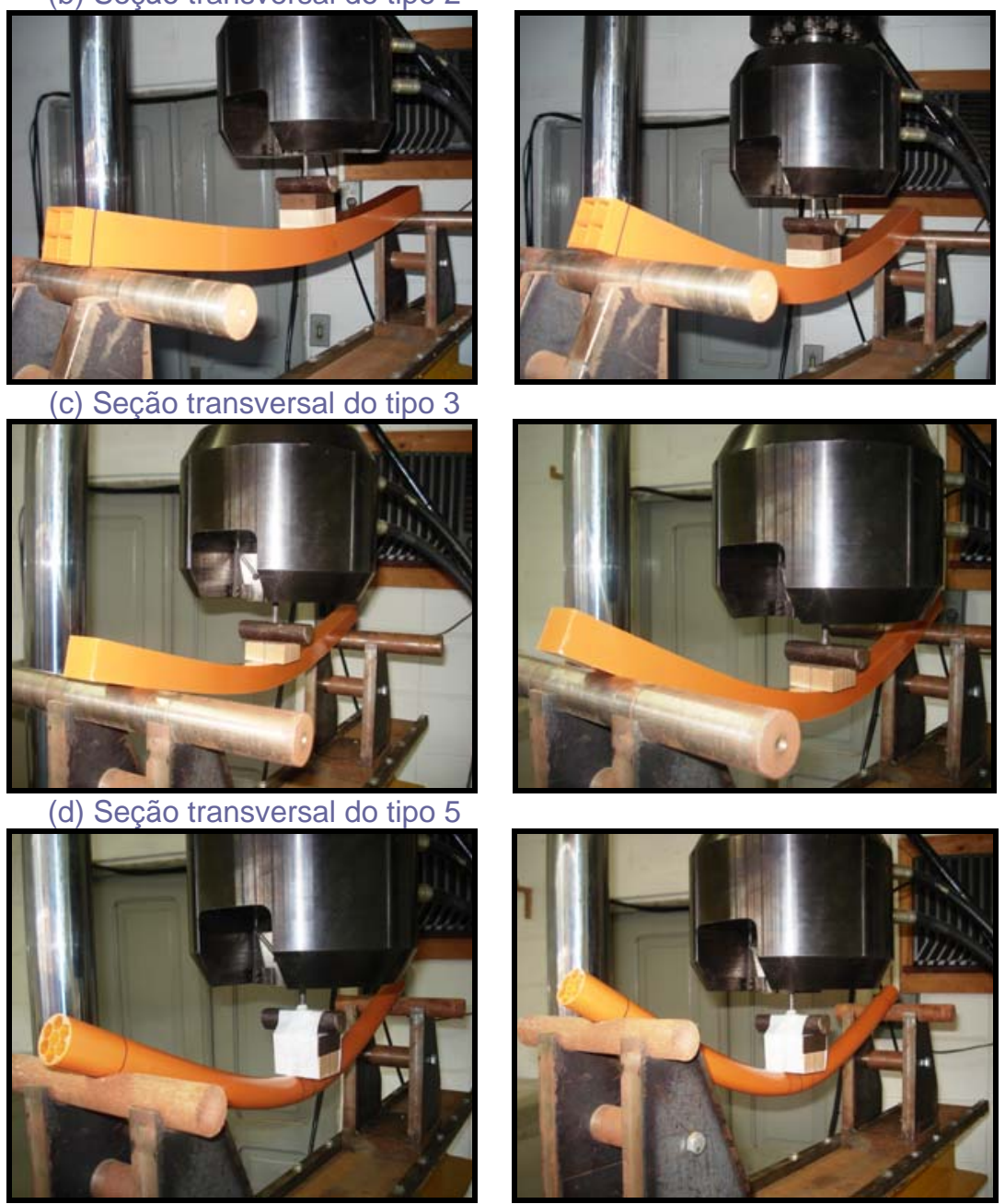

Figura 6.14 - Ensaio de flexão nos modelos de material polimérico. 


\section{ASPECTOS DA MODELAGEM NUMÉRICA}

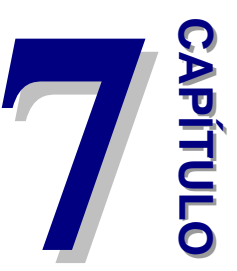

\subsection{Considerações iniciais}

Apresentam-se neste capítulo as características de um modelo numérico tridimensional, elaborado com base no Método dos Elementos Finitos (particularmente, elementos finitos de sólido e de viga), para analisar o comportamento à flexão de cruzetas poliméricas - cuja simulação numérica foi realizada por meio do programa comercial ANSYS. Assim, seguindo os objetivos deste trabalho, os modelos numéricos foram elaborados buscando, de forma realista e satisfatória, representar o comportamento estrutural de cruzetas biapoiadas de polímeros reciclados. Para atender a essa finalidade, as características dos modelos em elementos finitos seguiram as características dos ensaios realizados, tornando possível a comparação de resultados numéricos e experimentais para a comprovação da confiabilidade da análise numérica.

\subsection{Geometria dos modelos analisados}

A simulação é uma forma de análise numérica. Segundo Rubisnstein ${ }^{1}$ apud Beck (2006), simulação é uma técnica numérica para realizar experimentos em computador, com base em modelos lógicos e matemáticos, de modo a descrever o comportamento de sistemas ao longo de um determinado período de tempo. Uma análise numérica por elementos finitos é a simulação de um sistema físico (geometria, carregamento e vinculações) por uma aproximação matemática do sistema real, utilizando para tanto construções simples de blocos chamados de elementos, inter-relacionados em malhas, representando um sistema real com finitos blocos (ANSYS 1997) ${ }^{2}$. Nas análises realizadas neste trabalho, utilizaram-se malhas mapeadas que, segundo Moreno ${ }^{3}$ apud Godoy (2006), conferem melhores resultados em simulações via métodos dos elementos finitos (MEF), uma vez que estas trazem maior confiabilidade à análise.

As figuras 7.1 e 7.2 ilustram as peças adotadas nesta análise, sem e com furos, para fixação de elementos e de isoladores na cruzeta.

\footnotetext{
${ }^{1}$ RUBISNSTEIN, R. Y. (1981). Variables and Stochastic Processes. McGraw-Hill Book Company.

${ }^{2}$ Ansys Elements Reference - Release 5.4 (1997)

${ }^{3}$ MORENO, M. E. (2000). Desenvolvimento e implementação de metodologia de otimização da geometria do Blank em processos de conformação de chapas metálicas. São Carlos, EESC-USP, $88 p$.
} 


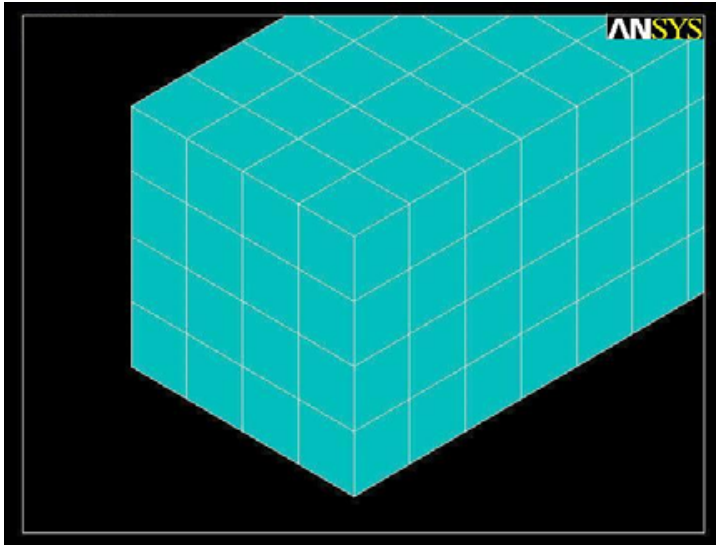

Seção 1

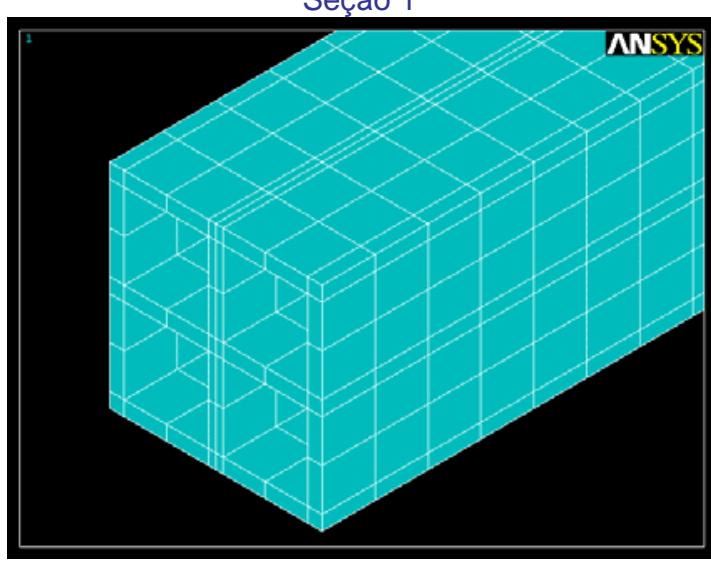

Secão 3

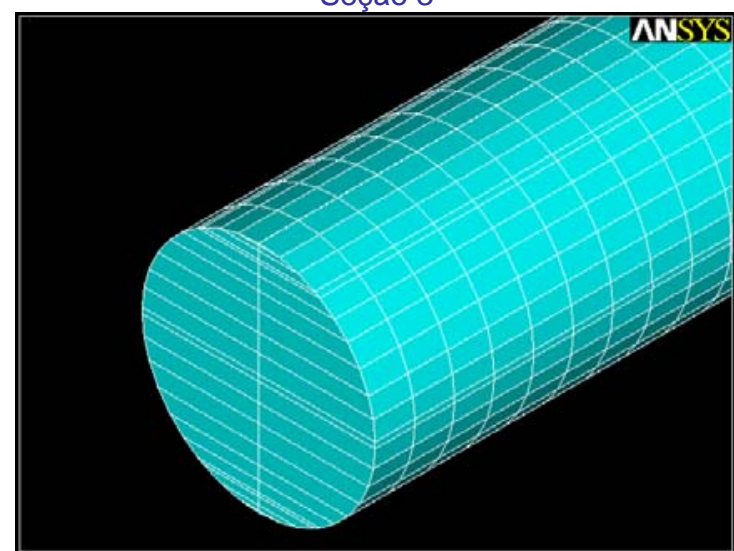

Seção 9

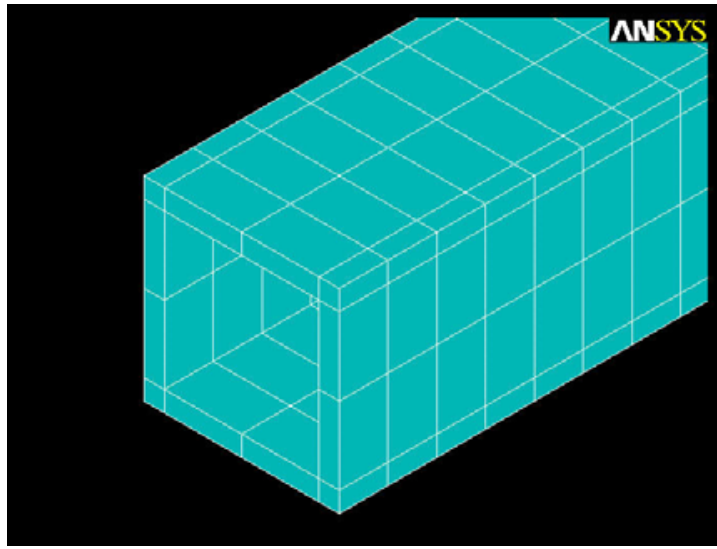

Secão 2

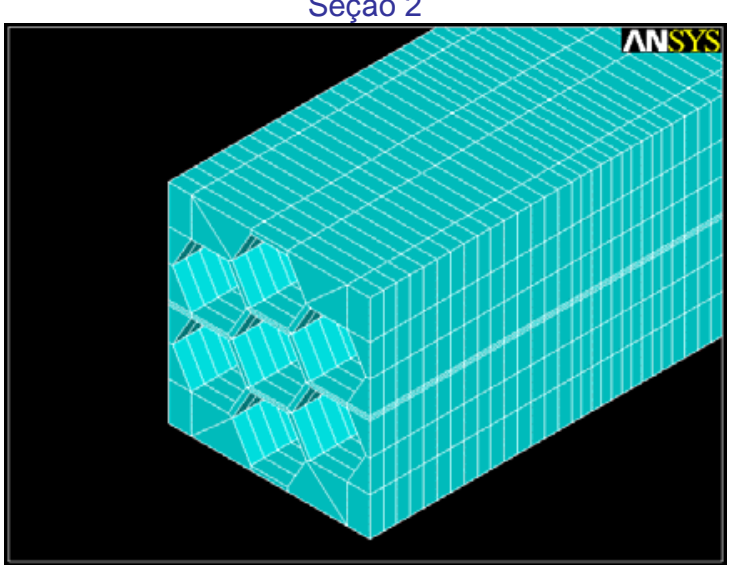

Seção 4

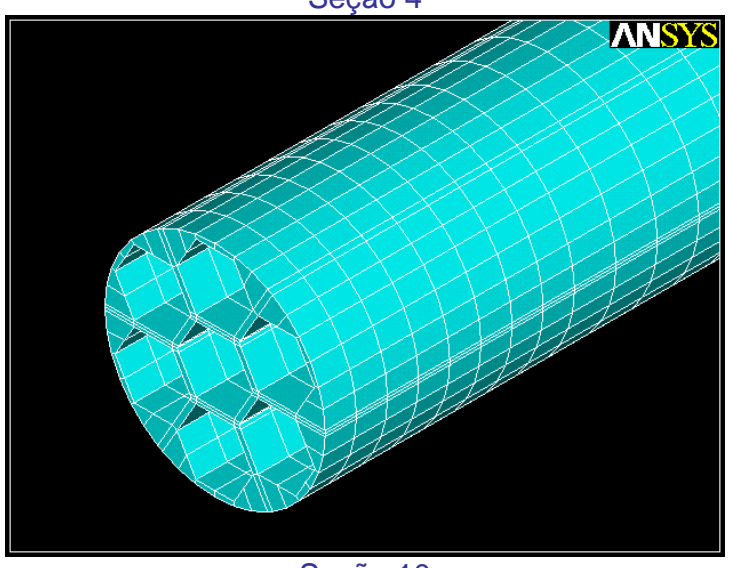

Seção 10

Figura 7.1 - Seções transversais - sem furos de fixação.

A malha das peças sem furos para a fixação dos elementos é mais simples e mais rápida de ser feita e representa com boa precisão os valores obtidos em ensaios de cruzetas reais. Neste trabalho também será feita uma análise numérica de cruzetas com furos (Fig. 7.2), a fim de ser feita uma comparação do comportamento desses diferentes tipos de estruturas. Entretanto, a parte experimental conta somente com cruzetas íntegras, isto é, sem furos. 


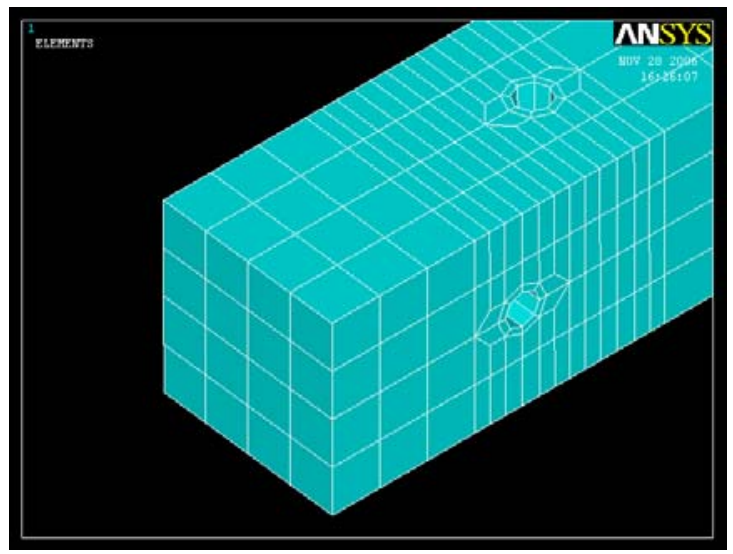

Seção 1

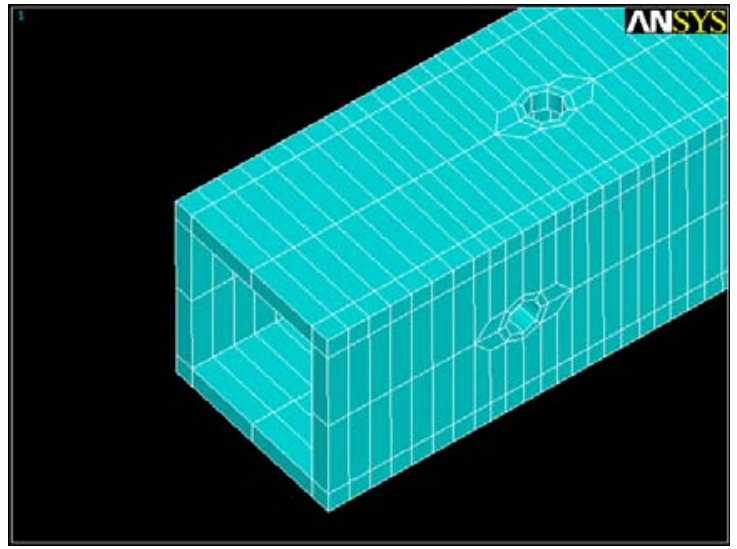

Seção 2

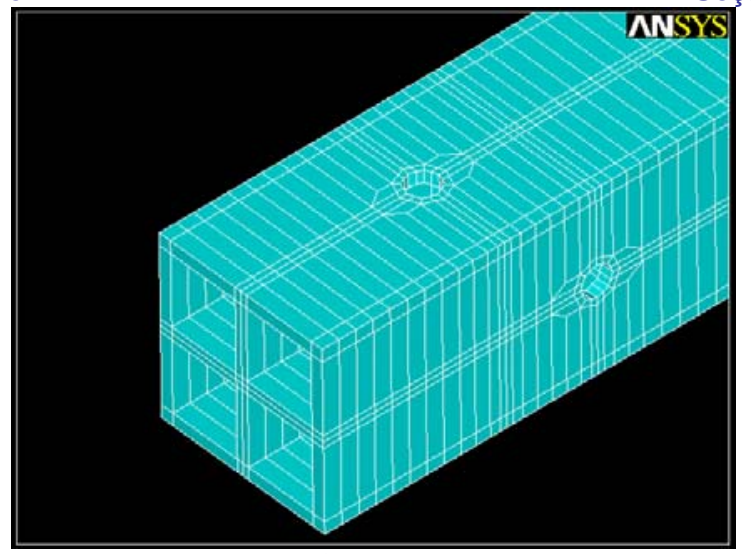

Seção 3

Figura 7.2 - Seções transversais - com furos de fixação.

\subsection{Elementos finitos utilizados}

Os elementos finitos adotados neste trabalho são o SOLID45 e o BEAM189. O SOLID45 é um elemento designado para modelagem de estruturas sólidas e possui oito nós, sendo-Ihes atribuídos três graus de liberdade (três de translações com relação aos eixos x, y e z: ux, uy e uz). Este elemento finito está disponibilizado na biblioteca interna do ANSYS e é apresentado na fig. 7.3.

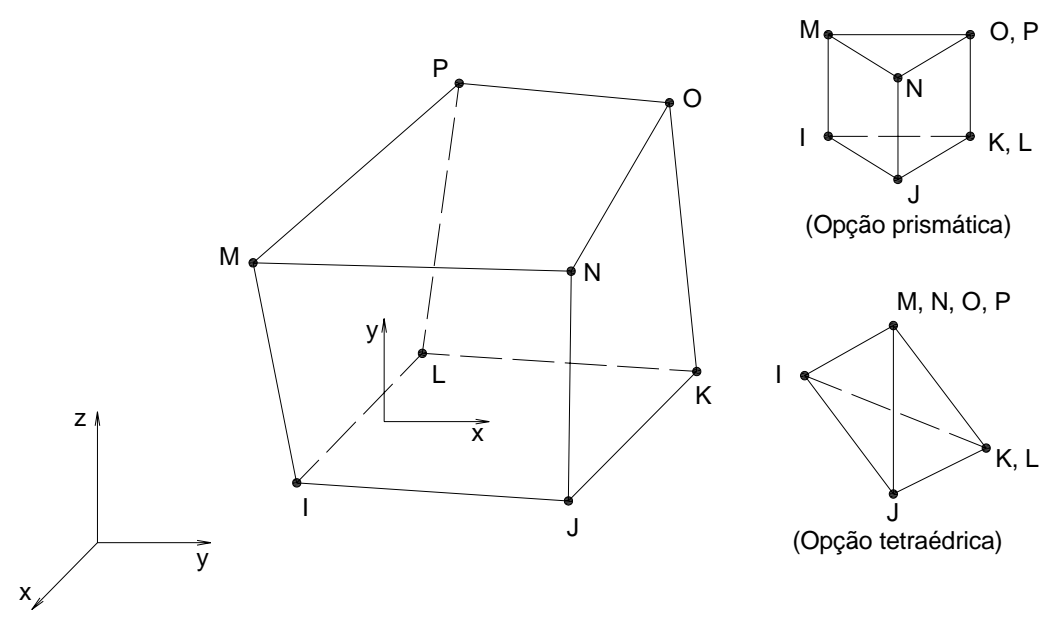

Figura 7.3 - Elemento finito tipo SOLID45.

Fonte - Documentação do ANSYS. 
Os modelos de cruzetas feitos com o SOLID45 são constituídos de elementos tetraédricos. O plano da seção transversal adotado foi o x-y, sendo z o eixo ao longo do comprimento das cruzetas.

Com relação ao elemento BEAM189, este foi utilizado na modelagem de dois tipos de cruzetas retangulares: maciça e com um furo. Trata-se de um elemento de viga, com três nós (I, J e K) e seis (ou sete, quando se considera o empenamento de torção) graus de liberdade por nó, o que inclui as translações (ux, uy e uz) e rotações (rotx, roty e rotz) com relação aos eixos x, y e z. A orientação local desse elemento se dá com o eixo x, partindo do nó I em direção ao nó J, enquanto os eixos y e z são definidos com o auxílio de um nó adicional (L).

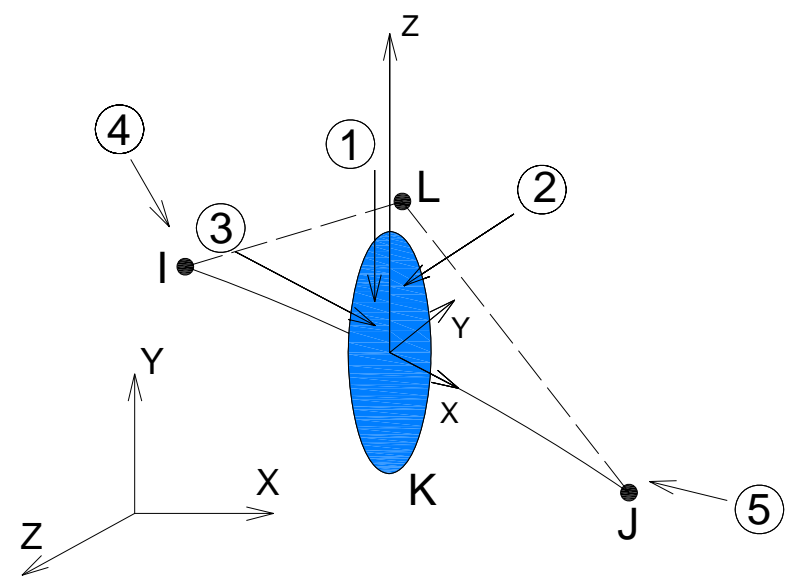

Figura 7.4 - Elemento finito tipo BEAM189.

Fonte - Documentação do ANSYS.

Este elemento foi escolhido por proporcionar uma modelagem mais simples das cruzetas, pelo fato de ser unidimensional e apresentar alguns tipos de seções transversais pré-definidas (Fig. 7.5).
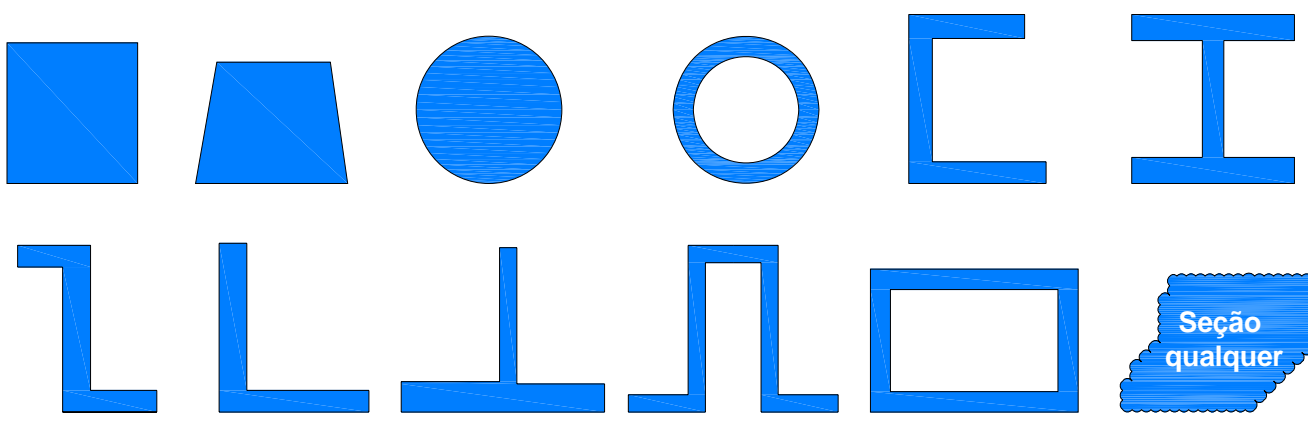

\section{Seção}

qualquer

Figura 7.5 - Tipos de seções pré-definidas do elemento BEAM189.

Fonte - Documentação do ANSYS. 


\subsection{Critérios adotados para a análise não-linear da cruzeta}

A maioria dos programas em elementos finitos que fazem análise não-linear para grandes deformações, como Ansys e Abaqus, utilizam rotinas criadas para pares tensãodeformação denominados de valores corrigidos (true values)", que são dadas pelas equações 7.1 e 7.2 .

$\varepsilon_{\mathrm{t}}=\ln \left(1+\varepsilon_{\mathrm{e}}\right)$

$\sigma_{\mathrm{t}}=\sigma_{\mathrm{e}}\left(1+\varepsilon_{\mathrm{e}}\right)$

$\varepsilon_{\mathrm{t}}$ : deformação corrigida (true);

$\sigma_{\mathrm{t}}:$ tensão corrigida (true);

$\varepsilon_{\mathrm{e}}$ : deformação convencional (engineering);

$\sigma_{\mathrm{e}}$ : tensão convencional (engineering).

Assim, admite-se uma correção entre os valores do ensaio de tração (caracterização) e os implementados no ANSYS e, dessa forma, leva-se em consideração a estricção da seção transversal do corpo-de-prova durante o ensaio de tração, fazendo com que a curva tensão versus deformação sempre seja crescente.

Observa-se nas figuras 7.6 (a)-(b) que, para análises em regime de pequenas deformações, as curvas geradas por esses dois conjuntos de valores (convencional ou corrigido) são muito próximas. Porém, quando a análise entra em regime de grandes deformações, as duas curvas do modelo de comportamento de materiais se distanciam, implicando em respostas diferentes do modelo.

A fim de analisar o comportamento dos elementos diante dessas alterações no modelo de comportamento de materiais, promovidas pelas correções de valores ora descritas, neste trabalho foram considerados tanto os valores convencionais, obtidos durante o ensaio de tração, quanto os corrigidos nas simulações numéricas das cruzetas. Os modelos de comportamento adotados são ilustrados na figura 7.6, obtidos por meio de ensaios de tração, cujos resultados são apresentados no capítulo 8.

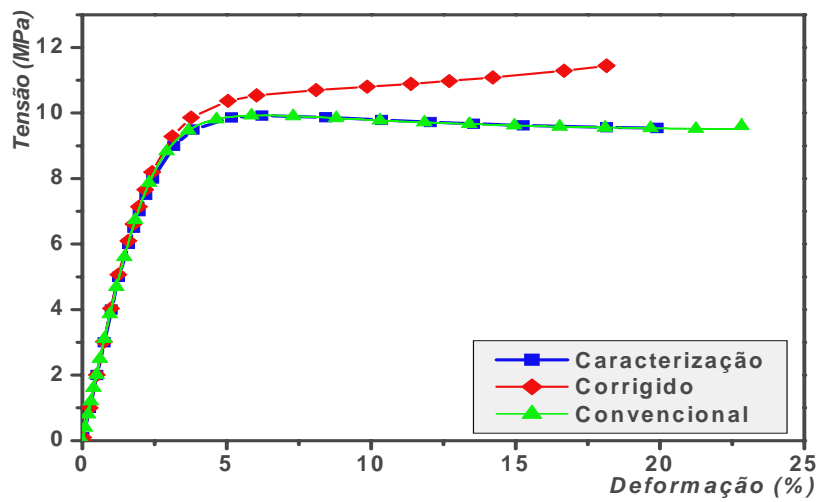

(a)

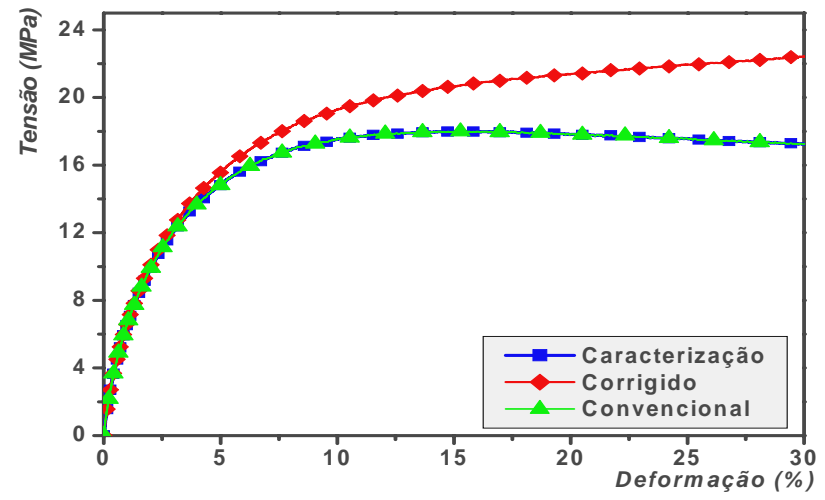

(b)

Figura 7.6 - Exemplo de modelo de comportamento de materiais - valores convencionais e corrigidos:

(a) PU e (b) PEAD. 
É importante ressaltar que na modelagem dos elementos, os modelos de comportamento de materiais foram inseridos no programa ANSYS utilizando-se as opções: (i) Material Props Material Models - Structural - Linear - Elastic - Isotropic e (ii) Nonlinear - Inelastic - Rate independent - Isotropic Hardening Plasticity - Mises Plasticity - Multilinear Elastic, para ambos os modelos. Os módulos de elasticidade utilizados para as análises são baseados nos resultados convencionais (caracterização) e nos valores corrigidos, sendo, respectivamente, de $415 \mathrm{MPa}$ e 426MPa para o PU e de 422MPa e 425MPa para o de PEAD. O coeficiente de Poisson utilizado foi de 0,3, o qual representa a média dos valores obtidos na bibliografia (de 0,2 a 0,4 - Capítulo 3 item 3.3.1.b).

Para analisar o comportamento estrutural das cruzetas poliméricas, adotaram-se as mesmas formas e condições de contorno utilizadas nos ensaios experimentais [ver figura 7.7(a)] Assim, quanto à vinculação utilizada na modelagem, para as análises efetuadas com o SOLID45, utilizaram-se um apoio fixo (com restrições em x, y e z) e outro móvel (com restrição somente em y), aplicados diretamente nos nós dos elementos - ver figura 7.7( $\left.b_{1}\right)$. Para simular a aplicação de carga nos modelos, conforme apresentado na figura $7.7\left(\mathrm{~b}_{2}\right)$, utilizou-se um nó mestre, acoplado aos demais nós que delimitavam a região destinada ao dispositivo de aplicação de carga. Dessa forma os nós da extremidade do dispositivo de aplicação de carga foram "escravizados" pelo nó mestre que, uma vez sofrendo um deslocamento, este seria igualmente transferido aos nós acoplados a ele. Por outro lado, para as análises feitas com o BEAM189, também se utilizaram apoios fixos e móveis. Entretanto, a aplicação de cargas foi feita diretamente no nó de meio-vão do modelo e a vinculação é realizada restringindo-se os deslocamentos transversais ( $x, y$ e $z$ para apoio fixo ou apenas y no caso de apoio móvel) do nó em que se materializa o apoio [ver figuras 7.7 $\left(\mathrm{c}_{1}\right)-\left(\mathrm{c}_{2}\right)$, as quais apresentam, de forma tridimensional, o elemento de viga].

Quanto às solicitações, estas foram aplicadas no modelo por meio de incrementos de carga, coerentes com as identificadas nos ensaios experimentais em modelos de cruzetas poliméricas.

$\mathrm{Na}$ análise não-linear física, o modelo constitutivo adotado para o material é associado ao critério de plastificação de von-Mises, para o qual se utilizaram as curvas apresentadas na figura 7.6 (a)-(b), que objetiva simular o comportamento elastoplástico com encruamento isótropo do material, tanto na tração como na compressão.

Com relação à não-linearidade geométrica, em ambas as modelagens (e.g., Solid45 e Beam189), utilizou-se formulação lagrangeana atualizada para a descrição do movimento da cruzeta. Ou seja, a configuração de referência, por sua vez, corresponde à última configuração de equilíbrio determinada. Assim, na análise incremental, ao final de cada incremento de carga, o referencial é transferido para a recém calculada configuração de equilíbrio, caracterizando um referencial móvel. Neste caso, tornou-se necessário utilizar um método de solução, dentre os existentes. O escolhido foi o método incremental/iterativo 
de Newton-Raphson (Full NR), com atualização da matriz de rigidez em todas as iterações de cada incremento de carga.
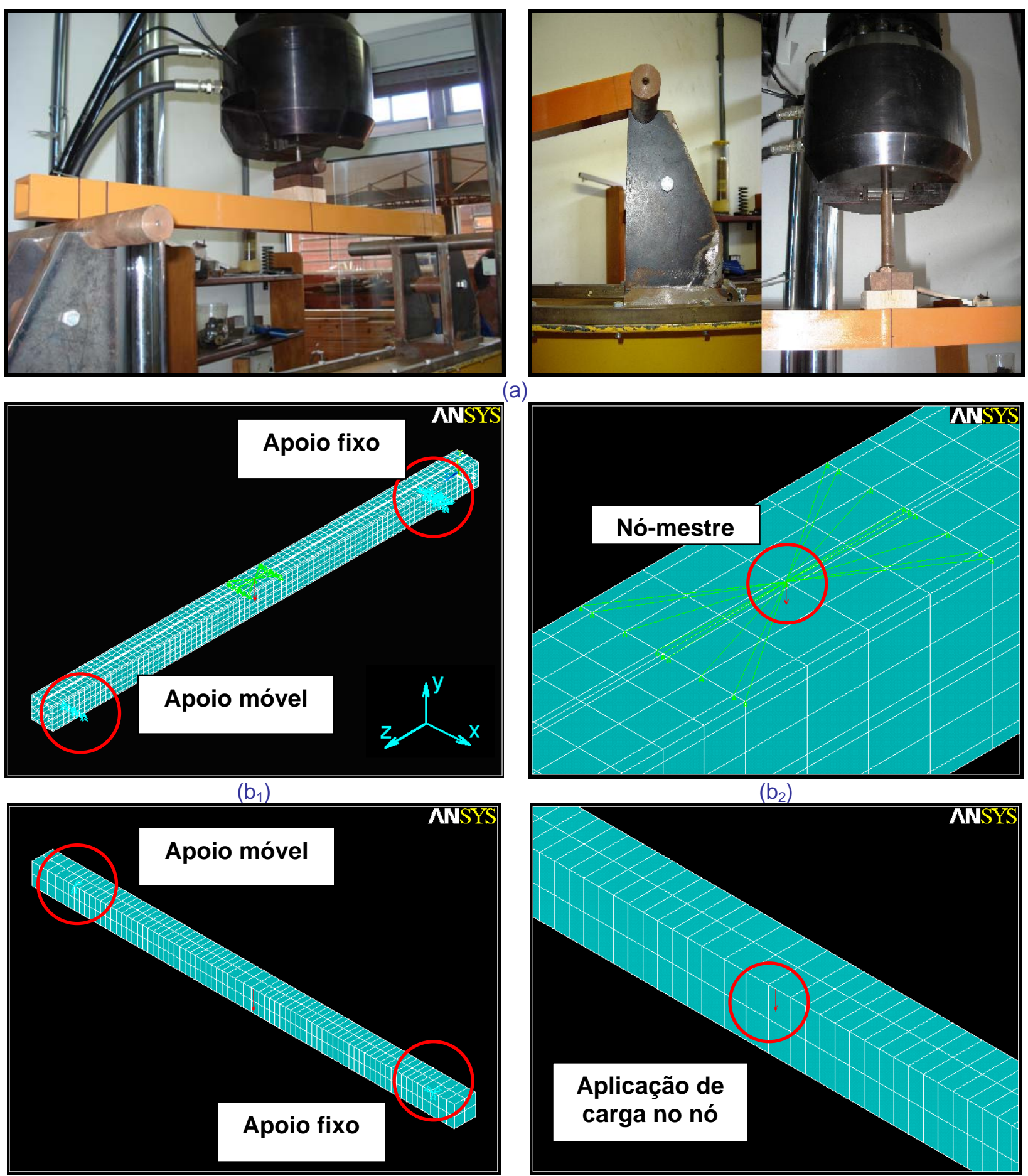

$\left(\mathrm{C}_{1}\right)$

$\left(\mathrm{C}_{2}\right)$

Figura 7.7 - Detalhes (a) dos apoios e do dispositivo de aplicação de carga, utilizados no ensaio experimental, e da vinculação e do acoplamento de nós na análise numérica, para (b) SOLID45 e (c) BEAM189. 


\subsection{Simulação numérica}

A simulação numérica dos modelos de cruzetas poliméricas é baseada na norma NBR 8458:1984 e em estudos realizados por Silva (2003) e Godoy (2006). Esta etapa será dividida em duas partes, sendo a primeira referente aos modelos, com comprimentos de $600 \mathrm{~mm}$ e $800 \mathrm{~mm}$, e a segunda referente aos protótipos de cruzeta, com comprimento de $2000 \mathrm{~mm}$.

\subsubsection{Modelos de cruzeta polimérica}

As figuras 7.8, 7.9 e 7.10 mostram as malhas de elementos finitos utilizadas na análise numérica. Durante a discretização dos modelos numéricos, procurou-se manter sua semelhança com o modelo real. A aplicação de cargas no modelo foi correspondente aos deslocamentos do pistão da máquina universal de ensaios visando, assim, a validação dos resultados de acordo com o ensaio de flexão.

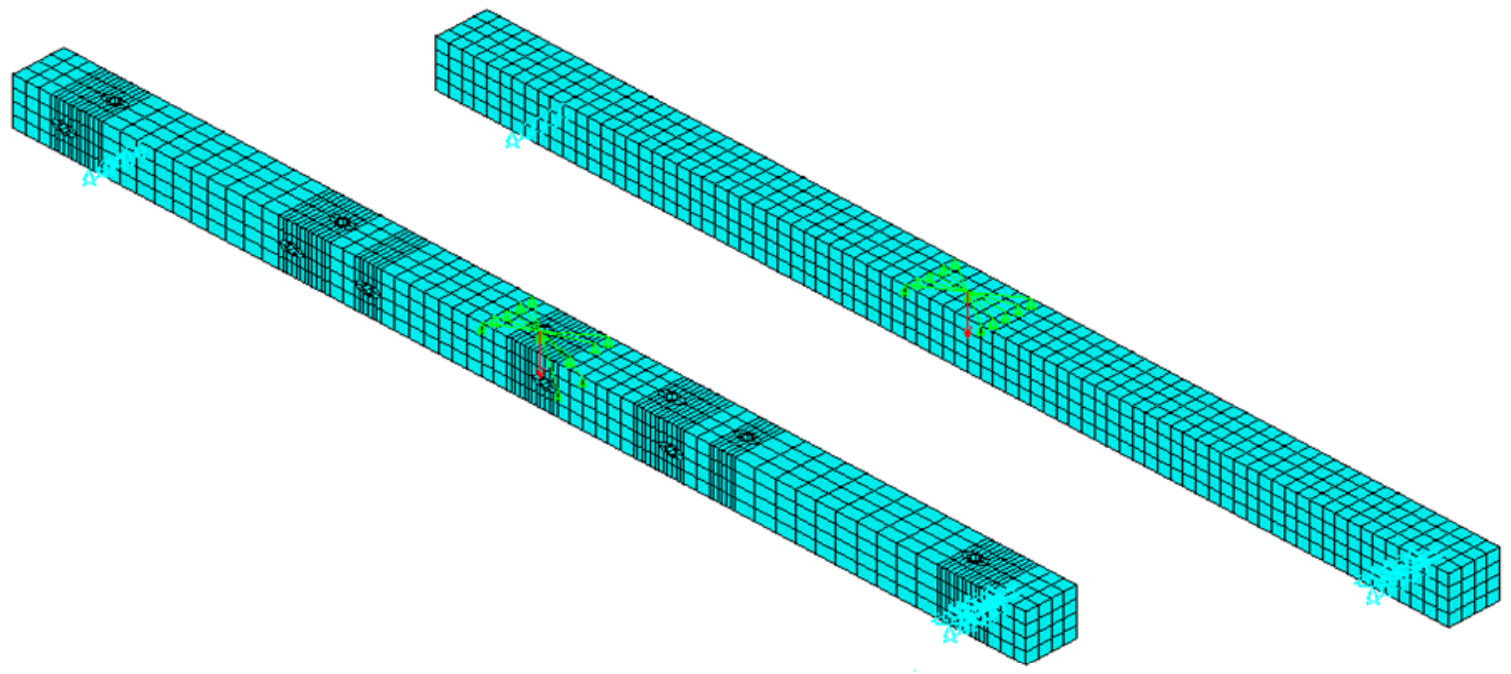

Malhas em elementos finitos referentes às seções 1 (800mm) e 5 (600mm) - com e sem furos.

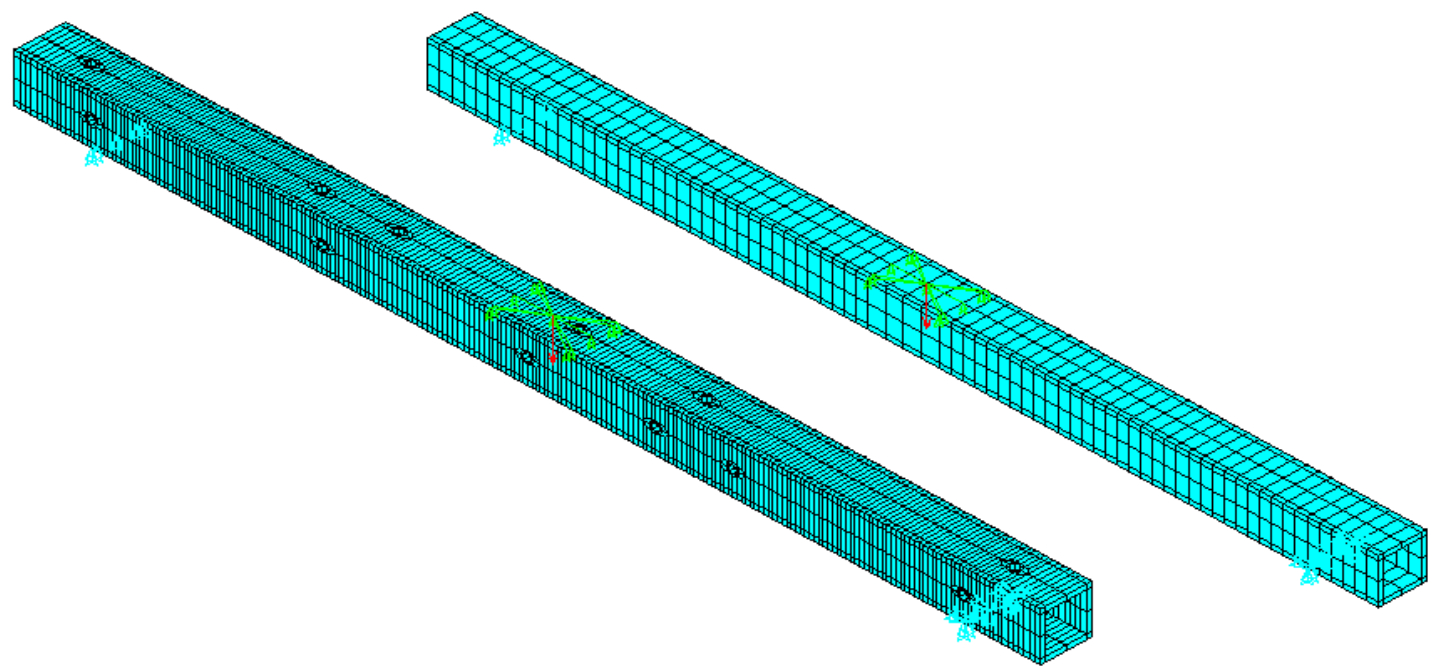

Malhas em elementos finitos referentes às seções $2(800 \mathrm{~mm})$ e $6(600 \mathrm{~mm})$ - com e sem furos. 


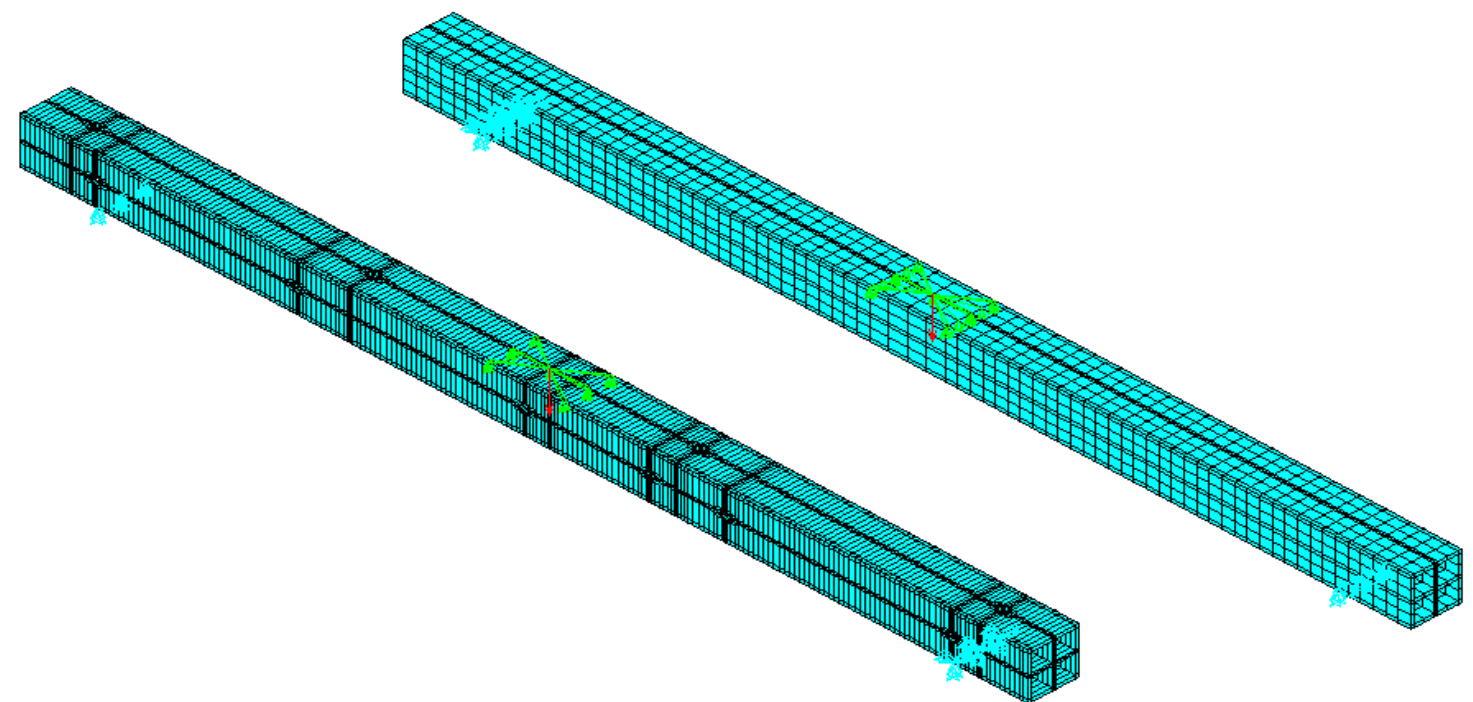

Malhas em elementos finitos referentes às seções $3(800 \mathrm{~mm})$ e $7(600 \mathrm{~mm})$ - com e sem furos.

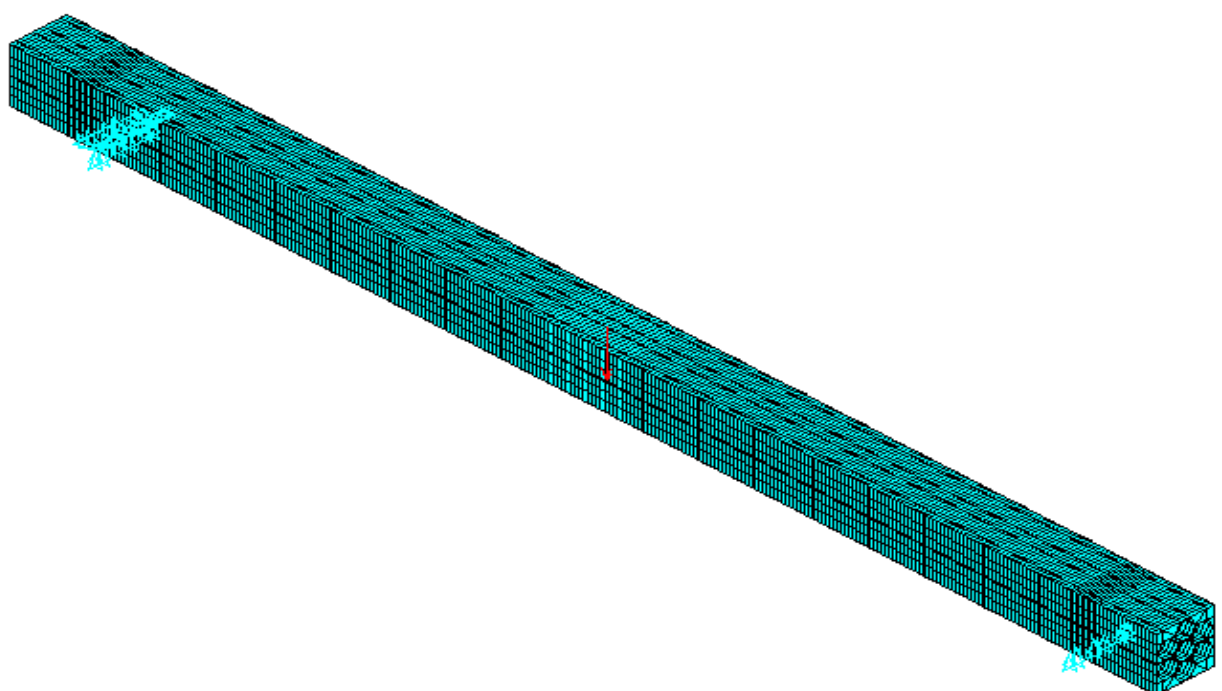

Malha em elementos finitos referente às seções $4(800 \mathrm{~mm})$ e $8(600 \mathrm{~mm})$ - sem furos.

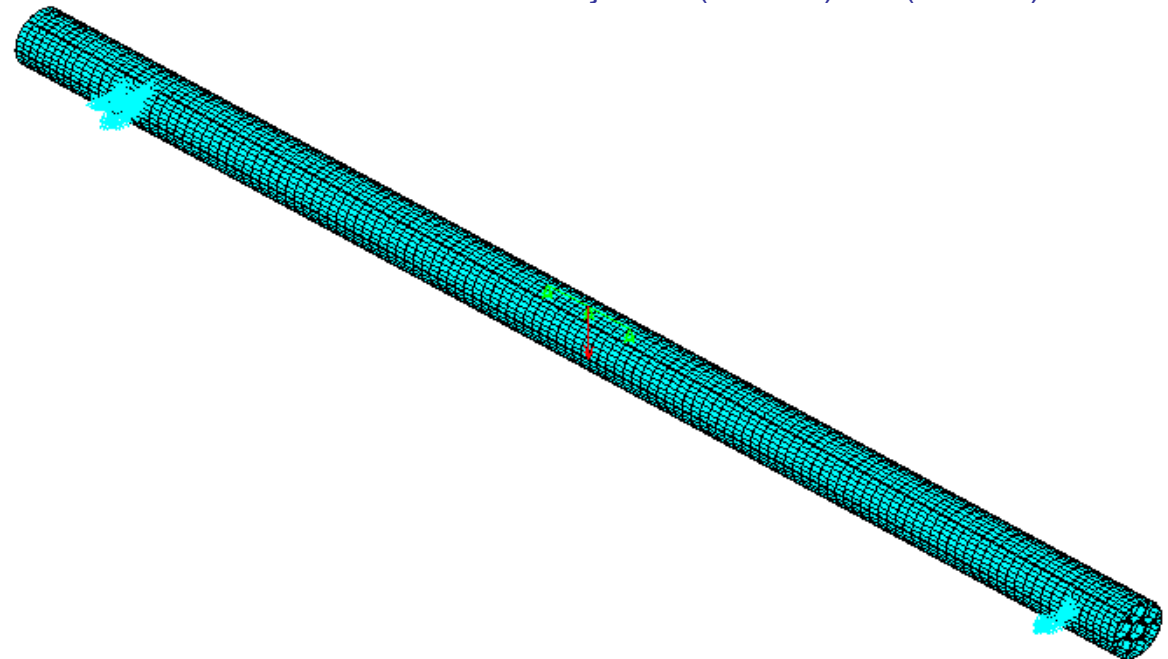

Malha em elementos finitos referente à seção 9 (600mm) - sem furos. 


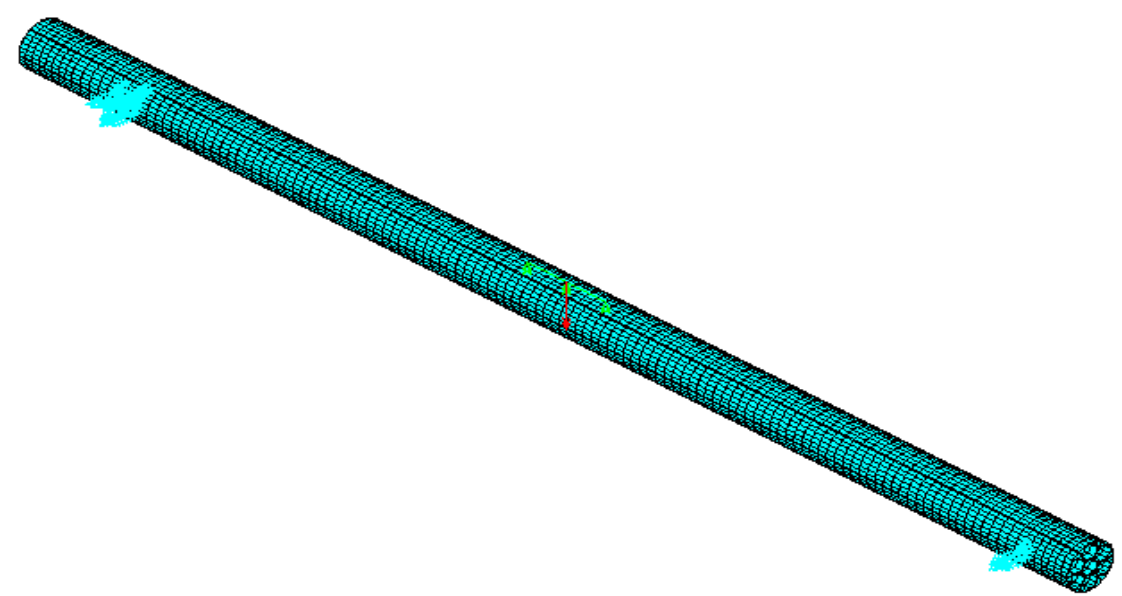

Malha em elementos finitos referente à seção 10 (600mm) - sem furos.

Figura 7.8 - Malhas para os modelos numéricos - Solid45.

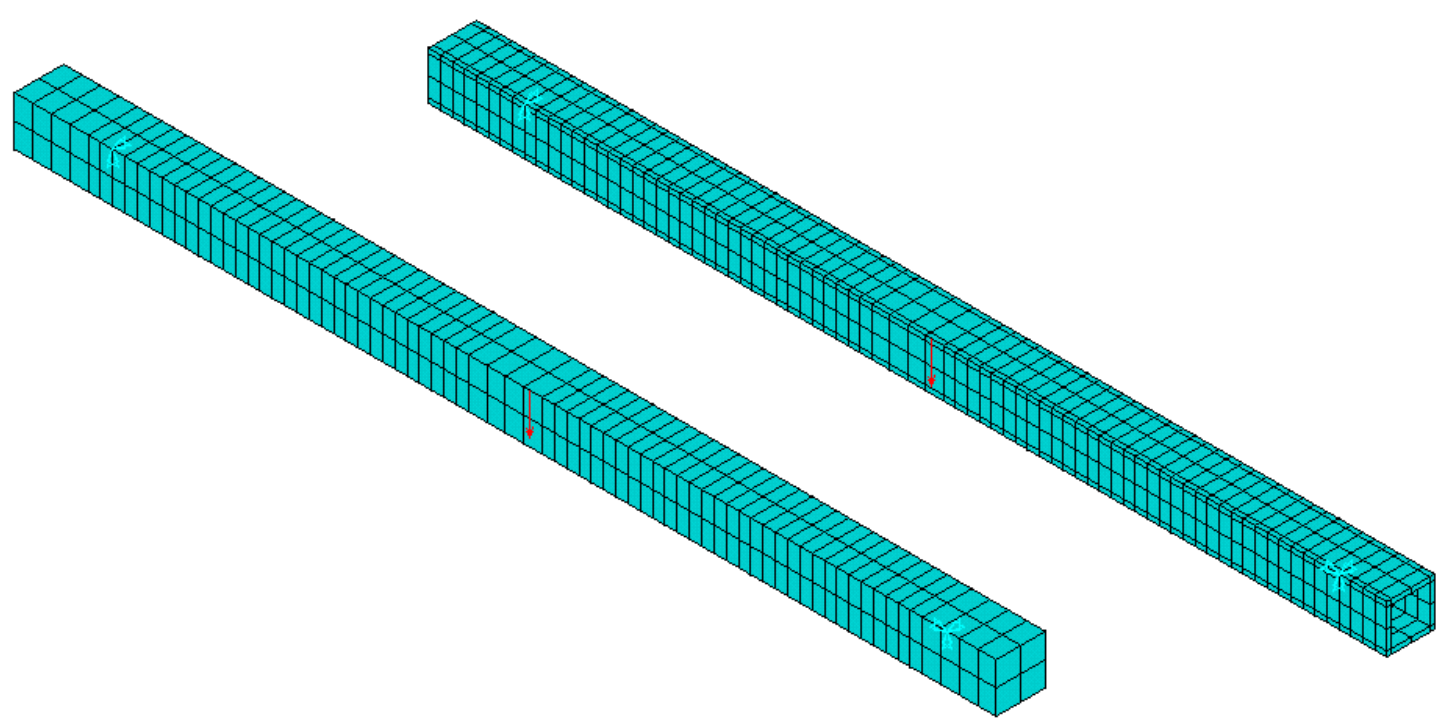

Malhas em elementos finitos referentes às seções 1 e $2(600 \mathrm{~mm})$ e 5 e 6 (800mm) - sem furos.

Figura 7.9 - Malhas para os modelos numéricos - Beam189.

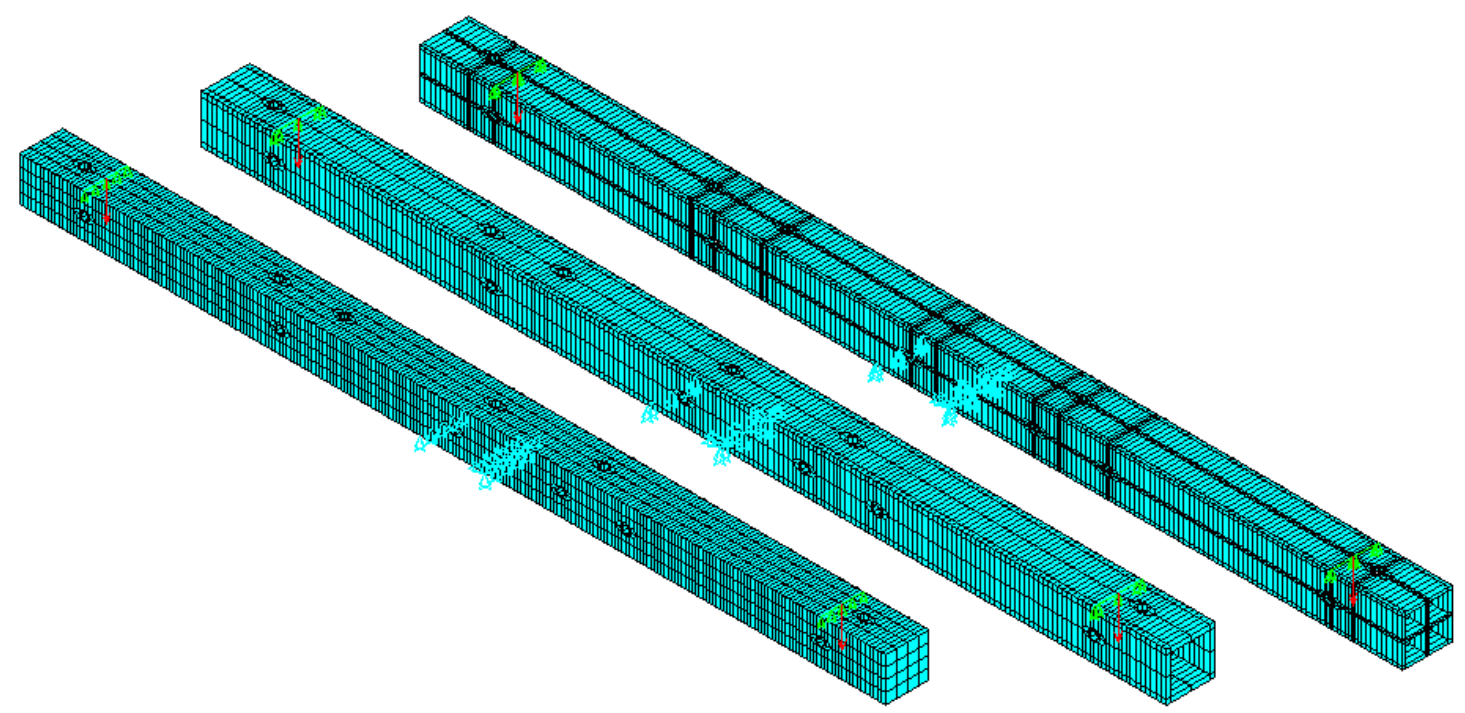

Malhas em elementos finitos referentes aos protótipos das seções 1, 2 e $3-2000 \mathrm{~mm}$.

Figura 7.10 - Malhas para os modelos numéricos - Solid45. 


\subsection{Considerações finais}

Este capítulo propôs o desenvolvimento de uma estratégia de modelagem numérica para simulação do comportamento estrutural de cruzetas de materiais poliméricos. Optou-se por desenvolver os modelos por meio do pacote ANSYS, versões 8.0 e 9.0, adotando para tanto elementos finitos disponibilizados na biblioteca do programa em questão.

Para as análises, foram utilizados dois tipos de elementos finitos, o SOLID45 e o $B E A M 189$, visando o estudo da relação entre o tipo de elemento adotado e a sua resposta, dos quais se espera que não ocorra perda de representatividade entre a análise numérica e a experimental.

A simulação numérica do comportamento de elementos estruturais se justifica pela diminuição inicial de recursos necessários para seu estudo, tais como as obtidas com: (i) fabricação de moldes e de calibradores, (ii) produção do elemento, (iii) despesas com materiais e mão-de-obra, dentre outras. Outra questão muito importante a ser destacada é a de que o modelo computacional pode ter suas características e propriedades facilmente alteradas, o que muitas vezes inviabilizaria uma investigação experimental, no caso de alterações da composição do material ou das dimensões do elemento estrutural. 


\section{RESULTADOS}

\section{8量}

Inicialmente, apresentam-se resultados experimentais para determinar as propriedades mecânicas do poliuretano. Posteriormente, esses resultados são utilizados para alimentar o modelo de material, utilizado na análise numérica.

Paralelamente, apresentam-se a análise numérica e a discussão dos resultados obtidos. Ainda, faz-se a comparação dos resultados obtidos, tanto experimental quanto numericamente.

\subsection{Ensaios dos corpos-de-prova}

Foram realizados ensaios de: tração, compressão, flexão e impacto.

\subsubsection{Ensaio de tração}

Neste ensaio utilizaram-se cinco corpos-de-prova de poliuretano e os resultados apresentados são valores médios. As curvas de tensão versus deformação obtidas nos ensaios de tração apresentaram um comportamento de acordo com a curva da Figura 8.1.

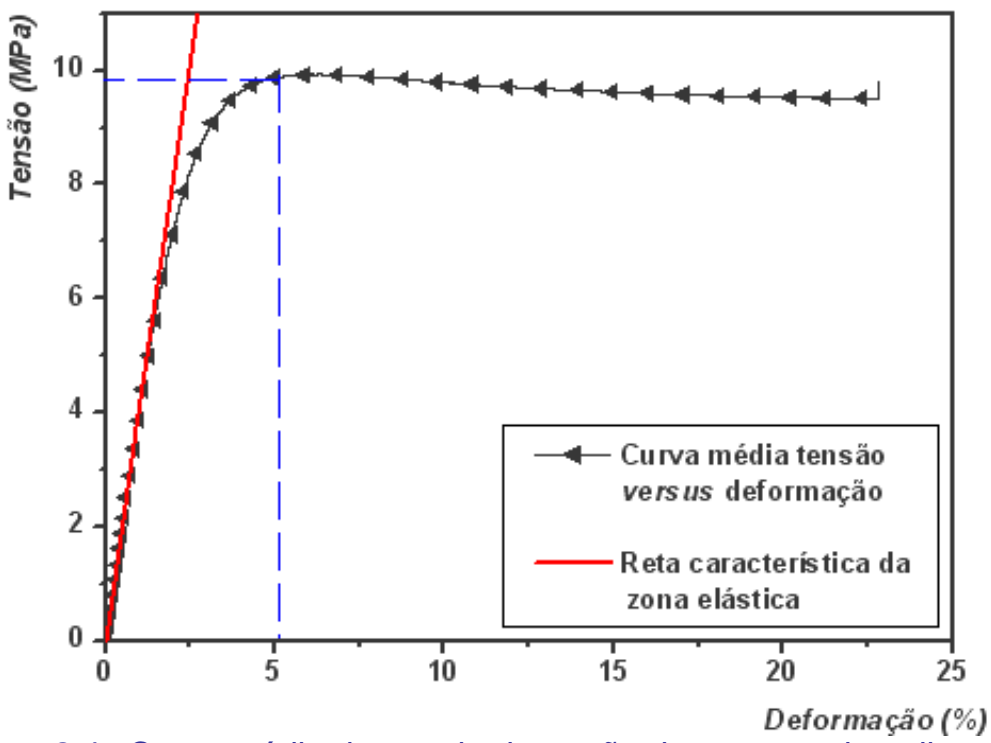

Figura 8.1 - Curva média do ensaio de tração da amostra de poliuretano.

É possível notar que a resposta do poliuretano à tração é dúctil, apresentando uma curva característica dos polímeros que sofrem escoamento na tensão máxima após a região linear elástica, seguida de deformação plástica até a ruptura. Por meio do alongamento é 
possível se obter uma medida comparativa da ductilidade, ou seja, quanto maior o alongamento, mais dúctil é um material. Isso significa que, quanto mais dúctil, maior sua deformação ou alongamento antes da ruptura.

Quando se atinge a carga máxima (neste caso, a resistência à tração no escoamento), ocorre a estriç̧ão do material (diminuição da seção transversal do corpo-deprova) na região onde deve ocorrer sua ruptura. A carga de ruptura, neste caso, é inferior à carga máxima do limite de escoamento e recebe o nome de tensão de tração na ruptura.

Os valores médios encontrados para a resistência à tração no escoamento, porcentagem de deformação na ruptura e módulo de elasticidade para as amostras são apresentados na tabela 8.1. A medida do módulo de elasticidade é o coeficiente angular da reta característica (linha vermelha) da zona elástica, mostrada na Figura 8.1.

Tabela 8.1 - Valores encontrados no ensaio de tração das amostras de poliuretano.

\begin{tabular}{l|c}
\hline Propriedades & Resultados \\
\hline Resistência à tração no escoamento (MPa) & $9,9 \pm 0,6$ \\
\hline Deformação no escoamento (\%) & $6,4 \pm 0,5$ \\
\hline Resistência à tração na ruptura (MPa) & $9,4 \pm 1,6$ \\
\hline Deformação na ruptura (\%) & $22,8 \pm 1,3$ \\
\hline Módulo de Elasticidade (MPa) & $415,0 \pm 41,2$ \\
\hline
\end{tabular}

Também foi realizado um ensaio piloto do PEAD reciclado. Essas amostras foram fornecidas pela Reciclagem Nova Ribeirão, localizada na Rua Americana, 2270, na cidade de Ribeirão Preto, no estado de São Paulo, no dia 20 de março de 2006. Nesse ensaio utilizaram-se dois corpos-de-prova extrusados, cujos resultados experimentais são apresentados na figura 8.2 e na tabela 8.2 .

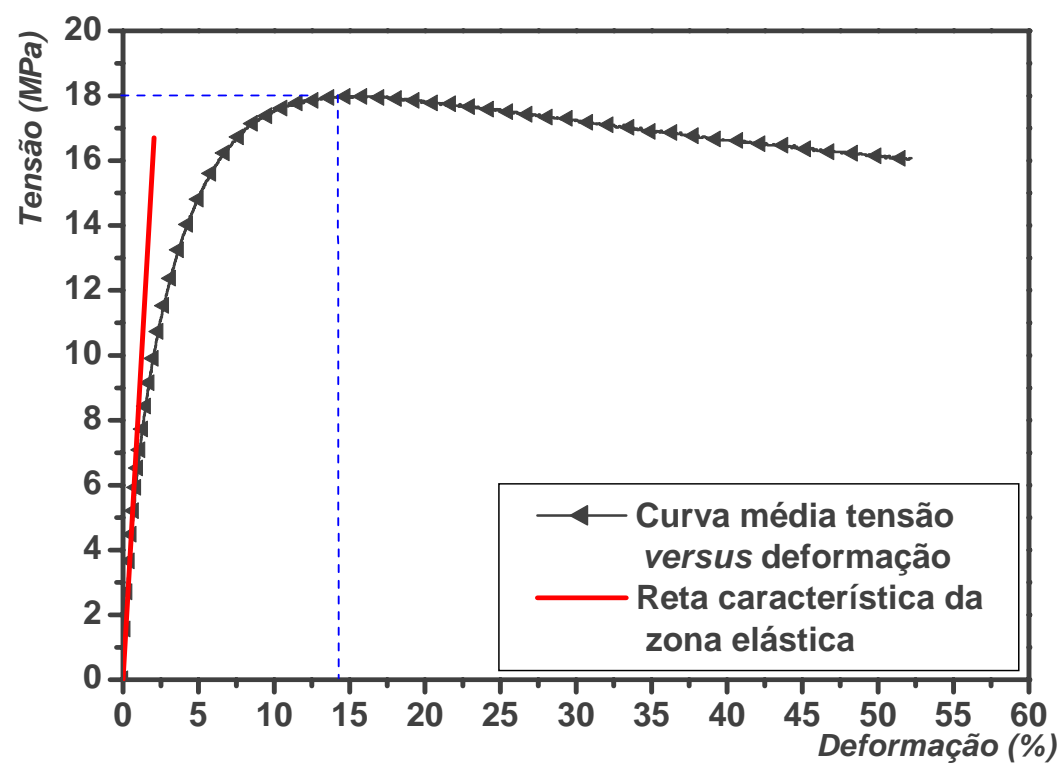

Figura 8.2 - Curva média do ensaio de tração da amostra de polietileno de alta densidade (PEAD). 
Tabela 8.2 - Valores encontrados no ensaio de tração das amostras de PEAD.

\begin{tabular}{l|c}
\hline Propriedades & Resultados \\
\hline Resistência à tração no escoamento (MPa) & $18,01 \pm 0,02$ \\
\hline Deformação no escoamento (\%) & $15,25 \pm 0,11$ \\
\hline Módulo de Elasticidade (MPa) & $932,29 \pm 25,02$ \\
\hline Resistência à tração na ruptura (MPa) & $>16,02 \pm 0,07$ \\
\hline Deformação na ruptura (\%) & $>52,11 \pm 0,14$ \\
\hline
\end{tabular}

O PEAD, quando submetido à tração, também possui resposta dúctil, apresentando escoamento na tensão máxima após a região linear elástica, seguida de deformação plástica até a ruptura.

Com esses valores percebe-se que a resistência à tração no limite de escoamento e o módulo de elasticidade do poliuretano e do PEAD estão abaixo das propriedades de outros materiais comumente empregados em cruzetas, comprovando-se a necessidade de reforçá-los.

\subsubsection{Ensaio de compressão}

Neste ensaio utilizaram-se cinco corpos-de-prova de poliuretano e os resultados do ensaio de compressão, segundo as curvas de tensão versus deformação, apresentaram um comportamento de acordo com a Figura 8.3.

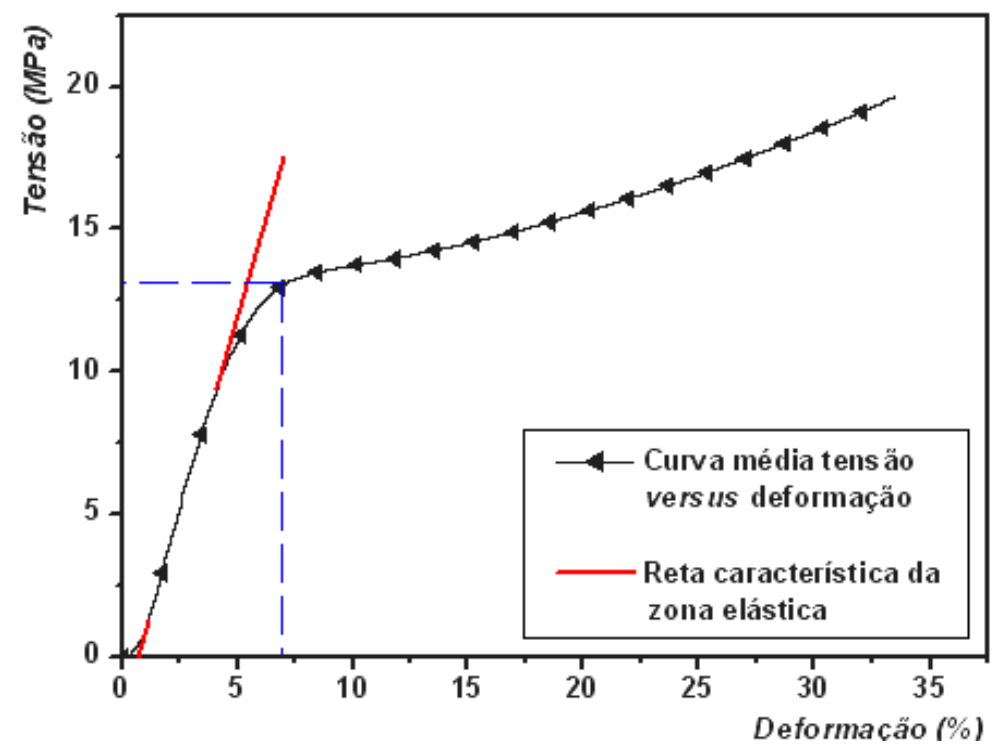

Figura 8.3 - Curva média do ensaio de compressão da amostra de poliuretano.

Nota-se que a resposta do poliuretano à compressão também é dúctil, sofrendo escoamento e plastificando logo após a zona elástica. Neste caso, só se pode estimar com certa precisão as propriedades referentes à zona elástica, uma vez que é impossível medir a tensão e a deformação na ruptura. 
O corpo-de-prova de poliuretano, quando sujeito ao esforço axial de compressão, tende a aumentar sua seção transversal com o acréscimo de carga. Considerando-se o cálculo da tensão como sendo força dividida pela área, com o aumento da carga ocorre uma diminuição da tensão, aumentando assim a resistência do material. Por essa razão o corpode-prova não se rompe, ficando cada vez mais achatado.

Como no ensaio de tração, pode-se determinar as propriedades referentes à zona elástica, onde é aplicada a Lei de Hooke. A resistência e a deformação no escoamento, assim como o módulo de elasticidade para as amostras, são apresentados na tabela 8.3.

Tabela 8.3 - Valores encontrados no ensaio de compressão das amostras de poliuretano.

\begin{tabular}{l|c}
\hline \multicolumn{1}{c|}{ Propriedades } & Resultados \\
\hline Resistência à compressão no escoamento (MPa) & $12,9 \pm 0,2$ \\
\hline Deformação no escoamento (\%) & $6,8 \pm 0,6$ \\
\hline Módulo de Elasticidade (MPa) & $222,6 \pm 8,6$ \\
\hline
\end{tabular}

\subsubsection{Ensaio de flexão}

Neste ensaio utilizaram-se cinco corpos-de-prova de poliuretano, e os valores apresentados são valores médios. Nesses ensaios, como não houve ruptura dos corpos-de-prova, foi considerada resistência à flexão a tensão relativa a uma deformação de $5 \%$, que corresponde a uma deformação de $13,65 \mathrm{~mm}$, conforme indicam os procedimentos de ensaios contidos na Norma ASTM D790-96. Os resultados desse ensaio nos corpos-de-prova de poliuretano, segundo as curvas de tensão versus deformação, apresentaram um comportamento de acordo com a Figura 8.4.

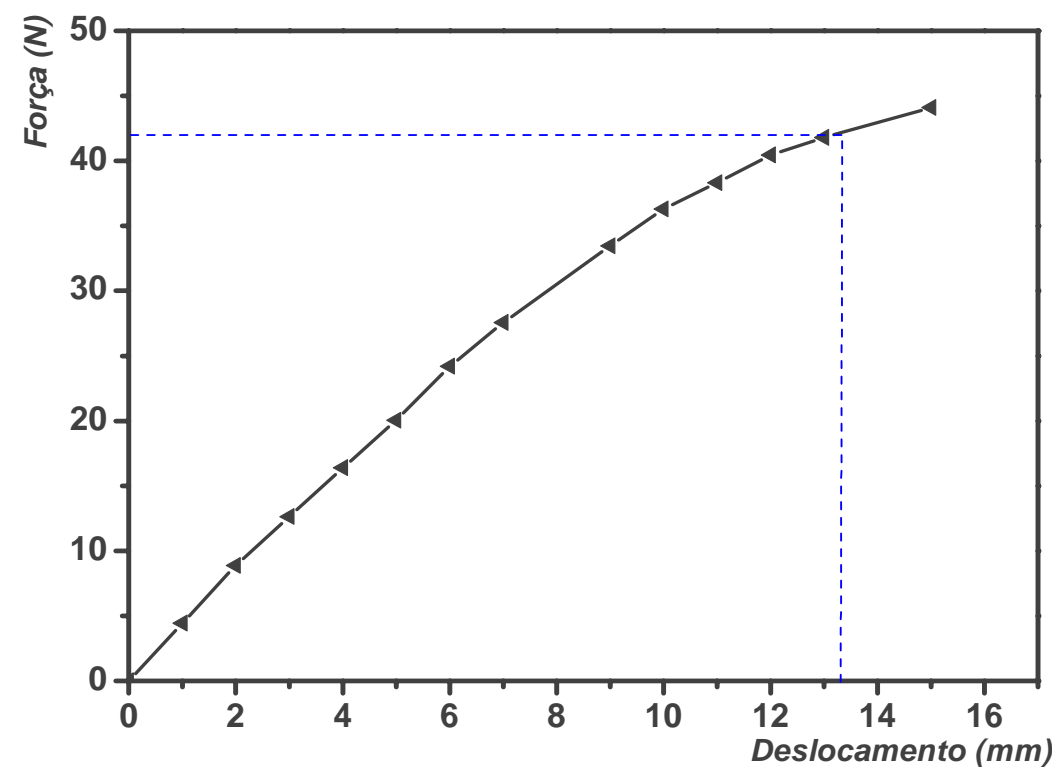

Figura 8.4 - Curva média do ensaio de flexão da amostra de poliuretano. 
Os valores médios encontrados para o módulo de elasticidade, a resistência à flexão e a força máxima para uma deformação de $5 \%$ são apresentados na tabela 8.4 . Como não houve ruptura dos corpos-de-prova, os ensaios foram interrompidos quando se atingiu um deslocamento de 13,65mm, previamente calculado no capítulo 6 - item 6.6.4.

Tabela 8.4 - Valores encontrados no ensaio de flexão das amostras de poliuretano.

\begin{tabular}{l|c}
\hline \multicolumn{1}{c|}{ Propriedades } & Resultados \\
\hline Força máxima à flexão para deformação de $5 \%(\mathrm{~N})$ & $42,5 \pm 3,3$ \\
\hline Módulo de Elasticidade $(\mathrm{MPa})$ & $371,5 \pm 23,5$ \\
\hline Resistência à flexão para deformação de $5 \%(\mathrm{MPa})$ & $13,0 \pm 0,8$ \\
\hline
\end{tabular}

\subsubsection{Ensaio de impacto}

Neste ensaio utilizaram-se cinco corpos-de-prova de poliuretano, e os resultados apresentados são valores médios, indicados na tabela 8.5 .

Tabela 8.5 - Valores encontrados no ensaio de impacto das amostras de poliuretano.

\begin{tabular}{l|c}
\hline \multicolumn{1}{c|}{ Propriedades } & Resultados \\
\hline Energia de impacto $(\mathrm{J} / \mathrm{m})$ & $419,8 \pm 5,1$ \\
\hline Energia de impacto $\left(\mathrm{kJ} / \mathrm{m}^{2}\right)$ & $41,3 \pm 0,5$ \\
\hline $\begin{array}{l}\text { Obs.: Não houve separação entre as duas partes dos } \\
\text { corpos-de-prova }\end{array}$
\end{tabular}

\subsection{Ensaios de flexão nos modelos de cruzeta}

O programa experimental também compreendeu o estudo da relação força versus flecha em modelos de cruzetas poliméricas submetidas à flexão. A quantidade dos modelos foi estabelecida da seguinte forma: seria realizada uma amostra para cada tipo de seção, totalizando um total de dez modelos; entretanto, devido a dificuldades para a produção de fôrmas e falta de tempo hábil para executá-los, o número, antes planejado, foi reduzido para cinco modelos.

\subsubsection{Análise experimental de cruzeta polìmérica}

Foram ensaiados cinco modelos de cruzetas poliméricas, sendo três com $800 \mathrm{~mm}$ e dois com 600mm. Nesse ensaio, foram utilizados dois dispositivos metálicos de apoio, que simularam a aplicação de carga, e um dispositivo de madeira para aplicação de cargas, simulando o apoio no ensaio normalizado para cruzetas de madeiras. Essa adaptação foi devida à limitação do deslocamento do travessão da máquina utilizada para o ensaio, ou seja, a máquina de ensaios universal Dartec, cujo deslocamento máximo é de $10 \mathrm{~cm}$ (Fig. 8.5). 

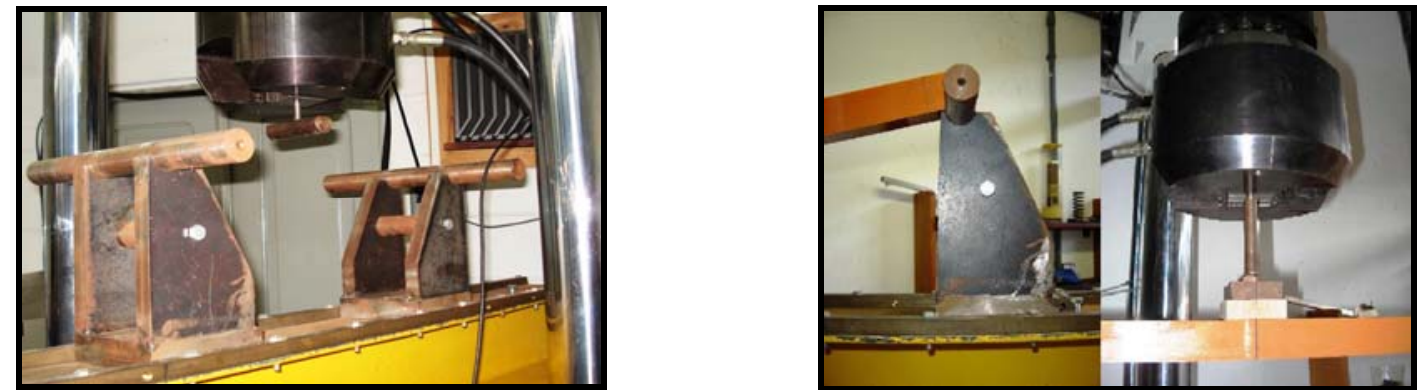

Figura 8.5 - Dispositivo utilizado no ensaio de flexão de cruzetas poliméricas.

Após os ensaios dos modelos poliméricos, foram feitas previsões do comportamento de protótipos de cruzetas poliméricas, com comprimento de 2000mm. A seguir, são apresentadas as curvas características para cada tipo de seção transversal estudada, assim com os valores obtidos no ensaio de flexão.

\section{a) Seção transversal tipo 1}

O primeiro ensaio de flexão foi realizado para a seção transversal tipo 1. A cruzeta é maciça, possui seção quadrada e as seguintes dimensões: $40 \mathrm{~mm}$ x 40mm x 800mm. Seu ensaio foi dividido em duas etapas, sendo que a primeira foi executada aos 15 dias. Esta etapa foi conduzida até a flecha de $100 \mathrm{~mm}$, correspondente a uma força de 831,62N. Pelo fato do ensaio ter atingido o máximo deslocamento do pistão da máquina, ela automaticamente se desligou, não sendo possível obter a curva de descarregamento da cruzeta. A flecha residual registrada foi de $7,90 \mathrm{~mm}$. A segunda etapa foi realizada aos 30 dias, no qual percebeu-se uma diferença na resposta dos modelos ensaiados, que pode ter sido ocasionada por uma pós-cura do material utilizado, devido as dimensões do modelos utilizados. A máxima força aplicada também foi de $831,62 \mathrm{~N}$; entretanto, as flechas registradas foram de $77,13 \mathrm{~mm}$, máxima, e de 5,20 mm, residual (Fig. 8.6).

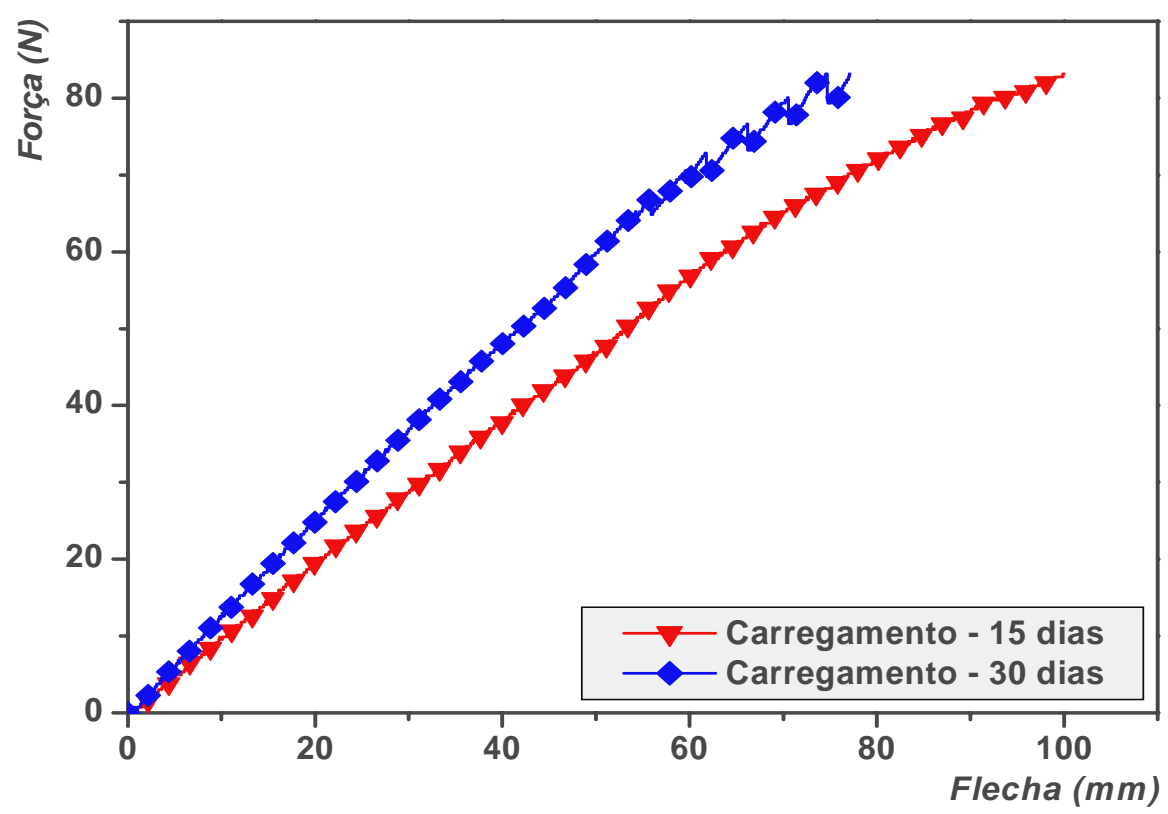

Figura 8.6 - Curva força versus flecha do ensaio de flexão na cruzeta de seção 1. 
O ensaio do modelo de cruzeta tipo 1, com idade 30 dias, apresentou interrupção no ensaio por causa do deslocamento excessivo, com deslizamento em um dos apoios. A tabela 8.6 traz os resultados obtidos no ensaio, assim como uma previsão da resistência e da flecha do protótipo.

Tabela 8.6 - Valores encontrados no ensaio do modelo e previsão de resultados para o protótipo.

\begin{tabular}{|c|c|c|c|c|c|c|}
\hline \multirow[b]{2}{*}{ Idade } & \multicolumn{3}{|c|}{$\begin{array}{c}\text { Modelo polimérico } \\
\text { (comprimento de } 800 \mathrm{~mm} \text { ) }\end{array}$} & \multicolumn{3}{|c|}{$\begin{array}{c}\text { Protótipo } \\
\text { (comprimento de } 2000 \mathrm{~mm} \text { ) }\end{array}$} \\
\hline & Força (N) & Flecha $(\mathrm{mm})$ & $\begin{array}{c}\text { Flecha } \\
\text { residual } \\
(\mathrm{mm})\end{array}$ & Força (N) & Flecha $(\mathrm{mm})$ & $\begin{array}{c}\text { Flecha } \\
\text { residual } \\
(\mathrm{mm})\end{array}$ \\
\hline 15 dias & 831,62 & 100,00 & ---------- & 5197,63 & 250,00 & ------ \\
\hline 30 dias & 831,62 & 77,13 & 5,20 & 5197,63 & 192,83 & 13,00 \\
\hline
\end{tabular}

Nota-se que o material utilizado na confecção dos modelos é muito deformável, quando comparado às madeiras consideradas pela norma NBR 8548:1984, por exemplo.

Como mencionado nos capítulos 5 e 6, devido à limitação do deslocamento do travessão da máquina utilizada para o ensaio e também pelos dispositivos utilizados, em alguns casos, não foi possível aplicar o carregamento previamente calculado, uma vez que o material é flexível e apresenta grandes deformações. Sendo assim, fez-se uma adaptação na configuração do ensaio dos modelos poliméricos, que é apresentada na figura 8.7.

(a)

$\sqrt{ } \mathbf{F}$
Fixação

\section{$\mathbf{F}$}

(b)

Figura 8.7 - Configuração de ensaio para cruzetas: (a) segundo a NBR 8458:1984 e (b) adaptação para o ensaio da cruzeta polimérica.

Para uma comparação dos resultados experimentais com os especificados pela norma de madeira, basta adaptar o esquema estático considerado (Fig. 8.7), obtendo-se as forças indicadas na Tabela 8.7.

Tabela 8.7 - Previsão de resultados para modelo e protótipo, após a correção do esquema estático.

\begin{tabular}{c|c|c|c|c|c|c}
\cline { 2 - 7 } \multicolumn{2}{c|}{} & \multicolumn{3}{c|}{$\begin{array}{c}\text { Modelo polimérico } \\
\text { (comprimento de 800 }\end{array}$} & \multicolumn{3}{c}{$\begin{array}{c}\text { Protótipo } \\
\text { (comprimento de 2000mm) }\end{array}$} \\
\hline Idade & Força (N) & Flecha $(\mathbf{m m})$ & $\begin{array}{c}\text { Flecha } \\
\text { residual } \\
(\mathbf{m m})\end{array}$ & Força (N) & Flecha $(\mathbf{m m})$ & $\begin{array}{c}\text { Flecha } \\
\text { residual } \\
\text { (mm) }\end{array}$ \\
\hline 15 dias & 415,81 & 50,00 & ------ & 2598,82 & 125,00 & $-\cdots$ \\
\hline $\mathbf{3 0}$ dias & 415,81 & 38,57 & 2,60 & 2598,82 & 96,42 & 6,50 \\
\hline
\end{tabular}


Para um carregamento de 2598,82N, em um protótipo com seção maciça de dimensões $100 \mathrm{~mm} \times 100 \mathrm{~mm} \times 2000 \mathrm{~mm}$, a flecha prevista é de $96,42 \mathrm{~mm}$. Segundo a NBR 8458:1984, para um carregamento de $4000 \mathrm{~N}$, a flecha máxima admitida em uma cruzeta de madeira é de $75 \mathrm{~mm}$, ou seja, o protótipo polimérico apresentaria uma flecha bem maior que a máxima permitida pela norma.

\section{b) Seção transversal tipo 2}

A seção transversal do tipo 2 possui $40 \mathrm{~mm} \times 40 \mathrm{~mm}$ e comprimento do modelo é de $800 \mathrm{~mm}$. Sua particularidade é que a seção é vazada, com um furo quadrado, de dimensão $31,70 \mathrm{~mm} \times 31,70 \mathrm{~mm}$, como ilustrado no capítulo 5 - item 5.3.6. Seu ensaio de flexão foi conduzido até a flecha de $89,91 \mathrm{~mm}$, com uma força de $530,25 \mathrm{~N}$ para este nível de deslocamento. Durante o ensaio ocorreu o escorregamento do modelo no dispositivo de apoio, fato este registrado e demonstrado na curva de carregamento. Em seguida procedeuse o descarregamento; a flecha residual registrada foi de $3,38 \mathrm{~mm}$. As curvas de carregamento e de descarregamento são ilustradas na figura 8.8.

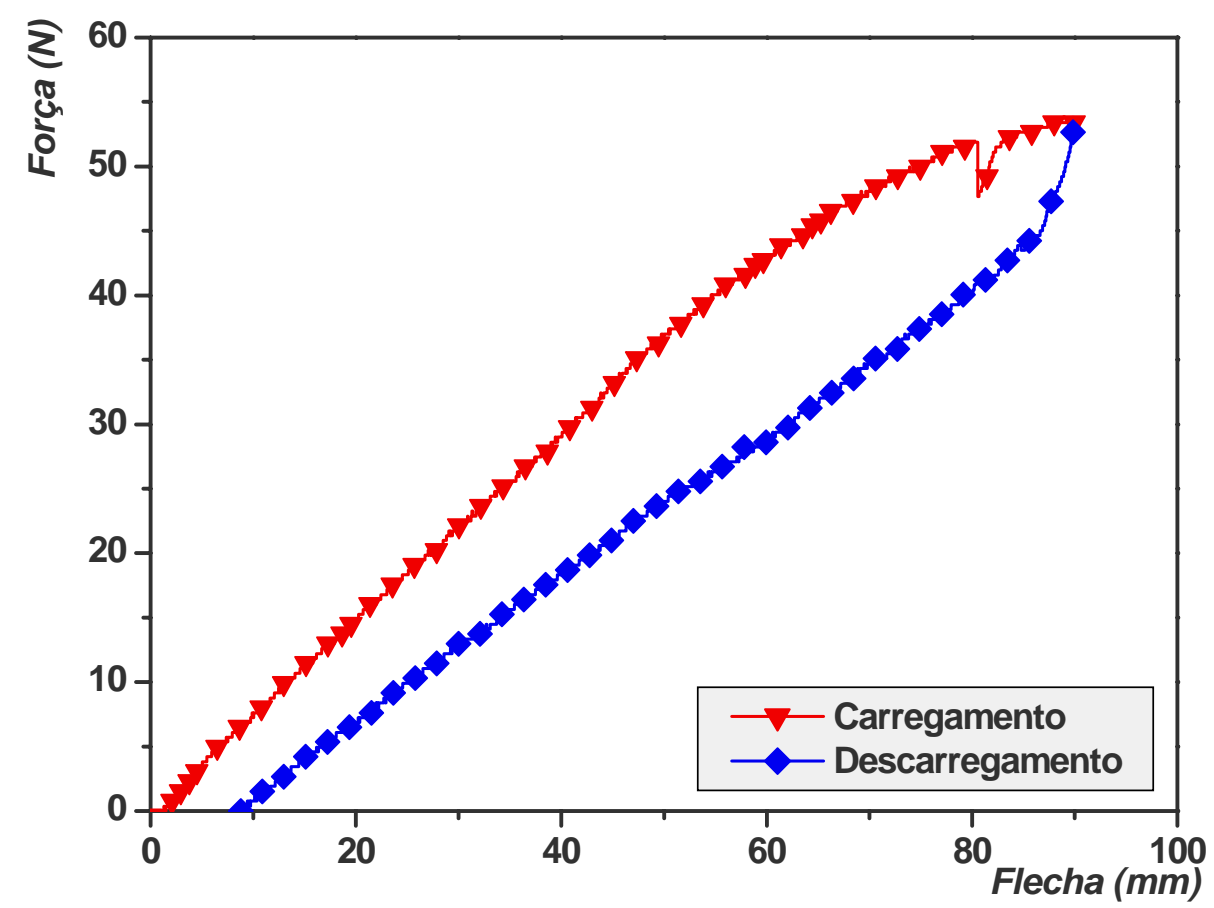

Figura 8.8 - Curva força versus flecha do ensaio de flexão na cruzeta de seção 2.

A tabela 8.8 indica os resultados obtidos no ensaio, assim como uma previsão da resistência e da flecha do protótipo. 
Tabela 8.8 - Valores encontrados no ensaio do modelo e previsão de resultados para o protótipo.

\begin{tabular}{c|c|c|c|c|c}
\hline \multicolumn{3}{c|}{$\begin{array}{c}\text { Modelo polimérico } \\
\text { (comprimento de 800mm) }\end{array}$} & \multicolumn{3}{c}{$\begin{array}{c}\text { Protótipo } \\
\text { (comprimento de 2000mm) }\end{array}$} \\
\hline Força (N) & Flecha (mm) & $\begin{array}{c}\text { Flecha } \\
\text { residual } \\
(\mathbf{m m})\end{array}$ & Força (N) & Flecha (mm) & $\begin{array}{c}\text { Flecha } \\
\text { residual } \\
(\mathbf{m m})\end{array}$ \\
\hline 530,25 & 89,91 & 3,38 & 3314,06 & 224,78 & 8,45 \\
\hline
\end{tabular}

Com o objetivo de comparar os resultados experimentais com os prescritos na norma de madeira, faz-se a adaptação do esquema estático, apresentando-se seus resultados na tabela 8.9.

Tabela 8.9 - Previsão de resultados para modelo e protótipo, após a adaptação do esquema estático.

\begin{tabular}{c|c|c|c|c|c}
\hline \multicolumn{3}{c|}{$\begin{array}{c}\text { Modelo polimérico } \\
\text { (comprimento de 800mm) }\end{array}$} & \multicolumn{3}{c}{$\begin{array}{c}\text { Protótipo } \\
\text { (comprimento de 2000mm) }\end{array}$} \\
\hline Força (N) & Flecha (mm) & $\begin{array}{c}\text { Flecha } \\
\text { residual } \\
(\mathbf{m m})\end{array}$ & Força (N) & Flecha (mm) & $\begin{array}{c}\text { Flecha } \\
\text { residual } \\
(\mathbf{m m})\end{array}$ \\
\hline 265,13 & 44,96 & 1,69 & 1657,03 & 112,39 & 4,23 \\
\hline
\end{tabular}

Para um protótipo de PU, com seção transversal de 100mm x 100mm e comprimento de $2000 \mathrm{~mm}$, a estimativa de carregamento é de $1657,03 \mathrm{~N}$, com flecha de $112,39 \mathrm{~mm}$ para esse nível de força. Quando comparada à seção 1, percebe-se que, embora seja mais deformável, a seção vazada apresenta a vantagem de consumir menos material para sua fabricação. Segundo a NBR 8458:1984, para um carregamento nominal de $4000 \mathrm{~N}$, a flecha máxima permitida para uma cruzeta de madeira é de $75 \mathrm{~mm}$. Assim, percebe-se que um material polimérico com propriedades semelhantes às do PU utilizado nesse modelo não atende as especificações de carregamento e de flecha indicadas na norma NBR 8458:1984.

\section{c) Seção transversal tipo 3}

A seção transversal do tipo 3 possui $40 \times 40 \mathrm{~mm}$ e o comprimento é de $800 \mathrm{~mm}$. A particularidade desta seção é que ela é vazada com quatro furos quadrados, de dimensões 15,875mm x 15,875mm. Seu ensaio de flexão foi conduzido até a flecha de 92,25 mm, obtendo-se assim uma força de $461,58 \mathrm{~N}$ para este nível de deslocamento. Neste ensaio também ocorreu o escorregamento do modelo. Em seguida procedeu-se o descarregamento, e a flecha residual registrada foi de 7,69 $\mathrm{mm}$. As curvas de carregamento e de descarregamento são ilustradas na figura 8.9. 


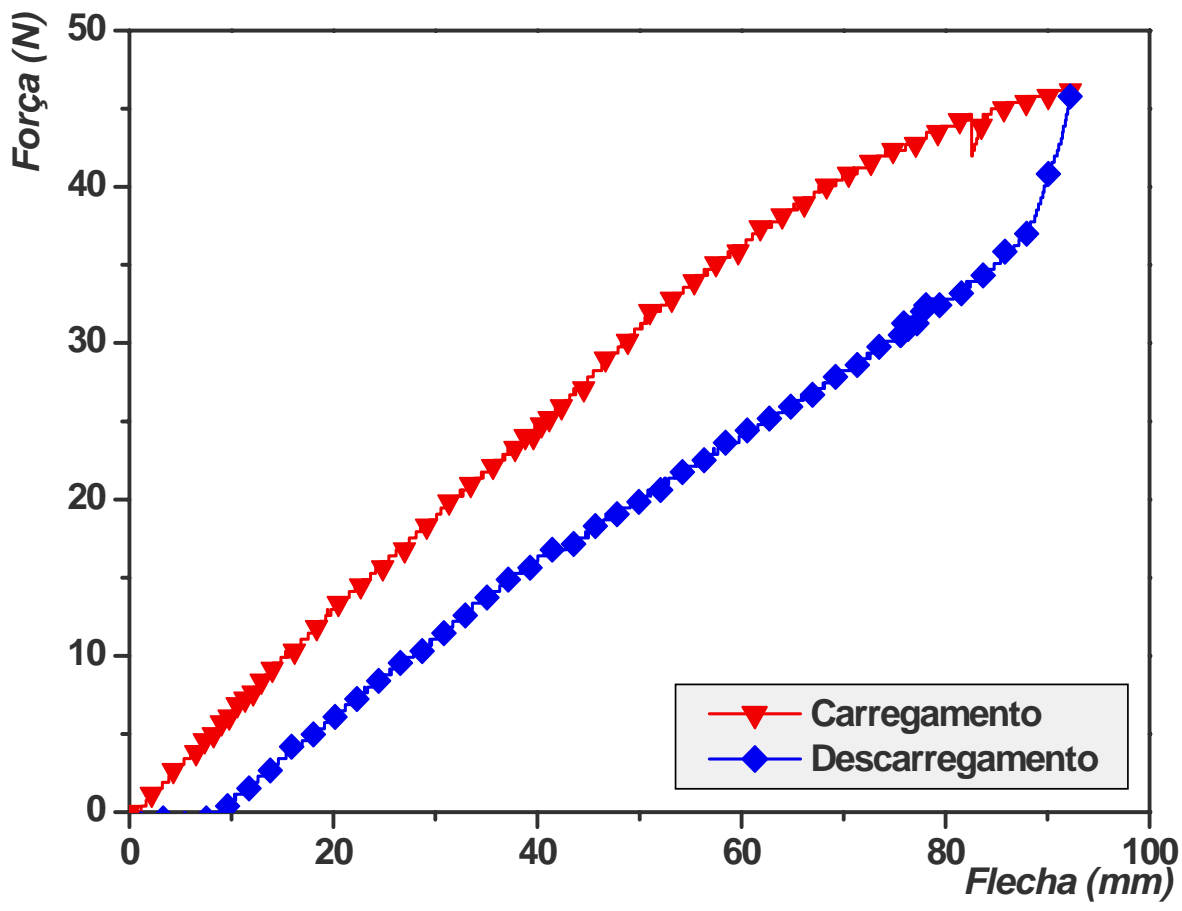

Figura 8.9 - Curva força versus flecha do ensaio de flexão na cruzeta de seção 3.

A tabela 8.10 traz os resultados obtidos no ensaio, assim como uma previsão da resistência e da flecha do protótipo.

Tabela 8.10 - Valores encontrados no ensaio do modelo e previsão de resultados para o protótipo.

\begin{tabular}{c|c|c|c|c|c}
\hline \multicolumn{3}{c|}{$\begin{array}{c}\text { Modelo polimérico } \\
\text { (comprimento de 800m) }\end{array}$} & \multicolumn{3}{c}{$\begin{array}{c}\text { Protótipo } \\
\text { (comprimento de 2000mm) }\end{array}$} \\
\hline Força (N) & Flecha (mm) & $\begin{array}{c}\text { Flecha } \\
\text { residual } \\
(\mathbf{m m})\end{array}$ & Força (N) & Flecha (mm) & $\begin{array}{c}\text { Flecha } \\
\text { residual } \\
(\mathbf{m m})\end{array}$ \\
\hline 461,58 & 92,25 & 3,38 & 2884,88 & 230,63 & 8,45 \\
\hline
\end{tabular}

Visando a comparação de alguns parâmetros da norma de madeira (e.g, carregamento e flecha) com os resultados experimentais obtidos, faz-se a alteração do modelo estático, obtendo-se os valores apresentados na tabela 8.11.

Tabela 8.11 - Previsão de resultados para modelo e protótipo, após correção do esquema estático.

\begin{tabular}{|c|c|c|c|c|c|}
\hline \multicolumn{3}{|c|}{$\begin{array}{c}\text { Modelo polimérico } \\
\text { (comprimento de } 800 \mathrm{~mm} \text { ) }\end{array}$} & \multicolumn{3}{|c|}{$\begin{array}{c}\text { Protótipo } \\
\text { (comprimento de } 2000 \mathrm{~mm} \text { ) }\end{array}$} \\
\hline Força (N) & Flecha (mm) & $\begin{array}{c}\text { Flecha } \\
\text { residual } \\
(\mathrm{mm})\end{array}$ & Força (N) & Flecha (mm) & $\begin{array}{c}\text { Flecha } \\
\text { residual } \\
(\mathrm{mm})\end{array}$ \\
\hline 230,79 & 46,13 & 1,69 & 1442,44 & 115,32 & 4,23 \\
\hline
\end{tabular}

Um protótipo de PU teria seção transversal de $100 \mathrm{~mm} \times 100 \mathrm{~mm}$, comprimento de 2000mm e apresentaria, para o nível de deslocamento $115,32 \mathrm{~mm}$, um carregamento admissível de $1442,44 \mathrm{~N}$, tendo, assim, um carregamento nominal inferior e flecha máxima superior aos valores estipulados pela norma NBR 8458:1984. 


\section{d) Seção transversal tipo 5}

A seção 5 também é quadrada e maciça. Entretanto, difere da seção 1 em relação a suas dimensões, uma vez que a cruzeta tem $25,4 \mathrm{~mm} \times 25,4 \mathrm{~mm} \times 600 \mathrm{~mm}$. Seu ensaio de flexão foi conduzido até a flecha de 90,89 mm, obtendo-se uma força de 267,03N para este nível de deslocamento. Em seguida procedeu-se o descarregamento, e a flecha residual registrada foi de $6,90 \mathrm{~mm}$. As curvas de carregamento e de descarregamento são ilustradas na figura 8.10.

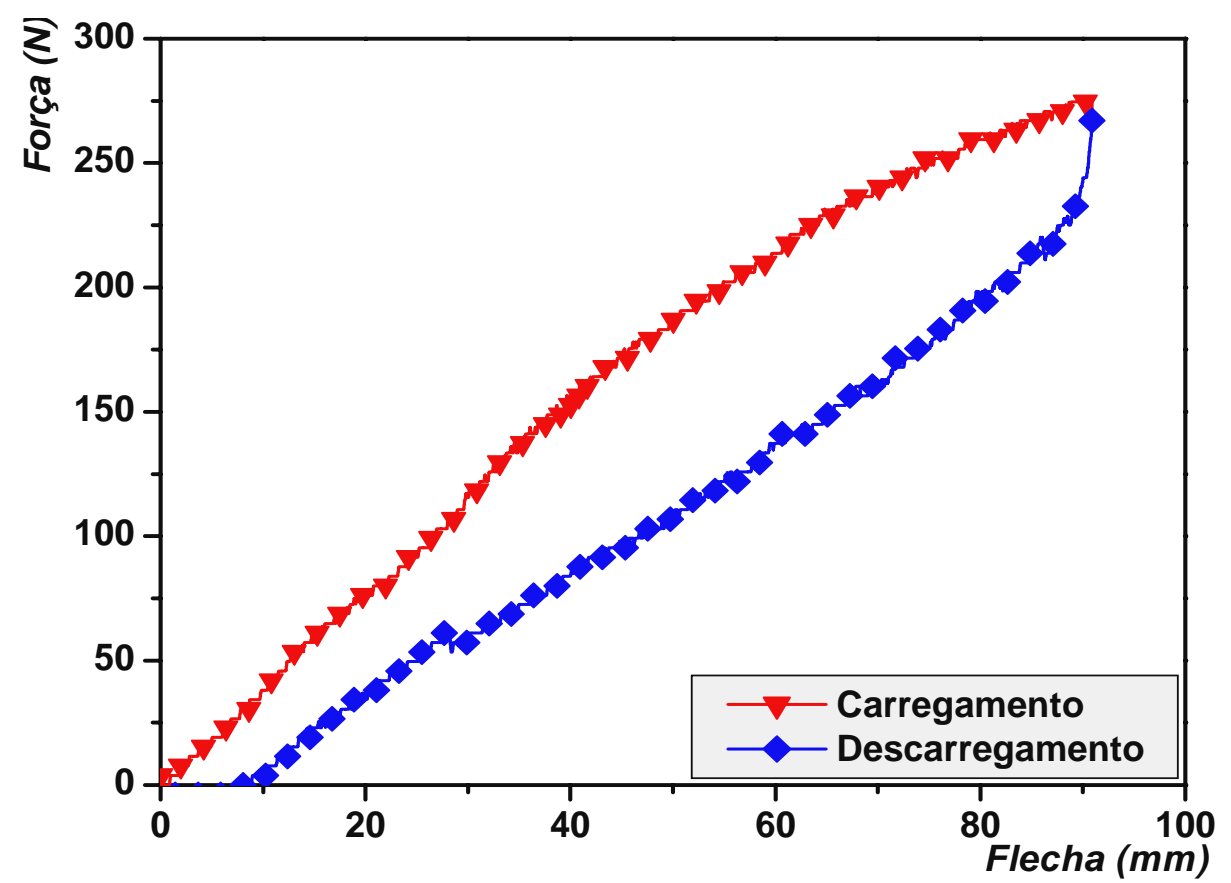

Figura 8.10 - Curva força versus flecha do ensaio de flexão na cruzeta de seção 5.

A tabela 8.12 traz os resultados obtidos no ensaio, assim como uma previsão da resistência e da flecha do protótipo.

Tabela 8.12 - Valores encontrados no ensaio do modelo e previsão de resultados para o protótipo.

\begin{tabular}{c|c|c|c|c|c}
\hline \multicolumn{3}{c|}{ Modelo polimérico } & \multicolumn{3}{c}{$\begin{array}{c}\text { Protótipo } \\
\text { (comprimento de 600mm) }\end{array}$} \\
\hline Força (N) & Flecha (mm) & $\begin{array}{c}\text { Flecha } \\
\text { residual } \\
(\mathbf{m m})\end{array}$ & Força (N) & Flecha (mm) & $\begin{array}{c}\text { Flecha } \\
\text { residual } \\
\text { (mm) }\end{array}$ \\
\hline 267,03 & 90,89 & 6,90 & 2961,07 & 302,66 & 22,98 \\
\hline
\end{tabular}

Com o objetivo de comparar os resultados experimentais com os descritos na norma de madeira, faz-se a correção do esquema estático, apresentando-se seus resultados na tabela 8.13.

Tabela 8.13 - Previsão de resultados para modelo e protótipo, após a correção do esquema estático.

\begin{tabular}{c|c|c|c|c|c}
\hline \multicolumn{3}{c|}{$\begin{array}{c}\text { Modelo polimérico } \\
\text { (comprimento de 600mm) }\end{array}$} & \multicolumn{3}{c}{$\begin{array}{c}\text { Protótipo } \\
\text { (comprimento de 2000 mm) }\end{array}$} \\
\hline Força (N) & Flecha (mm) & $\begin{array}{c}\text { Flecha } \\
\text { residual } \\
(\mathbf{m m})\end{array}$ & Força (N) & Flecha (mm) & $\begin{array}{c}\text { Flecha } \\
\text { residual } \\
(\mathbf{m m})\end{array}$ \\
\hline 133,52 & 45,45 & 3,45 & 1480,54 & 151,33 & 11,49 \\
\hline
\end{tabular}


Percebe-se que o material utilizado na confecção dos modelos apresenta grandes deformações quando submetido a carregamento. Para uma força aplicada de $1480,54 \mathrm{~N}$, a flecha prevista para um protótipo de PU, com seção retangular maciça e dimensões $84,67 \mathrm{~mm} \times 84,67 \mathrm{~mm} \times 2000 \mathrm{~mm}$, é de 151,33mm. Segundo a NBR 8458:1984, para um carregamento nominal de $4000 \mathrm{~N}$, a flecha máxima admitida em uma cruzeta de madeira é de $75 \mathrm{~mm}$, ou seja, o protótipo polimérico apresentaria, também, uma flecha superior à máxima permitida pela NBR 8458:1984.

\section{e) Seção transversal tipo 10}

A seção 10 é circular, vazada (com sete furos). Possui diâmetro de $26,5 \mathrm{~mm}$ e comprimento de $600 \mathrm{~mm}$. Seu ensaio de flexão foi conduzido até a flecha de $58,73 \mathrm{~mm}$, obtendo-se uma força de $76,30 \mathrm{~N}$ para este nível de deslocamento. Para níveis mais elevados de carregamento ocorreu o escorregamento do modelo, o que impossibilitou o registro da curva de descarregamento. A curva de carregamento é ilustrada na figura 8.11.

A tabela 8.14 traz os resultados obtidos no ensaio, assim como uma previsão da resistência e da flecha do protótipo.

Tabela 8.14 - Valores encontrados no ensaio do modelo e previsão de resultados para o protótipo.

\begin{tabular}{c|c|c|c|c|c}
\hline \multicolumn{3}{c|}{$\begin{array}{c}\text { Modelo polimérico } \\
\text { (comprimento de 600m) }\end{array}$} & \multicolumn{3}{c}{$\begin{array}{c}\text { Protótipo } \\
\text { (comprimento de 2000mm) }\end{array}$} \\
\hline Força (N) & Flecha (mm) & $\begin{array}{c}\text { Flecha } \\
\text { residual } \\
(\mathbf{m m})\end{array}$ & Força (N) & Flecha (mm) & $\begin{array}{c}\text { Flecha } \\
\text { residual } \\
(\mathrm{mm})\end{array}$ \\
\hline 76,30 & 58,73 & ------- & 846,08 & 195,57 & ------- \\
\hline
\end{tabular}

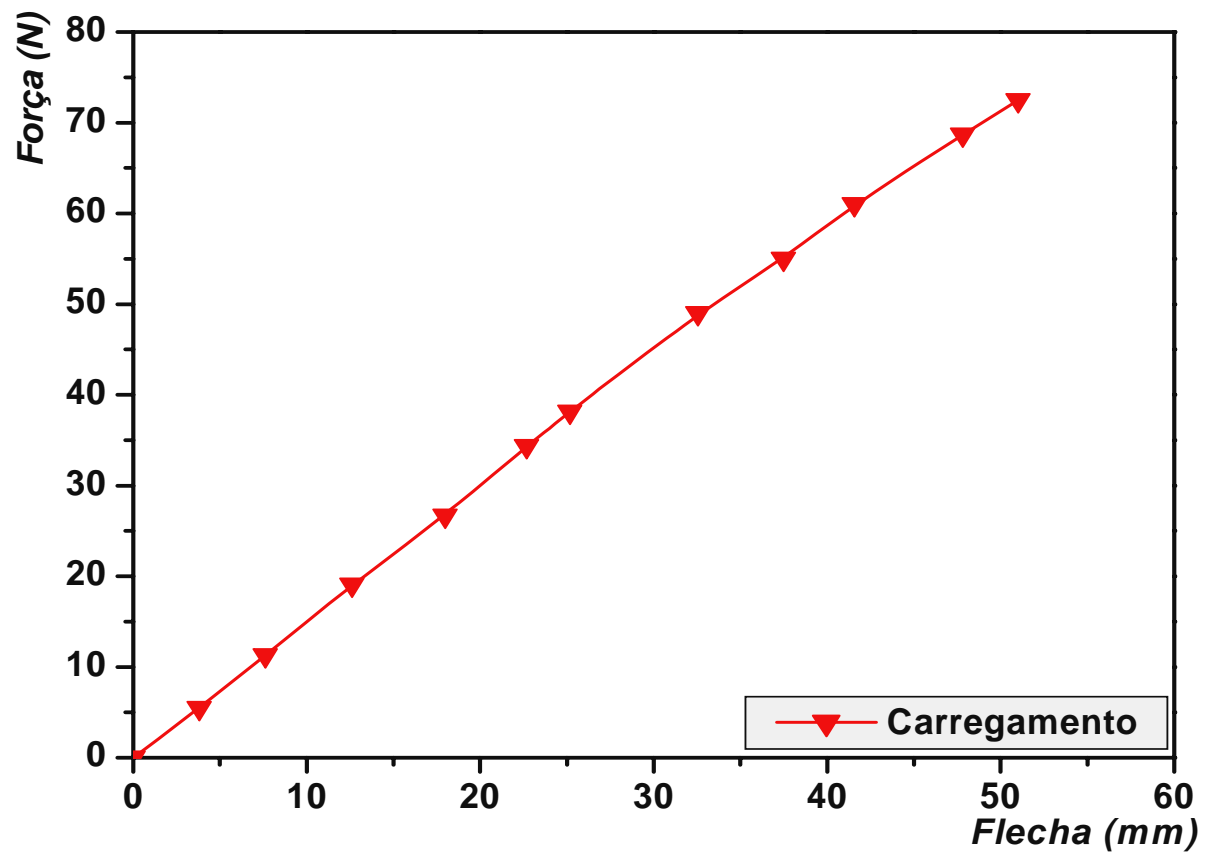

Figura 8.11 - Curva força versus flecha do ensaio de flexão na cruzeta de seção 10. 
Visando a comparação de alguns parâmetros da norma de madeira (e.g, carregamento e flecha) com os resultados experimentais obtidos, faz-se a alteração do modelo estático, obtendo-se os valores apresentados na tabela 8.15.

Tabela 8.15 - Previsão de resultados para modelo e protótipo, após correção do esquema estático.

\begin{tabular}{c|c|c|c|c|c}
\hline \multicolumn{3}{c|}{$\begin{array}{c}\text { Modelo polimérico } \\
\text { (comprimento de 600mm) }\end{array}$} & \multicolumn{3}{c}{$\begin{array}{c}\text { Protótipo } \\
\text { (comprimento de 2000mm) }\end{array}$} \\
\hline Força (N) & Flecha (mm) & $\begin{array}{c}\text { Flecha } \\
\text { residual } \\
(\mathbf{m m})\end{array}$ & Força (N) & Flecha (mm) & $\begin{array}{c}\text { Flecha } \\
\text { residual } \\
(\mathbf{m m})\end{array}$ \\
\hline 38,15 & 29,37 & ------- & 423,04 & 97,79 & ------ \\
\hline
\end{tabular}

Para uma força aplicada de 423,04N, em um protótipo com seção semelhante à do modelo utilizado nesse ensaio, com diâmetro de $88,3 \mathrm{~mm}$ e comprimento de $2000 \mathrm{~mm}$, a flecha prevista é de 97,79mm. Segundo a NBR 8458:1984, para um carregamento nominal de $4000 \mathrm{~N}$, a flecha máxima admitida em uma cruzeta de madeira é de $75 \mathrm{~mm}$, ou seja, o protótipo polimérico apresentaria, também, uma flecha muito superior à máxima permitida pela norma.

\subsubsection{Comparação dos resultados experimentais com os numéricos}

Este segmento procurou analisar o comportamento entre os resultados obtidos nos ensaios experimentais e na análise numérica, validando, assim, os modelos numéricos utilizados. Os modelos numéricos de cruzetas poliméricas tiveram um comportamento satisfatório sendo que, na maioria dos casos, apresentaram comportamento semelhante aos verificados experimentalmente. Vale salientar que os modelos de comportamento dos materiais (convencionais e corrigidos), as malhas em elementos finitos e os modelos utilizados nessas análises são semelhantes às apresentadas no capítulo 7 - figuras 7.6 e 7.8, respectivamente.

\section{a) Seção transversal tipo 1}

Apresenta-se a comparação entre os resultados obtidos na análise experimental e numérica para a cruzeta com seção transversal do tipo 1 (Figura 8.12).

Percebe-se que o modelo numérico pode representar satisfatoriamente o comportamento do ensaio de flexão. Comparando-se o ensaio experimental (com idade 15 dias) com a análise numérica e adotando-se uma flecha de referência de $90 \mathrm{~mm}$, têm-se como resultados forças de $782,02 \mathrm{~N}$ e $952,78 \mathrm{~N}$, respectivamente, obtendo-se um erro de $21,84 \%$. A comparação do ensaio experimental, aos 30 dias, com a análise numérica, adotando-se como flecha de referência 70 mm, obtêm-se forças de $793,47 \mathrm{~N}$ e $815 \mathrm{~N}$, respectivamente, um erro de $2,71 \%$. 

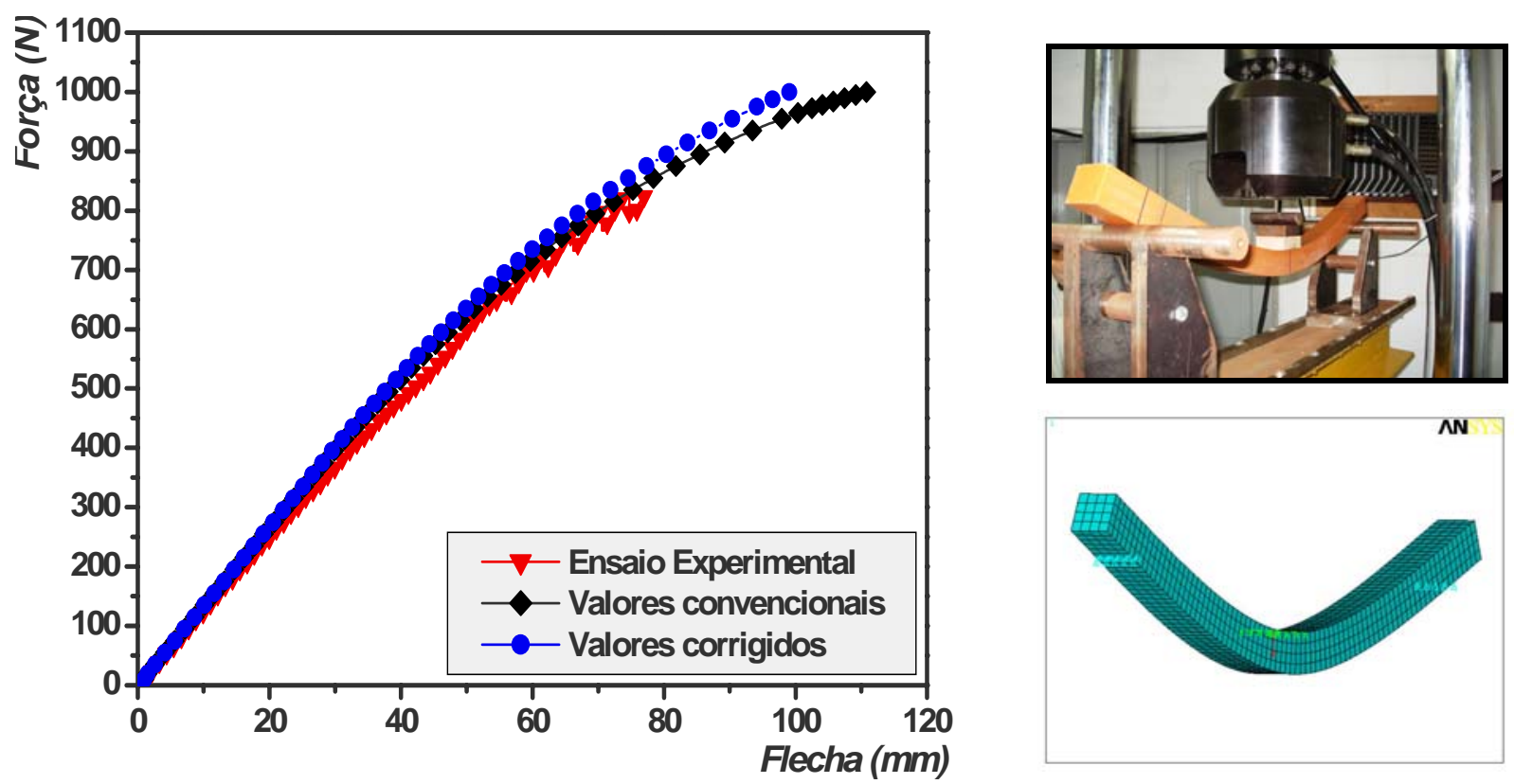

Figura 8.12 - Comparação das curvas obtidas no ensaio de flexão com o resultado numérico (Solid45) do modelo de cruzeta polimérica - seção 1.

Vale a pena acrescentar que o modelo numérico apresenta excelente resultado quando o material possui comportamento linear (zona elástica), divergindo quando ele inicia sua plastificação.

A resposta do programa em elementos finitos fornece o deslocamento com sinal negativo (-), nas unidades Newtons (carregamento) e milímetros (flecha). Pode-se perceber que o modelo, devido ao material utilizado na confecção, é muito flexível e deformável e que um protótipo apresentaria flechas superiores às permitidas pela norma de cruzetas de madeira.

A plastificação de elementos dúcteis pode ser dada, por exemplo, adotando-se o critério da energia de distorção (ou de mudança de forma), também conhecido como critério de Von Mises. Segundo esse critério, a falha em um elemento ocorre sempre que a energia de distorção, verificada num ponto qualquer da peça, atingir o valor da energia de distorção presente no corpo-de-prova de tração, quando este entra em escoamento. Uma visão geral da magnitude das tensões de Von Mises, ao longo do carregamento, é apresentada na Figura 8.13, lembrando que a tensão média de escoamento do material é 9,90 MPa.

A progressão mostra que, quando aplicado um carregamento de $875 \mathrm{~N}$, a tensão do elemento é de aproximadamente $9,90 \mathrm{MPa}$, semelhante à de escoamento do material à tração. $\mathrm{A}$ partir desse ponto a estrutura entra em regime plástico, até alcançar um valor máximo de 10,44MPa, a partir do qual o modelo não mais apresentou convergência, em correspondência a uma tolerância de 0,005 relativa às diferenças entre deslocamentos sucessivos. 

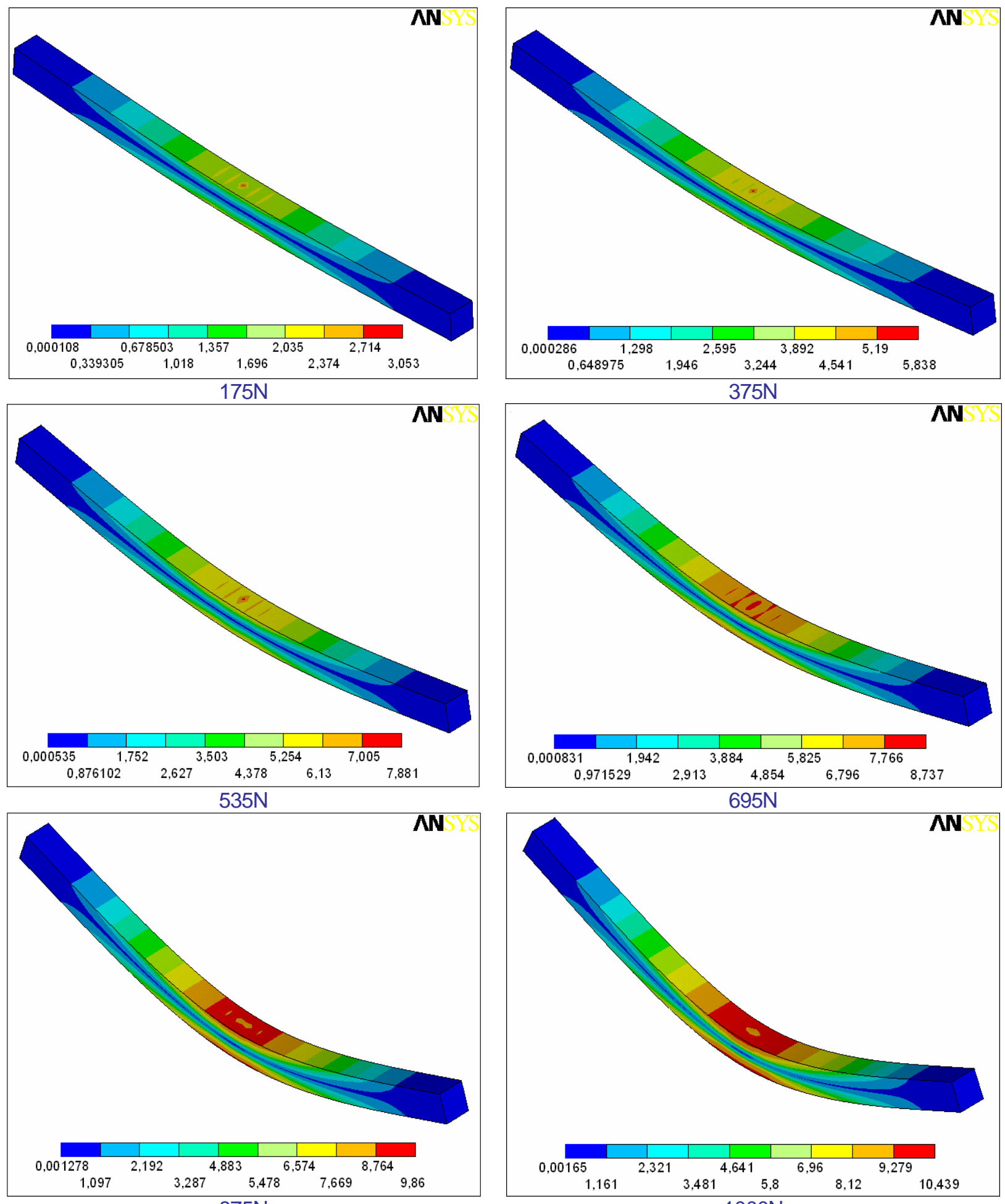

Figura 8.13 - Evolução das tensões de Von Mises ao longo do carregamento - seção 1.

\section{b) Seção transversal tipo 2}

A figura 8.14 traz as curvas força versus flecha obtidas no ensaio de flexão e na simulação numérica do modelo de cruzeta com seção transversal tipo 2 (vazada, com um furo). 

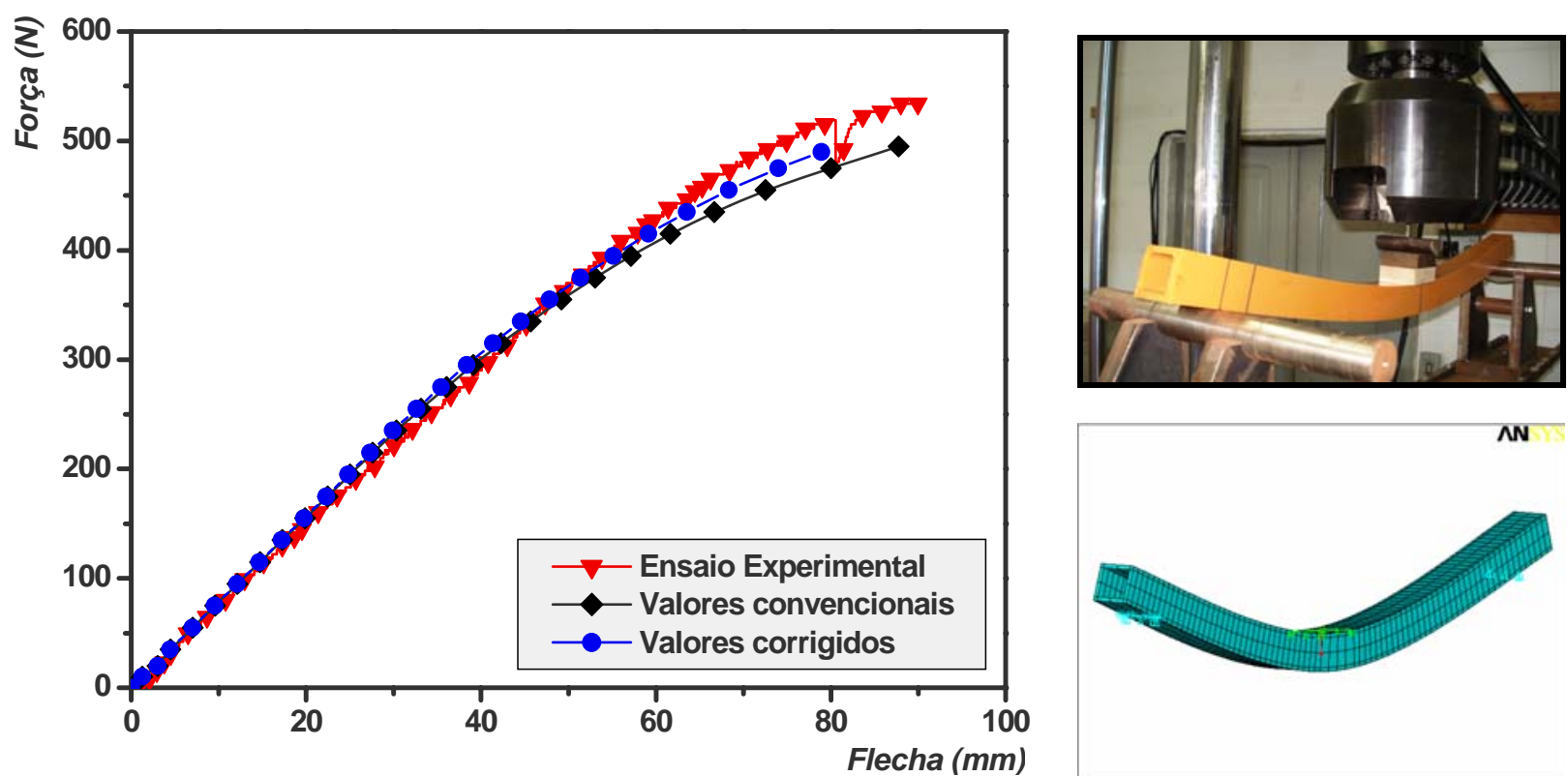

Figura 8.14 - Comparação das curvas obtidas no ensaio de flexão com o resultado numérico (Solid45) do modelo de cruzeta polimérica - seção 2.

Comparando-se o ensaio experimental com a análise numérica e adotando-se uma flecha de referência de $70 \mathrm{~mm}$, têm-se como resultados forças de 480,66N e 460,84N, respectivamente, obtendo-se um erro de 4,30\%. O modelo numérico, assim como para a análise numérica da seção 1 , também apresenta excelente resultado quando o material possui comportamento linear (zona elástica), divergindo quando ele inicia sua plastificação. Uma visão geral da magnitude das tensões de Von Mises, ao longo do carregamento, é apresentada na Figura 8.15.

Percebe-se que esse elemento atinge a tensão de escoamento do material com um carregamento de aproximadamente $400 \mathrm{~N}$, passando, então, a um regime plástico (Fig. 8.14). Quando comparado à seção 1, percebe-se claramente a perda de resistência provocada pelo tipo de seção transversal utilizada nessa análise. A seção alcançou valor máximo de 10,17MPa, a partir do qual o modelo não mais apresentou convergência, em correspondência a uma tolerância de 0,005 relativa às diferenças entre deslocamentos sucessivos. 

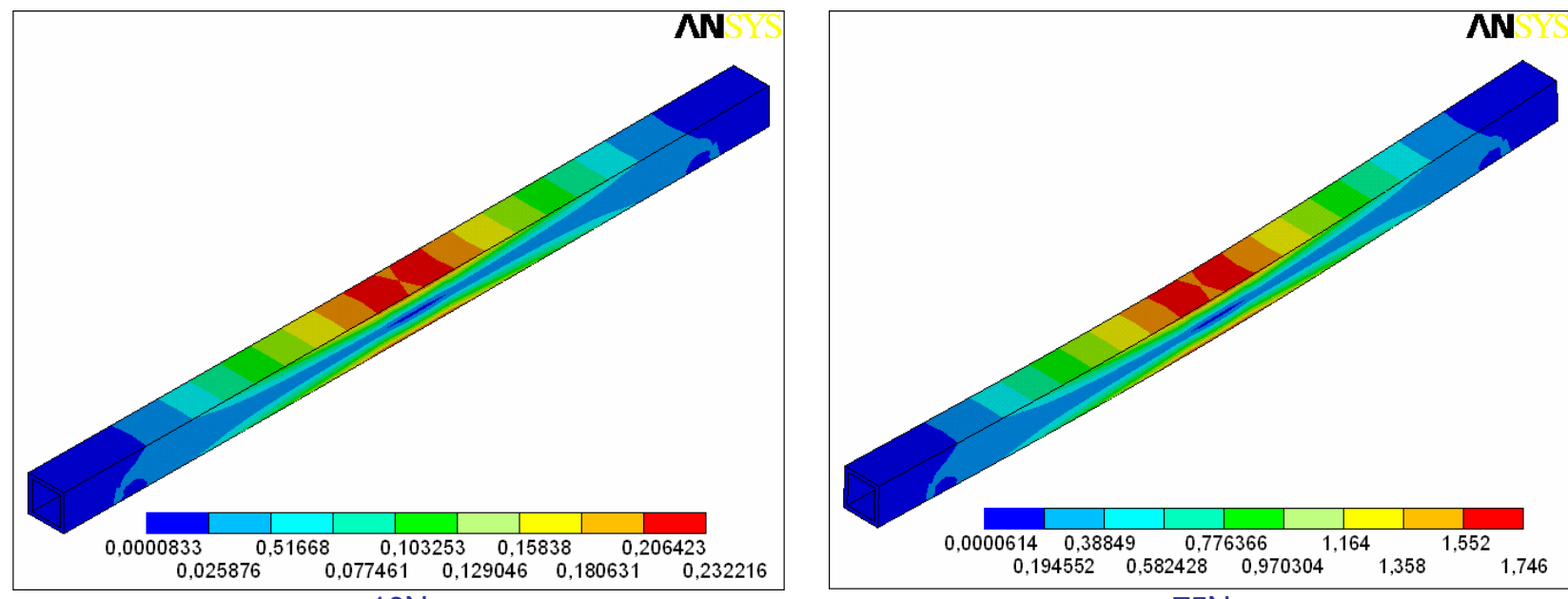
$10 \mathrm{~N}$
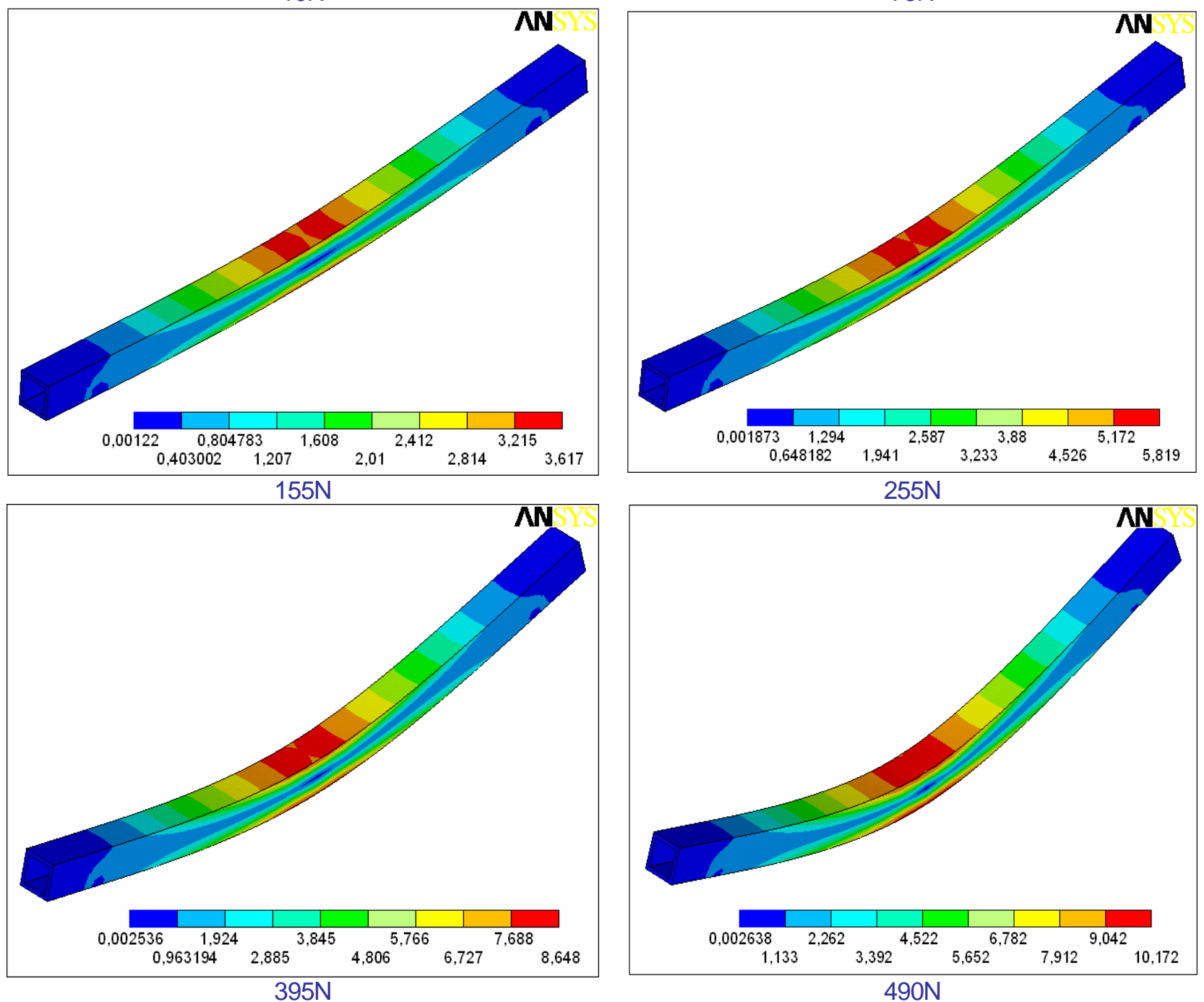

Figura 8.15 - Evolução das tensões de Von Mises ao longo do carregamento - seção 2.

\section{c) Seção transversal tipo 3}

A figura 8.16 traz as curvas força versus flecha obtidas no ensaio de flexão e na simulação numérica do modelo de cruzeta com seção 3 - vazada com quatro furos. 

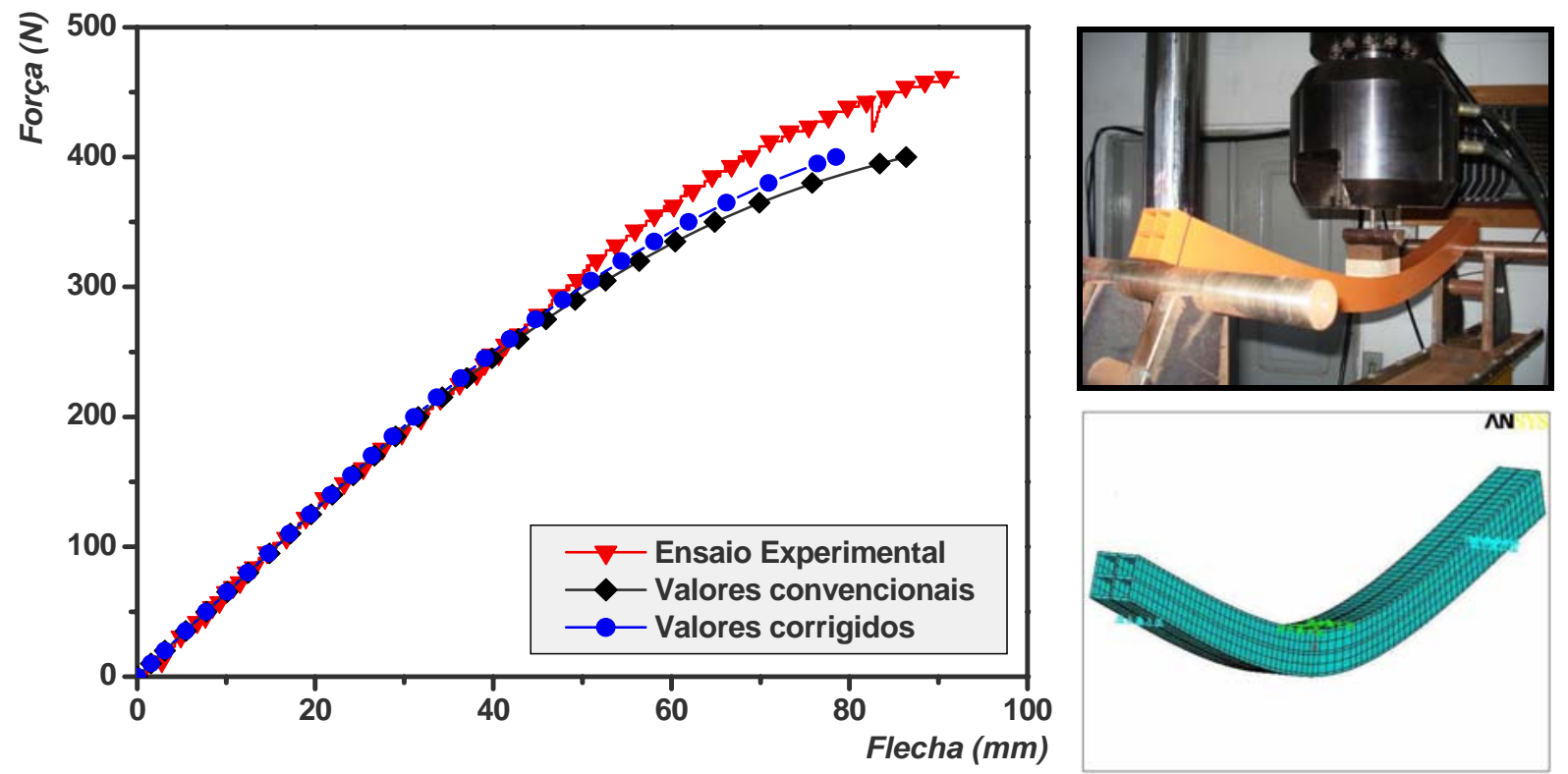

Figura 8.16 - Comparação das curvas obtidas no ensaio de flexão com o resultado numérico (Solid 45) do modelo de cruzeta polimérica - seção 3.

Comparando-se o ensaio experimental com a análise numérica e adotando-se uma flecha de referência de $75 \mathrm{~mm}$, têm-se como resultados forças de 423,44N e 392,06N, respectivamente, obtendo-se um erro de $8 \%$. A Figura 8.17 ilustra o desenvolvimento das tensões de Von Mises, ao longo do carregamento do elemento.
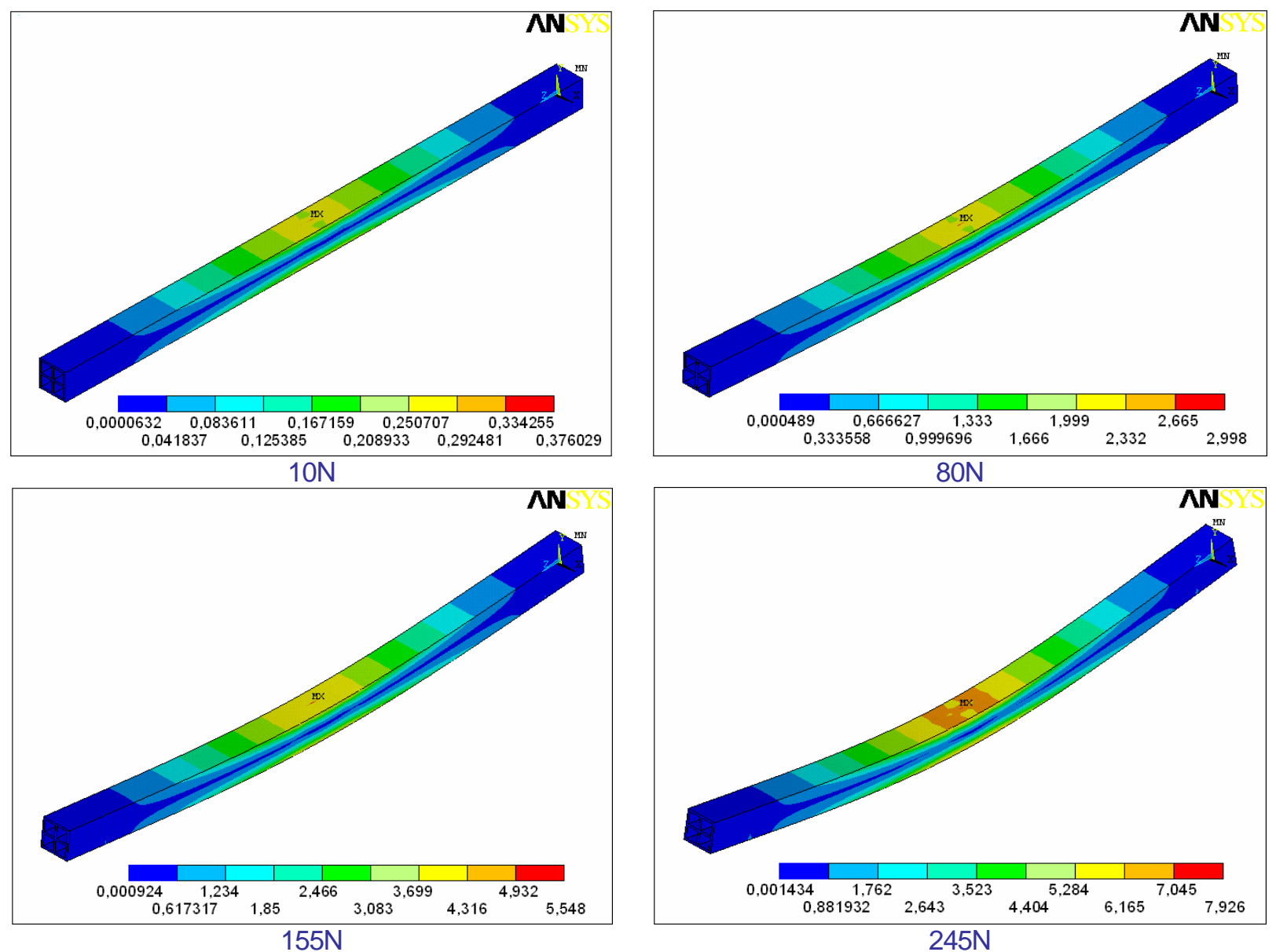

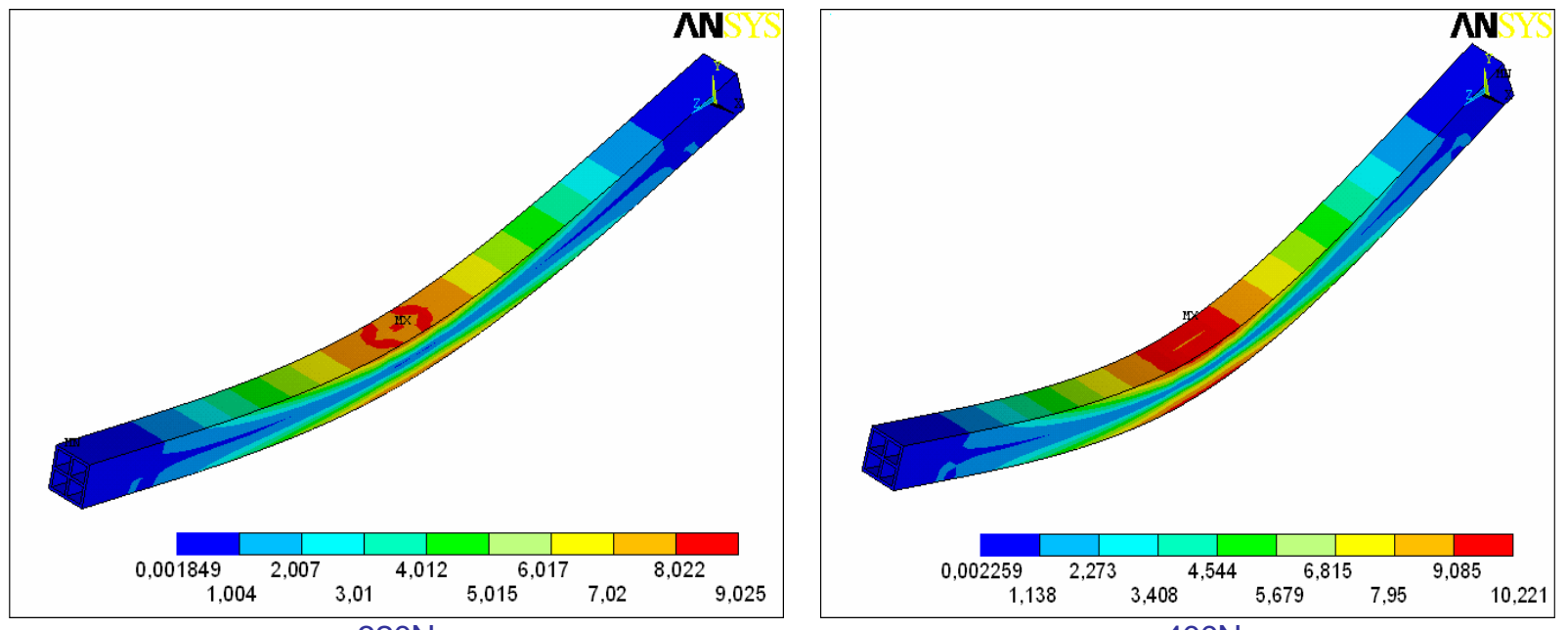

Figura 8.17 - Evolução das tensões de Von Mises ao longo do carregamento - seção 3.

Esse elemento atinge a tensão de escoamento do material com um carregamento de aproximadamente $350 \mathrm{~N}$, o que pode ser confirmado nas curvas de comparação entre os resultados obtidos na análise experimental e na numérica (Fig. 8.16). Percebe-se que essa seção, quando comparada à seção 2, apresenta-se mais deformável e, conseqüentemente, admite menor capacidade de carga. A seção alcançou valor máximo de 10,22MPa, a partir do qual o modelo não mais apresentou convergência, em correspondência a uma tolerância de 0,005 relativa às diferenças entre deslocamentos sucessivos.

\section{d) Seção transversal tipo 5}

Apresenta-se a comparação entre os resultados obtidos na análise experimental e na numérica para a cruzeta com seção transversal do tipo 5 (Figura 8.18).
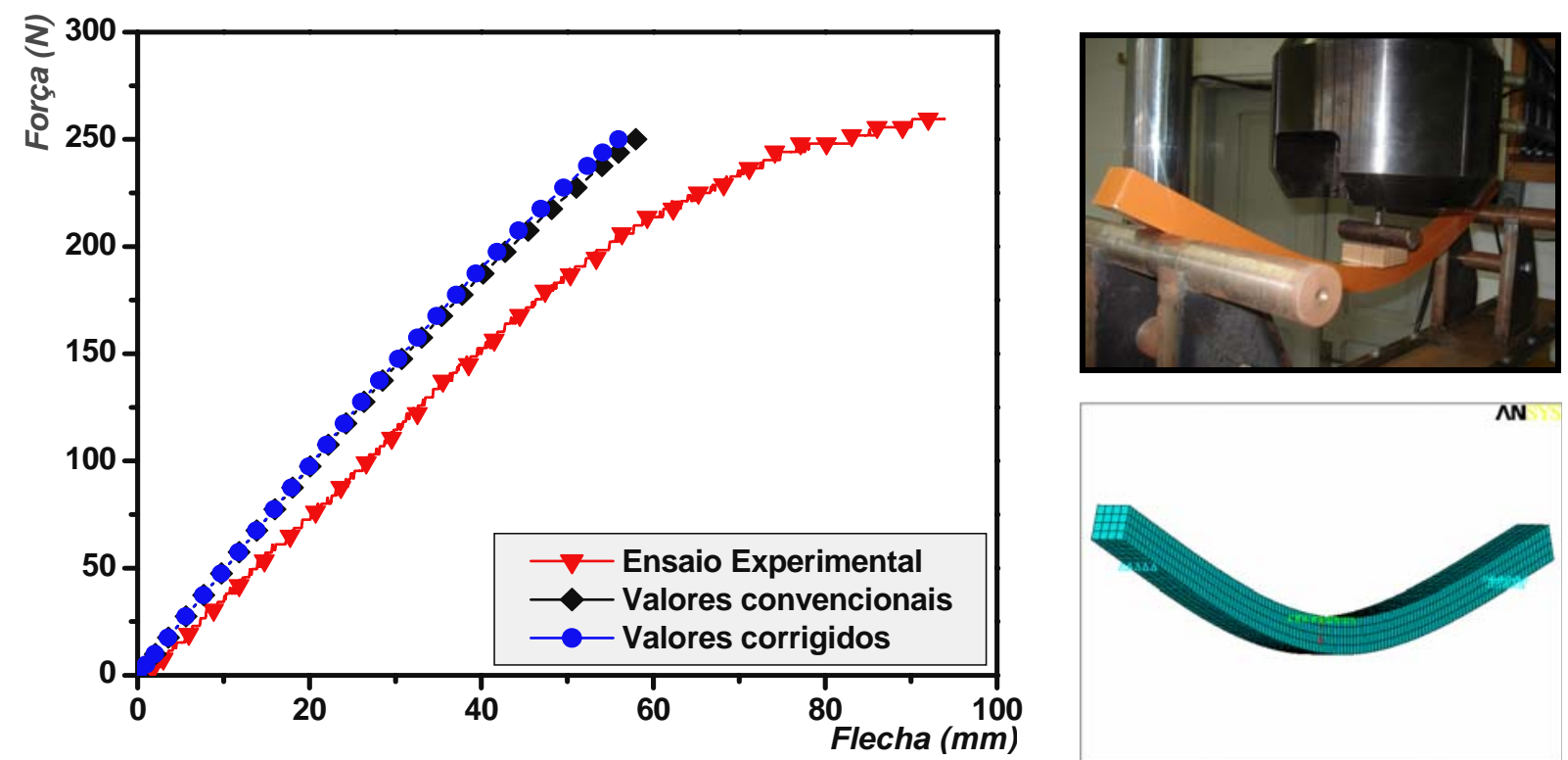

Figura 8.18 - Comparação das curvas obtidas no ensaio de flexão com o resultado numérico (Solid45) do modelo de cruzeta polimérica - seção 5. 
Seu ensaio foi realizado com 20 dias, apresentando assim um comportamento diferente do esperado. O modelo numérico, como visto nos elementos anteriormente apresentados, tem boa representatividade no caso das cruzetas e simula o comportamento de uma cruzeta com idade de 30 dias.

\section{e) Seção transversal tipo 10}

Para finalizar os ensaios com modelos de cruzetas poliméricas, foi feito um modelo circular, vazado, com sete furos e comprimento de $600 \mathrm{~mm}$. As curvas força versus flecha do ensaio de flexão, assim como os resultados numéricos, são apresentados na figura 8.19.
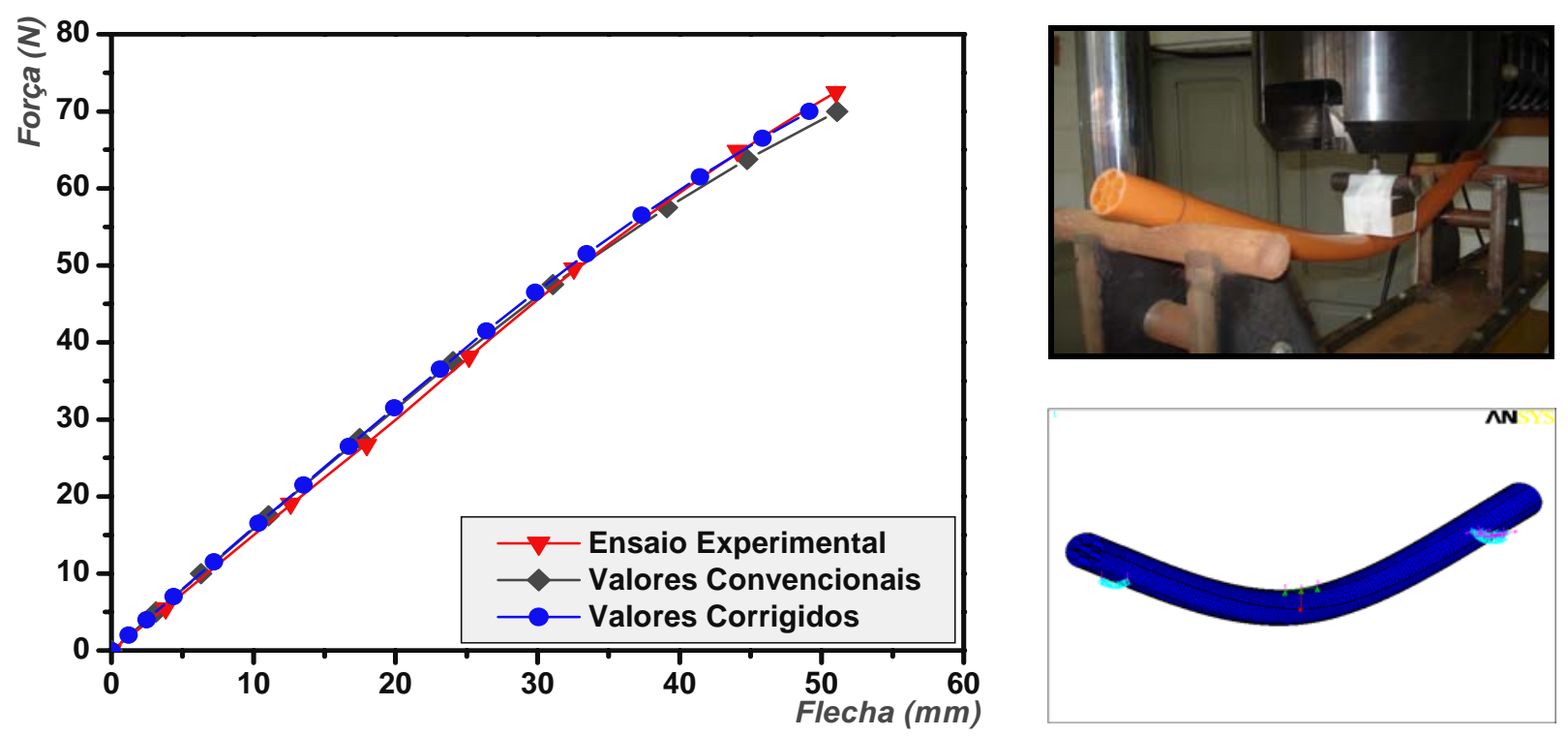

Figura 8.19 - Comparação das curvas obtidas no ensaio de flexão com o resultado numérico (Solid45) do modelo de cruzeta polimérica - seção 10.

Comparando-se o ensaio experimental com a análise numérica, para uma flecha de referência de $70 \mathrm{~mm}$, têm-se como resultados forças de $51,01 \mathrm{~N}$ e $51,08 \mathrm{~N}$, respectivamente, obtendo-se um erro de 0,14\%. A Figura 8.20 ilustra o desenvolvimento das tensões de Von Mises, ao longo do carregamento do elemento.
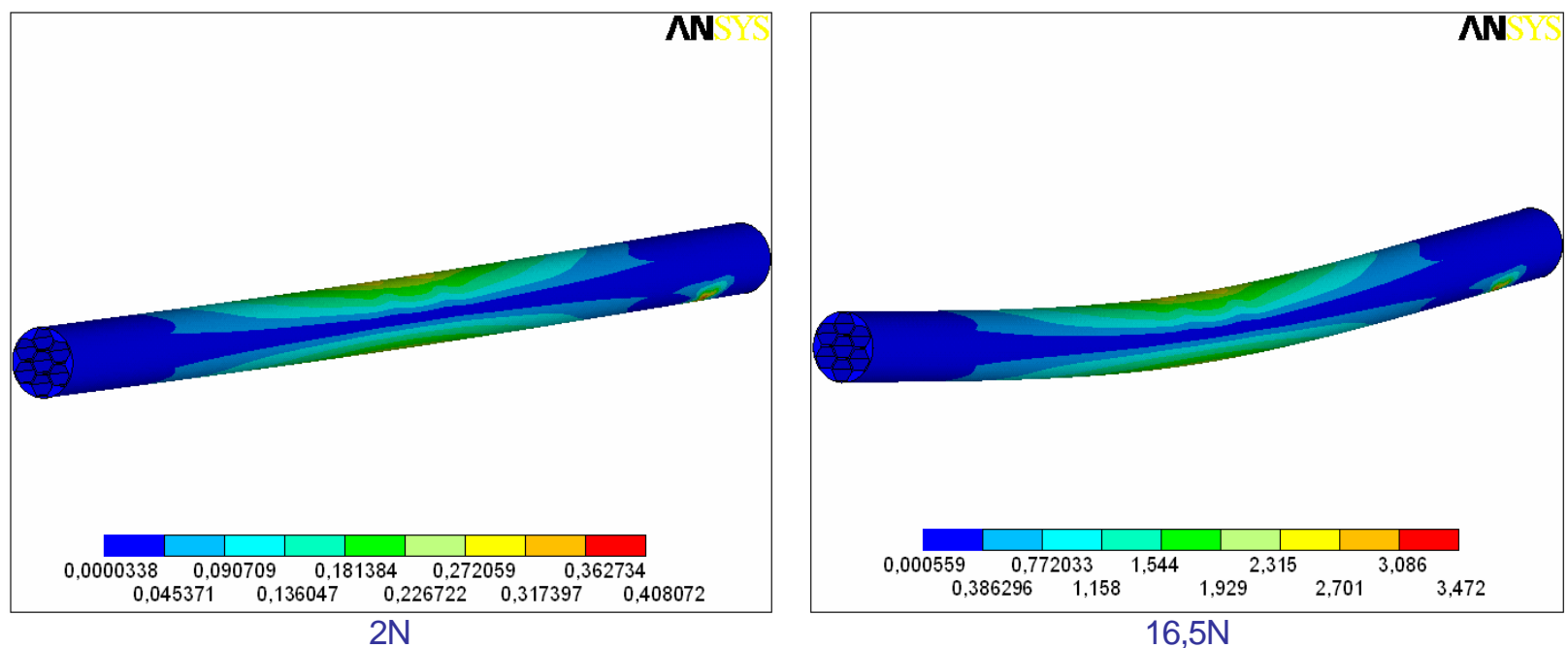

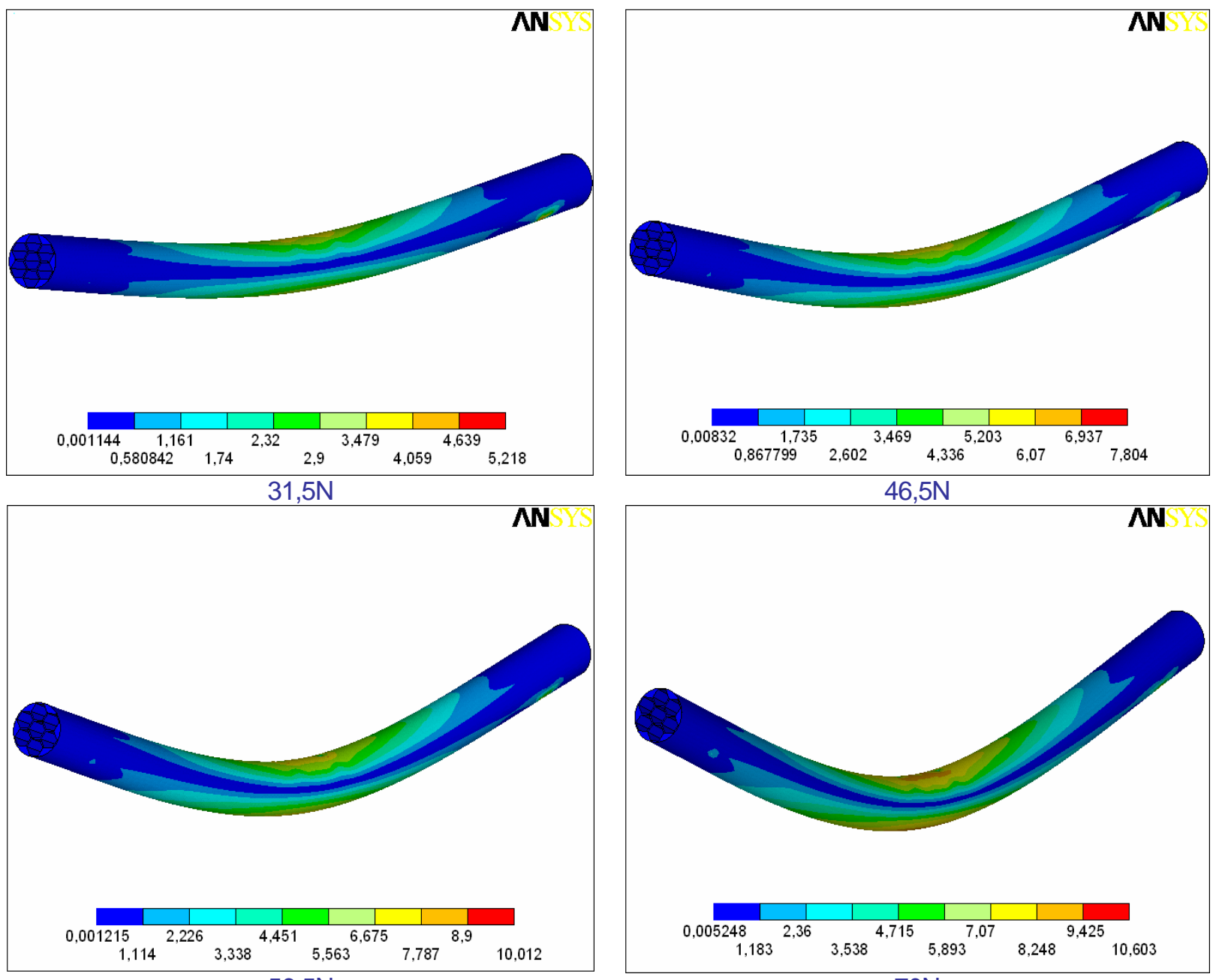

Figura 8.20 - Evolução das tensões de Von Mises ao longo do carregamento - seção 10.

Esse elemento atinge a tensão de escoamento do material com um carregamento de aproximadamente 50N (Fig. 8.19). A seção alcançou valor máximo de 10,60MPa, a partir do qual o modelo não mais apresentou convergência, em correspondência a uma tolerância de 0,005 relativa às diferenças entre deslocamentos sucessivos.

Como foi constatado neste trabalho, os modelos numéricos adotados representam, com boa precisão, o comportamento dos modelos de cruzetas poliméricas. Os resultados obtidos nos ensaios experimentais, quando comparados aos da análise numérica, apresentam valores bem próximos, validando, assim, os modelos.

Com base nessa constatação, o próximo item aborda a análise numérica referente ao comportamento de mais alguns tipos de cruzetas poliméricas, cujos ensaios experimentais não foram realizados.

\subsubsection{Resultados complementares da análise numérica}

Serão analisados numericamente outros tipos de seções transversais. 


\section{a) Seção transversal tipo 4}

Uma seção transversal adotada neste trabalho é a do tipo colméia. É uma seção vazada com sete furos, o que faz com que ocorra grande economia de material. Os resultados numéricos referentes a essa seção encontram-se ilustrados na figura 8.21.
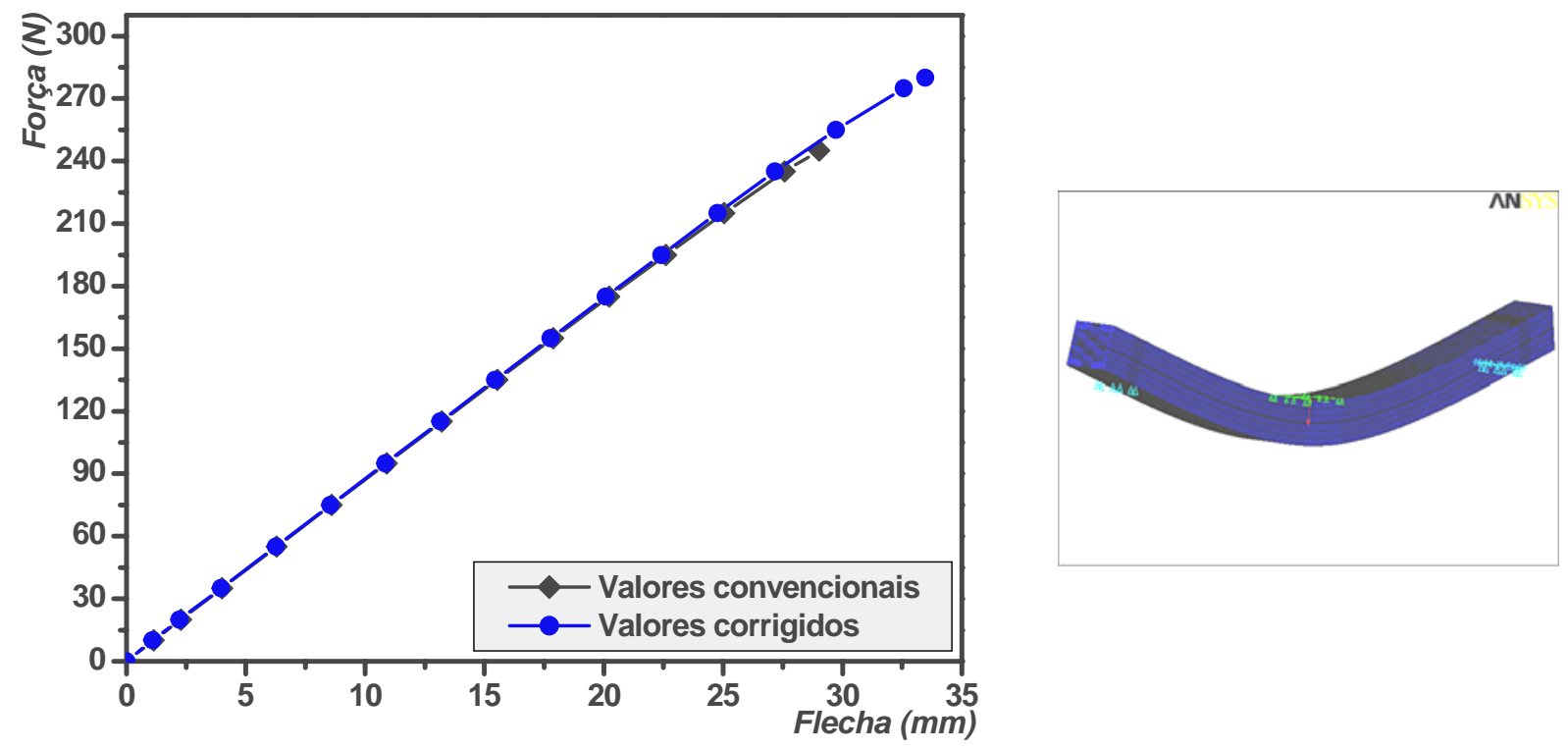

Figura 8.21 - Curvas obtidas na análise numérica, com o elemento finito Solid45, do modelo de cruzeta polimérica - seção 4.

Esse tipo de seção transversal possui um ótimo comportamento quando solicitada à compressão. Entretanto, a economia de material faz com que o elemento fique demasiadamente deformável, o que resulta num desempenho inferior à flexão, quando comparado a outros tipos de seções. O modelo numérico apresenta comportamento similar ao apresentado na figura 8.22.
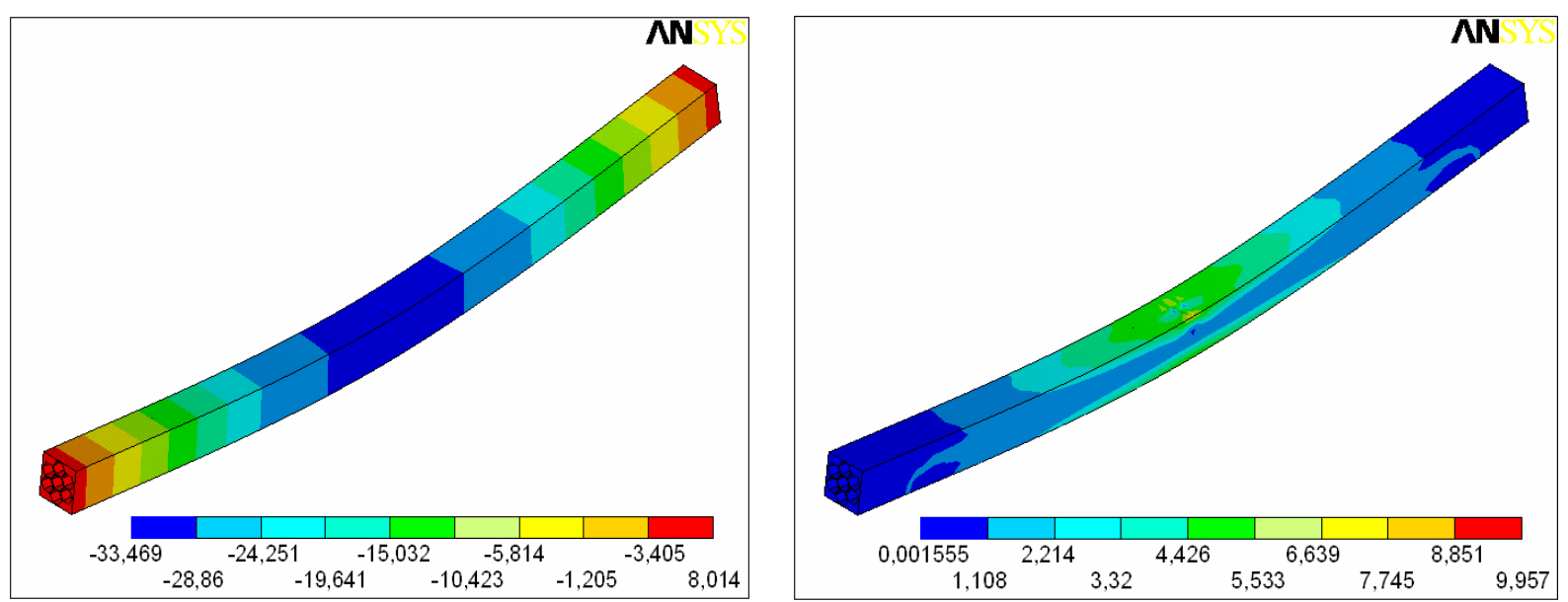

Figura 8.22 - Flecha máxima (a) e tensões de Von Mises (b) para carga de 280N - seção 4.

Essa seção apresentou força e flecha máxima de $280 \mathrm{~N}$ e $33,47 \mathrm{~mm}$, respectivamente. A partir desses valores, o modelo não mais apresentou convergência, em correspondência a uma tolerância de 0,005 relativa às diferenças entre deslocamentos sucessivos. Quando comparado 
aos demais modelos com comprimento de $800 \mathrm{~mm}$, percebe-se que essa seção apresenta um nível de deformação bem próximo aos alcançados pelas do tipo 2 e 3, com força de $240 \mathrm{~N}$ para um nível de deslocamento de 30mm, aproximadamente.

\section{b) Seção transversal tipo 6}

Os resultados apresentados a seguir referem-se à análise numérica de modelos de cruzeta com comprimento de $600 \mathrm{~mm}$. A seção 6 (vazada, com um furo) é semelhante à seção 2, porém, com dimensões reduzidas. As curvas força versus flecha da análise numérica são apresentadas na figura 8.23.
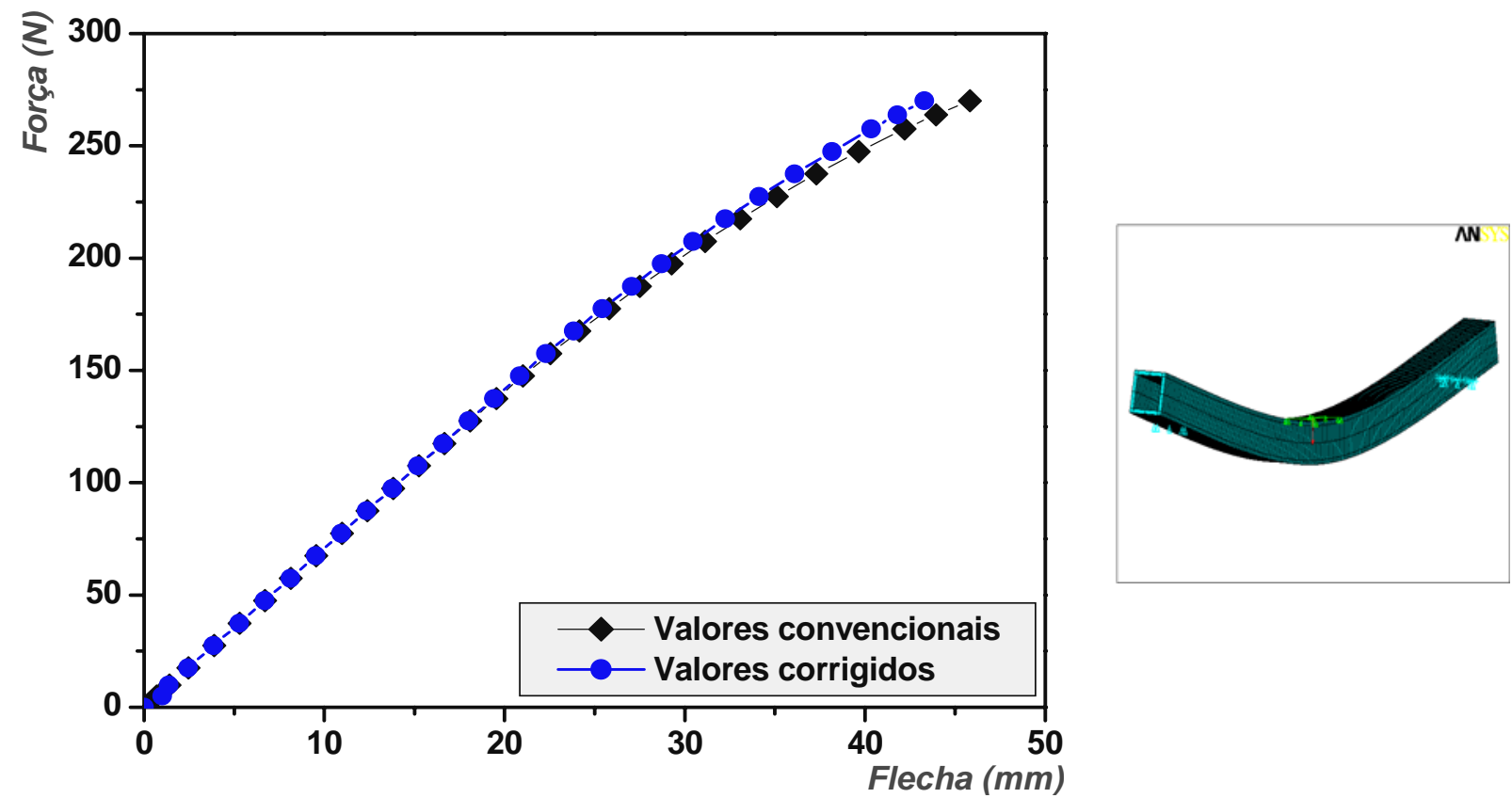

Figura 8.23 - Curvas obtidas na análise numérica, com o elemento finito Solid45, do modelo de cruzeta polimérica - seção 6.

Comparando-se as curvas das seções 6 e 2, percebe-se que o comportamento dos elementos é semelhante. A figura 8.24 apresenta os resultados obtidos na análise numérica desse elemento.

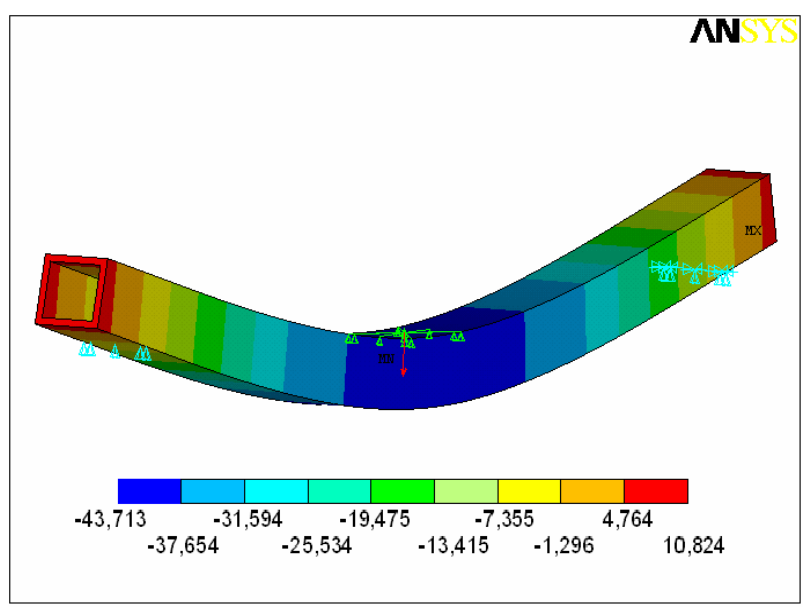

(a)

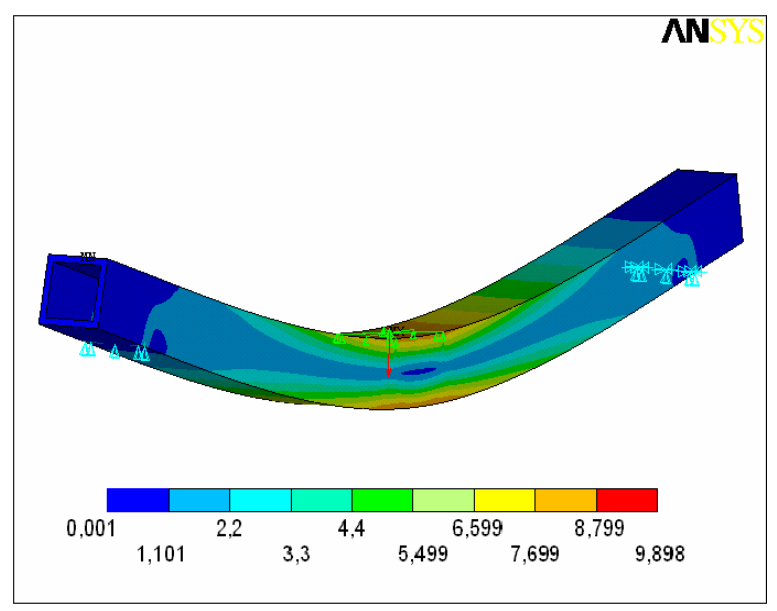

(b)

Figura 8.24 - Flecha máxima (a) e tensões de Von Mises (b) para carga de $270 \mathrm{~N}$ - seção 6. 
Essa seção apresentou carregamento, flecha (máxima) e tensão de 270N, 43,72mm e 9,90MPa, respectivamente. A partir desses valores, o modelo não mais apresentou convergência, em correspondência a uma tolerância de 0,005 relativa às diferenças entre deslocamentos sucessivos.

\section{c) Seção transversal tipo 7}

A seção 7 (vazada, com quatro furos) é semelhante à seção 3. As curvas força versus flecha da análise numérica são apresentadas na figura 8.25.
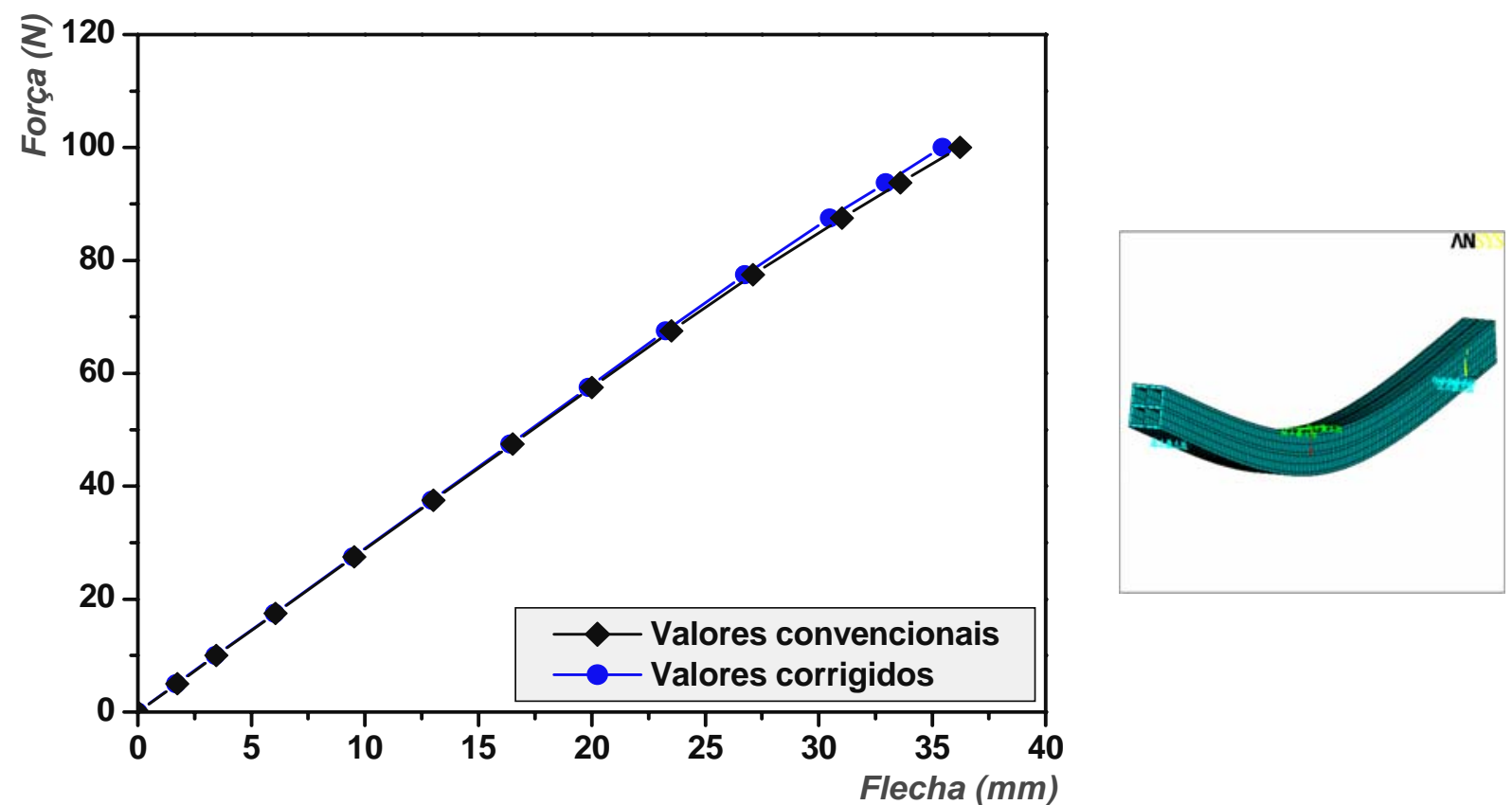

Figura 8.25 - Curvas obtidas na análise numérica, com o elemento finito Solid45, do modelo de cruzeta polimérica - seção 7.

Comparando-se as curvas das seções 7 e 3 , percebe-se que 0 comportamento dos elementos é semelhante. A figura 8.26 apresenta os resultados obtidos na análise numérica desse elemento.

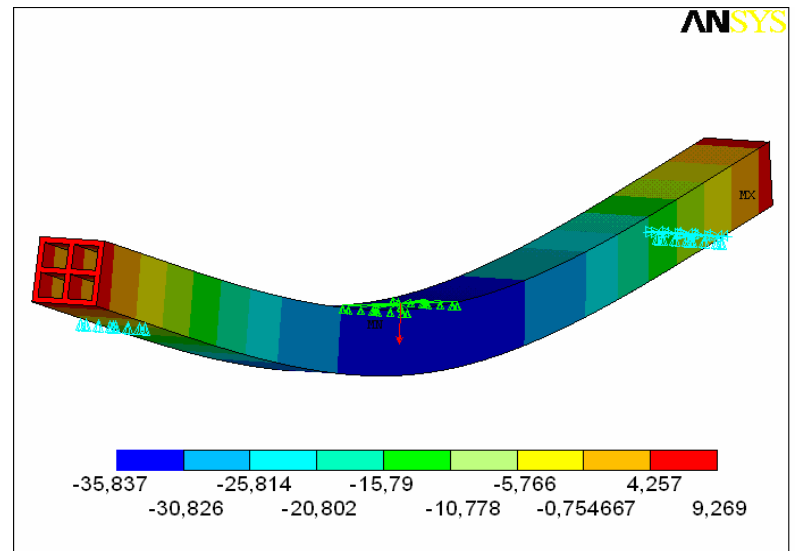

(a)

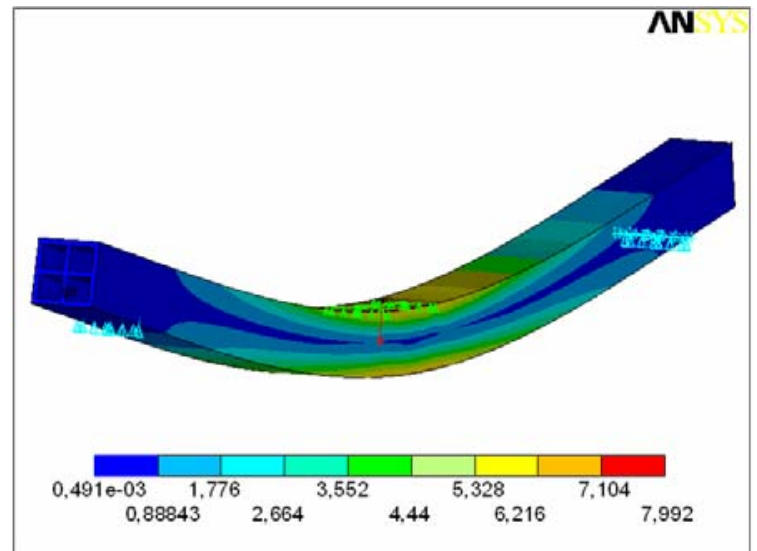

(b)

Figura 8.26 - Flecha máxima (a) e tensões de Von Mises (b) para carga de 100N - seção 7. 
Essa seção apresentou carregamento máximo de $100 \mathrm{~N}$, com uma flecha de $35,84 \mathrm{~mm}$ para esse nível de carregamento. A tensão máxima desse elemento é de 8MPa, abaixo do valor de escoamento do material, que é de 9,90MPa. Portanto, para o nível de carregamento alcançado, percebe-se que o elemento não atingiu a plastificação, o que pode ser comprovado pelas curvas obtidas na análise numérica, uma vez que elas demonstram comportamento linear. $A$ partir desses valores, o modelo não mais apresentou convergência, em correspondência a uma tolerância de 0,005 relativa às diferenças entre deslocamentos sucessivos.

\section{d) Seção transversal tipo 8}

A seção 8 (vazada, com sete furos) é semelhante à seção 4 . As curvas força versus flecha da análise numérica são apresentadas na figura 8.27.
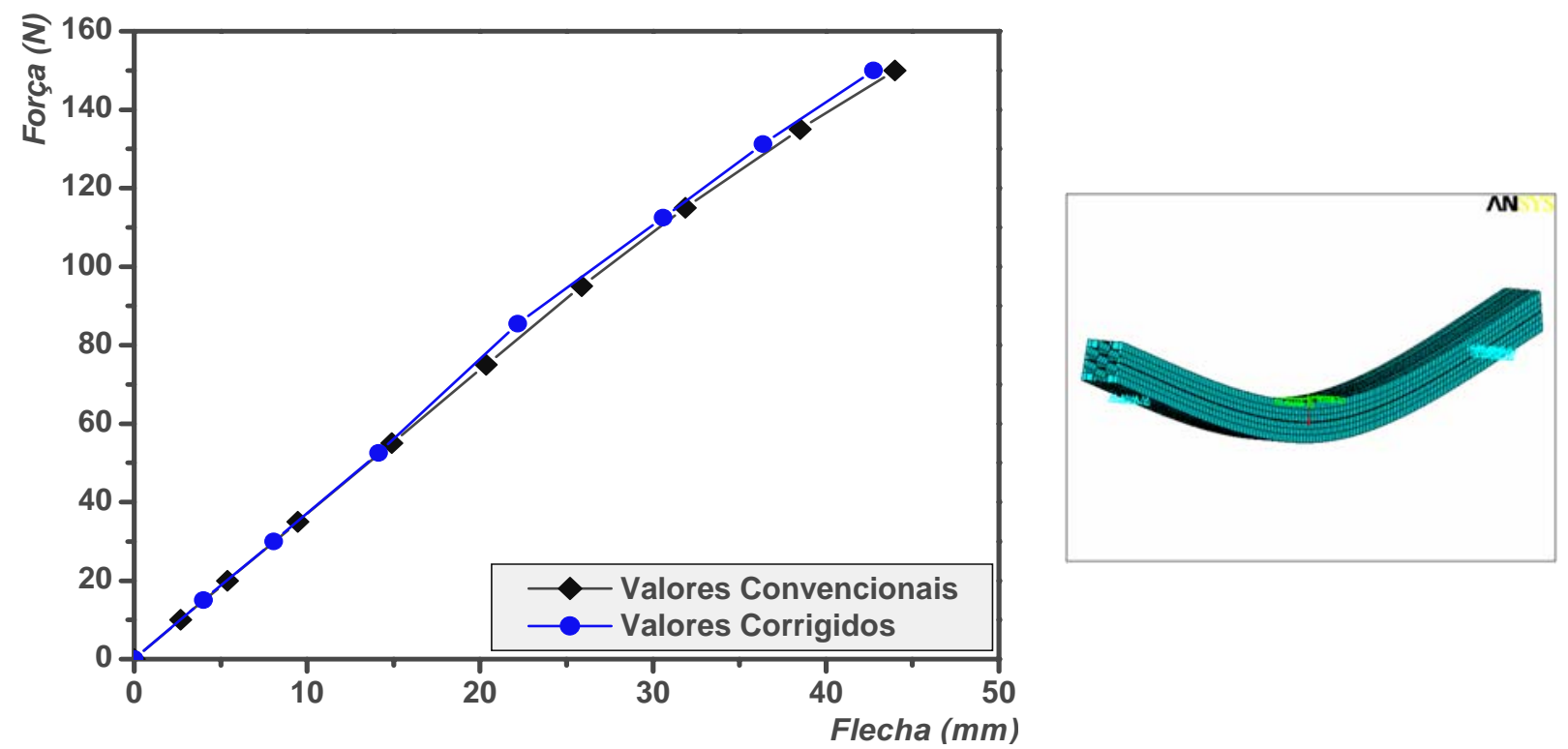

Figura 8.27 - Curvas obtidas na análise numérica, com o elemento finito Solid45, do modelo de cruzeta polimérica - seção 8.

Comparando-se as curvas das seções 8 e 4, percebe-se que o comportamento dos elementos é semelhante. Para uma carga de $150 \mathrm{~N}$, o modelo de cruzeta polimérica apresenta tensões de Von Mises e flecha máxima de 43,97mm, conforme são apresentadas na figura 8.28.
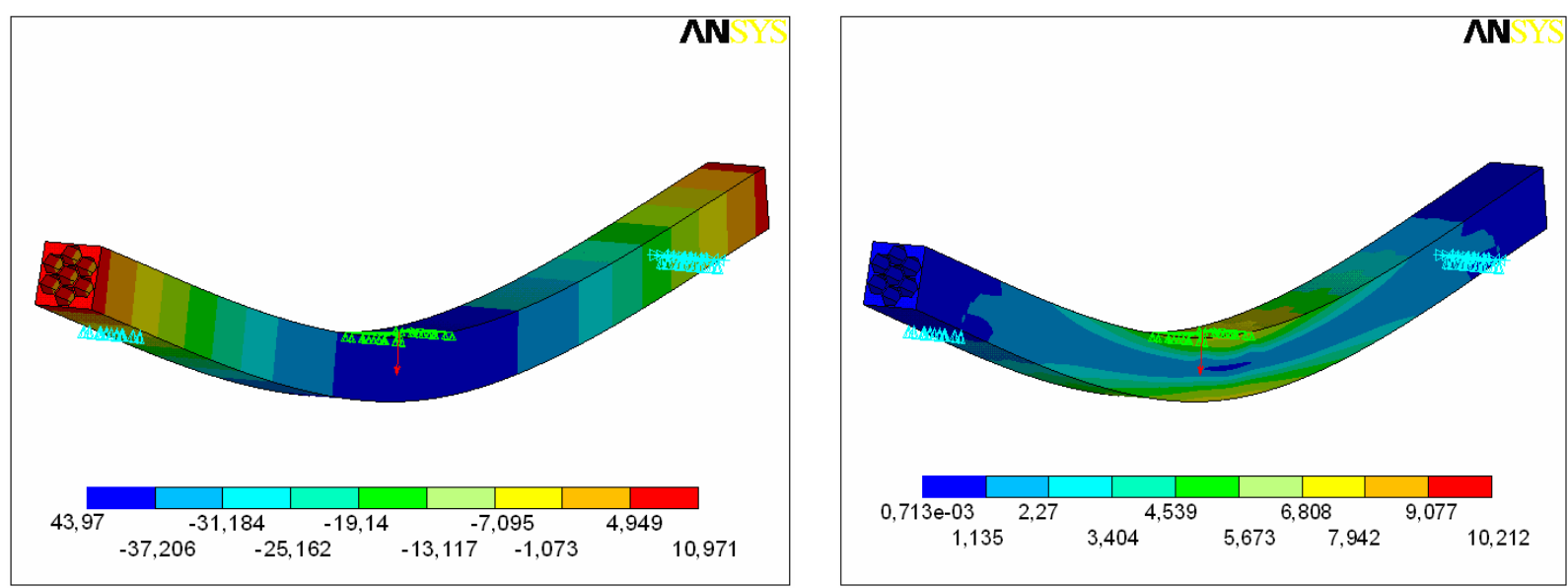

Figura 8.28 - Flecha máxima (a) e tensões de Von Mises (b) para carga de 150N - seção 8. 
A partir desses valores, o modelo não mais apresentou convergência, em correspondência a uma tolerância de 0,005 relativa às diferenças entre deslocamentos sucessivos.

\section{e) Seção transversal tipo 9}

A seção 9 é do tipo circular maciça. Embora sua utilização como cruzeta seja praticamente descartada, devido às dificuldades para fixação de elementos (e.g, isoladores, mão-francesa), foi proposto seu estudo para avaliar a influência dos tipos de seções transversais no comportamento do elemento. As curvas força versus flecha da análise numérica são apresentadas na figura 8.29.
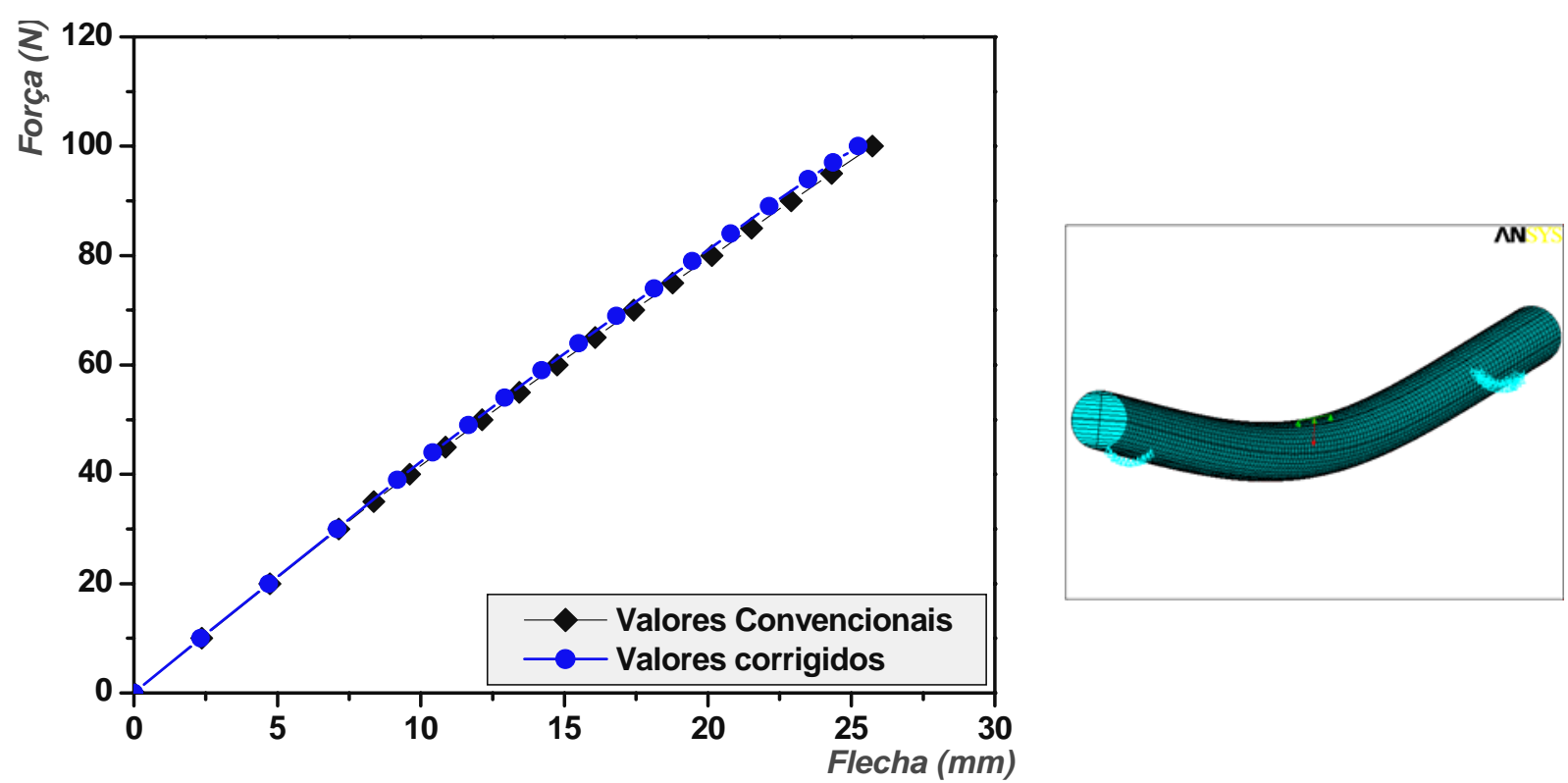

Figura 8.29 - Curvas obtidas na análise numérica, com o elemento finito Solid45, do modelo de cruzeta polimérica - seção 9 - seção circular maciça.

A figura 8.30 apresenta a flecha, o carregamento e a tensão de Von Mises obtida no último passo de carga aplicada.
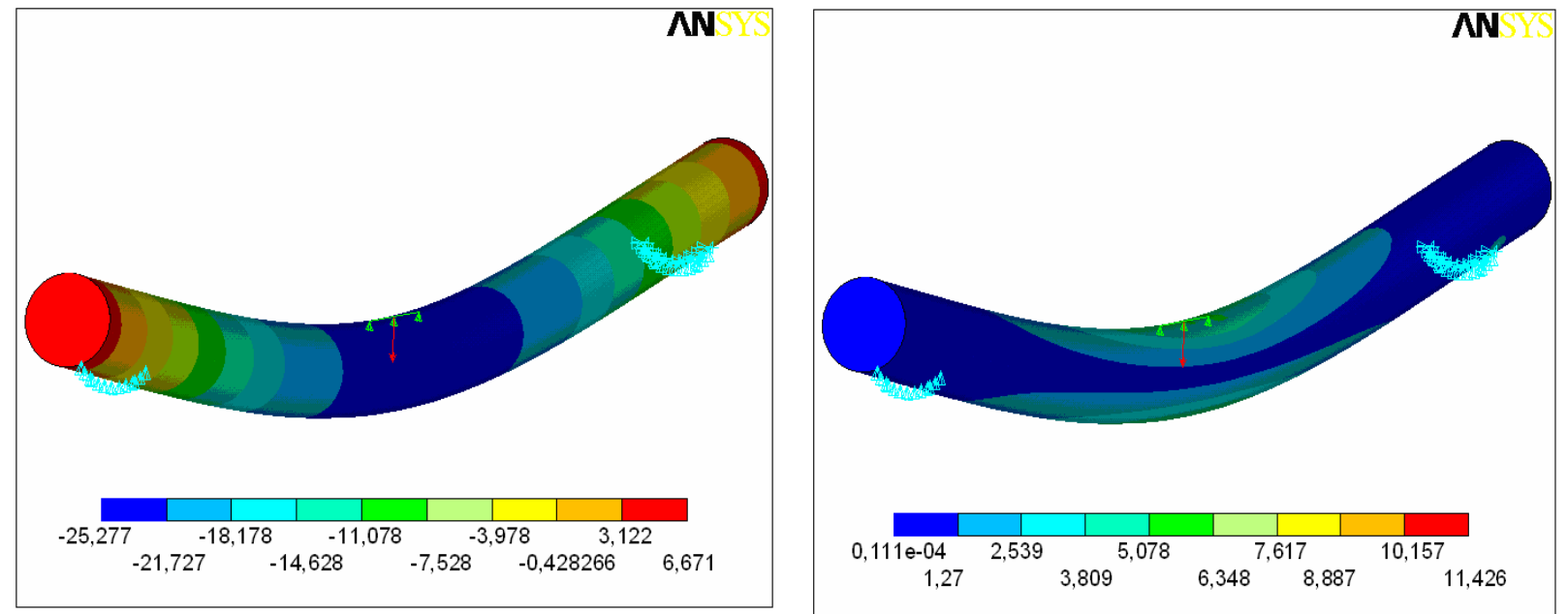

Figura 8.30 - Flecha máxima (a) e tensões de Von Mises (b) para carga de 150N - seção 9. 
Essa seção apresentou carregamento máximo de $100 \mathrm{~N}$, com uma flecha de 11,43mm para esse nível de carregamento. Portanto, para o nível de carregamento alcançado, percebe-se que o elemento atingiu a plastificação. A partir desses valores, o modelo não mais apresentou convergência, em correspondência a uma tolerância de 0,005 relativa às diferenças entre deslocamentos sucessivos.

\subsubsection{Estudo da ìnfluência de furos}

Outro estudo realizado diz respeito à influência da existência de furos para fixação de elementos na cruzeta. A figura 8.31 traz as curvas força versus flecha de seis tipos de seções, maciças e vazadas.

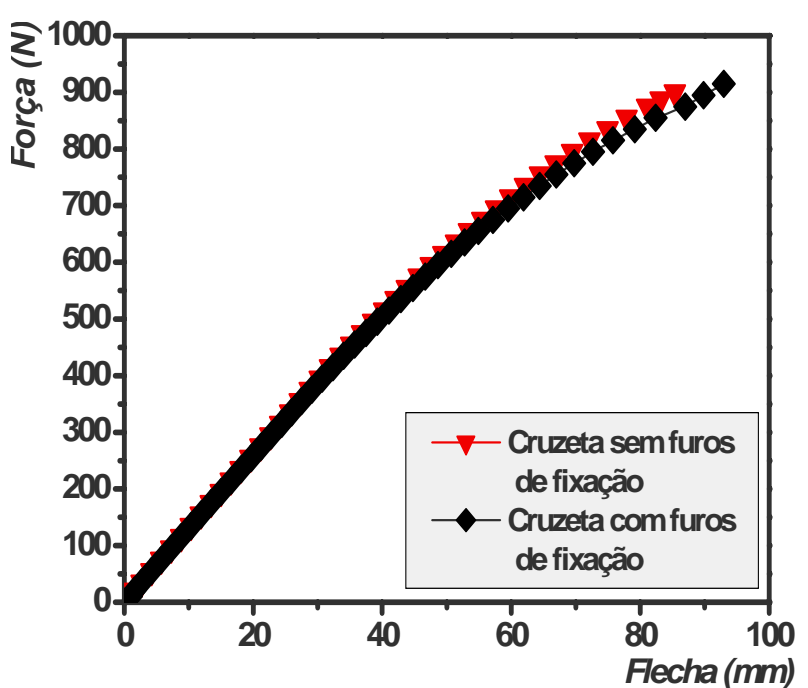

Seção 01

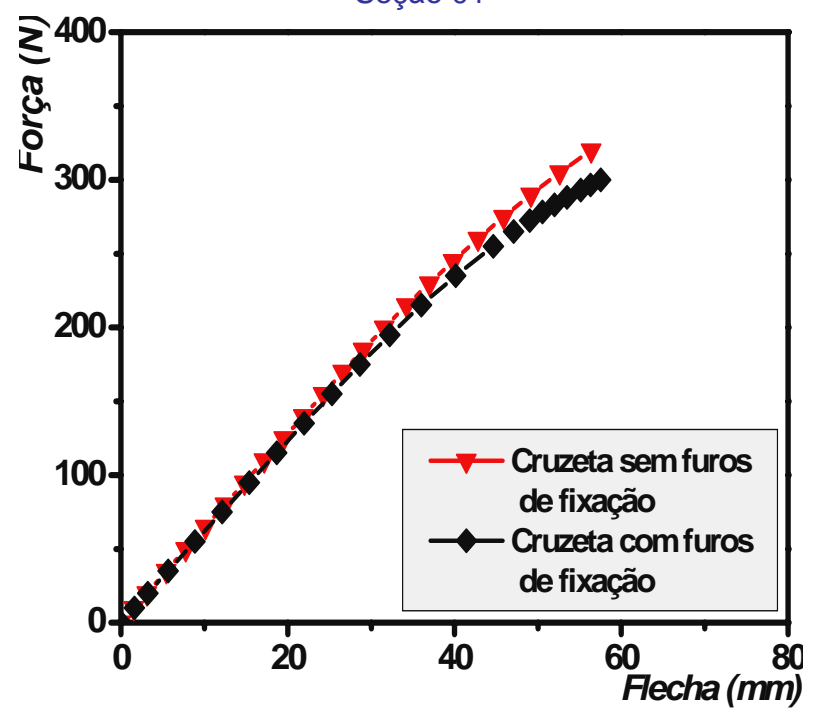

Seção 03

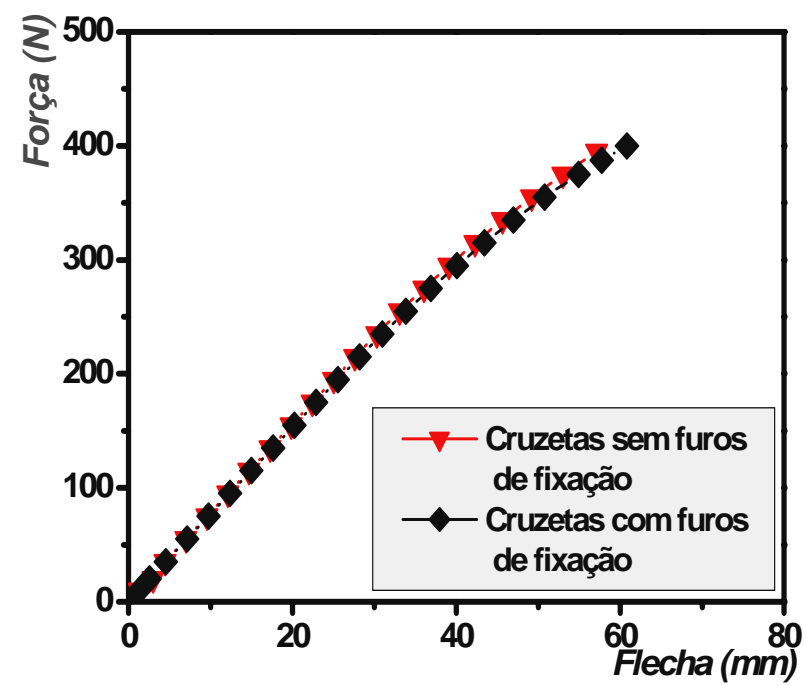

Seção 02

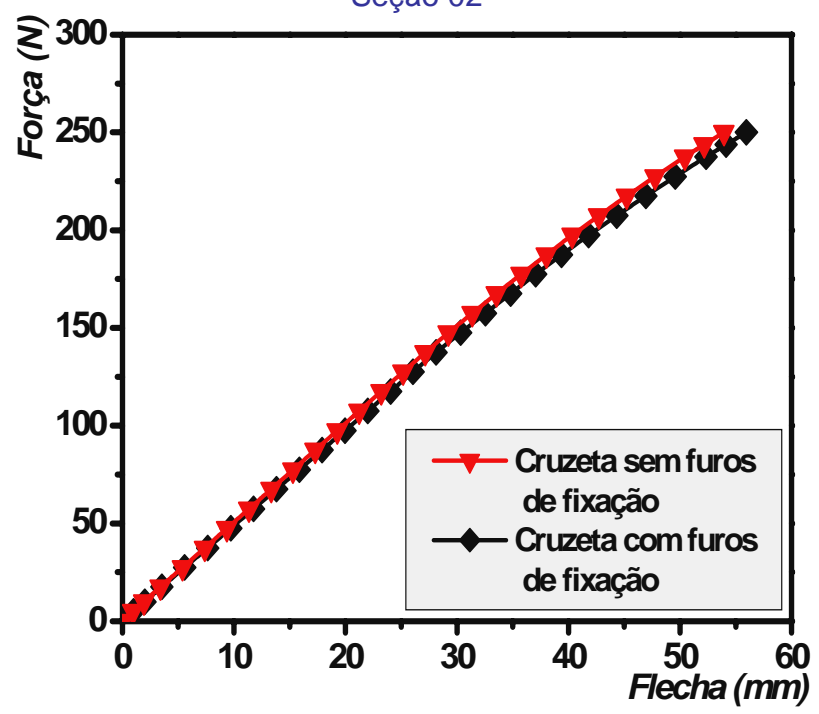

Seção 05 


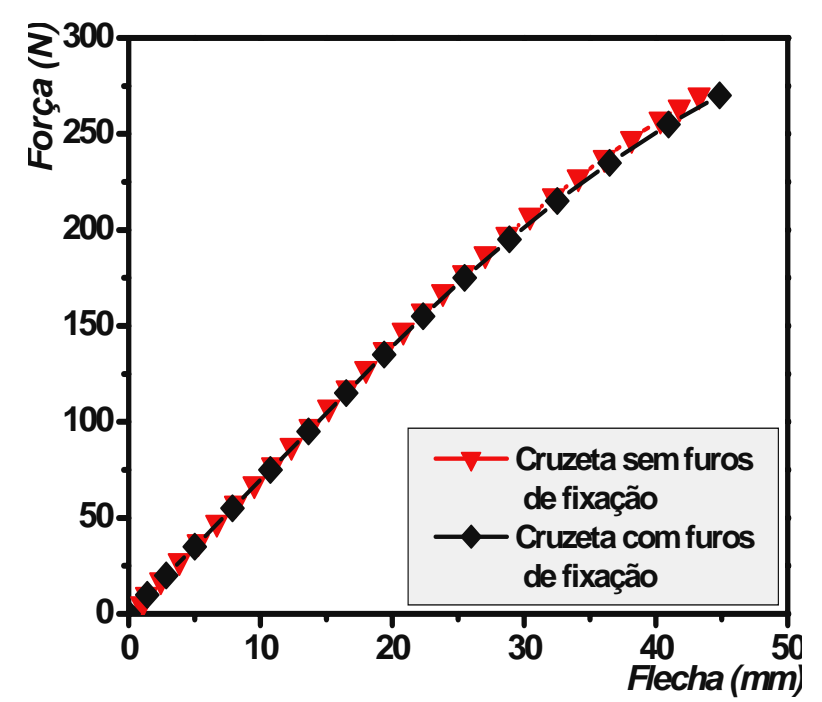

Seção 06

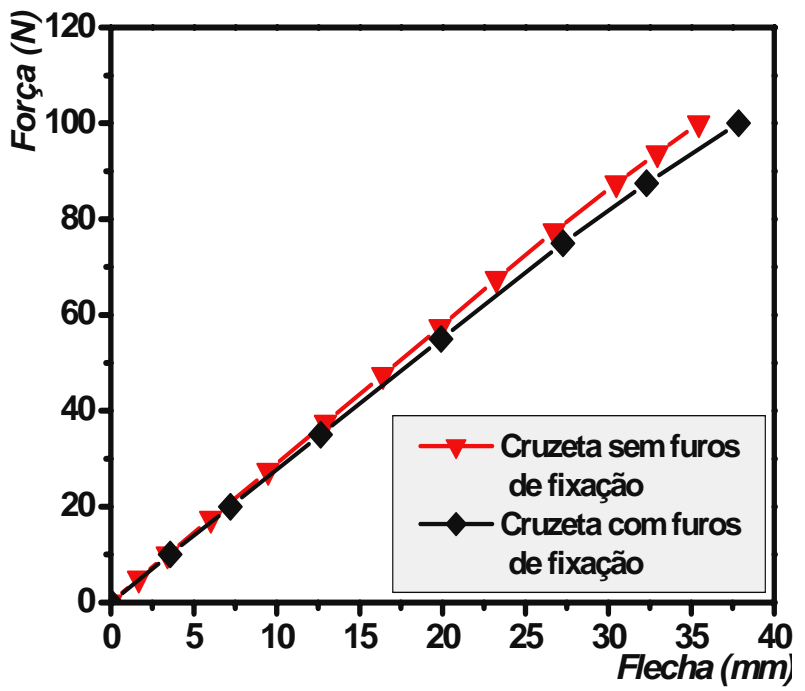

Seção 07

Figura 8.31 - Comparação das curvas de cruzetas poliméricas com e sem furos de fixação, obtidas por meio de simulação numérica (Solid45).

Pelos resultados apresentados, pode-se concluir que:

- Seções sem furos apresentam maior resistência. Entretanto, em relação à seção com furos, essa diferença é pequena;

- Seções maciças dos tipos 1 e 5 apresentam pouca variação de resistência frente à existência de furos de fixação, talvez devido à grande quantidade de material presente na seção transversal, o que faz com que não existam grandes interferências no seu comportamento. A resposta elástica de ambas as seções é coincidente; quando se inicia a plastificação, a presença de furos faz com que o elemento alcance valores de resistência um tanto inferiores;

- Seções vazadas dos tipos 2 e 6 (que possuem um furo) também apresentam boa resposta quando submetidas aos ensaios de flexão, principalmente quando os resultados analisados referem-se à zona elástica da estrutura. Com a plastificação, ocorre uma pequena diminuição dos valores esperados para uma seção sem furos de fixação; entretanto, essa diferença ainda é pequena;

- Seções vazadas dos tipos 3 e 7 (com quatro furos) já possuem seu desempenho comprometido, obtendo-se valores de resistência mais baixos em elementos com furos para fixação, uma vez que, mesmo na zona elástica, os resultados já indicam certa diferença entre o comportamento de ambas as seções.

Assim, pode-se concluir que é possível utilizar a análise de modelos numéricos, sem furos de fixação, para previsão do comportamento de cruzetas poliméricas; entretanto, devese lembrar que o valor de resistência obtido deverá ser minorado, dependendo do tipo de seção transversal analisado, garantindo assim certa segurança sobre os resultados de previsão de seu comportamento. 


\subsubsection{Comparação entre os elementos Solĩd45 e Beam189}

Neste trabalho também foi feito um estudo entre o tipo de elemento finito utilizado na análise numérica e seu comportamento. Para isso, utilizam-se dois tipos de elementos disponíveis no programa comercial baseado em elementos finitos (ANSYS): SOLID45 e BEAM189.

O SOLID45 é utilizado para modelagem de estruturas sólidas e possui três graus de liberdade por nó (referentes às translações ux, uy e uz), enquanto o BEAM189 é um elemento de viga, unidimensional, que possui seis graus de liberdade por nó: ux, uy e uz (referentes às translações) e rotx, roty e rotz (referentes às rotações).

Pelo fato deste trabalho apresentar a análise de elementos estruturais à flexão, é interessante verificar se existe alguma influência da rotação no comportamento dos elementos. Sendo assim, a figura 8.32 traz os resultados das análises numéricas de quatro tipos de seções transversais (maciças e vazadas, com um furo), cuja modelagem foi feita com os elementos finitos aqui citados.
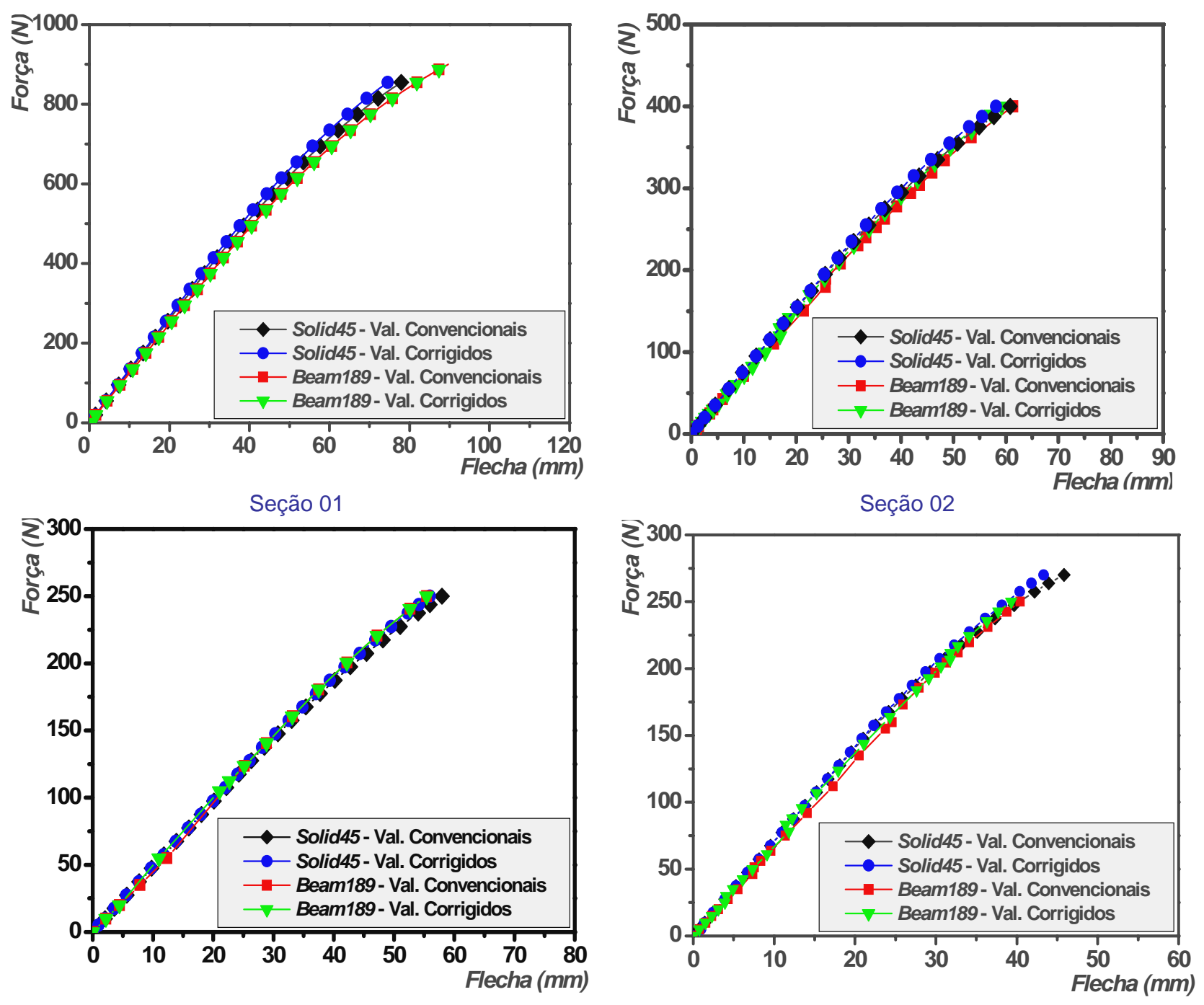

Seção 05

Figura 8.32 - Curvas força versus flecha - Solid45 e Beam189. 
Por meio da análise dos gráficos apresentados, nota-se que o comportamento dos elementos modelados com o SOLID45 e o BEAM189 são semelhantes, obtendo níveis de carregamento e de flechas correspondentes. Sendo assim, a modelagem de cruzetas poliméricas pode utilizar tanto o elemento finito SOLID45 quanto o BEAM189. A principal diferença entre os dois elementos finitos está ligada à facilidade de construir o modelo, uma vez que o BEAM189 já possui alguns tipos de seções transversais pré-determinados, o que facilita e reduz o tempo de modelagem.

A análise aqui descrita enfoca somente a modelagem de cruzetas poliméricas íntegras, isto é, sem furos. Seria interessante, também, conduzir um estudo referente à modelagem de cruzetas com furos, utilizando o elemento BEAM189, para avaliar as vantagens e as desvantagens em sua utilização, uma vez que a modelagem considerando os furos é trabalhosa e demorada, quando efetuada com o SOLID45.

\subsubsection{Sìmulação numérica de flexão em protótipos de cruzetas de PEAD}

De acordo com os resultados experimentais e numéricos apresentados anteriormente, pode-se verificar que é possível representar o comportamento dos modelos de cruzetas em $\mathrm{PU}$, pois os resultados apresentaram uma previsão satisfatória do carregamento e das flechas obtidas no ensaio. Assim, neste item, pretende-se extrapolar o estudo para protótipos de cruzetas de PEAD, por meio de análises numéricas, visando o estudo do comportamento desse tipo de elemento.

As seções transversais e as malhas adotadas nessa análise são as dos tipos 1, 2 e 3, ilustradas no capítulo 5 (figura 5.1) e no capítulo 7 (figura 7.10), respectivamente. Os modelos de comportamento dos materiais (convencional e corrigido) também foram apresentados no capítulo 7, no item 7.4, e o esquema estático adotado é o mesmo utilizado para o ensaio de cruzetas de madeira, conforme ilustra a figura 4.3. As características dos protótipos, com comprimento de 2000mm, são apresentadas a seguir:

- A seção transversal tipo 1 é maciça, quadrada, com dimensões de 100mm x 100mm;

- A seção transversal tipo 2 é quadrada, vazada, e possui um furo, de dimensões $79,25 \mathrm{~mm} \times 79,25 \mathrm{~mm}$;

- A seção transversal tipo 3 também é quadrada e possui quatro furos, de dimensões $39,69 \mathrm{~mm} \times 39,69 \mathrm{~mm}$. As figuras $8.33,8.34$ e 8.35 trazem as curvas força versus flecha desses tipos de elementos. 


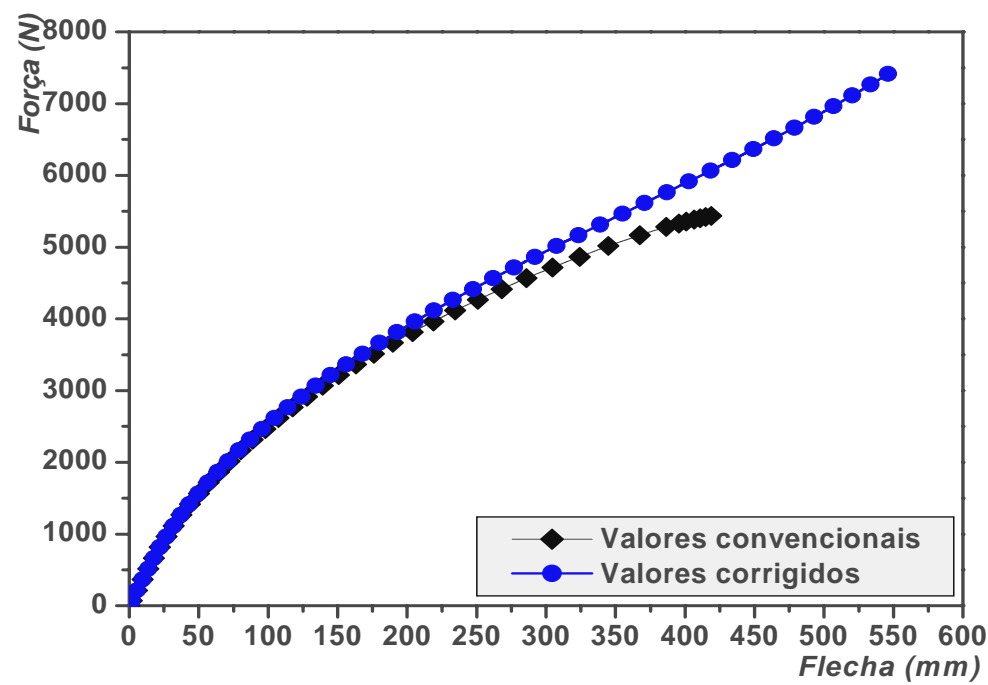

Figura 8.33 - Curvas força versus flecha para o protótipo 1 - Solid45.

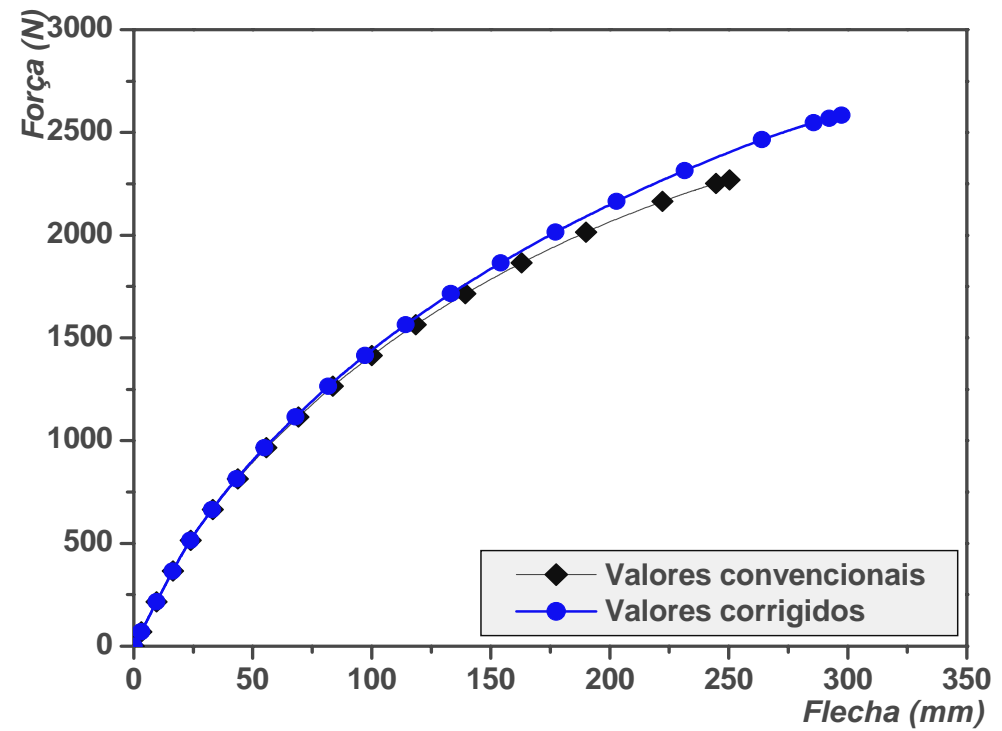

Figura 8.34 - Curvas força versus flecha para o protótipo 2 - Solid45.

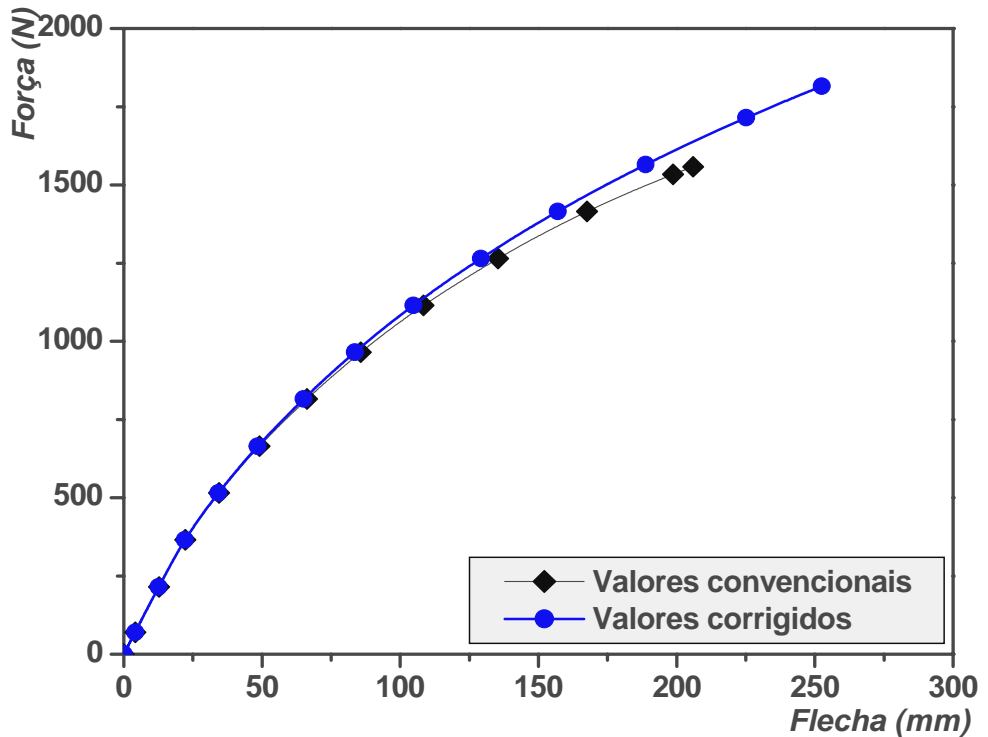

Figura 8.35 - Curvas força versus flecha para o protótipo 3 - Solid45. 
Nota-se que nenhum elemento atingiu o máximo valor de carregamento estipulado pela NBR 8458:1984, cujo valor é de 8000N (mínimo de ruptura). A tabela 8.16 apresenta os resultados numéricos obtidos na análise dos modelos.

Tabela 8.16 - Comparação dos valores encontrados na análise numérica dos protótipos de cruzeta polimérica com os valores da norma NBR 8458:1984.

\begin{tabular}{|c|c|c|c|c|}
\hline & & \\
\hline & & $\begin{array}{l}\text { Descrição do } \\
\text { carregamento }\end{array}$ & $\begin{array}{l}\text { Resistência } \\
\text { (F) N }\end{array}$ & $\begin{array}{c}\text { Flecha máxima } \\
\text { (mm) }\end{array}$ \\
\hline \multirow{6}{*}{ 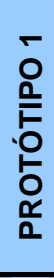 } & \multirow{3}{*}{ Valores convencionais } & Nominal & 4000 & 222,51 \\
\hline & & Máximo excepcional & 5600 & --------- \\
\hline & & Mínimo de ruptura & 8000 & --------- \\
\hline & \multirow{3}{*}{ Valores corrigidos } & Nominal & 4000 & 208,78 \\
\hline & & Máximo excepcional & 5600 & 369,19 \\
\hline & & Mínimo de ruptura & 8000 & --------- \\
\hline \multirow{6}{*}{ 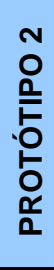 } & \multirow{3}{*}{ Valores convencionais } & Passo de carga máximo & 2269,60 & 250,35 \\
\hline & & Máximo excepcional & 5600 & -------- \\
\hline & & Mínimo de ruptura & 8000 & --------- \\
\hline & \multirow{3}{*}{ Valores corrigidos } & Passo de carga máximo & 2583,40 & 297,44 \\
\hline & & Máximo excepcional & 5600 & --------- \\
\hline & & Mínimo de ruptura & 8000 & -------- \\
\hline \multirow{6}{*}{ 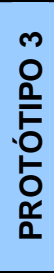 } & \multirow{3}{*}{ Valores convencionais } & Passo de carga máximo & 1557,80 & 205,95 \\
\hline & & Máximo excepcional & 5600 & --------- \\
\hline & & Mínimo de ruptura & 8000 & ---------- \\
\hline & \multirow{3}{*}{ Valores corrigidos } & Passo de carga máximo & 1820,00 & 253,97 \\
\hline & & Máximo excepcional & 5600 & --------- \\
\hline & & Mínimo de ruptura & 8000 & --------- \\
\hline & \multirow{3}{*}{ NBR 8458:1984 } & Nominal & 4000 & 75,00 \\
\hline & & Máximo excepcional & 5600 & 100,00 \\
\hline & & Mínimo de ruptura & 8000 & --------- \\
\hline
\end{tabular}

A única seção que atingiu a carga máxima excepcional, cujo valor é de $4000 \mathrm{~N}$, foi a seção tipo1, apresentando deslocamento de $208,78 \mathrm{~mm}$ para o modelo de comportamento do material corrigido. Quando comparado aos valores fornecidos pela NBR 8458:1984, nota-se que o deslocamento obtido é $178 \%$ superior ao fornecido pela norma, comprovando que o PEAD, embora possua módulo de elasticidade maior que o do PU utilizado na análise experimental, ainda não é o material ideal para ser empregado nesse tipo de elemento estrutural. As figuras 8.36, 8.37 e 8.38 trazem uma visão geral da magnitude das tensões de Von Mises ao longo do carregamento, lembrando que a tensão média de escoamento do material é 18MPa. 

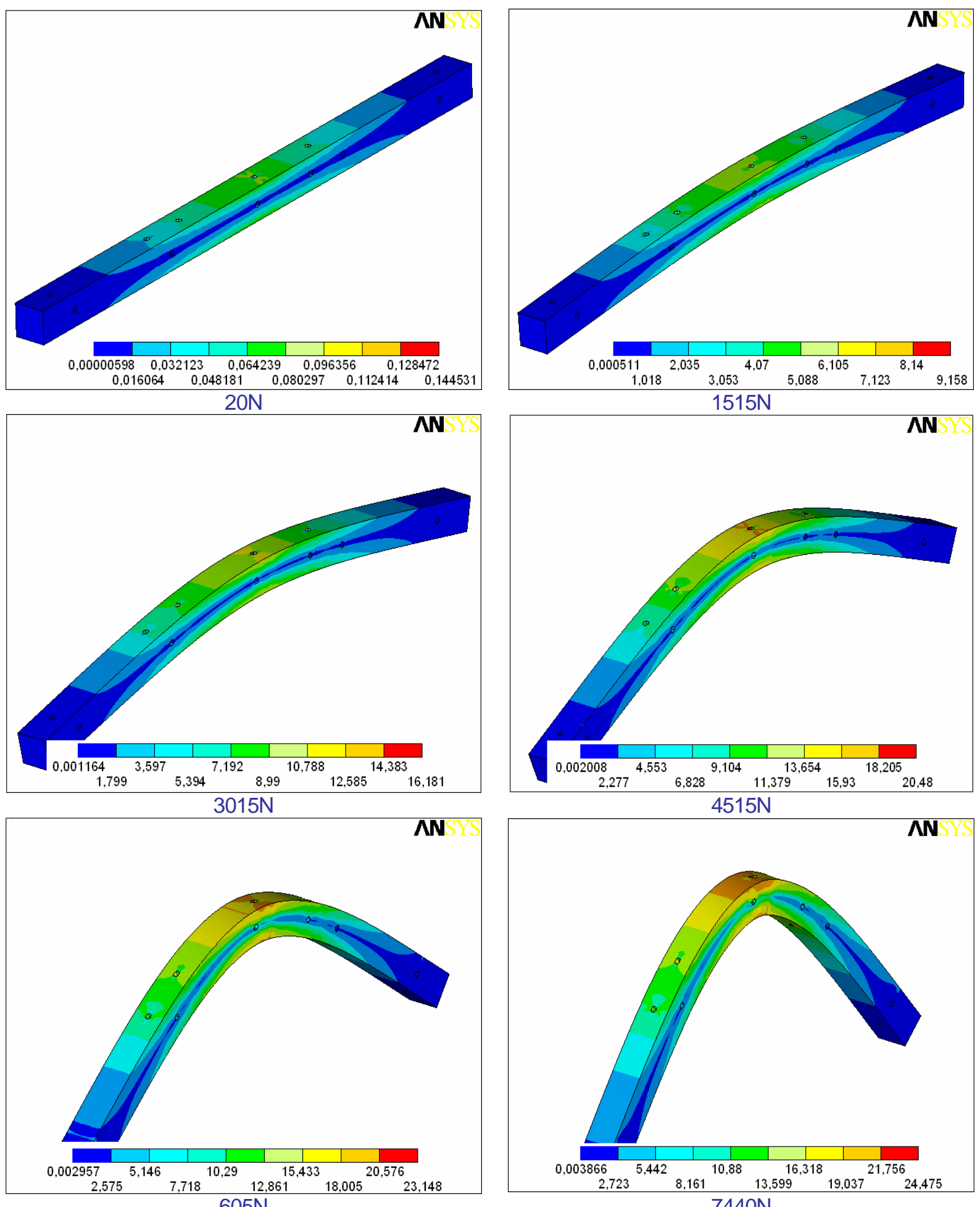

Figura 8.36 - Evolução das tensões de Von Mises ao longo do carregamento - protótipo 1. 

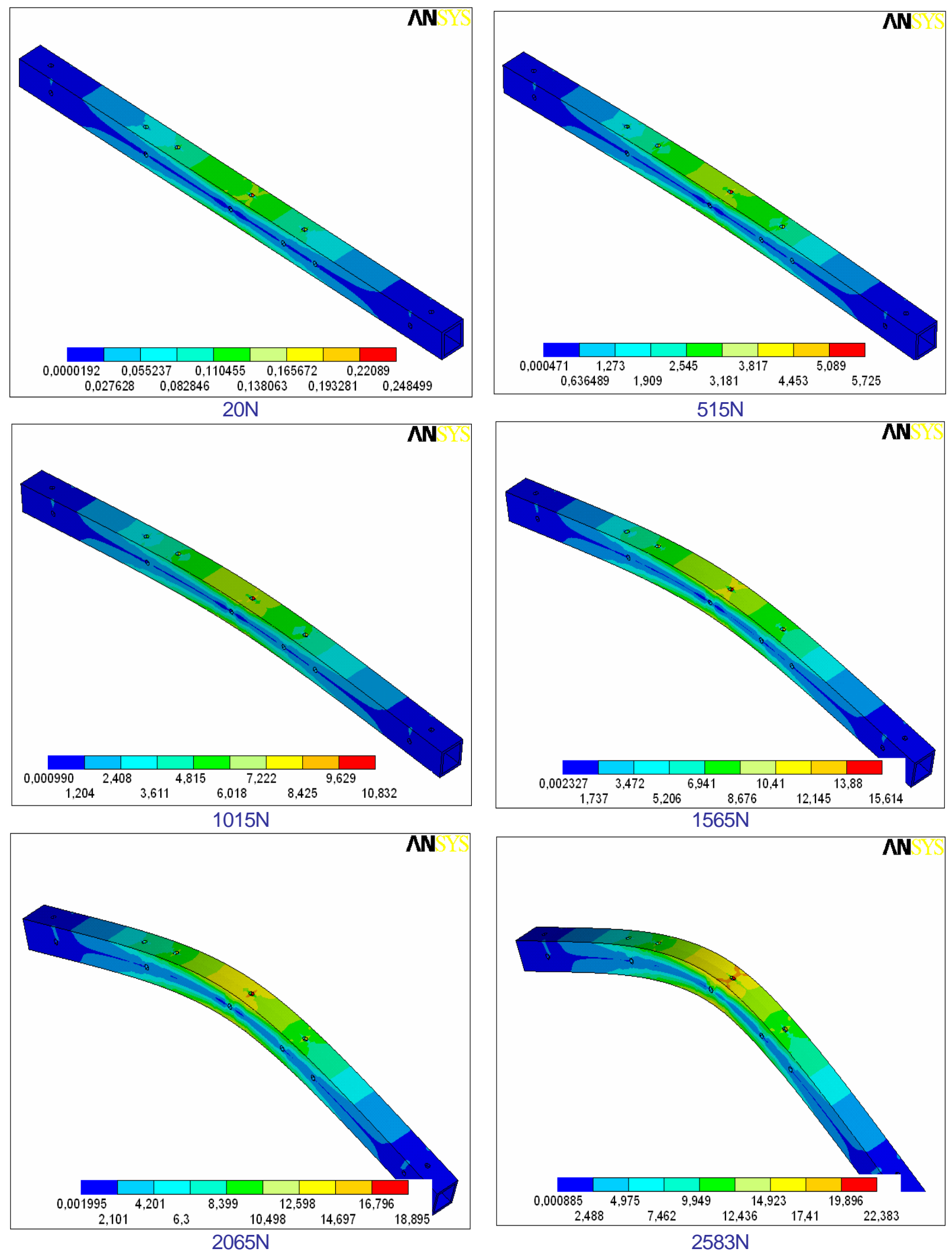

Figura 8.37 - Evolução das tensões de Von Mises ao longo do carregamento - protótipo 2. 

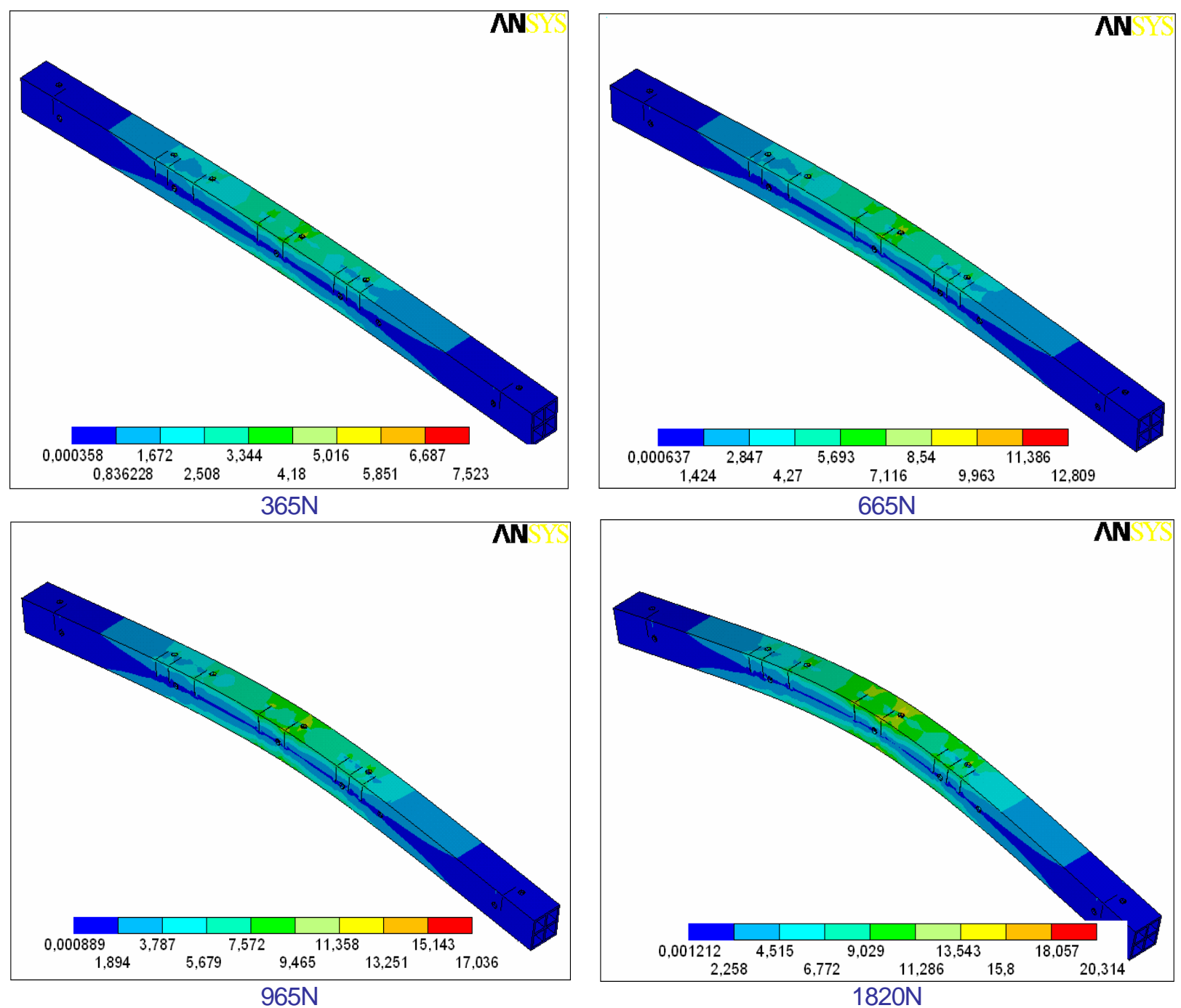

Figura 8.38 - Evolução das tensões de Von Mises ao longo do carregamento - protótipo 3.

Nota-se que plastificação do elemento com seção tipo 1 ocorreu entre os passos de carga $3015 \mathrm{~N}$ e $4515 \mathrm{~N}$, para tipo 2 ocorreu com aproximadamente $2065 \mathrm{~N}$ e para tipo 3, com 965N. Como nas análises efetuadas com o PU, a seção maciça se mostrou mais resistente. Entretanto, todas as seções não foram aprovadas quando tiveram seus resultados de carregamento e de flechas comparados com os da norma NBR 5848:1984. Vale ressaltar que, a partir dos valores indicados, os modelos não mais apresentaram convergência, em correspondência a uma tolerância de 0,005 relativa às diferenças entre deslocamentos sucessivos. 


\subsection{Considerações finais}

Neste capítulo foi realizado o programa experimental previsto, englobando o ensaio de corpos-de-prova e de alguns modelos de PU.

Com relação à fabricação dos elementos e aos ensaios dos corpos-de-prova, podese concluir que:

- Embora o material utilizado para a produção dos corpos-de-prova e dos modelos utilizados neste trabalho não sejam usuais na Engenharia Civil, na área da Engenharia de Estruturas, eles apresentam várias vantagens para seu uso, tais como: (i) grande apelo ecológico existente atualmente, que induz ao uso de materiais recicláveis, (ii) baixo custo e (iii) possibilidade de reutilização do mesmo material ao final da vida útil do elemento, obtendo o retorno de parte do capital utilizado em sua fabricação;

- É necessária a aquisição de células de carga de baixa capacidade, para a realização dos ensaios experimentais nos laboratórios do Departamento de Engenharia de Estruturas da EESC, uma vez que as células disponíveis são de elevada capacidade;

- A produção de cruzetas poliméricas é possível, desde que se utilize um material de reforço ou se empreguem estruturas mistas (tais como polímero/concreto ou polímero/madeira).

Com relação aos resultados obtidos nas análises numéricas, nota-se que:

- Os modelos numéricos adotados foram adequados para se medirem os carregamentos e as flechas obtidas nos ensaios experimentais, representando satisfatoriamente o ensaio.

Por fim, pode-se ressaltar a importância e a eficiência da modelagem numérica proposta neste trabalho, pois é uma ferramenta que pode auxiliar, futuramente, a edição de procedimentos de dimensionamento mais próximos do efetivo comportamento das cruzetas. 


\section{CONCLUSÕES E SUGESTÕES}

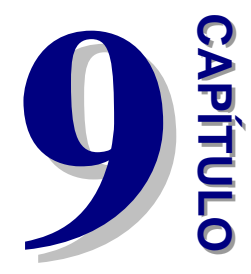

Este capítulo apresenta as conclusões do trabalho, bem como algumas sugestões para pesquisas futuras que possam complementar este estudo, visando tanto o aprimoramento de elementos estruturais em polímeros reciclados quanto o maior conhecimento das inúmeras possibilidades de aplicação dos polímeros na construção civil, especialmente na área de Engenharia de Estruturas.

\subsection{Considerações finais}

Ao longo deste trabalho, considerou-se um material estrutural alternativo aos comumente utilizados, já empregado em algumas obras civis realizadas, tais como casas, pontes, passarelas, deques, ferrovias, dentre outras, construídas em países como Estados Unidos, Japão e Canadá. Apresentaram-se, também, as vantagens (e.g., o forte apelo ecológico, o baixo peso específico, a indiferença à deterioração por decomposição e ataque de microorganismos, a alta resistência à corrosão, o fácil processamento e o reduzido custo de manutenção, a possibilidade de ser moldado nas mais diversas formas etc.) e as desvantagens (e.g., comportamento dependente da temperatura, da taxa de deformação e do tempo, baixa rigidez e baixa resistência, inflamabilidade, dentre outras) no uso de materiais poliméricos. Entretanto, essas deficiências podem ser corrigidas por meio de: (i) alteração geométrica, com incorporação de elementos tais como nervuras e costelas de reforço, (ii) utilização de blendas poliméricas e (iii) adição de cargas minerais e de fibras de reforço, com alto módulo de elasticidade e alta resistência, ingressando, assim, em uma área muito promissora: a da tecnologia dos materiais compósitos.

Quanto às cruzetas, promoveu-se um estudo dos materiais habitualmente utilizados, carregamentos e flechas admitidas para esse tipo de elemento, assim como do procedimento de ensaio, especificado em norma, procedimento esse que foi utilizado neste trabalho.

Um artifício de grande valor foi a compreensão e a utilização de modelos reduzidos, que se justifica pela facilidade de produção e de ensaio dos elementos, além de promover economia de material durante a análise experimental. Assim, os valores experimentais, obtidos para os modelos, representam os protótipos, ou seja, podem ser estendidos aos 
protótipos, pois existe semelhança entre eles, tanto pela geometria quanto pelos carregamentos.

De acordo com o que foi proposto inicialmente, o objetivo principal desta pesquisa foi estudar o comportamento de cruzetas poliméricas de materiais reciclados submetidas à flexão. Além disso, este trabalho propôs diversos modelos numéricos consistentes para a representação dos ensaios, de forma a permitir uma análise mais abrangente do comportamento desse tipo de estrutura estudada.

A seguir, serão esboçadas as conclusões parciais do trabalho, obtidas em função da análise dos resultados obtidos.

\subsubsection{Comentários sobre a análise experimental}

A produção dos modelos, mesmo sendo um processo artesanal, possibilitou a obtenção de elementos com bom acabamento superficial e estabilidade dimensional. Devido às suas dimensões reduzidas, possibilitaram fácil posicionamento na máquina de ensaios, facilitando os procedimentos de execução e minimizando possíveis erros durante os ensaios.

Com relação aos resultados experimentais, os modelos apresentaram comportamento diferenciado com a idade, talvez devido à pós-cura do material, uma vez que o modelo ensaiado aos 30 dias mostrou-se mais rígido.

Comparando-se os resultados experimentais com os especificados pela norma NBR 8458:1984, nota-se que as cruzetas poliméricas de PEAD não atendem as condições de carregamento e as flechas indicadas pela norma; entretanto, este trabalho comprovou a necessidade de utilização de materiais com maior rigidez e maior resistência, que podem ser obtidos com a utilização de blendas, cargas minerais e fibras de reforço.

Para que o grupo de pesquisa cresça e se fortaleça, faz-se necessária a aquisição de uma célula de carga com baixa capacidade de carregamento, para a execução de ensaios com polímeros, assim como de uma máquina de ensaios para polímeros, uma vez que as disponíveis no Departamento de Engenharia de Estruturas (SET/EESC) não são adequadas para esses fins.

\subsubsection{Simulação numérica dos modelos polìméricos}

Os resultados das simulações apresentaram uma previsão satisfatória da resistência dos modelos, assim como das flechas correspondentes a diversos níveis de carregamentos, apresentando algumas diferenças de resultados em alguns modelos, principalmente devido à idade do modelo ensaiado e à presença ou não de furos de fixação de elementos nas cruzetas. De acordo com os resultados obtidos, pode-se concluir que: 
- Devido ao módulo de elasticidade, os modelos apresentaram-se muito deformáveis, apresentando grandes deslocamentos;

- As curvas da análise experimental foram semelhantes às obtidas pela simulação numérica, comprovando a eficiência dos modelos adotados;

- Pelo estudo da influência de furos de fixação no elemento realizado, nota-se que é possível utilizar a análise de modelos numéricos sem furos de fixação para previsão do comportamento de cruzetas poliméricas; entretanto, deve-se minorar o valor de resistência obtido pela análise numérica, principalmente em seções transversais vazadas, de forma a garantir certa margem de segurança sobre os resultados de previsão de seu comportamento;

- A modelagem dos elementos com o SOLID45 e o BEAM189 apresentou comportamento semelhante, obtendo-se níveis de carregamento e flechas correspondentes. Desse modo, conclui-se que a modelagem numérica da cruzeta pode ser feita com qualquer um desses elementos, sem que ocorra perda de qualidade nos resultados.

A simulação numérica, como visto anteriormente, justifica-se pela diminuição de recursos necessários para seu estudo, tais como os relativos à fabricação de moldes e de calibradores, despesas com materiais, mão-de-obra etc. Outra questão muito importante a ser destacada é que o modelo computacional pode ter suas características e propriedades facilmente alteradas, o que muitas vezes inviabilizaria uma investigação experimental, no caso de alterações da composição do material ou das dimensões do elemento estrutural.

São necessárias mais investigações, com um maior número de repetições dos ensaios, de modo a se obter uma média mais confiável e, também, realizar análises experimentais com protótipos, de maneira a validar os resultados numéricos das cruzetas poliméricas de PEAD.

\subsubsection{Conclusões}

Visando contribuir para a redução do impacto ambiental causado pelo plástico, este trabalho propôs a utilização de material reciclado e reciclável na confecção de elementos estruturais.

De acordo com os resultados obtidos, observou-se que os ensaios de flexão apresentaram pequena variação entre a análise experimental e a numérica, demonstrando ser esta uma boa ferramenta para avaliação do comportamento dos modelos poliméricos.

De modo geral, este trabalho foi bem sucedido, uma vez que as investigações experimentais foram conduzidas dentro dos procedimentos recomendáveis. 
Em relação à análise numérica, pode-se dizer que os modelos numéricos desenvolvidos mostraram-se adequados para representar o comportamento relativo aos testes com modelos físicos. O modelo forneceu uma boa estimativa para o carregamento e para sua respectiva flecha, e pode se constituir em uma ferramenta interessante para a extensão dos resultados para outros casos.

Para finalizar, espera-se que este trabalho contribua para o aumento da reciclagem dos plásticos no País, dando um uso mais nobre a esses resíduos, agregando-lhes valor e retirando de aterros sanitários e lixões um material que pode levar mais de 450 anos para se degradar, além de contribuir para o surgimento de novos mercados.

\subsection{Sugestões para trabalhos futuros}

Este é o primeiro trabalho experimental de uma série que se pretende realizar no Departamento de Estruturas da EESC/USP. A seguir são apresentadas algumas sugestões de estudos que são fundamentais para a consolidação desta nova linha de pesquisa.

- Influência da adição de fibras nas propriedades mecânicas, para adequação do plástico reciclado para uso em elementos estruturais;

- Análise experimental e numérica de diferentes elementos estruturais de plástico reciclado;

- Aplicações de blendas poliméricas;

- Estruturas mistas envolvendo polímeros;

- Ligações entre elementos estruturais de plástico reciclado;

- Modelos de previsão viscoelásticos mais sofisticados e sua implementação computacional;

- Métodos de dimensionamento para as estruturas de plástico reciclado;

- Instabilidade dos elementos estruturais de plástico reciclado;

- Comportamento mecânico dos materiais poliméricos ao longo do tempo;

- Ensaios de envelhecimento de materiais poliméricos com a utilização de luz ultravioleta. 


\section{BIBLIOGRAFIA}

AGNELLI, J. A. M. (2005). Introdução a materiais poliméricos. Engenharia de Materiais DEMa, UFSCar, São Carlos - SP. Notas de aula.

ANDOLFATO, R. P. (2002). Desenvolvimento das técnicas de produção de blocos de concreto para alvenaria estrutural na escala (1:4). 110 p. Dissertação (Mestrado). UNESP Universidade Estadual Paulista "Júlio de Mesquita Filho", Ilha Solteira. 2002.

ANÔNIMO (1985). Apostila de processamento de polímeros. Florianópolis: Imprensa Universitária da UFSC.

ANSYS (1997). Structural nonlinearities: user's guide for revision 5.5. Houston. v.1.

ASSOCIAÇÃO BRASILEIRA DE NORMAS TÉCNICAS (1983). NBR 8158 - Ferragens eletrotécnicas para redes aéreas, urbanas e rurais de distribuição de energia elétrica. 14 p. Rio de Janeiro.

ASSOCIAÇÃO BRASILEIRA DE NORMAS TÉCNICAS (1984). NBR 8454 - Cruzeta de concreto armado para redes de distribuição de energia elétrica - Dimensões. 6 p. Rio de Janeiro.

ASSOCIAÇÃO BRASILEIRA DE NORMAS TÉCNICAS (1984). NBR 8458 - Cruzetas de madeira para redes de distribuição de energia elétrica - Especificação. 13 p. Rio de Janeiro.

ASSOCIAÇÃO BRASILEIRA DE NORMAS TÉCNICAS (1984). NBR 8459 - Cruzetas de madeira - Dimensões. 4 p. Rio de Janeiro.

ASSOCIAÇÃO BRASILEIRA DE NORMAS TÉCNICAS (1980). NBR 6124 - Determinação da elasticidade, carga de ruptura, absorção de água e da espessura do cobrimento em postes e cruzetas de concreto armado - Método de ensaio. 5 p. Rio de Janeiro.

ASSOCIAÇÃO BRASILEIRA DE NORMAS TÉCNICAS (1994). NBR 13230: Simbologia indicativa de reciclabilidade e identificação de materiais plásticos. 6 p. Rio de Janeiro. 
AMERICAN SOCIETY FOR TESTING AND MATERIALS (2004). D256-04: Standard Test Methods for Determining the Izod Pendulum Impact Resistance of Plastics.

AMERICAN SOCIETY FOR TESTING AND MATERIALS (1999). D257-99: Standard Test Methods for DC Resistance or Conductance of Insulating Materials.

AMERICAN SOCIETY FOR TESTING AND MATERIALS (1996). D638-96: Standard Test Method for Tensile Properties of Plastics.

AMERICAN SOCIETY FOR TESTING AND MATERIALS (2002). D695-02a: Standard Test Method for Compressive Properties of Rigid Plastics.

AMERICAN SOCIETY FOR TESTING AND MATERIALS (2003). D790-03: Standard Test Methods for Flexural Properties of Unreinforced and Reinforced Plastics and Electrical Insulating Materials.

AMERICAN SOCIETY FOR TESTING AND MATERIALS (1994). D5592-94: Standard guide for material properties needed in engineering design using plastics.

BECK, A. T. (2006). Curso de confiabilidade estrutural. Departamento de Engenharia de Estruturas da EESC - USP, São Carlos - SP.

BITTENCOURT, E. (200-?). Tratamento de problemas não-lineares na mecânica dos sólidos. Universidade Federal do Rio Grande do Sul - UFRGS. Notas de aula.

BLASS, A. (1985). Processamento de polímeros. Florianópolis: Editora da UFSC.

CALIL JÚNIOR; C. (1988). Análise experimental de materiais e de estruturas. Editora da USP, São Carlos.

CANDIAN, L. M. (2007). Estudo do polietileno de alta densidade (PEAD) reciclado para uso em elementos estruturais. Dissertação (Mestrado). Universidade de São Paulo, São Carlos (em fase de elaboração).

CANEVAROLO JÚNIOR, S. V. (2004). Técnicas de Caracterização de Polímeros. Editora Artliber ABPol. São Paulo. 
CARASCHI, J. C.; LEÃO, A. L. (2002). Avaliação das propriedades mecânicas dos plásticos provenientes de resíduos urbanos. In: Acta Scientiarum. Maringá, v. 24, n. 6, p. 1599-1602.

CERQUEIRA, V.; HEMAIS, C. A. (2001). Estratégia Tecnológica e a Indústria Brasileira de Transformação de Polímeros. Polímeros, Jul./Set. 2001, v.11, n.3, p.7-10. ISSN 0104-1428.

CHAVES, André L. O. (1999). Polímeros: subsídios para utilização na construção civil. 209p. Dissertação (Mestrado). Universidade de São Paulo, São Carlos. 1999.

CHODRAUI, Gustavo M. B. (2006). Análise teórica e experimental de perfis de aço formados a frio submetidos à compressão. Tese (Doutorado). Universidade de São Paulo, São Carlos. 294p.

CRAWFORD, R. J. (1987). Plastics engineering. 2nd Edition. Belfast: Pergamon Press.

FERRAROLI, F.; MOTTA, I. (2001). Uma nova dimensão dos termoplásticos: o consumo energético. Polímeros, Jul./Set. 2001, v.11, n.3, p.12-13. ISSN 0104-1428.

GODOY, João P. M. (2006). Análise de estruturas de madeiras, com e sem impregnação de reina poliuretana derivada do óleo de mamona, aplicadas em linhas de distribuição de energia elétrica. Dissertação (Mestrado). Universidade de São Paulo, São Carlos. 144p.

GOMES, F. A. M. (1986). A eletrificação no Brasil. São Paulo, Eletropaulo.

HOLLAWAY, L. (1993). Polymer composites for civil and structural engineering. Blackie Academic \& Professional, an imprint of Chapman \& Hall, Wester Cleddens Road, Bishopbriggs, Glasgow G64 2 NZ.

HOLLAWAY, L. C. (2003). The evolution of and the way forward for advanced polymer composites in the civil infrastructure. Disponível em: < http://www.sciencedirect.com >. Acesso em 10 de setembro de 2005.

JOSHI, J.; LEHMAN, R.; NOSKER, T. (2004). Selected physical characteristics of polystyrene/high density polyethylene composites prepared from virgin and recycled materials. Disponível em: <http://www.amipp.rutgers.edu/html/scholarly_pub.html>. Acesso em 20 Fev 2005. 
KRISHNASWAMY, P.; MIELE, C. R.; FRANCINI, R. B.; YURACKO, K.; YERACE, P. (1997). Field evaluation of recycled plastic lumber pallets. Department of Natural Resources of Ohio. Columbus: Battelle.

KRISHNASWAMY, P. (2001a). Feature-recycled plastic lumber standards. Disponível em: <http://www.astm.org/SNEWS/DECEMBER_2001/>. Acesso em 4 Fev 2005.

KRISHNASWAMY, P.; MCLAREN, M. G.; ASSIS, G.; PENSIERO, J.; MELEWSKI, P. M.; LASHWAY, K. F. (2001b). Introducing to the first recycled plastic bridge in the world. Disponível em: <http://www.maclaren.com/IBC\%20Paper.htm>. Acesso em 4 Fev 2005.

MANO, E. B.; MENDES, L. C. Introdução aos polímeros. 2. ed. São Paulo: Edgard Blücher, 1999. 191p.

MARAT-MENDES, R. (2003). Conceitos básicos de mecânica dos sólidos. Escola Superior de Tecnologia - IPS. Notas de aula.

MARCZAK, R. J. (2004). Polímeros como materiais de engenharia. Porto Alegre. UFRGS. Notas de aula. Disponível em:

<http://www-gmap.mecanica.ufrgs.br/sumulas/eng03005/download/Parte\%20I\%20-\%20v22.pdf> Acesso em 4 Fev 2005.

MCRUM, N. G. (1987). Principles of polymer engineering, 1st. Ed., Oxford Public.

MENEZES, M. S. (1989). Plástico reciclado: possibilidades de uso na construção e no mobiliário. 257p. Dissertação (Mestrado). Universidade de São Paulo, São Carlos. 1989.

MOTTA, Leila A. C.; SILKUNAS, N.; RODOLFO JÚNIOR, A. (2002). Durabilidade dos polímeros. Departamento de Engenharia de Construção Civil - PCC, Universidade de São Paulo, Escola Politécnica, São Paulo. Notas de aula.

MUSSOI, R. L. R.; VILLAÇA, M. V. M. (2000). Capacitores. Centro Federal de Educação Tecnológica de Santa Catarina - CEFET/SC, Florianópolis - SC. Notas de aula.

NOSKER, T.; RENFREE, R. (1999a). Developing a recycled plastic composite railroad tie. Plastics Engineering, v. 55, April 1999. 
PARENTE, Ricardo A. (2006). Elementos estruturais de plástico reciclado. Dissertação (Mestrado). Engenharia Estruturas - SET/EESC/USP, São Carlos - SP.

QUARMBY, A. (1976). Materiales plasticos y arquitectura experimental. Editorial Gustavo Gili, S.A. Barcelona.

ROCHA, Adélia C. P. F. (1990). Materiais plásticos para a construção civil. Lisboa, LNEC (Laboratório Nacional de Engenharia Civil) - ICT - informação científica.

SABINO, J. (2003). Critérios de resistência. Departamento de Engenharia Mecânica - DEM, ISEP, Porto - Portugal. Notas de aula.

SCHUT, J. H. (2004). They've been working on the railroad. Disponível em: <http://www.plastictechnology.com/article/200404fa3.html>. Acesso em 4 Fev 2005.

SILVA, José F. R. (2003). Cruzetas para redes de distribuição de energia elétrica à base de polipropileno. 92p. Dissertação (Mestrado). Universidade de São Paulo, São Carlos. 2003.

SILVESTRE FILHO, G. D. (2001). Comportamento mecânico do poliuretano derivado do óleo da mamona reforçado por fibra de carbono: contribuição para o projeto de hastes de implante de quadril. Dissertação (Mestrado). Universidade de São Paulo, São Carlos. 2001.

SOUZA, P. F. (2004). Estudo Experimental sobre o comportamento de dutos metálicos com geometria ziguezague. (Mestrado). Pontifícia Universidade Católica do Rio de Janeiro PUC - RIO, Rio de Janeiro. 2004.

SOUSA, J. A., HAJE, J. E. (2005). Compósitos termoplásticos. Engenharia de Materiais DEMa, UFSCar, São Carlos - SP.

SULLIVAN, H.W.; WOLFGANG, A.M. (1999). Polymeric compositions and methods for making construction materials from them. United States Patent. Patent Number: 5.886.078. 23 Mar 1999.

ZANIN, M., MANCINI, S. D. (2004). Resíduos plásticos e reciclagem: aspectos gerais e tecnologia. São Carlos; EdUFSCar. 


\section{Sítios Eletrônicos:}

AES Eletropaulo, Brasil. Disponível em: <http://www.eletropaulo.com.br>. Acesso em $17 / 05 / 2006$.

Centro de Materiais Avançados via Processamento de Polímeros Imiscíveis (AMIPP), New Jersey, EUA. Disponível em: <http://www.amipp.rutgers.edu>. Acesso em 01/05/2006.

Companhia Energética de Goiás, Brasil. Disponível em: <http://www.celg.com.br>. Acesso em $16 / 05 / 2006$.

Companhia Energética de Minas Gerais, Brasil. Disponível em: <http:// www.cemig.com.br>. Acesso em 17/05/2006.

Companhia Estadual de Energia Elétrica do Rio Grande do Sul, Brasil. Disponível em: <http:// www.ceee.com.br>. Acesso em 18/05/2006.

Companhia Paulista de Força e Luz, Brasil. Disponível em: <http://www.cpfl.com.br>. Acesso em 17/05/2006.

Departamento Estadual de Habitação e Obras Públicas do Sergipe, Brasil. Disponível em: <http://www.cehop.se.gov.br>. Acesso em 17/05/2006.

Empresa Cogumelo, Brasil. Disponível em: <http://www.cogumelo.com.br>. Acesso em $16 / 05 / 2006$.

Empresa Fibertex, Brasil. Disponível em: <http://www.fibertex.com.br>. Acesso em 01/07/2006.

Empresa Jabu Engenharia Elétrica, Brasil. Disponível em: <http://www.jabu.com.br>. Acesso em 18/04/2006.

Empresa Maxepoxi, Brasil. Disponível em: <http://maxepoxi.com.br>. Acesso em 10/02/2006.

Empresa Owenscorning, Brasil. Disponível em: <http://www.owenscorning.com.br>. Acesso em 20/02/2007. 
Empresa Postes Indaial, Brasil. Disponível em: <http://www.postes.com.br>. Acesso em 18/05/2006.

Instituto Avançado do Plástico - IAP. Disponível em:

<www.planetaplastico.com.br/lite_intro.htm>. Acesso em 31/01/2006.

Instituto Avançado do Plástico - IAP: Principais Impactos Ambientais Decorrentes do Manuseio e Transformação de Plásticos. Disponível em:

<www.planetaplastico.com.br/ lite_ambiente.htm>. Acesso em 03/04/2006.

INTERNATIONAL ASSOCIATION OF PLASTICS DISTRIBUTORS - IAPD: How plastics are made. Disponível em: <www.modernplastics.com/pdf/IAPD_plastics_intro1.pdf>. Acesso em 16/01/2006.

Jornal de plásticos, Brasil. Disponível em: <http://www.jorplast.com.br/cbip.html>. Acesso em 01/04/2006.

Laboratório de engenharia de polímeros e compósitos - LEPCom, da Universidade Federal de Minas Gerais (UFMG). Disponível em:

$<$ http://www.demet.ufmg.br/docentes/rodrigo/processamento.htm>

Mosanto House of the Future, EUA. Disponível em:

<http://www.yesterland.com/futurehouse.html>. Acesso em 10/05/2006.

Princípios e projetos de estruturas, EUA. Disponível em:

<http://www.dr-z.net/article_info.php/articles_id/1>. Acesso em 11/05/2006.

Revista Arquitecture Week, EUA. Disponível em:

<http://www.architectureweek.com/2005/0914/design_1-2.html>. Acesso em 16/05/2006.

Sindicato da Indústria de Resinas Plásticas (SIRESP), Brasil. Disponível em: $<$ http://www.siresp.org.br>. Acesso em 29/05/2006.

Universidade Federal de Santa Catarina, Brasil. Disponível em: <http://www.arq.ufsc.br/ labcon/arq5661/trabalhos_2004-2/plasticos/exemplos>. Acesso em $16 / 05 / 2006$. 


\section{Ensaios mecânicos}

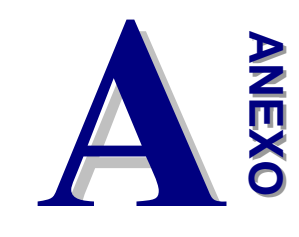

\section{Considerações Iniciais}

Os ensaios de tração, flexão e compressão são executados na "Máquina Universal de Ensaios", que consiste em um conjunto formado por duas travessas, sendo uma fixa e a outra móvel, célula de carga, mecanismo de direcionamento, acessórios de fixação dos corpos-de-prova e dos extensômetros.

Na travessa móvel são acoplados: (i) o mecanismo de direcionamento, que é responsável pelo controle do sentido de aplicação da carga e pela velocidade do ensaio (que deve ser constante e pré-determinada para cada tipo de ensaio) e (ii) uma célula de carga, que registra a carga aplicada durante o ensaio. Essas células devem ser escolhidas de modo a se obter uma boa sensibilidade nos ensaios, o que é feito por meio da tomada de valores de fundo de escala (que corresponde à capacidade da célula de carga, que normalmente é de $0,5 \mathrm{kN}, 5 \mathrm{kN}$ e $50 \mathrm{kN}$ ), seu erro percentual e os valores estimados das cargas máximas necessárias para ensaio do material.

Nos ensaios de tração são acoplados dispositivos de fixação dos corpos-de-prova (garras) às travessas móveis; nos ensaios de compressão são utilizadas duas barras, fixadas na travessa móvel e na fixa, e no ensaio de flexão utilizam-se apoios para ensaios de três ou de quatro pontos, sendo que um ou dois pontos são acoplados à travessa móvel (aplicação de carga), e os outros dois são conectados a uma base presa na travessa fixa.

Os extensômetros são utilizados em ensaios que necessitem de precisão elevada para medir as deformações do material durante os ensaios. Essas deformações também podem ser registradas pelo deslocamento da travessa móvel em relação à travessa fixa, em ensaios que não exijam maior precisão.

Com relação aos ensaios de impacto, sua utilização é muito importante devido ao fato de que as peças de plástico podem ser submetidas a solicitações elevadas, num período de tempo muito curto. Sendo assim, a resistência ao impacto é uma das propriedades mais requisitadas para a avaliação do comportamento mecânico dos polímeros. Esses ensaios são realizados em uma máquina que utiliza martelos (strikers), acoplados a pêndulos ou em queda livre, que permitem medir a energia consumida pelo material durante a solicitação sob impacto, por meio de um balanço de energias potencial e cinética ao qual o martelo é submetido. 


\subsection{Propriedades mecânicas sob tração}

Nos ensaios de tração os corpos-de-prova são afixados em garras, que são acopladas à travessa móvel e à fixa da Máquina Universal de Ensaios. A taxa de deformação de tração é controlada pelo mecanismo de direcionamento, enquanto que a tensão de tração é registrada pela célula de carga.

A figura A.1 representa esquematicamente o dispositivo utilizado em ensaios de tração uniaxial.

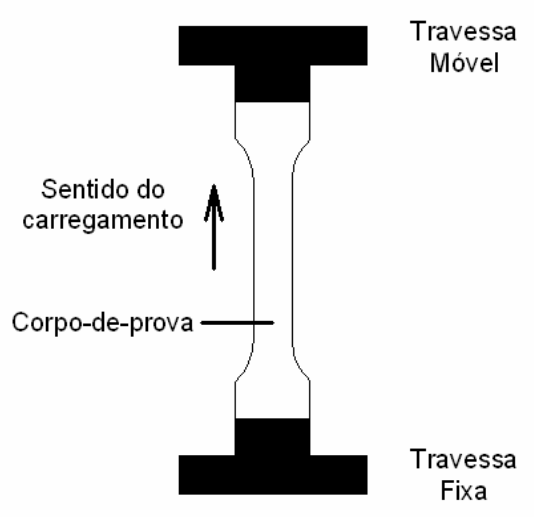

Figura A.1: Representação esquemática do dispositivo de ensaio de tração uniaxial.

Fonte: Canevarollo (2005).

Dois tipos de garras podem ser utilizados nos ensaios de tração: com acionamento manual ou pneumático. A maioria dos termoplásticos rígidos é ensaiada utilizando-se garras de acionamento manual, que possuem serrilhados nas superfícies de contato com os corpos-de-prova, impedindo assim seu deslizamento durante o ensaio.

No caso da utilização de extensômetros, sua escolha é condicionada de acordo com o parâmetro mecânico a ser medido. Para medidas do módulo de elasticidade a baixas e médias extensões, são utilizados extensômetros de elevada precisão (maior que 98\%); para medidas de elevadas extensões, como elongação na ruptura, são utilizados extensômetros específicos. Os do tipo micrômetro, que medem até $0,02 \mathrm{~mm}$, são utilizados para medir a variação da largura e da espessura dos corpos-de-prova, obtendo-se assim parâmetros como o coeficiente de Poisson do material.

\subsubsection{Corpos-de-prova}

Os corpos-de-prova para o ensaio de tração possuem forma de halteres, e suas dimensões devem ser escolhidas de acordo com o comportamento mecânico do polímero a ser ensaiado. Na figura A.2 é mostrada a geometria do corpo-de-prova a ser utilizado no ensaio de tração segundo a norma ASTM 638/03. 
L (Comprimento do corpo-de-prova)

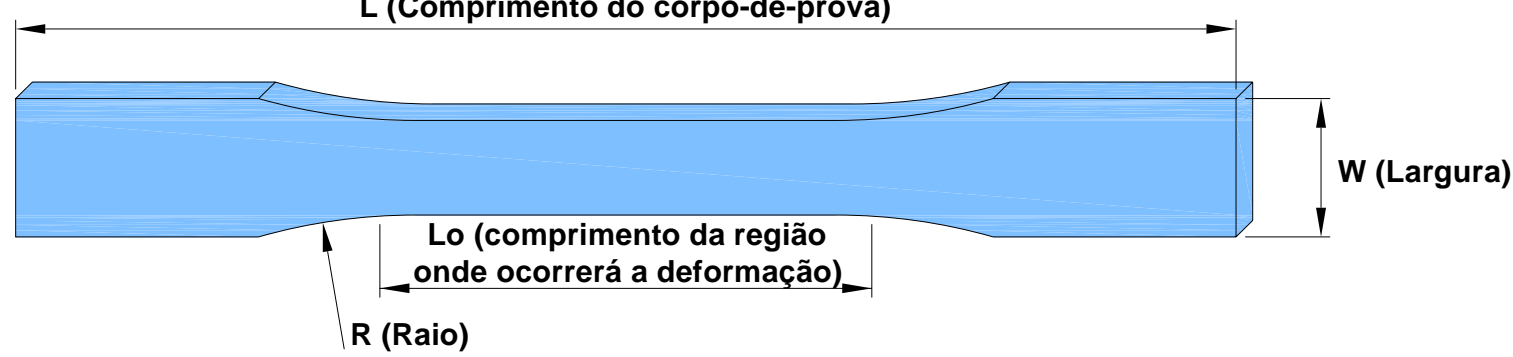

Figura A.2: Geometria e dimensões típicas de corpos-de-prova para ensaios de tração em polímeros.

Fonte: Canevarollo (2005).

Para plásticos rígidos e semi-rígidos, existem cinco tipos de corpos-de-prova que podem ser utilizados, sendo que o tipo I é destinado aos casos em que o corpo-de-prova possui espessura de $7 \mathrm{~mm}$ ou menos; o tipo II é utilizado quando o material não rompe onde ocorre o estreitamento de seção transversal; o tipo III é destinado para os elementos com espessura maior que $7 \mathrm{~mm}$ e inferior a $14 \mathrm{~mm}$; o tipo IV deve ser utilizado para comparar materiais com rigidezes diferentes; e o tipo $V$ deve ser utilizado para espessuras de $4 \mathrm{~mm}$, ou menos, ou quando se tem um grande número de corpos-de-prova para serem ensaiados.

\subsubsection{Velocidade do ensaio}

A velocidade do ensaio define a taxa de deformação que será aplicada ao polímero.

\subsubsection{Definição dos parâmetros}

Nos ensaios de tração, os principais parâmetros mecânicos medidos ou calculados são:

- Tensão nominal de tração $\left(\sigma_{t}\right)$ : é a razão entre a carga ou força de tração $(F)$ e a área da seção transversal inicial do corpo-de-prova ( $\left.A_{0}\right)$, em MPa (Equação A.1).

$$
\sigma_{t}=\frac{F}{A_{0}}
$$

- Resistência nominal à tração: é a máxima tensão (nominal) sob tração sustentada pelo corpo-de-prova durante o ensaio. Quando a tensão máxima ocorre no ponto de escoamento, ela recebe o nome de Resistência à Tração no Escoamento. São expressas em MPa.

- Comprimento inicial entre marcas $\left(L_{o}\right)$ : é o comprimento de uma região do corpode-prova onde ocorrerá a deformação ou a mudança no comprimento. É expresso em milímetros. 
- Elongação (D): é o incremento do comprimento entre marcas, produzido no corpode-prova, para o qual será determinada a deformação ou a mudança no corpo-deprova. É expresso em milímetros.

- Elongação percentual $(\Delta L)$ : é o incremento da distância entre marcas em um determinado estágio da extensão (D), em relação ao comprimento inicial entre marcas $\left(L_{0}\right)$. É determinado pela equação A.2 e expresso em percentagem (\%).

$$
\Delta L=\frac{D}{L_{0}}
$$

- Deformação de tração $\left(\varepsilon_{t}\right)$ : é a razão entre a variação do incremento da distância entre marcas $(\Delta L)$ e o comprimento inicial entre marcas $\left(L_{0}\right)$, dada pela equação A.3.

$$
\varepsilon_{t}=\frac{\Delta L}{L}=\frac{\left(L_{0}-L\right)}{L}
$$

- Empescoçamento: redução da seção transversal que pode ocorrer em material quando ele é submetido à tração.

- Ponto de escoamento: é o primeiro ponto de uma curva tensão versus deformação, no qual um aumento de deformação ocorre sem aumento de tensão.

- Tensão de escoamento: é a tensão na qual existe um desvio do limite de elasticidade. Para materiais em que o ponto de escoamento é nítido, é denominada tensão no ponto de escoamento; se ocorrer tensão máxima no ponto de escoamento, é denominada Resistência à Tração no Escoamento.

- Módulo de Elasticidade na Tração (E): é a razão entre a tensão de tração nominal e a deformação correspondente, abaixo do limite de proporcionalidade do material (Equação A.4). É expressa em MPa.

$$
\mathrm{E}=\frac{\sigma}{\varepsilon}
$$

- Limite de proporcionalidade: é a maior tensão que o material suporta sem que exista perda de proporcionalidade entre tensão e deformação. É expresso em MPa.

- Módulo secante: razão entre a tensão nominal e uma deformação em qualquer ponto específico da curva tensão versus deformação. Deve ser fornecido juntamente com a tensão ou deformação adotada para cálculo, e é adotado para materiais cujo diagrama tensão versus deformação não demonstra proporcionalidade entre tensão e deformação. 
Se o material apresenta comportamento linear (hookeano), o módulo de elasticidade pode ser determinado utilizando-se a reta $C D$, por meio da divisão da tensão pela deformação em qualquer ponto dessa reta (Fig.A.3a). O ponto deslocado B é admitido como o de deformação nula, e é o ponto a partir do qual são medidas todas as deformações, incluindo a deformação deslocada de escoamento, BE, que corresponde a $1 \%$ da deformação. A partir do ponto $E$, traça-se uma paralela à reta $\mathrm{CD}$, obtendo-se o ponto de escoamento $\mathrm{F}$.

Se o material não apresentar comportamento linear (Fig.A.3b), a mesma correção deve ser feita por meio da construção de reta tangente na máxima inclinação, no ponto de inflexão, obtendo-se a reta H'K'. Prolongando-se essa reta até o eixo de deformação, obtémse o ponto B'. Para obtenção do módulo secante é necessário que seja traçada uma reta entre o ponto B' e o ponto de escoamento, que é representado por G', que é obtido por meio da soma de $1 \%$ ao segmento A'B' e traçando-se uma paralela à reta $\mathrm{H}^{\prime} \mathrm{K}^{\prime}$, a partir do ponto $\mathrm{B}^{\prime}$ deslocado de uma deformação de $1 \%$.

Em uma curva típica de tensão versus deformação, pode existir uma região que não representa o comportamento do material ensaiado (segmento $A C$ ), pois corresponde a uma folga ou ao ajuste das garras, no início do ensaio.

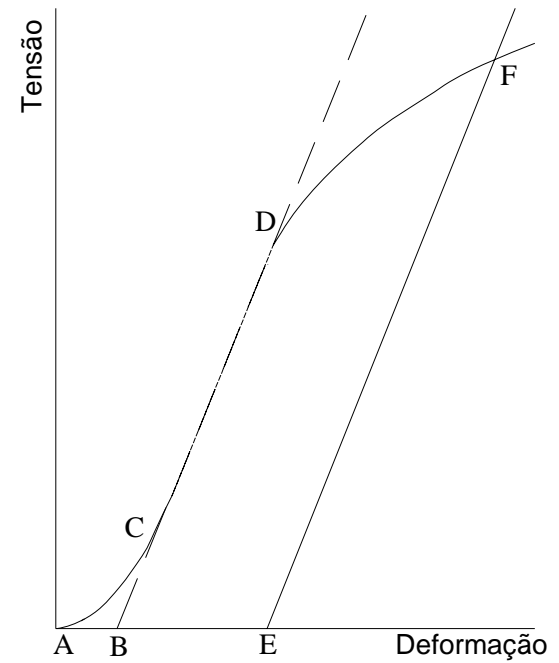

(a)

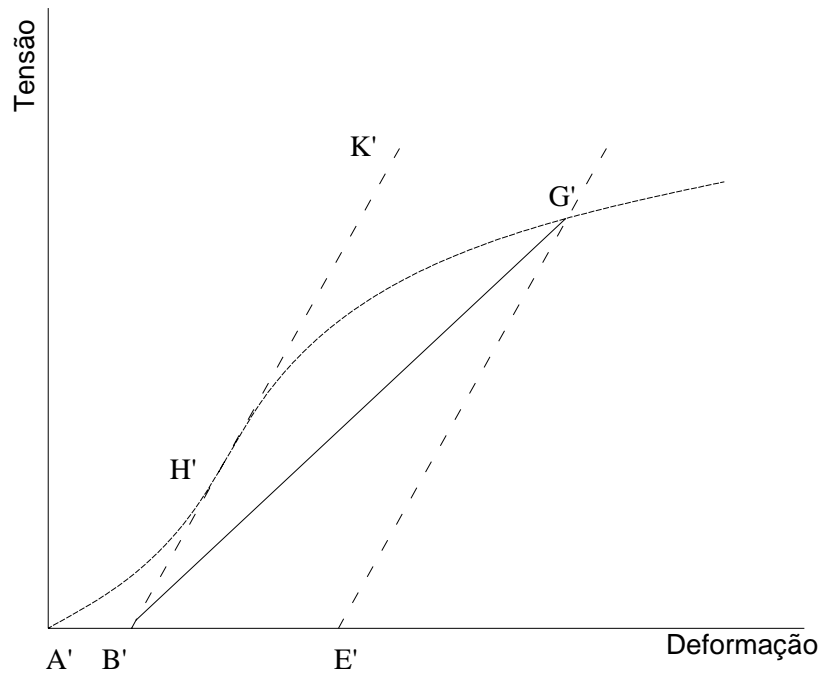

(b)

Figura A.3: Diagrama tensão versus deformação para material com comportamento linear (a) e não linear (b).

Fonte: ASTM D638/03. 


\subsection{Propriedades mecânicas sob flexão}

A Norma ASTM D790/03 é designada para os ensaios de flexão que utilizam o carregamento em um sistema de ensaio de três pontos. Para os casos em que os materiais não rompem na máxima deformação permitida para o ensaio de três pontos, deve ser utilizada a Norma ASTM D6272, que utiliza um sistema de ensaio de quatro pontos.

Segundo a ASTM D790/03, existem dois procedimentos de ensaio, sendo que o procedimento $A$ é utilizado para materiais que rompem quando submetidos a pequenos deslocamentos, enquanto o procedimento B é utilizado para materiais que suportam grandes deslocamentos durante o ensaio.

Nos ensaios de flexão em três pontos, o corpo-de-prova, que possui o formato ilustrado na figura A.4 e dimensões citadas no item 1.2.2. Para o ensaio o corpo-de-prova é ajustado entre dois apoios fixados a um suporte (travessa fixa), e o carregamento é aplicado pelo terceiro apoio (travessa móvel), posicionado a uma distância média entre os apoios fixados aos suportes. Os apoios devem possuir superfícies cilíndricas, evitando-se assim possíveis falhas devido à concentração de tensão nos corpos-de-prova.

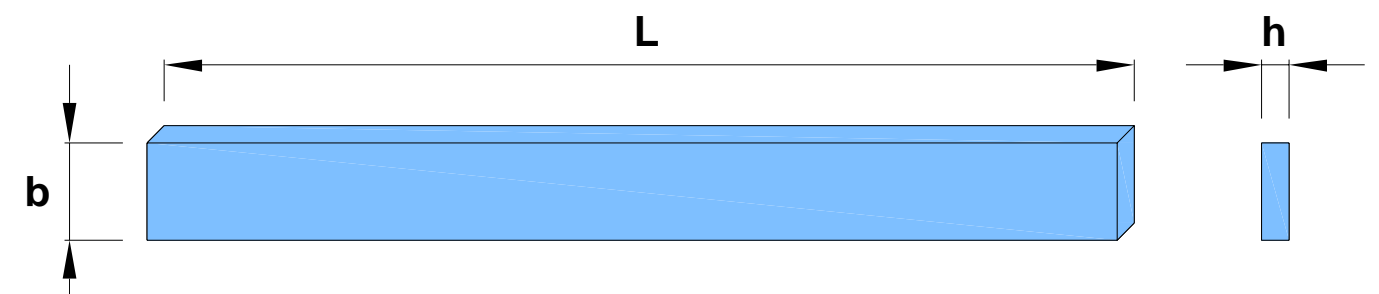

Figura A.4: Geometria dos corpos-de-prova para ensaios de flexão em polímeros.

Fonte: Canevarollo (2005).

A distância entre os apoios deve ser ajustada de modo que a razão $L / h$ seja igual a 16. Nesse ensaio, o corpo-de-prova é fletido até que ocorra ruptura na face oposta à do carregamento ou até que uma deformação máxima de $5 \%$ seja alcançada, não podendo ser determinada para os materiais que não obedecem a esses critérios.

Para um ensaio de flexão em três pontos, o deslocamento no qual a deformação máxima permitida (5\%) irá ocorrer pode ser calculada pela equação A.5, na qual $r$ é igual a $0,05 \mathrm{~mm} / \mathrm{mm}, D$ é o deslocamento no ponto médio entre os apoios, $L$ é a distância entre os apoios e $h$ é a profundidade do corpo-de-prova.

$$
D=\frac{r L^{2}}{6 h}
$$

Para os materiais que não rompem até a máxima deformação permitida, é indicado o ensaio de flexão de quatro pontos. A diferença básica entre os dois métodos de ensaio está 
relacionada com a localização do momento de carga máxima e na tensão de tração máxima axial na superfície oposta à do carregamento, pois a tensão máxima no ensaio de três pontos ocorre abaixo do ponto de carregamento, enquanto no ensaio de quatro pontos ocorre na região entre os pontos de carregamento.

A figura A.5 ilustra os dispositivos de ensaio de três pontos, segundo a Norma ASTM D790/03.

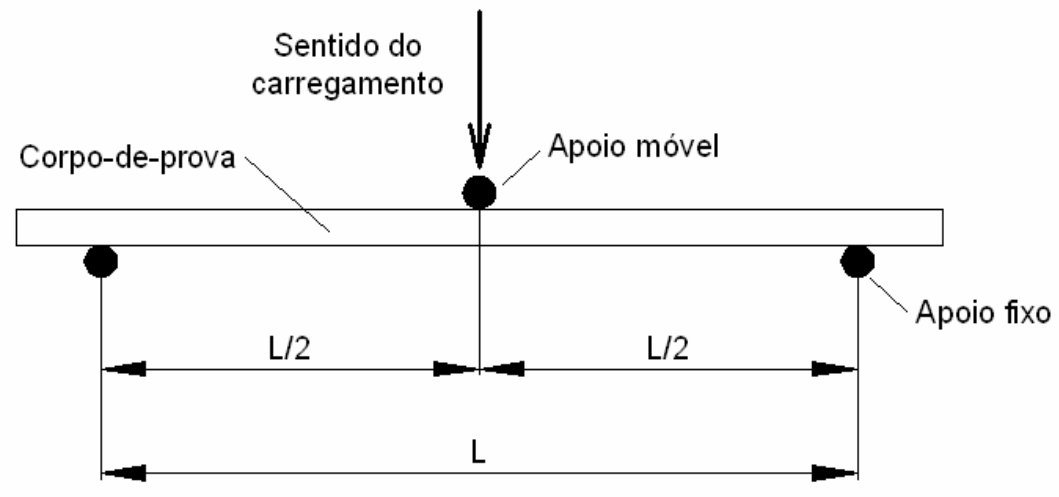

Figura A.5: Representação esquemática de ensaio de flexão em três pontos.

Fonte: Canevarollo (2005).

\subsubsection{Corpos-de-prova}

Os corpos-de-prova para ensaios de resistência à flexão são preparados na forma de barras retangulares com seção transversal plana. A figura A.6 ilustra a geometria típica dos corpos-de-prova para ensaios de flexão, onde $L$ é o vão, $b$ é a largura e $h$ é a altura. Para a execução desse ensaio, foram adotadas as dimensões: $L=101,5 \mathrm{~mm}, \quad b=12,7 \mathrm{~mm}$ e $\mathrm{h}=6,4 \mathrm{~mm}$.

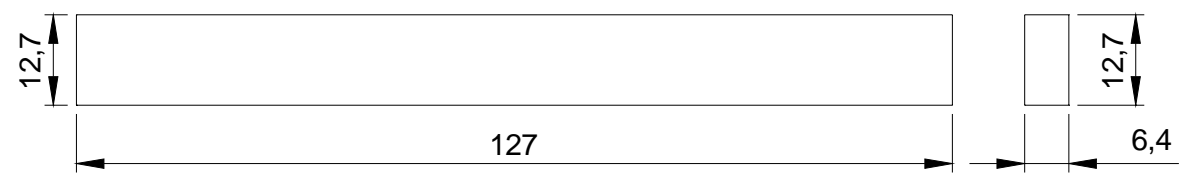

Figura A.6: Corpo-de-prova utilizado no ensaio de flexão.

Fonte: Canevarollo (2005).

\subsubsection{Velocidade do ensaio}

A velocidade do ensaio deve estar de acordo com o procedimento a ser utilizado. Os valores são de $0,01 \mathrm{~mm} / \mathrm{mm} / \mathrm{min}$ ou $0,10 \mathrm{~mm} / \mathrm{mm} / \mathrm{min}$.

A velocidade da travessa fixa é calculada a partir da taxa de deformação a ser utilizada (Equação A.6), onde $R$ é a velocidade da travessa fixa, $L$ é a distância entre os 
apoios, $h$ é a altura do corpo-de-prova e $z$ é a taxa de deformação na superfície oposta à do carregamento.

$$
R=\frac{z L^{2}}{6 h}
$$

\subsubsection{Definição dos parâmetros}

Os principais parâmetros mecânicos a serem medidos ou calculados nos ensaios de flexão são:

- Tensão de Flexão $\left(\sigma_{f}\right)$ : em ensaios de flexão em três pontos, é a tensão máxima que ocorrerá na superfície oposta à do carregamento. Para materiais cuja tensão é proporcional à deformação até o ponto de ruptura, pode ser calculada em qualquer ponto da curva carga versus deslocamento por meio da equação A.7, em que $P$ é a carga (em Newtons), L é a distância entre os apoios, b é a largura e h é a altura do corpo-de-prova (em milímetros).

$$
\sigma_{f}=\frac{3 P L}{2 b h^{2}}
$$

- Resistência à flexão $\left(\sigma_{f M}\right)$ : é a máxima tensão sob flexão resistida pelo corpo-deprova, durante o ensaio de flexão. É expressa em MPa.

- Deformação na flexão $\left(\varepsilon_{f R}\right)$ : é a variação percentual no incremento do comprimento de um elemento na superfície oposta à do carregamento, na qual a deformação máxima irá ocorrer. É dada pela equação A.7.

$$
\varepsilon_{f}=\frac{6 D h}{L^{2}}
$$

- Módulo de elasticidade tangente $\left(E_{f}\right)$ : também chamado de módulo de elasticidade, é a razão (dentro do limite de elasticidade) entre a tensão de flexão e a deformação correspondente. É calculado traçando-se uma tangente na porção linear da curva carga versus deslocamento, e aplicando-se a equação A.8, em que $m$ é a inclinação da curva.

$$
\mathrm{E}_{f}=\frac{L^{3} m}{4 b h^{3}}
$$

\subsection{Propriedades mecânicas sob compressão}

Segundo a Norma ASTM D695/02a, os corpos-de-prova devem ter formas de cilindros ou prismas, cujo comprimento e altura são o dobro de suas larguras ou diâmetro 
(Figura A.7a). Os corpos-de-prova mais utilizados nesse ensaio possuem 12,7mm x 12,7mm x 25,4mm para os prismáticos e $12,7 \mathrm{~mm} \times 25,4 \mathrm{~mm}$ para os cilíndricos. Entretanto, quando se deseja obter o módulo de elasticidade e a tensão no ponto de escoamento, utilizam-se as dimensões de $12,7 \mathrm{~mm} \times 12,7 \mathrm{~mm} \times 50,8 \mathrm{~mm}$ para os prismáticos e $12,7 \mathrm{~mm} \times 50,8 \mathrm{~mm}$ para os cilíndricos. O dispositivo utilizado em ensaios de compressão é esquematizado na figura A.7b.
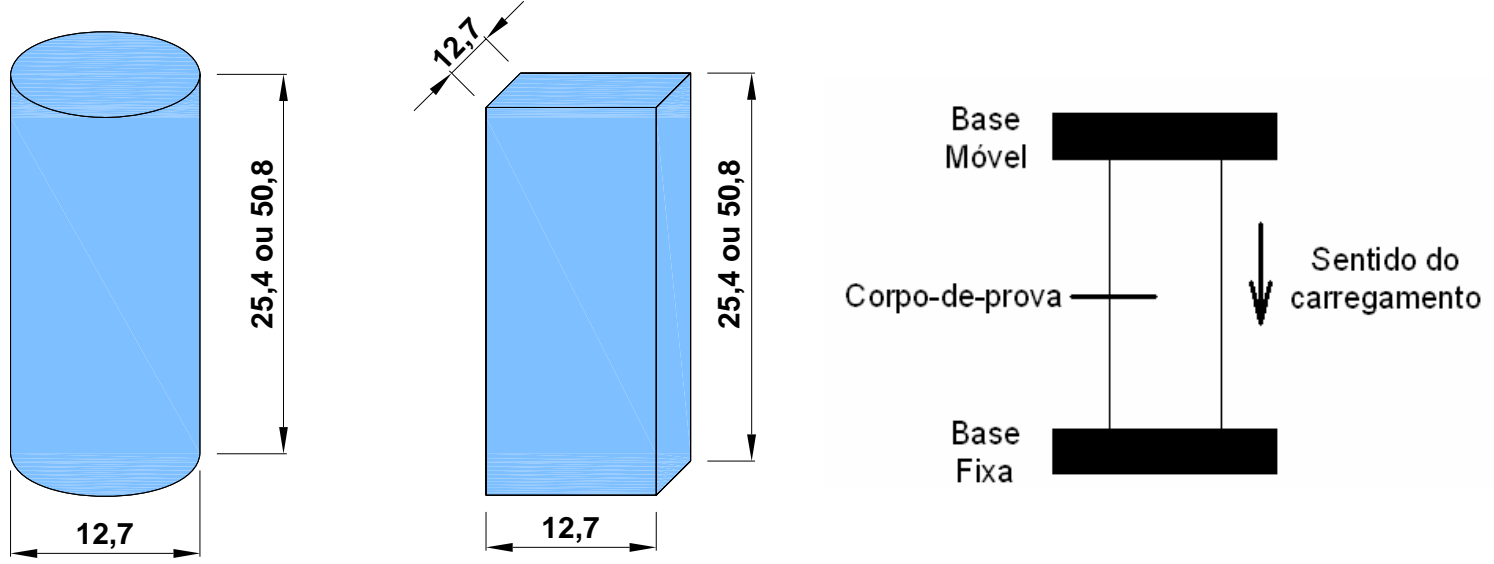

Figura A.7: Corpo-de-prova utilizado no ensaio de compressão (a) e representação esquemática de ensaio de compressão (b).

Fonte: Canevarollo (2005).

\subsubsection{Velocidade do ensaio}

A velocidade padrão dos ensaios de compressão é de $1,3 \pm 0,3 \mathrm{~mm} / \mathrm{min}$. Quando materiais dúcteis forem ensaiados, após o corpo-de-prova atingir o ponto de escoamento, a velocidade deve ser elevada para 5 a $6 \mathrm{~mm} / \mathrm{min}$ e prosseguir até a ruptura do material.

\subsubsection{Definição dos parâmetros}

Os principais parâmetros mecânicos que são medidos ou calculados nos ensaios de compressão são:

- Tensão nominal de compressão $\left(\sigma_{c}\right)$ : é a razão entre a carga ou força de compressão (F) e a área da seção transversal inicial do corpo-de-prova $\left(A_{0}\right)$, e é dada pela equação A.9, sendo expressa em MPa.

$$
\sigma_{c}=\frac{F}{A_{0}}
$$

- Resistência nominal à compressão: é a máxima tensão (nominal) sob compressão, resistida pelo corpo-de-prova durante o ensaio de compressão. É expressa em MPa. 
- Resistência (nominal) à compressão na ruptura: é a tensão (nominal) sob compressão, resistida pelo corpo-de-prova no momento da ruptura. É expressa em MPa.

- Ponto de escoamento: é o primeiro ponto na curva tensão versus deformação no qual existe um aumento de deformação sem que haja aumento de tensão.

- Resistência (nominal) à compressão no escoamento: é a tensão (nominal) sob compressão, resistida pelo corpo-de-prova, no ponto de escoamento. É expressa em MPa.

- Deformação sob compressão $\left(\varepsilon_{c}\right)$ : é a razão entre a variação do comprimento do corpo-de-prova e o comprimento original ao longo do eixo longitudinal, e é dada pela equação A.10.

$$
\varepsilon_{c}=\frac{\Delta L}{L_{0}}=\frac{\left(L-L_{0}\right)}{L_{0}}
$$

- Módulo de Elasticidade $\left(\mathrm{E}_{c}\right)$ : é a razão (dentro do limite de proporcionalidade) entre a tensão de compressão nominal e a deformação correspondente. É expresso em MPa.

\subsection{Resistência ao impacto}

Tenacidade pode ser definida como a capacidade que um material possui de absorver energia sem sofrer ruptura. É um parâmetro muito importante na caracterização de um material, pois simula a aplicação repentina de uma força. Assim, a resistência ao impacto (ou tenacidade sob impacto) depende da força máxima que um material deve suportar sob impacto sem se romper. Essa força, multiplicada pela deformação correspondente, representa o valor da tenacidade sob impacto.

\subsubsection{Parâmetros que afetam as propriedades sob impacto}

\section{a) Taxa ou velocidade de solicitação sob impacto}

A velocidade com que um corpo-de-prova ou uma peça plástica é ensaiado ou atingido por algum objeto tem um efeito significativo sobre o comportamento do material polimérico. Um exemplo disso é o fato dos plásticos mais rígidos apresentarem boa resistência ao impacto a baixas taxas de velocidade. 


\section{b) Sensibilidade ao entalhe}

Um entalhe inserido em um corpo-de-prova ou a utilização de cantos vivos em peças plásticas reduzem consideravelmente a resistência do material ao impacto, pois criam tensões localizadas e aumentam o valor da tensão em relação à tensão suportada pelo material antes de se romper.

A profundidade e o raio de curvatura da extremidade do entalhe têm efeito significativo sobre a perda de resistência do corpo-de-prova. Assim como furos passantes, cantos vivos também provocam a concentração de tensão, devendo ser evitados durante o projeto.

\section{c) Temperatura}

O comportamento dos plásticos é dependente da temperatura de uso e de ensaio, pois, a temperaturas muito baixas, a resistência ao impacto é reduzida e, a temperaturas acima da transição vítrea, a resistência ao impacto apresenta um aumento significativo. $\mathrm{Na}$ maioria dos casos, os componentes plásticos são projetados para serem utilizados à temperatura ambiente $\left(20^{\circ} \mathrm{C}\right)$. Entretanto, sob ação de intempéries, a temperatura pode variar bastante.

\section{d) Orientação molecular}

A maneira como as moléculas se orientam em uma peça durante a sua produção influenciam de maneira direta o comportamento mecânico do material polimérico. As peças devem ser moldadas de maneira isotrópica, evitando assim que exista um desequilíbrio de resistências numa peça, causando assim uma resistência global inferior.

\section{e) Condições e tipos de processamento}

Condições inadequadas de processamento podem causar a perda de tenacidade sob impacto de materiais poliméricos, pois podem provocar linhas de solda e conseqüente concentração de tensões, assim como a ocorrência de temperaturas elevadas de processamento pode causar degradação térmica e influir na resistência ao impacto.

\subsubsection{Ensaio Izod}

O objetivo desse ensaio é medir o comportamento de um corpo-de-prova ao impacto, por meio de uma máquina de ensaio pendular (Fig.A.8), sendo os resultados expressos em termos de energia cinética consumida pelo pêndulo durante a ruptura do corpo-de-prova. $A$ energia requerida para quebrar um corpo-de-prova padrão é a soma das energias 
necessárias para deformá-lo, iniciar seu processo de fratura e propagá-lo ao longo de sua seção transversal.

Segundo a norma ASTM D256/04, o corpo-de-prova utilizado nesse tipo de ensaio deve ser entalhado e posicionado em forma vertical em relação à base do equipamento, devendo o entalhe ficar posicionado no lado no qual o martelo do pêndulo atingirá o corpode-prova.

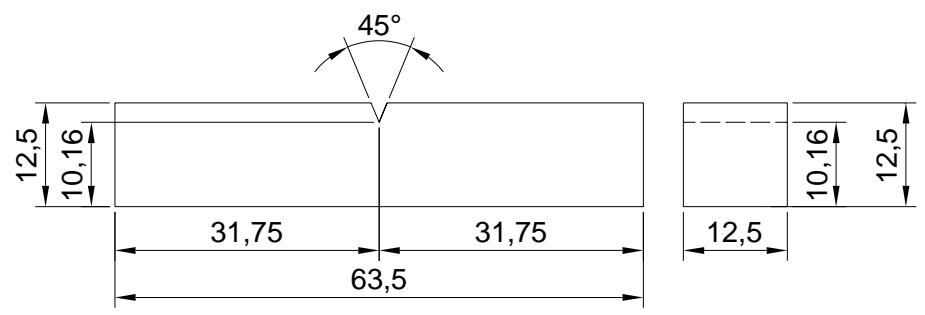

Figura A.8: Corpo-de-prova utilizado no ensaio de impacto.

Fonte: Canevarollo (2005).

O ensaio consiste em, inicialmente, zerar a escala de medida de energia, utilizando o martelo com um peso adequado (após o movimento completo do pêndulo, o registrador deve ser zerado). Em seguida é feita a fixação do corpo-de-prova na posição vertical, na base do equipamento, voltando o entalhe para o lado em que o martelo o atingirá. Libera-se o martelo, que atinge o corpo-de-prova e determina a energia utilizada para rompê-lo.

Para cálculo da resistência ao impacto, basta dividir o valor de energia pela espessura do corpo-de-prova, preferencialmente, ou pela área da seção transversal do corpo-de-prova na região do entalhe. As unidades de resistência ao impacto Izod são joules por metro de espessura $(\mathrm{J} / \mathrm{m})$ ou joules por metro quadrado $\left(\mathrm{J} / \mathrm{m}^{2}\right)$. 
A transformação dos materiais e a utilização da energia e da água, juntamente com a geração de resíduos, fazem parte de nosso cotidiano. Essa geração de resíduos depende de vários fatores, como os fatores culturais, de consumo, de renda, padrão de vida da população, economia de um país, dentre outros.

Segundo Zanin e Mancini (2004), a relação do homem com a natureza, a disponibilidade dos recursos materiais e energéticos do país e o aumento do volume de resíduos e o seu destino são questões muito discutidas atualmente. Devido a esse aumento na geração de resíduos houve uma alteração na conscientização sobre o destino dos resíduos, que antes eram desperdiçados e agora passaram a ser reciclados, recuperando assim matéria-prima, diminuindo as quantidades encaminhadas aos aterros e lixões, reduzindo a exploração de recursos naturais e criando oportunidade e renda a populações carentes. Assim, o resíduo passou a se distinguir do lixo e passou a ser visto como um produto que tem valor na cadeia produtiva da reciclagem, aos quais são atribuídos custos econômicos e ambientais.

Atualmente, a política tradicional de tratamento de lixo, que antes era baseada em um modelo linear de desenvolvimento (Fig. B1) e no fato de se considerar a natureza como uma fonte inesgotável de recursos materiais e energéticos, está sendo substituída por um modelo baseado em ciclos de vida e integração da gestão de resíduos, que possui como objetivos: (i) evitar ou, quando não for possível, diminuir a produção de resíduos, (ii) reutilizar ou, quando não for possível, reciclar os resíduos, (iii) utilizar a energia presente nos resíduos e (iv) inertizar e dispor os resíduos sem valor.

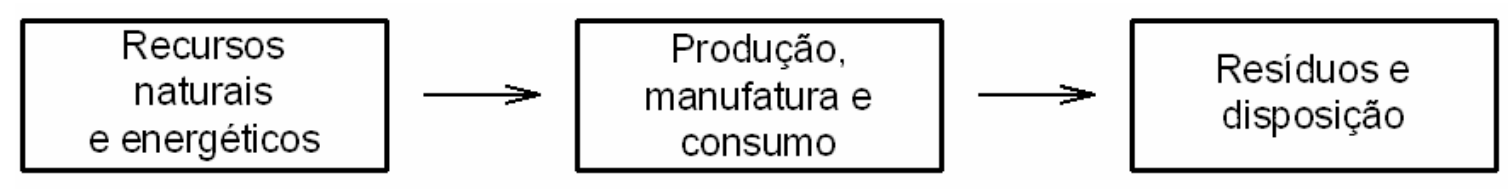

Figura B1: Modelo linear de desenvolvimento. Fonte: Zanin e Mancini (2004).

Segundo Zanin e Mancini (2004), a atividade de reciclagem é tão recente quanto aos polímeros. No Brasil, em termos de produção, a indústria da reciclagem é comparável à de países desenvolvidos. Entretanto, ela lida com alguns problemas particulares, tais como: 
- as grandes dimensões do país, que acarretam em problemas de transporte de matériaprima (por ser leve e volumosa) e de produtos, o que gera uma descentralização da atividade industrial;

- o fato de o mercado consumidor não estar preocupado com o meio ambiente e de só consumir o material reciclado quando este for mais barato que o virgem;

- os problemas com coletas seletivas mal executadas, que resultam em plásticos de baixa qualidade e que demandam tratamento posterior; e

- dificuldade de abastecimento freqüente de matéria-prima para as indústrias consumidoras, o que resulta em paradas das linhas de produção e causa perda de lucros e desestímulo na utilização desse tipo de material.

Apesar das dificuldades enfrentadas por esse setor, as vantagens obtidas pela reciclagem fazem com que essa indústria cresça a cada ano.

\subsection{Tipos de reciclagem de plásticos}

Segundo Zanin e Mancini (2004), a ASTM D5033-90 descreve a divisão entre os tipos de reciclagem para os materiais poliméricos, que podem ser: reciclagem primária, secundária, terciária e quaternária.

A reciclagem primária é aquela designada aos materiais adquiridos em fontes limpas e confiáveis. Nesse processo o material é submetido a uma seleção de resíduos, moagem, lavagem, secagem e a um reprocessamento em extrusoras ou injetoras. Ao final desse processo o material reciclado possui propriedades semelhantes às da resina virgem. Quando os materiais provêm de resíduos sólidos urbanos, sua reciclagem possui o nome de reciclagem secundária. Nesse caso o material passa pelo mesmo processo de tratamento da reciclagem primária, porém, suas propriedades finais são inferiores às da resina virgem. $\mathrm{Na}$ reciclagem terciária o processo utilizado para reciclar o plástico é baseado na despolimerização, ou seja, quando é promovida uma decomposição química do material, que poderá ser submetido a novos processos de polimerização e, após seu processamento, poderá ser reutilizado. A reciclagem quaternária utiliza a combustão e visa obtenção de energia, por meio da liberação de gases, como o dióxido de carbono, proveniente dessa queima.

Além dessa divisão entre os tipos de reciclagem, a ASTM D5033-90 ainda possui uma outra classificação, baseada no processo de reciclagem que o plástico sofrerá. 


\subsubsection{Reciclagem mecânica}

A reciclagem mecânica (Fig. B.2) é o processo pelo qual o plástico passa por etapas de seleção, moagem, lavagem, secagem, aglutinação (no caso de filmes) e reprocessamento, obtendo-se, assim, grânulos ou uma peça de material polimérico reciclado.

Segundo Zanin e Mancini (2004), esse processo admite que sejam incorporadas cargas ou aditivos durante o processamento, visando a obtenção de um produto com melhores propriedades finais.

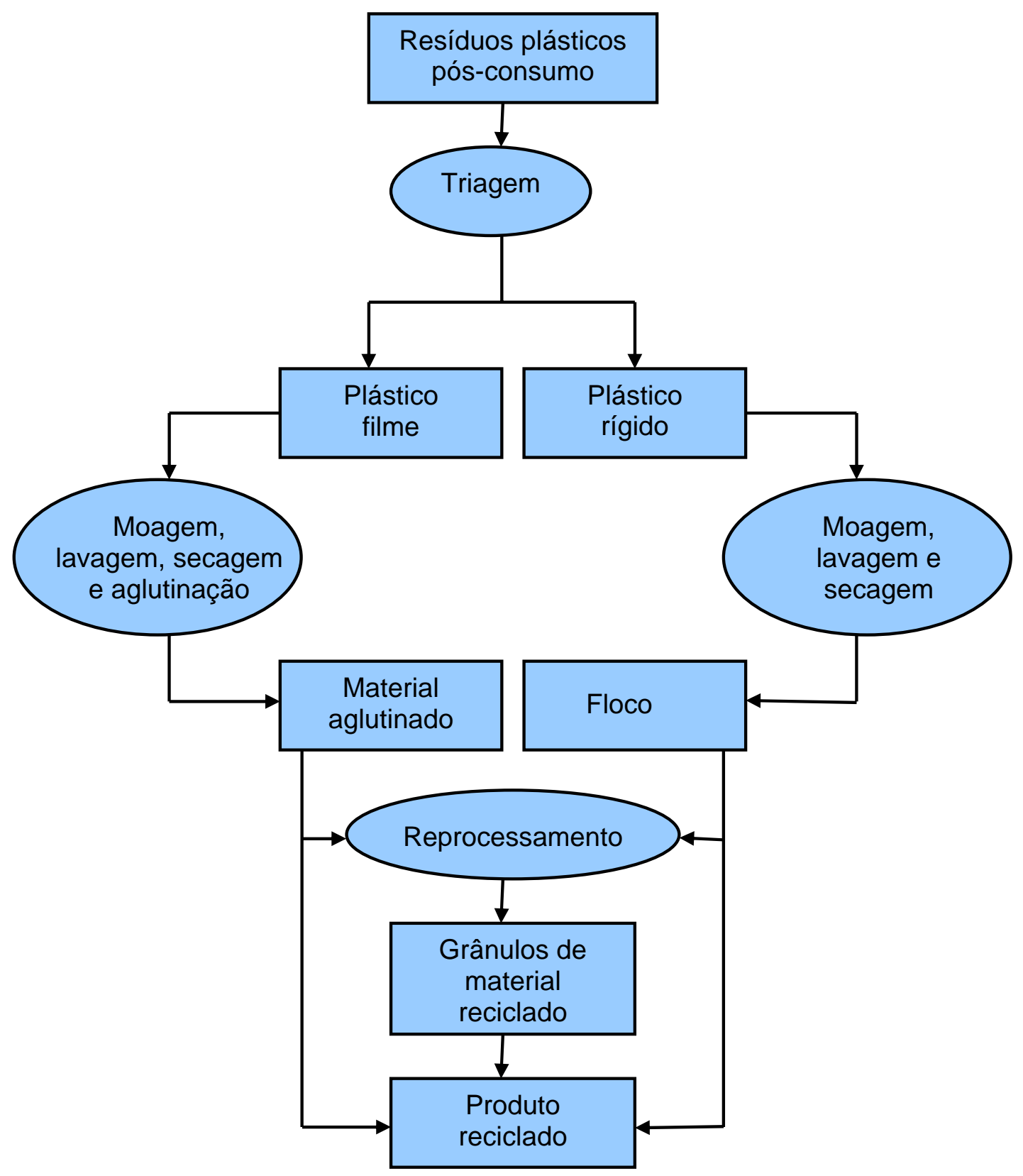

Figura B.2: Etapas simplificadas do processo de reciclagem mecânica de plásticos. Fonte: Zanin e Mancini (2004) 
Esse tipo de reciclagem teve um grande desenvolvimento nas últimas décadas e, devido a sua semelhança com a indústria de produção de plásticos, possui uma elevada capacidade de colocar no mercado consumidor uma grande quantidade de material reciclado.

$\mathrm{Na}$ indústria de plásticos esse processo é muito utilizado, pois aproveita material previamente processado (galhos de injeção ou peças fora de especificação) sem que ocorram perdas em suas propriedades.

A seguir, serão descritas as etapas de separação, moagem, lavagem, enxágüe, secagem, aglutinação e transformação dos plásticos.

- Separação

Para que se obtenha um bom resultado no processo de reciclagem mecânica, é necessário que seja feita uma separação criteriosa, por tipo de plástico, por cor e por condição de limpeza. No primeiro caso o objetivo é evitar a mistura de diferentes tipos de plásticos; no segundo a finalidade é obter um material reciclado mais homogêneo, em termos de aparência, e o terceiro para que ocorra uma uniformização na etapa de lavagem.

- Moagem

Após a etapa de seleção, os resíduos passam por uma etapa de redução do tamanho. Esse material moído, que geralmente possui o nome de floco (flake), deve ter tamanho e formato adequados para as etapas subseqüentes.

Segundo Zanin e Mancini (2004), existem vários tipos de moinhos (bolas, martelo, facas), sendo que o de facas é o mais empregado no ramo de reciclagem de plásticos. No caso do moinho de facas, ele possui um compartimento de facas fixas (voltadas para cima), facas giratórias (voltadas para baixo) e uma tela metálica, que funciona como uma peneira, e faz a separação entre os blocos menores e os maiores.

- Lavagem

A lavagem é feita com o objetivo de separar os plásticos de outros materiais que podem ter se fixado a eles, como areias, papéis, outros tipos de plásticos, terra e matéria orgânica, obtendo-se assim um material livre de impurezas.

Geralmente, a lavagem é feita em tanques, cujo tamanho depende da eficiência da lavagem requerida, da existência de agentes de lavagem, dentre outros. Os agentes de lavagem são utilizados para remover as impurezas, e geralmente são utilizados quando existe muita matéria orgânica impregnada e quando somente a água não seria necessária para retirar as impurezas. São utilizados detergentes ou soluções aquosas de hidróxido de 
sódio (soda cáustica), como agentes de lavagem. Deve-se levar em conta o efeito corrosivo da soda sobre os equipamentos, obrigando assim que as instalações sejam resistentes à corrosão.

- Enxágüe

O enxágüe é uma etapa obrigatória quando se utilizam produtos químicos, como sabões, detergentes ou soda cáustica, pois tem a finalidade de remover qualquer vestígio desses produtos, cuja presença pode: (i) comprometer o processamento dos materiais, uma vez que podem provocar reações químicas, degradar o material e comprometer suas propriedades finais e (ii) contaminar o produto que ficará em contato com o plástico reciclado, impedindo sua aplicação.

- Secagem

A secagem é uma etapa fundamental na reciclagem dos plásticos, pois tem a finalidade de eliminar a água aderida à superfície do polímero.

A secagem para PET, nylon e policarbonato, por exemplo, possui a função de eliminar a água que possa ter se fundido ao polímero. Essa umidade, quando não retirada e submetida a altas temperaturas, pode provocar a degradação eletrolítica (também chamada de pirólise, ou seja, a quebra das cadeias por meio da ação de moléculas de água) das cadeias de material polimérico, fazendo com que o material reciclado possua propriedades inferiores.

- Aglutinação

A aglutinação é empregada na reciclagem de filmes plásticos (sacos e sacolas) ou de outros produtos que possuem espessura fina, como copos descartáveis. Seu objetivo é aumentar a densidade e o peso dos flocos para que, quando forem colocados nos funis alimentadores dos equipamentos de transformação, possam ter queda por gravidade.

Eventualmente, a aglutinação também pode ser utilizada para incorporar aditivos, tais como cargas, pigmentos, auxiliares de fluxo, dentre outros.

\subsubsection{Reciclagem química}

Na reciclagem química ocorre a despolimerização controlada do plástico. Divide-se em dois tipos: termólise e solvólise.

Na termólise ocorre a destruição da estrutura química do plástico por meio do calor, e é dividida em três processos básicos: pirólise, gaseificação e hidrogenação. A pirólise é feita em fornos com temperatura inerte, com temperaturas de $400^{\circ} \mathrm{C}$ a $800^{\circ} \mathrm{C}$, degradando $\mathrm{O}$ plástico e transformando-o em um produto líquido. A gaseificação consiste na adição de 
oxigênio, em temperaturas da ordem de $900^{\circ} \mathrm{C}$, ao líquido obtido do processo de pirólise, transformando-o em um gás sintético à base de monóxido de carbono e hidrogênio. A hidrogenação consiste na adição de hidrogênio no resíduo líquido da pirólise.

Na solvólise a despolimerização é feita por meio da utilização de solventes e de calor; porém, em níveis inferiores aos da termólise.

\subsubsection{Reciclagem energética}

Segundo Zanin e Mancini (2004), a reciclagem energética visa a combustão completa do plástico a ser incinerado em unidades semelhantes às usinas termoelétricas e possui a finalidade de gerar energia para alimentar o próprio sistema de produção, armazená-la, distribuí-la ou vendê-la.

Uma desvantagem da reciclagem energética é que ela elimina o plástico utilizado em seu processo, impedindo a participação desse material em um novo ciclo produtivo. 
FÔRMAS PARA OS MODELOS E MOLDES DE SILICONE

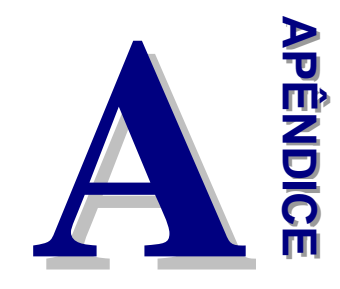



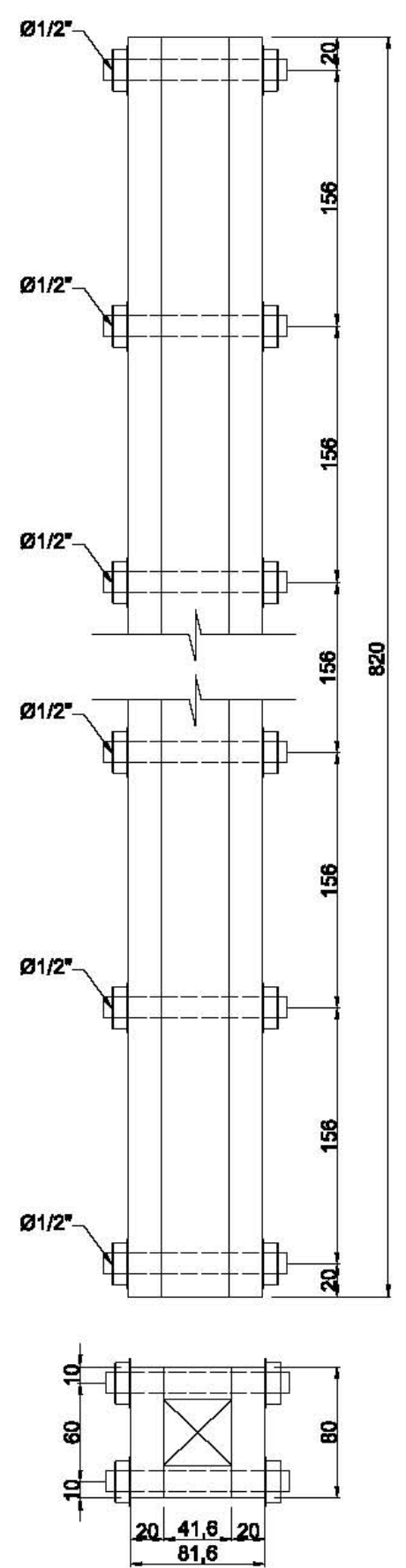

Dispositivo para cruzetas com seção $40 \mathrm{~mm} \times 41,60 \mathrm{~mm}-820 \mathrm{~mm}$

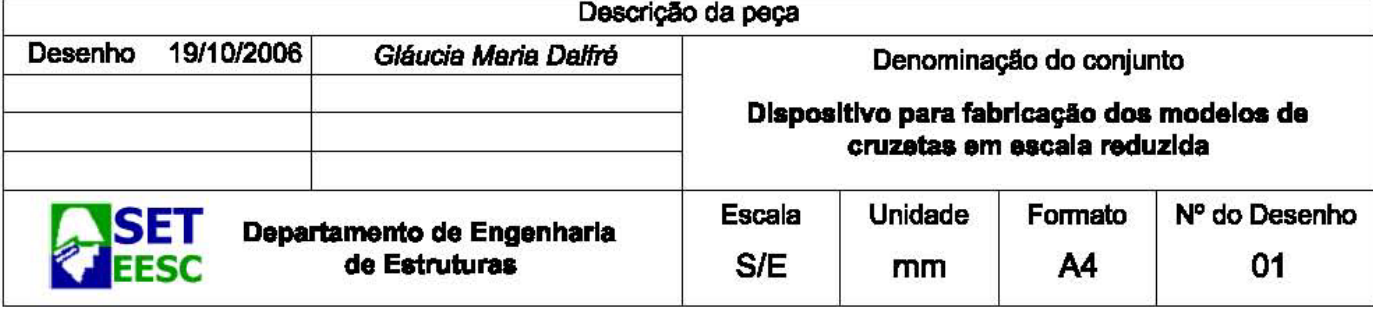




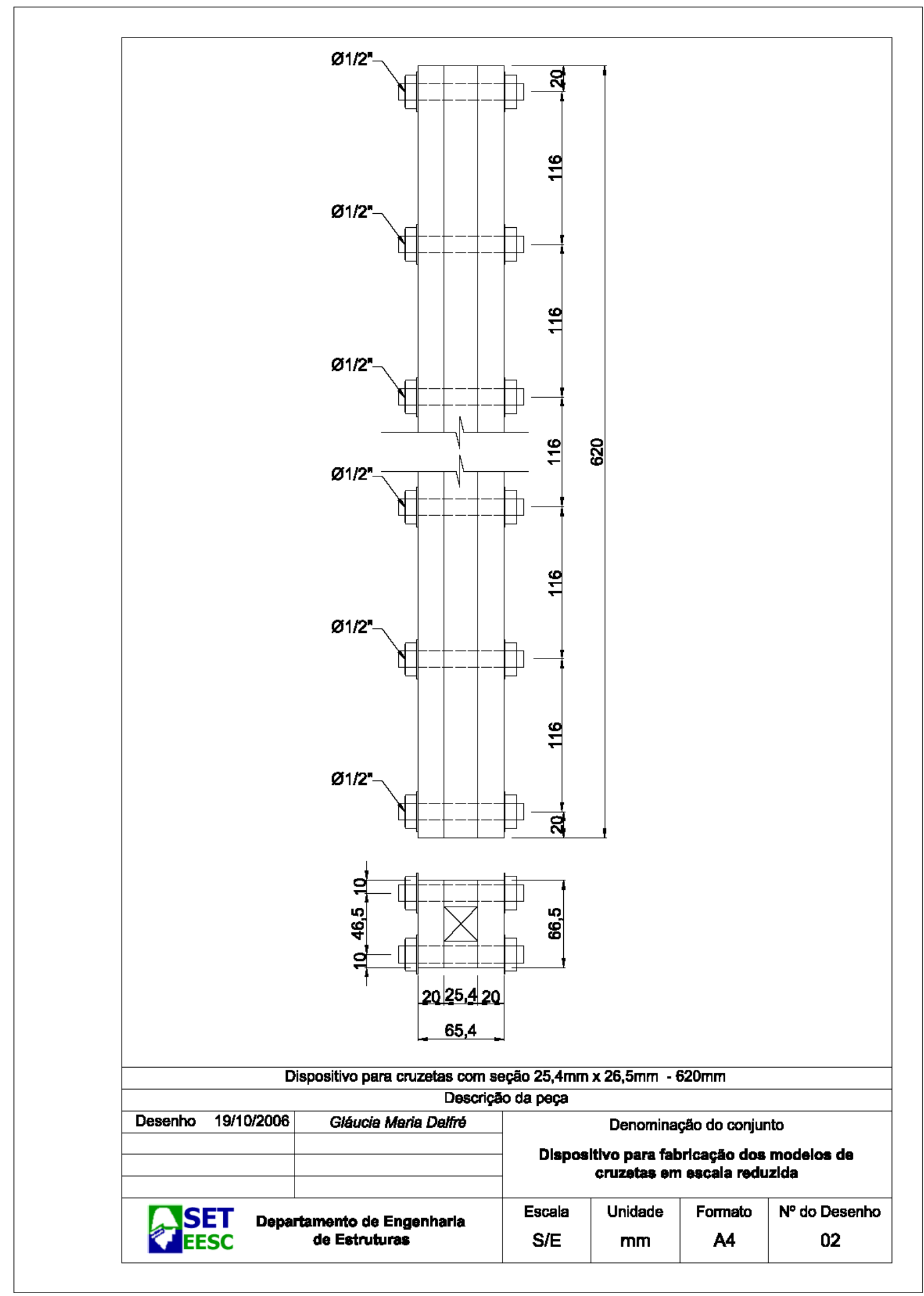




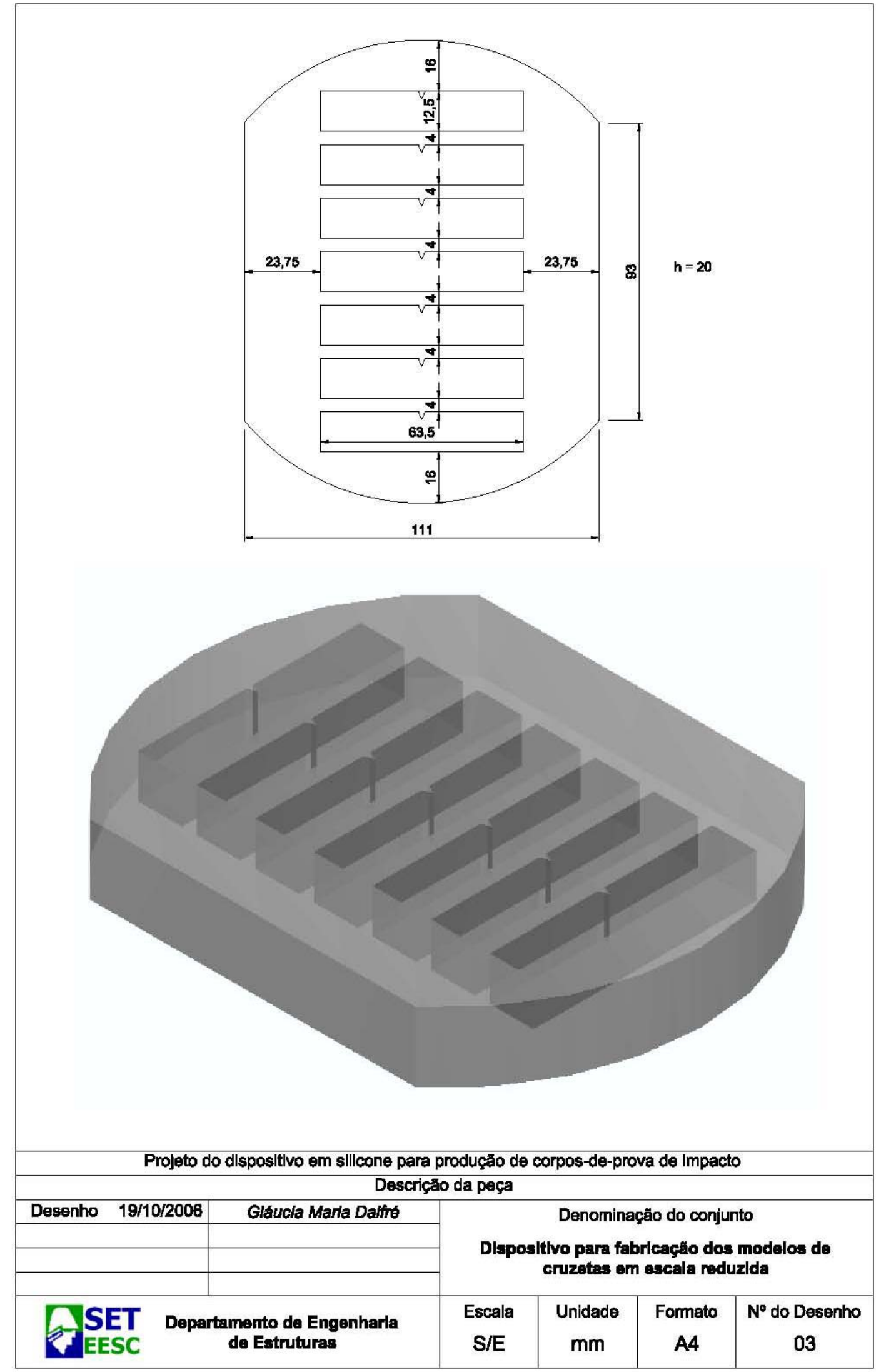




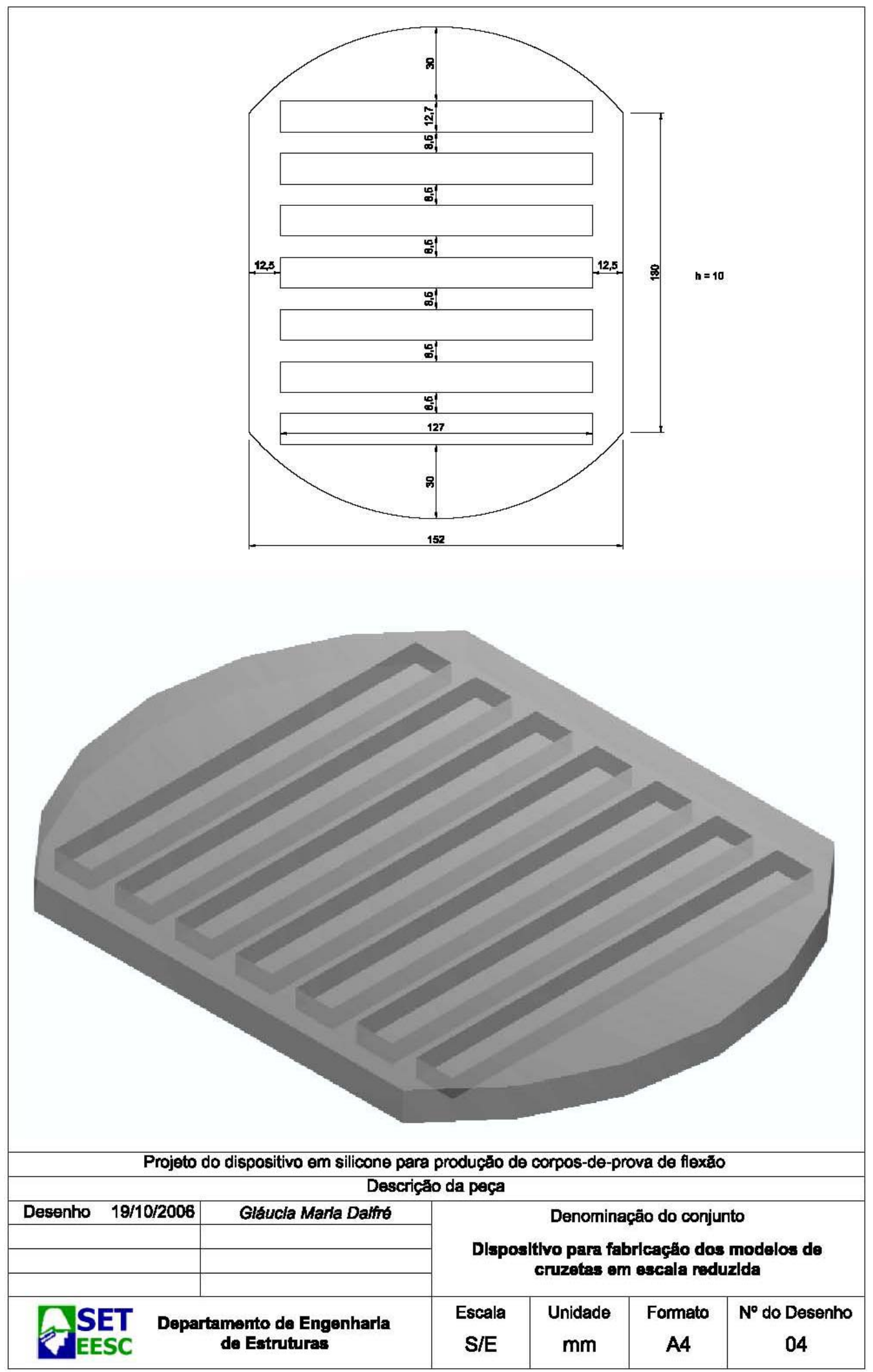




\section{CURVAS DE CARACTERIZAÇÃO}

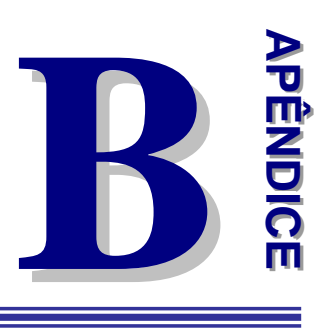

PU

Tração

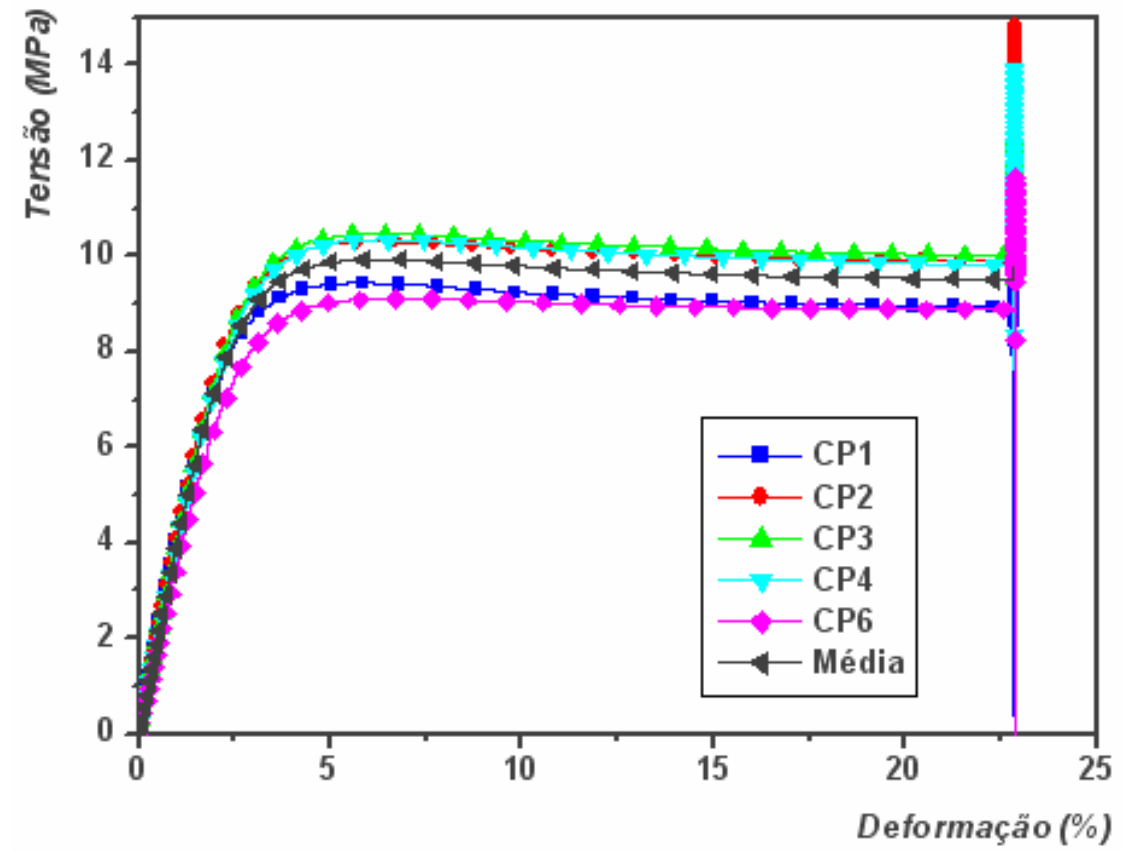

Figura Ap.1 - Curvas do ensaio de tração da amostra de poliuretano.

\section{Compressão}

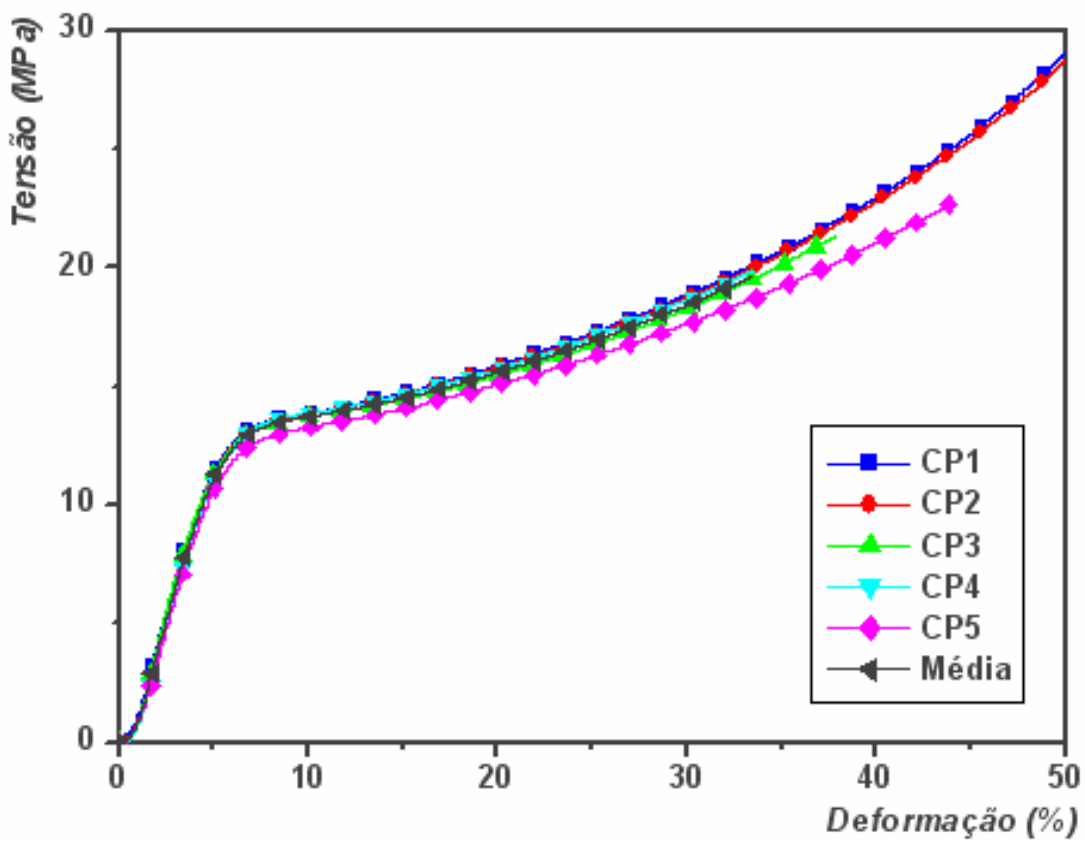

Figura Ap.2 - Curvas do ensaio de compressão da amostra de poliuretano. 
Flexão

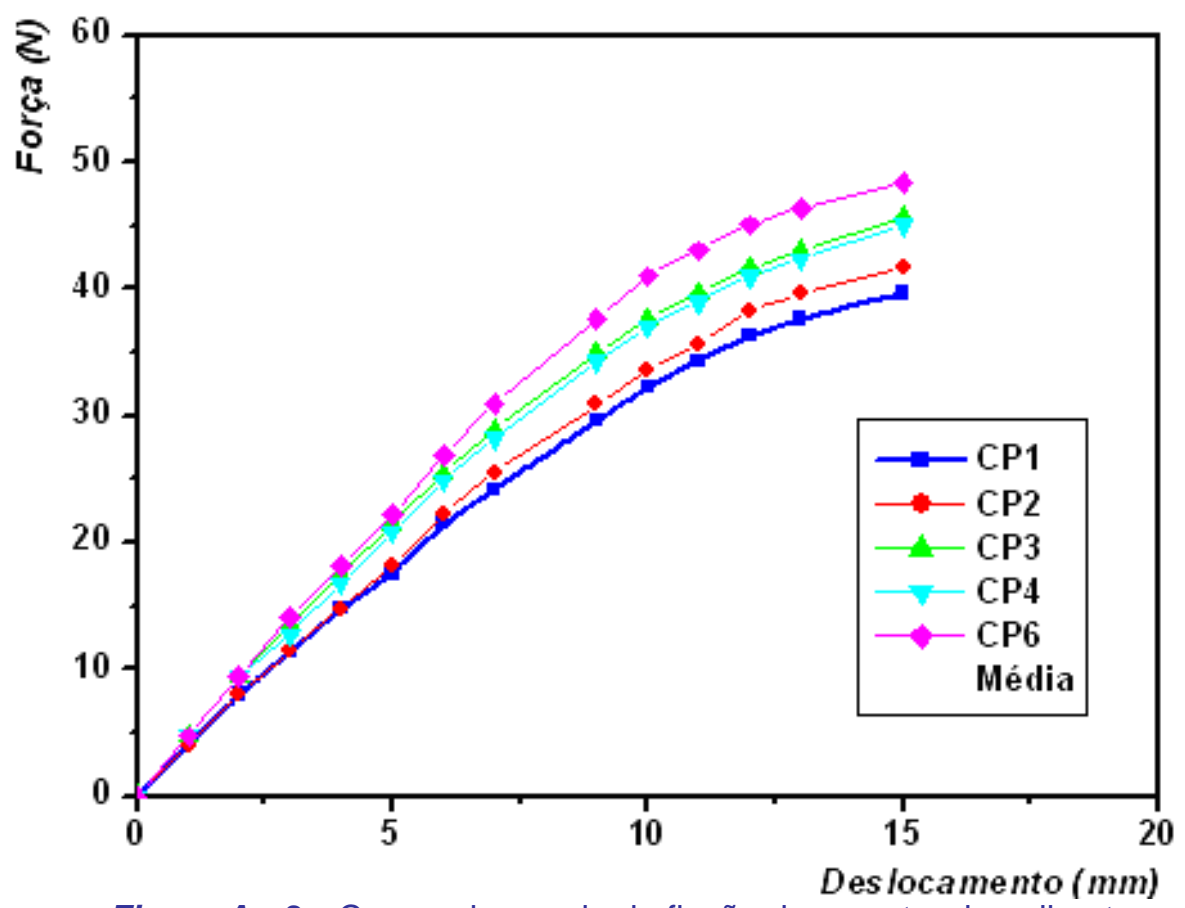

Figura Ap.3 - Curvas do ensaio de flexão da amostra de poliuretano.

\section{PEAD}

\section{Tração}

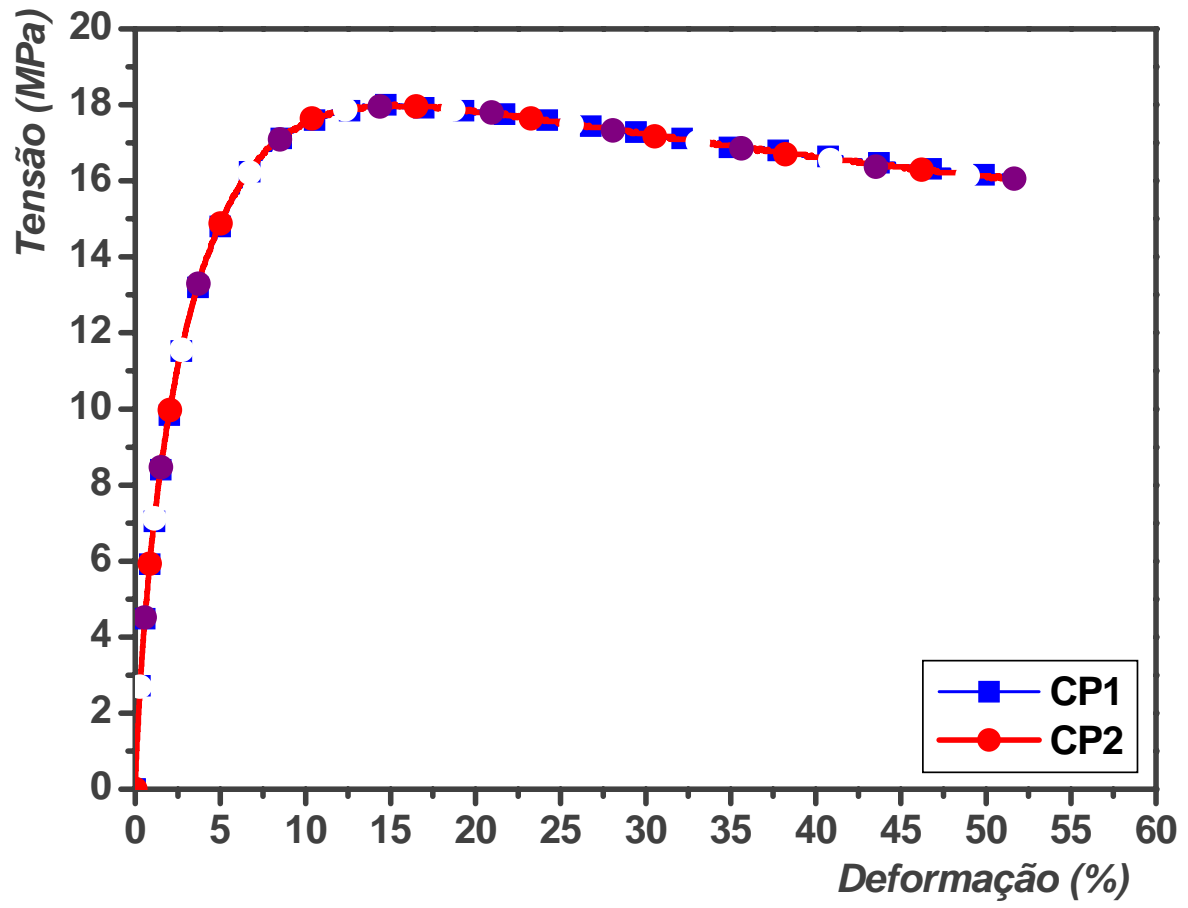

Figura Ap.4 - Curvas do ensaio de tração da amostra de PEAD reciclado. 